AUTARQUIA ASSOCIADA A UNIVERSIDADE DE SAO PAULO

Processamento e caracterização de filmes flexíveis de nanocompósitos de EVOH/GO tratados por radiação ionizante

\author{
JULYANA GALVÃO SANTANA
}

\begin{abstract}
Dissertação apresentada como parte dos requisitos para obtenção do Grau de Mestre em Ciências na Área de Tecnologia Nuclear - Materiais

Orientadora: Profa. Dra. Esperidiana Augusta Barretos de Moura
\end{abstract}


INSTITUTO DE PESQUISAS ENERGETICAS E NUCLEARES

Autarquia associada à Universidade de São Paulo

Processamento e caracterização de filmes flexíveis de nanocompósitos de EVOH/GO tratados por radiação ionizante

JULYANA GALVÃO SANTANA

Dissertação apresentada como parte dos requisitos para obtenção do Grau de Mestre em Ciências na Área de Tecnologia Nuclear-Materiais

Orientadora: Profa. Dra. Esperidiana Augusta Barretos de Moura

Versão Corrigida

Versão Original disponível no IPEN

São Paulo 
Autorizo a reprodução e divulgação total ou parcial deste trabalho, para fins de estudo e pesquisa, desde que citada a fonte

Como citar:

SANTANA, J. G. PROCESSAMENTO E CARACTERIZAÇÃo DE FILMES FLEXÍVEIS E NANOCOMPÓSITOS DE EVOH/GO TRATADOS POR RADIAÇÃO IONIZANTE. 2019.

130 p. Dissertação (Mestrado em Tecnologia Nuclear), Instituto de Pesquisas Energéticas e Nucleares, IPEN-CNEN/SP, São Paulo. Disponível em:

$<w w w . t e s e s . u s p . b r>$ (data de consulta no formato: $\mathrm{dd} / \mathrm{mm} / \mathrm{aaaa}$ )

Ficha catalográfica elaborada pelo Sistema de geração automática da Biblioteca IPEN/USP, com os dados fornecidos pelo(a) autor(a)

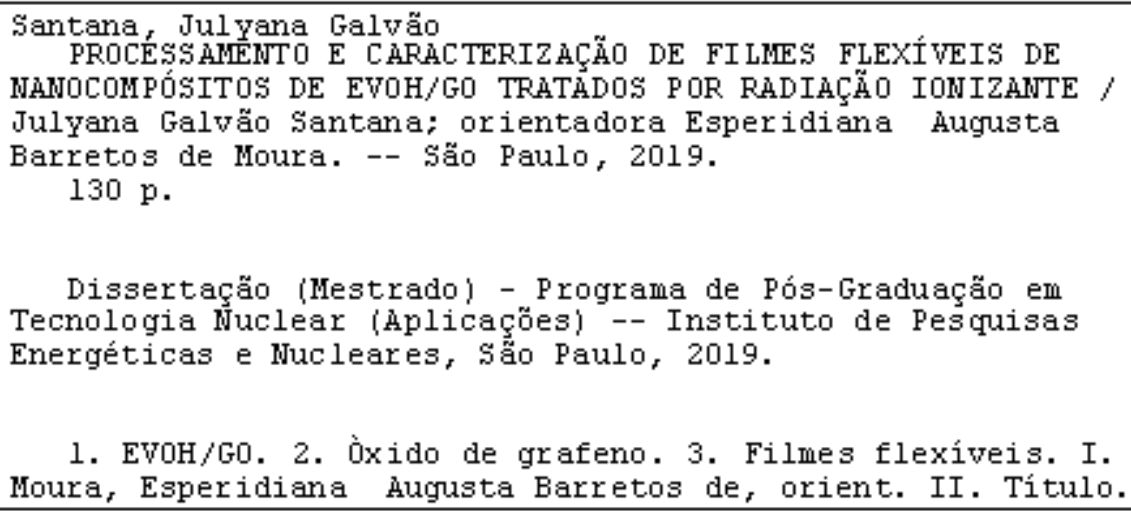

1. EVoH/Go. 2. òxido de grafeno. 3. Filmes flexíveis. I. Moura, Esperidiana Augusta Barretos de, orient. II. Título. 
Aos meus pais Célia e Josias, meu Noivo Gustavo, por todo amor e compreensão, em todos os momentos. 


\section{AGRADECIMENTOS}

À professora Dra. Esperidiana Augusta Barretos de Moura pela oportunidade de realizar este trabalho, pela orientação e ajuda em todo 0 percurso durante o mestrado.

Ao Prof. Dr. Francisco Rolando Valenzuela Díaz, pelas conversas e orientações, estando presente desde o início deste trabalho, e pela participação com a doação da Grafite.

A todos os alunos e amigos que os estudos me proporcionaram, aqueles que me acompanharam ao longo do desenvolvimento deste trabalho em diversos momentos: Pedro Reis, Renata Coiado, Heloísa Zen, Elizabeth Cardoso, Meshude Akbulut, Marcus Seixas, René Oliveira, Carlos P. Soares, Jorge Colleti, Gustavo Farias, todos que em algum momento, estiveram ali, com uma palavra, um conselho, uma ajuda, um braço, me ajudando a não desistir e me apoiando sempre a seguir em frente.

Ao querido Dr. Olgun Guven pelas sábias palavras de apoio e força, pela orientação e grande apoio e oportunidade de intercâmbio que me foi dada, me recebendo em seu laboratório na Universidade de Hacettepe, com toda sua atenção e cuidado.

À minha família que sempre me apoiou em todos os momentos, meu noivo Gustavo com toda sua paciência, que principalmente nos momentos mais difíceis esteve ao meu lado de dando toda a atenção e ajuda a continuar e não desistir.

À Comissão Nacional de Energia Nuclear (CNEN), pelo apoio financeiro.

À Intermarketing Brasil e Kuraray Co., Ltd pela doação do poli(etileno-coálcool vinílico) EVOH.

Ao Dr Angel Visentim Ortiz e toda a sua equipe da empresa Viscofan S.A., pelas análises de permeabilidade.

E a todos aqueles amigos e colegas que fizeram parte, contribuindo direta ou indiretamente para a realização deste trabalho. 
"Todos nós sabemos alguma coisa. Todos nós ignoramos alguma coisa. Por isso, aprendemos sempre."

(Paulo Freire) 


\title{
PROCESSAMENTO E CARACTERIZAÇÃO DE FILMES FLEXÍVEIS DE NANOCOMPÓSITOS DE EVOH/GO TRATADOS POR RADIAÇÃO IONIZANTE
}

\author{
Julyana Galvão Santana
}

\section{RESUMO}

O poli(etileno-co-álcool vinílico) $(\mathrm{EVOH})$ pertence à família de materiais poliméricos semicristalinos; é dotado de excelentes propriedades de barreira a gases e muito utilizado na fabricação de embalagens para alimentos e outros produtos sensíveis a certos níveis de oxigênio ou dióxido de carbono. Entretanto, o EVOH é muito higroscópico e em condições de alta umidade relativa perde a propriedade de altíssima barreira a oxigênio bem como as propriedades mecânicas. De acordo com literatura, a inclusão de cargas lamelares, como argila e óxido de grafeno, contribui para a melhora significativa das propriedades de barreira a gás e mecânicas do EVOH. Este trabalho estudou os efeitos da incorporação de nanofolhas de óxido de grafeno (GO) nas propriedades dos filmes de $\mathrm{EVOH}$. O GO foi obtido pelo método de Hummer's modificado e posteriormente submetido à redução induzida por radiação ionizante. Foram incorporados 0,1-0,3\% em peso de GO e GO reduzido (RGO) na matriz de EVOH via processo de extrusão, utilizando primeiramente uma extrusora duplarosca e após, uma mini extrusora balão de laboratório para a obtenção de filmes flexíveis de $\mathrm{EVOH} / \mathrm{GO}$ e $\mathrm{EVOH} / \mathrm{RGO}$. Os filmes obtidos foram submetidos à radiação ionizante, em acelerador de elétrons de 1,5 MeV, com o objetivo de estudar a contribuição do tratamento por radiação ionizante, nas propriedades finais. As irradiações foram realizadas à temperatura ambiente, em ar, e faixa de dose de radiação 100-250 kGy. As amostras de GO e RGO foram caracterizadas por meio dos ensaios de difração de raios $X(D R X)$, microscopia eletrônica de varredura com fonte de emissão de campo (MEV-FEG), microscopia eletrônica de transmissão (MET), espectroscopia vibracional de absorção no infravermelho com transformada de Fourier (FTIR), espectrometria Raman e termogravimetria (TG). As amostras dos filmes irradiadas e não irradiadas foram caracterizadas por meio de ensaios mecânicos de tração, DRX, MEV-FEG, FTIR, TG, calorimetria exploratória diferencial (DSC), taxa de permeabilidade ao oxigênio $\left(\mathrm{TPO}_{2}\right)$ e espectroscopia de aniquilação de pósitrons (PALS). Os resultados dos ensaios das amostras de GO e RGO indicaram que o GO obtido pelo método de Hummer's modificado foi reduzido por irradiação de raios gama, como a redução dos grupos funcionais contendo oxigênio, grupos epóxi e carboxílicos. As imagens de MEV-FEG das amostras de RGO mostraram folhas separadas sem regiões dobradas e domínios agregados, já o GO apresentou uma superfície com rugosidade e empilhamento de folhas. Os filmes flexíveis de EVOH contendo GO (EVOH/GO) e RGO (EVOH/RGO) apresentaram boa dispersão do GO na matriz de EVOH. Os filmes preparados com RGO (EVOH/RGO) e submetidos à radiação ionizante apresentaram uma dispersão mais homogênea do RGO na matriz e maior adesão interfacial matriz/RGO, e, consequentemente, propriedades mecânicas superiores àquelas obtidas para os filmes de $\mathrm{EVOH}$ puro ou de EVOH/GO.

Palavras-chave: EVOH/GO; óxido de grafeno; filmes flexíveis 


\title{
PROCESSING AND CHARACTERIZATION OF FLEXIBLE FILMS OF EVOH/GO NANOCOMPOSITES TREATED WITH IONIZING RADIATION
}

\author{
Julyana Galvão Santana
}

\begin{abstract}
Poly(ethylene-co-vinyl alcohol) (EVOH) belongs to the family of semicrystalline polymeric materials; is endowed with excellent gas barrier properties, it is much used in the research area for food packaging and other products sensitive to certain levels of oxygen or carbon dioxide. However, EVOH is very hygroscopic and the high flow conditions relative to the very high barrier property are oxygen as well as the mechanical properties. According to the literature, an inclusion of lamellar loads, such as clay and graphene oxide, contribute to the strengthening of the gas properties and the mechanical discharges of EVOH. This work was studied the addition graphene oxide (GO) nanosheets into EVOH properties. The GO was obtained by the modified Hummer's method and subsequently submitted to the reduction induced by ionizing radiation, $0.1-0.3 \%$ by weight of $\mathrm{GO}$ and reduced $\mathrm{GO}(\mathrm{RGO})$ were incorporated into the $\mathrm{EVOH}$ matrix via the extrusion process, using firstly a double-screw extruder and then a mini-laboratory extruder for obtaining films EVOH / GO and EVOH / RGO. The obtained films were submitted to ionizing radiation, in an electron accelerator of $1,5 \mathrm{MeV}$, in order to study the contribution of the treatment by ionizing radiation, in the final properties. The irradiations were performed at room temperature in air, and radiation dose range 100-250 kGy. The GO and RGO samples were characterized by X-ray diffraction (XRD), scanning electron microscopy with field emission source (SEMFEG), transmission electron microscopy (TEM), vibration absorption spectroscopy in the Fourier transform infrared (FTIR), Raman spectrometry and thermogravimetric (TG). The irradiated and non-irradiated films were characterized by mechanical tests, XRD, SEM-FEG, FTIR, TG, differential scanning calorimetry (DSC), oxygen permeability rate $\left(\mathrm{TPO}_{2}\right)$ and positron annihilation spectroscopy (PALS). Tests results of GO and RGO samples indicated that the GO obtained by the modified Hummer's method was reduced by gamma irradiation, such as the reduction of the oxygen-containing functional groups, epoxy groups and carboxylic groups. The SEM-FEG images of RGO samples showed separate leaves without folded regions and aggregate domains, whereas the GO showed a surface with roughness and stacking of leaves. EVOH flexible films containing GO (EVOH / GO) and RGO (EVOH / RGO) showed good dispersion of GO in the EVOH matrix. The films prepared with RGO (EVOH / $R G O)$ and subjected to ionizing radiation presented a more homogeneous dispersion of RGO in the matrix and higher interfacial matrix / RGO adhesion, and, consequently, superior mechanical properties to those obtained for pure $\mathrm{EVOH}$ or EVOH/GO films.
\end{abstract}

Keywords: Graphene oxide; Nanocomposites; EVOH; 


\section{LISTA DE TABELAS}

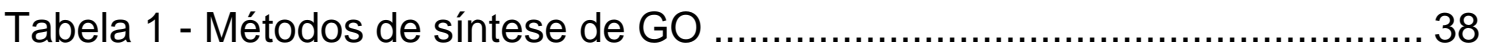

Tabela 2 - Formulações dos nanocompósitos................................................ 65

Tabela 3 - Intensidade das bandas D, $2 \mathrm{D}$ e G e as taxas de intensidade de $\mathrm{I}_{\mathrm{D}} / \mathrm{I}_{\mathrm{G}}$

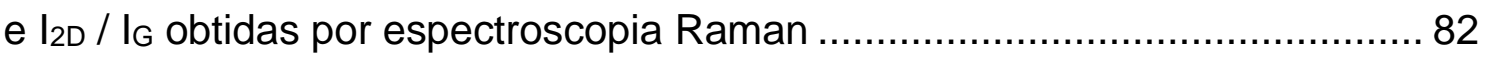

Tabela 4 - Temperaturas de decomposição e perda de massa das nanofolhas de

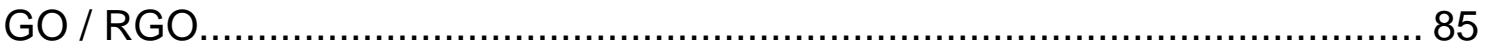

Tabela 5 - Temperatura inicial de degradação térmica e perda de massa do

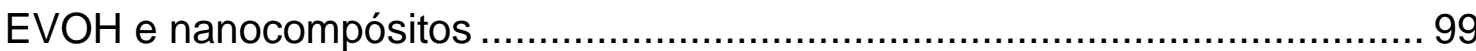

Tabela 6 - Entalpia e Temperatura de Fusão para o EVOH puro e EVOH/GO 103

Tabela 7 - Volume livre (r3) determinado por PALS ..................................... 105

Tabela 8 - Taxa de permeabilidade ao oxigênio $\left(\mathrm{TPO}_{2}\right)$............................... 106

Tabela 9 - Resistência à tração e Elongação no ponto de ruptura para os filmes

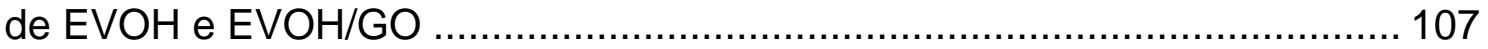

Tabela 10 - Resistência à tração e Elongação no ponto de ruptura e Módulo Young para os filmes de EVOH e EVOH/RGO .......................................... 112 


\section{LISTA DE FIGURAS}

Figura 1- Estrutura do Poli(etileno-co-álcool vinílico) (EVOH) ......................... 29

Figura 2 - Representação da estrutura do Grafeno ........................................... 35

Figura 3 - Esquema do processo de produção do GO e RGO a partir da oxidação

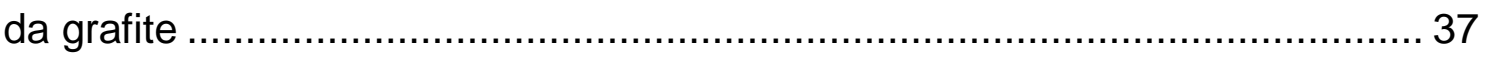

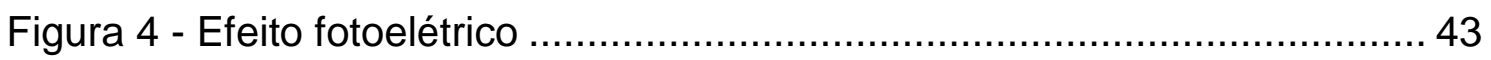

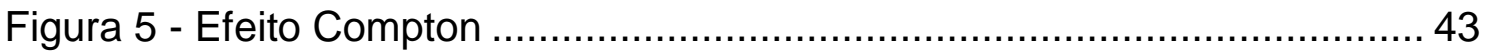

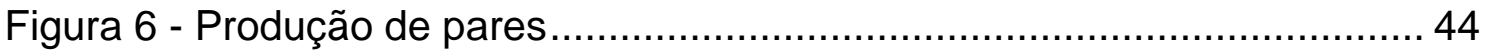

Figura 7- Processo de degradação por radiação ………………….............. 46

Figura 8 - Processo de reticulação por radiação ............................................. 47

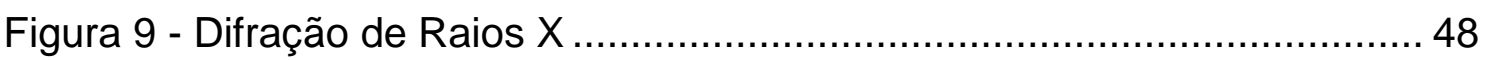

Figura 10 - Representação esquemática do MEV-FEG ................................. 49

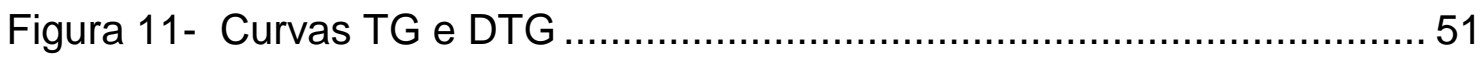

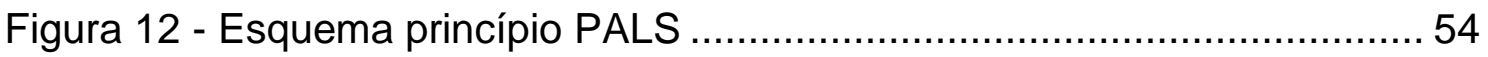

Figura 13 - Funcionamento de um equipamento de avaliação da $\mathrm{TPO}_{2} \ldots \ldots \ldots . . .55$

Figura 14 - Fluxograma da metodologia de obtenção do GO …...................... 57

Figura 15- Centrífuga modelo Q222T204 …………............................... 57

Figura 16 - Desruptor de Célula Ultrassônico.................................................. 58

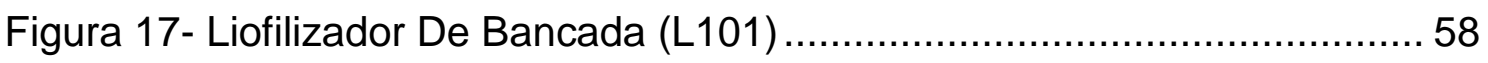

Figura 18- Fluxograma da metodologia de obtenção do GO ........................... 59

Figura 19- Equipamento de Difração de Raios X (DRX) ............................... 60

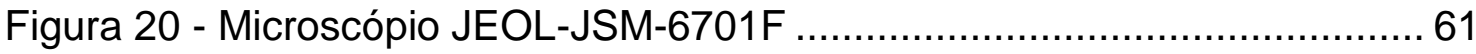

Figura 21 - Microscópio Eletrônico de Transmissão JEOL JEM-1200 ............. 62

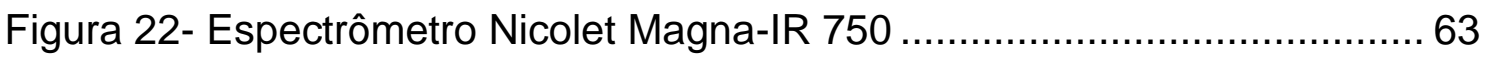

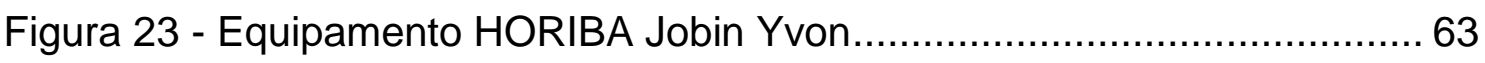

Figura 24- Mettler Toledo TGA modulo "TGA/SDTA851E" ............................... 64

Figura 25 - Extrusora dupla rosca HAAKE Rheomex, Thermo Scientific ......... 66

Figura 26 - Extrusora monorosca de laboratório HAAKE Rheomex, Thermo

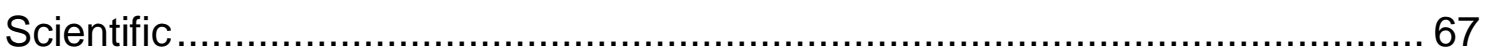

Figura 27 - Acelerador de elétrons modelo "Dynamitron II"............................ 68

Figura 28- Máquina universal de ensaios modelo Instron 5567 ...................... 70

Figura 29 - Difratograma de DRX da Grafite, GO e RGO 100 kGy ................. 72 
Figura 30- Micrografias obtidas por MEV- FEG do GO (19.000x) .................. 74

Figura 31- Micrografias obtidas por MEV- FEG do GO (100.000x) …............. 75

Figura 32- Micrografias obtidas por MEV- FEG do RGO (19.000x) ............... 76

Figura 33- Micrografias obtidas por MEV- FEG do RGO (100.000x) .............. 77

Figura 34 - Imagem obtida por microscopia eletrônica de transmissão do GO

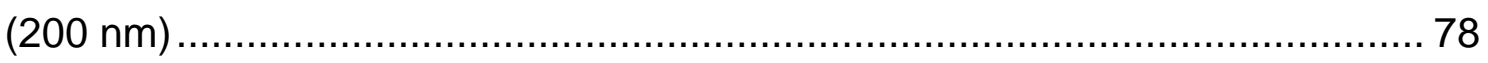

Figura 35 - Imagem obtida por microscopia eletrônica de transmissão do GO (50

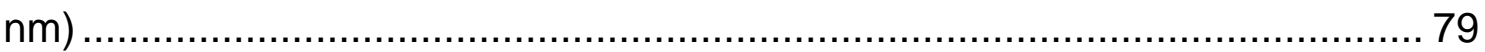

Figura 36 - Espectros obtidos por FTIR para o GO e RGO ………................ 80

Figura 37- Bandas do espectro de RAMAN para o GO e RGO........................ 81

Figura 38- Curvas de TG para o GO e RGO .............................................. 84

Figura 39- Curvas de DTG para o GO e RGO ………................................. 84

Figura 40 - Difratograma do EVOH e EVOH/GO ..................................... 86

Figura 41 - Difratograma comparativo do EVOH em função da dose de radiação

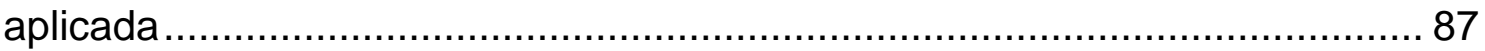

Figura 42 - Difratograma comparativo do $\mathrm{EVOH} / \mathrm{GO}$ 0,1 \% em função da dose de radiação aplicada 87

Figura 43 - Difratograma comparativo do $\mathrm{EVOH} / \mathrm{GO}$ 0,2 \% em função da dose de radiação aplicada 88

Figura 44 - Difratograma comparativo do EVOH/GO 0,3 \% em função da dose de radiação aplicada 88

Figura 45 - Micrografias obtidas por MEV-FEG das superfícies criofraturadas do $\mathrm{EVOH}(5000 \mathrm{X})$ 89

Figura 46 - Micrografias obtidas por MEV- FEG das superfícies criofraturadas do $\mathrm{EVOH}(10.000 \mathrm{X})$ 90

Figura 47 - Micrografias obtidas por MEV-FEG das superfícies criofraturadas do EVOH/GO 0,1\% (5000 X) 91

Figura 48 - Micrografias obtidas por MEV- FEG das superfícies criofraturadas do EVOH/GO 0,1\% (10.000 X)....... 91

Figura 49 - Micrografias obtidas por MEV-FEG das superfícies criofraturadas do $\mathrm{EVOH} / \mathrm{GO} 0,2 \%(5000 \mathrm{X})$ 92

Figura 50 - Micrografias obtidas por MEV- FEG das superfícies criofraturadas do $\mathrm{EVOH} / \mathrm{GO} 0,2 \%(10.000 \mathrm{X})$. 93 
Figura 51 - Micrografias obtidas por MEV- FEG das superfícies criofraturadas do

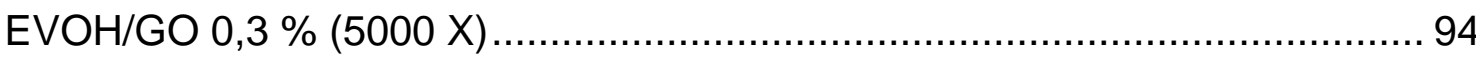

Figura 52 - Micrografias obtidas por MEV- FEG das superfícies criofraturadas do

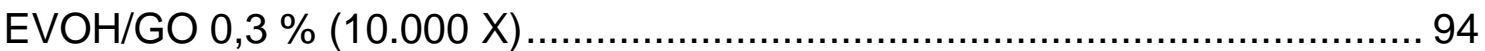

Figura 53 - Curva de TG do EVOH e EVOH/GO 0,1 - 0,3\%........................ 95

Figura 54 - Curva de TG do EVOH/GO 0,1 - 0,3 \% (100 kGy) ....................... 96

Figura 55 - Curva de TG do EVOH/GO 0,1 - 0,3\% (150 kGy) ..................... 97

Figura 56 - Curva de TG do EVOH/GO 0,1 - 0,3 \% (200 kGy) ...................... 97

Figura 57 - Curva de TG do EVOH/GO 0,1 - 0,3 \% (250 kGy) ..................... 98

Figura 58 - Curvas de DSC para o EVOH, EVOH/GO 0,1, 0,2, e 0,3 \% ........ 100

Figura 59 - Curvas de DSC para EVOH/GO 0,1 \% 100 a 250 kGy .............. 101

Figura 60 - Curvas de DSC para EVOH/GO 0,2 \% 100 a 250 kGy ................ 101

Figura 61 - Curvas de DSC para EVOH/GO 0,3 \% 100 a 250 kGy ............... 102

Figura 62 - Espectro de infravermelho para o EVOH puro e EVOH/GO ........ 104

Figura 63 - Diagrama tensão x deformação para o EVOH e EVOH 100 - 250

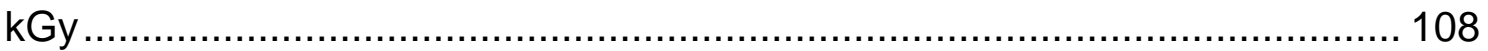

Figura 64 - Diagrama tensão x deformação para o EVOH/RGO 0,1 \% e $\mathrm{EVOH} / \mathrm{RGO} 0,1 \% 100-250 \mathrm{kGy}$ 109

Figura 65 - Diagrama tensão x deformação para o EVOH/RGO 0,2 \% e EVOH/RGO 0,2 \% 100 - 250 kGy. 110

Figura 66 - Diagrama tensão x deformação para o EVOH/RGO 0,3 \% e $\mathrm{EVOH} / \mathrm{RGO} 0,3 \% 100-250 \mathrm{kGy}$ 110 


\section{SUMÁRIO}

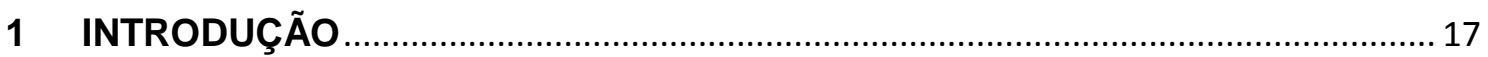

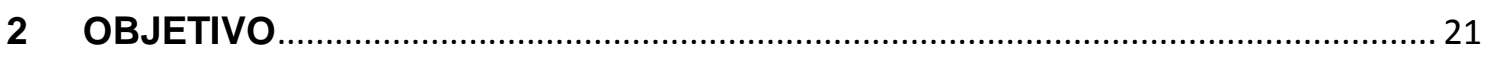

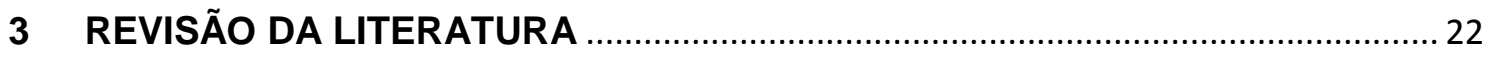

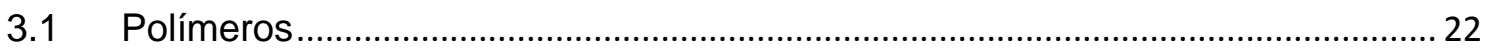

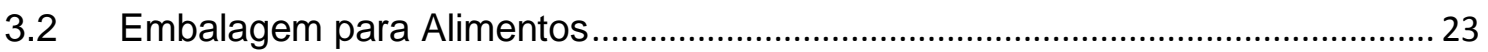

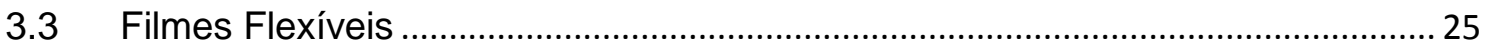

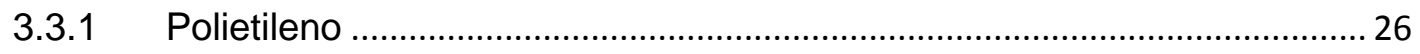

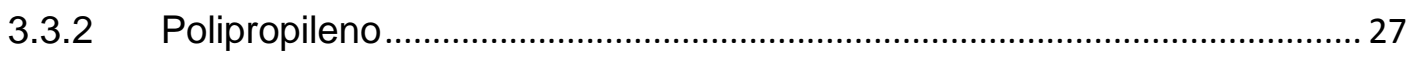

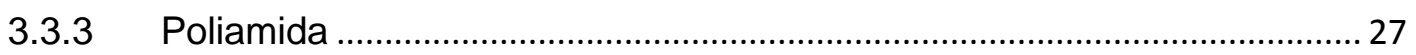

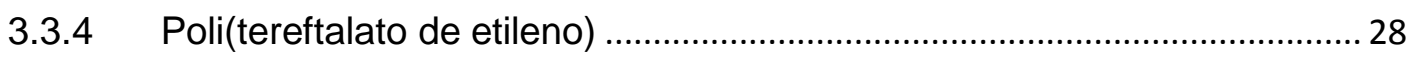

3.3.5 Poli(etileno-co-álcool vinílico) - EVOH ...................................................... 28

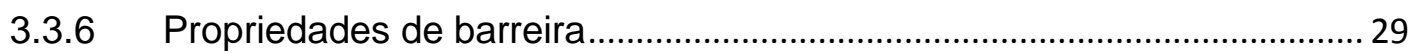

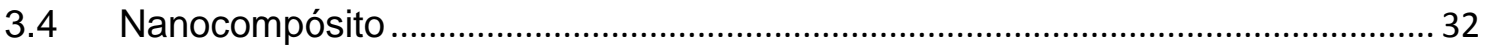

3.5 Processamento de Nanocompósitos de Matriz Polimérica .................................... 32

3.5.1 Processamento de nanocompósitos por mistura mecânica no estado

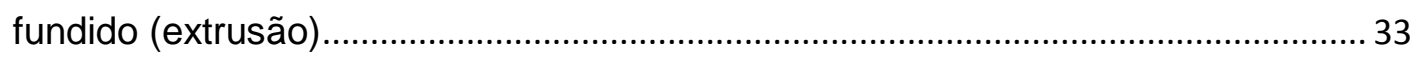

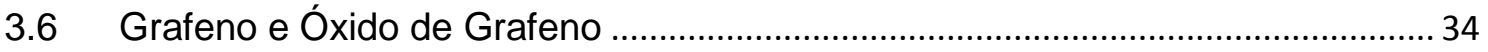

3.6.1 Processos de Obtenção do Grafeno ............................................................. 36

3.6.2 Síntese de Obtenção do Óxido e Grafeno ................................................. 37

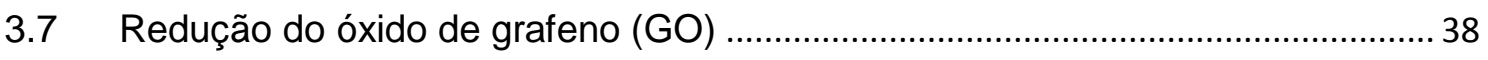

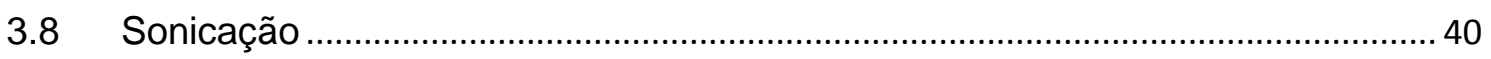

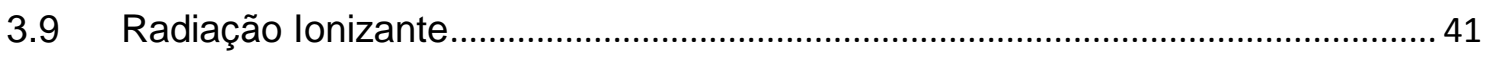

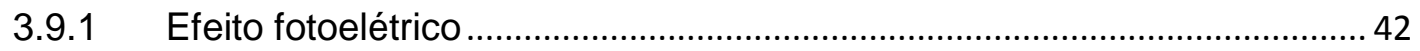

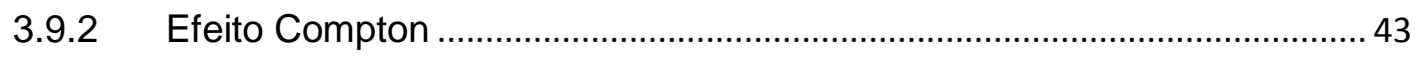

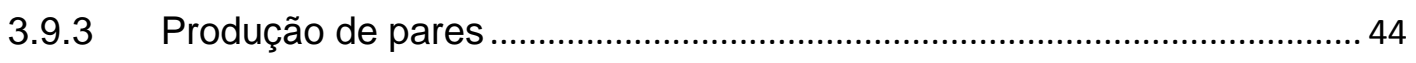

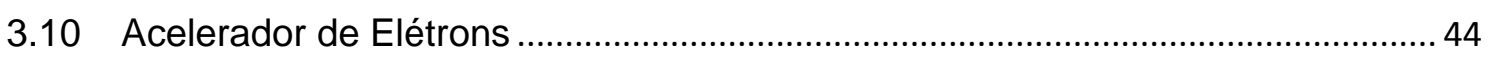

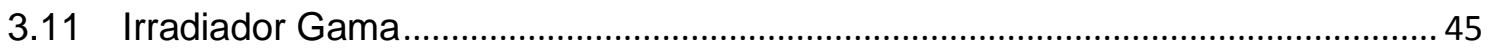




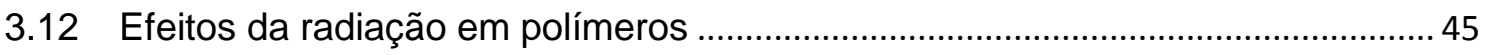

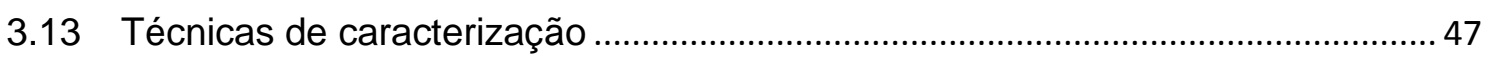

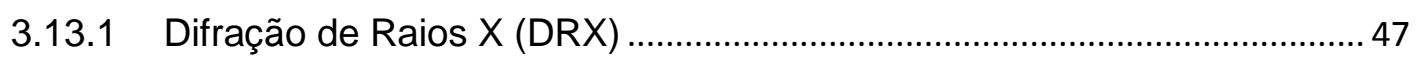

3.13.2 Microscopia eletrônica de varredura com fonte de emissão de campo

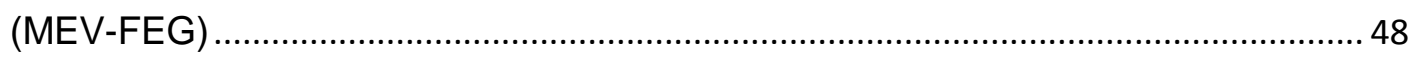

3.13.3 Microscopia Eletrônica de Transmissão (MET) …………………............... 49

3.13.4 Espectroscopia vibracional de absorção no infravermelho com

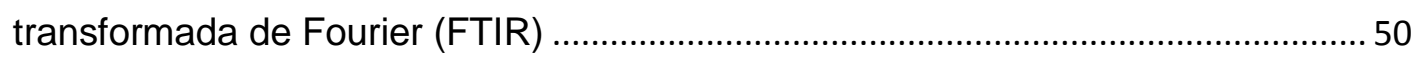

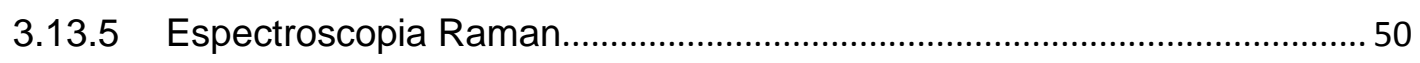

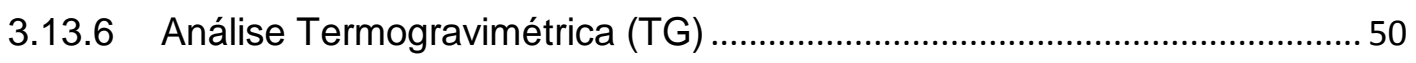

3.13.7 Calorimetria Exploratória Diferencial (DSC) ................................................ 51

3.13.8 Ensaios Mecânicos de Tração ................................................................. 52

3.13.9 Espectroscopia de tempos de vida de aniquilação de pósitrons (PALS) 53

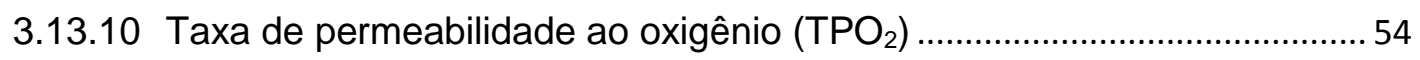

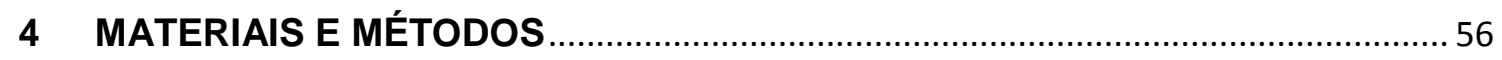

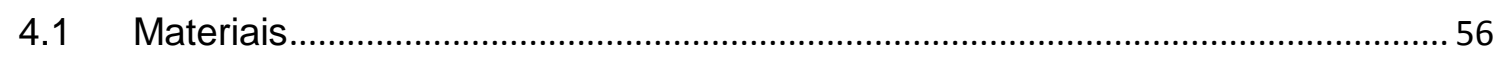

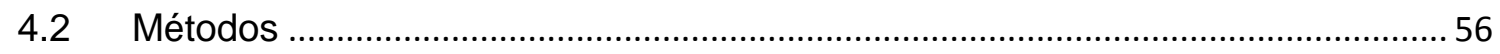

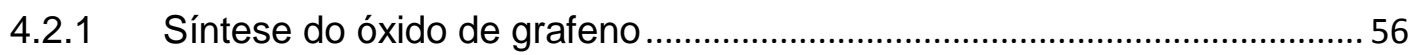

4.2.1.1 Centrifugação ................................................................................ 57

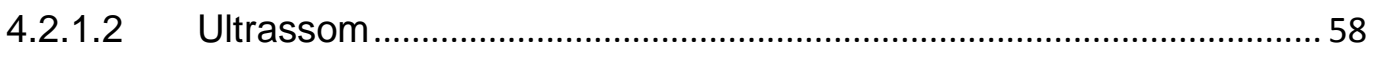

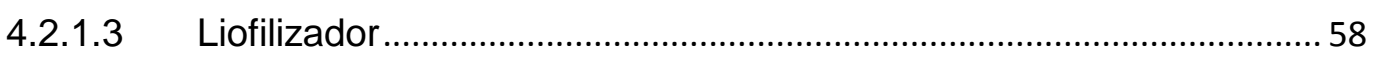

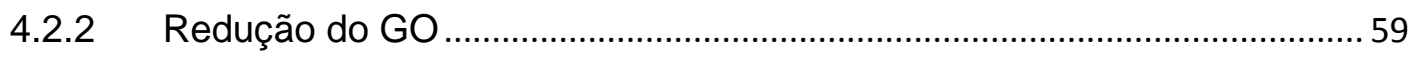

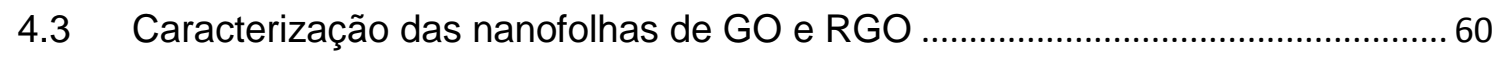

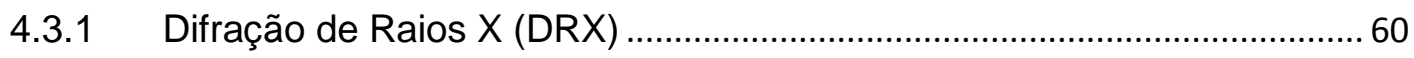

4.3.2 Microscopia Eletrônica de Varredura com fonte de emissão de campo

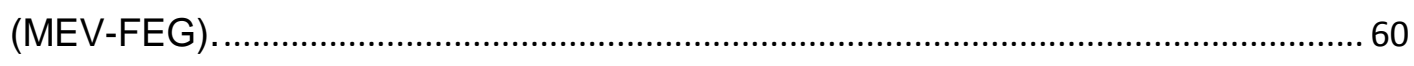

4.3.3 Microscopia Eletrônica de Transmissão (MET) .......................................... 61

4.3.4 Espectroscopia vibracional de absorção no infravermelho com

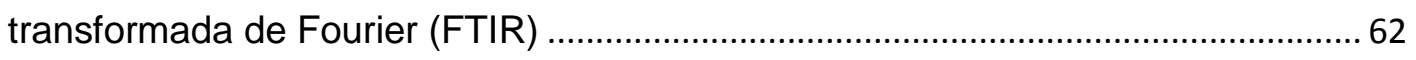




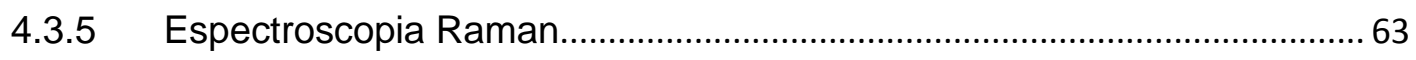

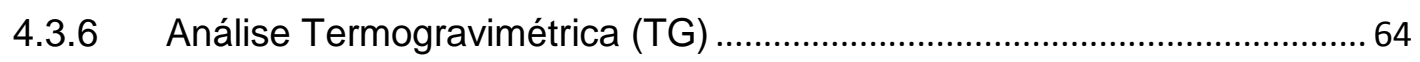

4.4 Preparação dos filmes flexíveis de EVOH e seus nanocompósitos.......................64

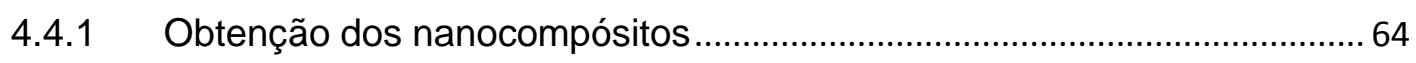

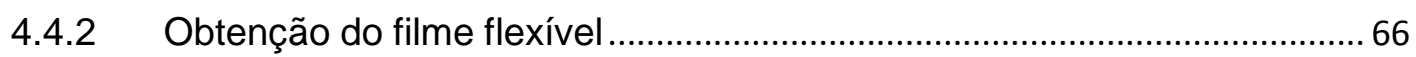

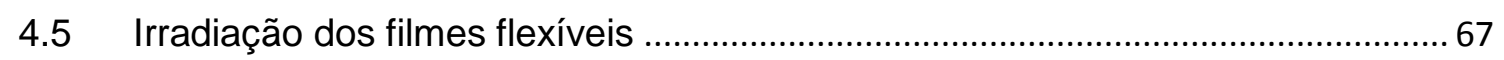

4.6 Caracterização do EVOH puro e seus nanocompósitos .........................................6 68

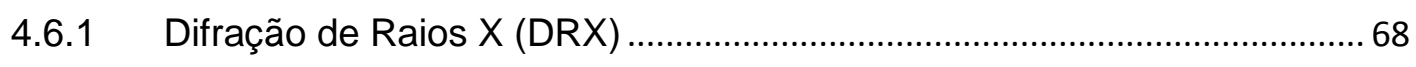

4.6.2 Microscopia Eletrônica de Varredura com fonte de emissão de campo

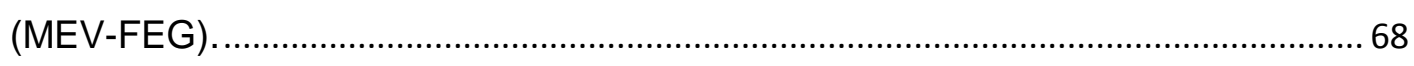

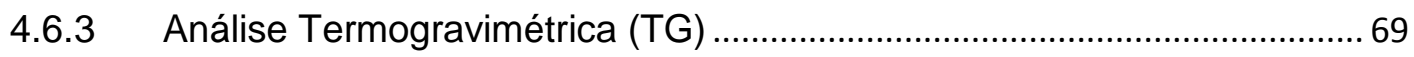

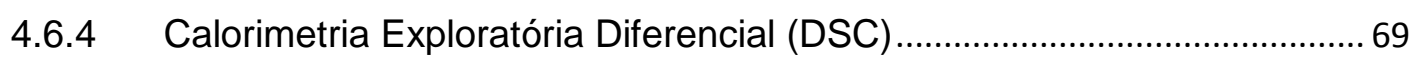

4.6.5 Espectroscopia vibracional de absorção do infravermelho por

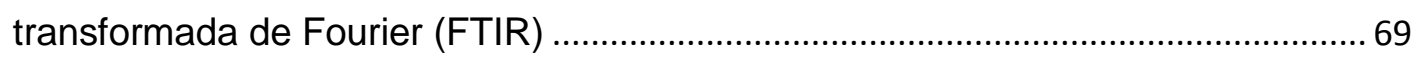

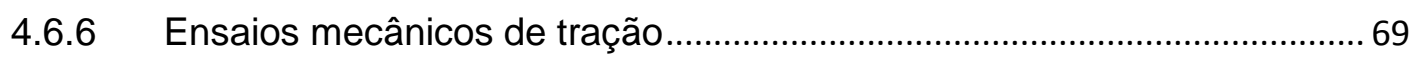

4.6.7 Espectroscopia de tempos de vida de aniquilação de pósitrons (PALS) 70

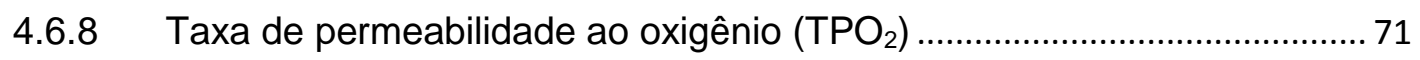

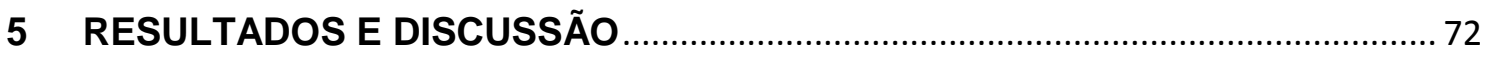

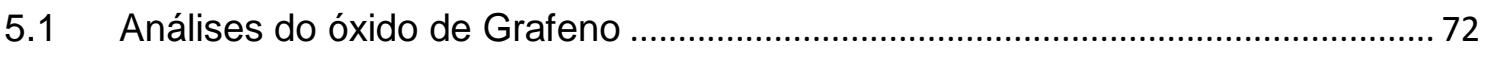

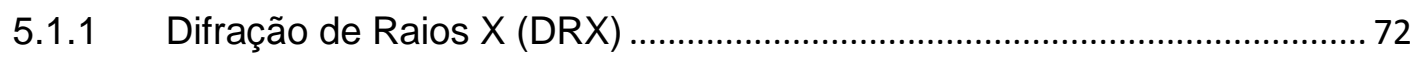

5.1.2 Microscopia Eletrônica de Varredura com fonte de emissão de campo

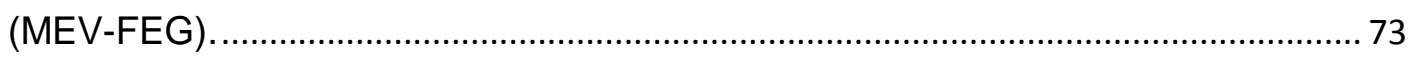

5.1.3 Microscopia Eletrônica de Transmissão (MET) .......................................... 77

5.1.4 Espectroscopia vibracional de absorção no infravermelho com transformada de Fourier (FTIR) ….......................................................................... 79

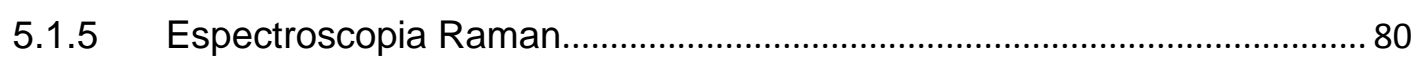

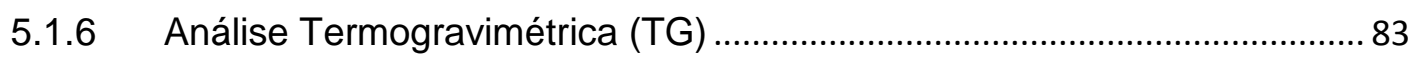

5.2 Análise do EVOH puro e seus nanocompósitos.................................................... 85

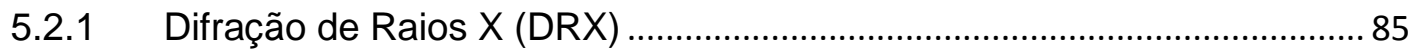


5.2.2 Microscopia Eletrônica de Varredura com fonte de emissão de campo (MEV-FEG)

5.2.3 Análise Termogravimetrica (TG) ........................................................... 95

5.2.4 Calorimetria Exploratória Diferencial (DSC) .............................................. 100

5.2.5 Espectroscopia vibracional de absorção no infravermelho com transformada de Fourier (FTIR) ............................................................................ 104

5.2.6 Espectroscopia de aniquilação de pósitrons (PALS) ................................. 105

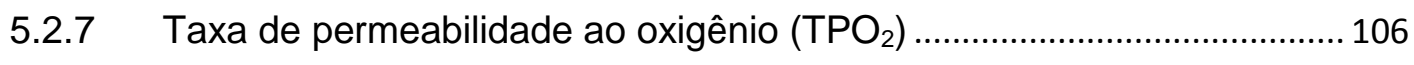

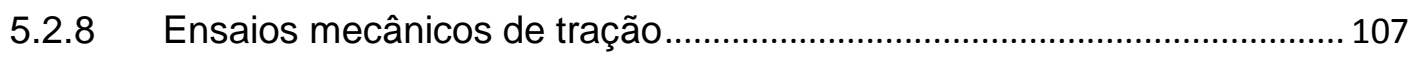

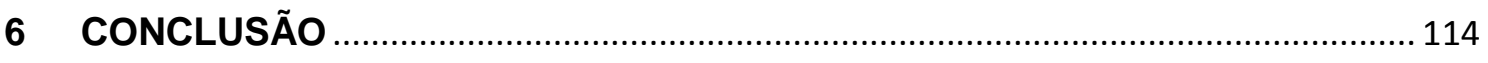

7 SUGESTÕES PARA TRABALHOS FUTUROS ……………………………........ 116

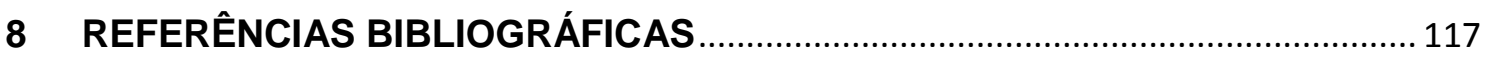




\section{INTRODUÇÃO}

A embalagem desempenha um papel fundamental na indústria de alimentos. As principais funções de uma embalagem específica para alimentos consistem na manutenção da segurança e qualidade dos mesmos, durante 0 armazenamento e transporte, e vida útil do produto embalado. A embalagem deve impedir ou dificultar o contato entre 0 ambiente externo e o produto alimentício, afim de impedir a ação de fatores ambientais ou condições desfavoráveis, como microrganismos, oxigênio, contaminantes químicos, luz e umidade (SARANTÓPOULOS et al., 2002; YOO et al., 2014).

Atualmente, os materiais mais utilizados para embalagem de alimentos são polímeros derivados do petróleo (plástico). As embalagens plásticas flexíveis e semirrígidas (potes e bandejas) vem substituindo gradativamente as tradicionais latas e frascos de vidro, sendo as embalagens plásticas flexíveis as comumente utilizadas. A crescente demanda do mercado de embalagens flexíveis para alimentos se baseia em menor custo de produção, maior flexibilidade e diversidade de materiais, assepsia, formatos, estruturas e baixo peso (BROCKGREITENS \& ABBAS, 2016).

Os materiais plásticos para embalagem apresentam permeabilidade relativa ao vapor d'água, a gases e moléculas penetrantes, entre outras. Assim, as embalagens plásticas flexíveis geralmente utilizadas no acondicionamento de alimentos sensíveis ao oxigênio não são eficazes: apresentam baixa permeabilidade ao oxigênio, (ou seja, possuem alta barreira ao oxigênio). No entanto, características como resistência química, mecânica, à perfuração e ao calor, transparência, brilho, capacidade de impressão, devem estar em conformidade com a legislação vigente, segundo a resolução - RDC no 91 do Ministério da Saúde (DESIGN, 1997).

O poli(etileno-co-álcool vinílico) (EVOH) representa um sistema polimérico para aplicação no segmento de embalagens flexíveis, que se destaca entre os filmes barreira ao oxigênio mais utilizados em embalagens para alimentos. $O$ EVOH pertence à família de materiais poliméricos semicristalinos, com excelentes propriedades de barreira a gases e com grande versatilidade de 
aplicação; pode ser usado em embalagens para acondicionamento a vácuo de produtos alimentícios, embalagens para solventes e produtos químicos, e até mesmo em tanques de gasolina, além de outras aplicações que exigem materiais com altíssima barreira a gás. O EVOH é amplamente utilizado na fabricação de embalagens flexíveis para alimentos e também em outros produtos sensíveis a determinados níveis de oxigênio ou dióxido de carbono. Entretanto, o EVOH é muito higroscópico e em condições de alta umidade relativa perde a sua propriedade de altíssima barreira a oxigênio, assim como as propriedades mecânicas.

A literatura tem relatado que a inclusão de cargas lamelares, tais como a argila, o grafeno e seus derivados, com alta razão de aspecto (relação comprimento/diâmetro) pode melhorar significativamente as propriedades de barreira a gás do EVOH.

O grafeno é um material que consiste de uma camada extremamente fina da grafite com alta razão de aspecto, estrutura bidimensional e estável sob condições ambientais. O grafeno tem atraído cada vez mais a atenção devido as suas excepcionais propriedades de barreira a gás, propriedades mecânicas, alta condutividade elétrica e térmica, estabilidade química, e flexibilidade estrutural. No entanto, tanto a produção em larga escala de grafeno quanto a sua incorporação homogeneamente dispersa na matriz polimérica permanecem um desafio (BAI, et al., 2011; KHOLMANOV et al., 2013; JIHAO Li et al., 2014; YOO et al., 2014).

De acordo com a literatura, a síntese de óxido de grafeno (GO) via oxidação química da grafite, e posterior redução, é uma possibilidade promissora para a produção em grande escala de grafeno e sua incorporação em matriz polimérica, além de outras aplicações. A incorporação de uma pequena quantidade em massa, aproximadamente $0,1-2 \%$, de (GO) no EVOH, pode conferir ganhos significativos nas suas propriedades físico-químicas, tais como, barreira a gás, resistência mecânica e estabilidade térmica. O GO contém grupos funcionais de oxigênio reativo, que o torna promissor na incorporação em matrizes poliméricas polares, como por exemplo, o EVOH. Entretanto, se as nanofolhas de GO não estiverem bem separadas umas das outras, tendem a formar agregados 
irreversíveis durante os processos de preparação e aplicação (COBOS; FERNÁNDEZ, 2018; ZHANG et al., 2018).

Devido ao pequeno tamanho, grande área superficial e a presença de elétrons " $\pi$ ", as nanofolhas de grafeno se tornam suscetíveis às forças de Van der Waals, que promovem a formação de agregados. Segundo a literatura, a redução química de parte dos grupos funcionais de oxigênio presentes no GO contribuem para uma melhor adesão na matriz polimérica de EVOH (X. HUANG et al., 2012; AL-JABAREEN et al., 2013).

A radiação ionizante é um método potencial para o desenvolvimento de novos materiais compósitos, pode ser aplicado, por exemplo, para a modificação da matriz polimérica, para a funcionalização de micro e nanocargas, e para criar um meio redutor para a preparação de nanopartículas metálicas e de materiais carbonosos nanoestruturados como o óxido de grafeno. A redução induzida por radiação ionizante é considerado um método simples, limpo, seguro e ambientalmente amigável quando comparado a redução química convencional para a modificação das propriedades de nanoestruturas de materiais carbonoso e para promover reações químicas em suas superfícies.

Os efeitos da radiação ionizante sobre os materiais dependem fortemente das condições de irradiação, do tipo de material e do meio de irradiação (ANSÓN-CASAOS et al., 2014). A indústria de embalagem tem usado a radiação ionizante para modificar as propriedades químicas, mecânicas, térmicas e de barreiras do seu produto final, de modo a ampliar o campo de aplicação e agregar valor. Estudos mostram que a melhoria das propriedades dos materiais poliméricos tratados por radiação ionizante é o resultado dos processos de reticulação e cisão (degradação) que ocorrem simultaneamente durante a irradiação e da compatibilização e estabilização da morfologia do material (GÜVEN et al., 2016).

Este trabalho estudou os efeitos da incorporação de nanofolhas de óxido de grafeno (GO) nas propriedades de filmes de EVOH. Primeiramente o GO foi obtido pelo método de Hummer's modificado e submetido a redução induzida por radiação ionizante, na presença de uma solução álcool/água (50/50 \%). Incorporações de 0,1 - 0,3 \% em massa de GO e GO reduzido (RGO) foram 
realizadas na matriz de $\mathrm{EVOH}$, via processo de mistura mecânica no estado fundido, utilizando uma extrusora dupla-rosca e, posteriormente, uma mini extrusora balão de laboratório para a obtenção de filmes flexíveis de EVOH/GO e EVOH/RGO.

Parte das amostras dos filmes flexíveis de EVOH e dos seus nanocompósitos foram tratadas por radiação ionizante com feixe de elétrons utilizando-se um acelerador de elétrons de 1,5 MeV pertencente ao Centro de Tecnologia das Radiações (CTR) do IPEN. O tratamento por radiação ionizante teve por objetivo promover a reticulação das cadeias poliméricas do $\mathrm{EVOH}$ e estudar o seu efeito na adesão interfacial entre a matriz de $\mathrm{EVOH}$ e as nanofolhas de GO, bem como também nas propriedades finais dos filmes flexíveis de EVOH/GO e EVOH/RGO.

A incorporação de pequenas porcentagens em massa de GO e RGO na matriz de EVOH foi realizada com o propósito de obter filmes flexíveis com propriedades mecânicas, térmicas e de barreira superiores quando comparados aos filmes de EVOH puro. 


\section{OBJETIVO}

O Objetivo deste trabalho é o processamento e caracterização de filmes flexíveis submetidos à radiação ionizante, em nanocompósito de poli(etileno-coálcool vinílico) (EVOH) com nanofolhas de óxido de grafeno $(\mathrm{EVOH} / \mathrm{GO})$ e de óxido de grafeno reduzido (EVOH/RGO), obtido a partir da grafite. A incorporação de nanofolhas de óxido de grafeno e de óxido de grafeno reduzido na matriz de EVOH tem como finalidade a obtenção de filmes flexíveis de EVOH/GO, contendo baixo teor de nanofolhas de GO e RGO (até 0,3\% em massa), com ótimas propriedades mecânicas, de barreira ao oxigênio e estabilidade térmica, quando comparados aos filmes flexíveis de EVOH puro, utilizados atualmente em embalagens para alimentos. 


\section{REVISÃO DA LITERATURA}

\subsection{Polímeros}

Os polímeros são compostos químicos orgânicos que têm, como base, elementos químicos como o carbono e o hidrogênio, entre outros não metálicos. Possuem elevada massa molecular, densidade relativamente baixa e resultam de reações químicas de polimerização. Segundo Canevarolo Jr, (2006), polímeros são materiais constituídos de pequenas unidades de repetição, denominadas meros, que formam longas cadeias poliméricas (macromoléculas), compostas por dezenas de milhares de meros, unidas por ligações intramoleculares fortes do tipo covalente: monômeros que ligam entre si, formando longas cadeias poliméricas (CALLISTER JR., 2008; CANEVAROLO JUNIOR, 2006).

Os materiais poliméricos podem ser amorfos e semicristalinos. Os polímeros amorfos são aqueles que não possuem capacidade de cristalização, devido à desordem das moléculas na cadeia. Os polímeros semicristalinos possuem regiões amorfas na cadeia e, nas regiões cristalinas, as cadeias moleculares estão perfeitamente ordenadas, formando um empacotamento regular, denominado cristalito (CANEVAROLO, 2006).

A maioria das propriedades físicas, mecânicas e termodinâmicas dos polímeros semicristalinos depende do grau de cristalinidade e da morfologia das regiões cristalinas. Quanto maior a cristalinidade, mais elevadas são as propriedades de densidade, rigidez, estabilidade dimensional, resistência química, resistência à abrasão, temperatura de fusão $\left(T_{m}\right)$, temperatura de transição vítrea $\left(\mathrm{T}_{\mathrm{g}}\right)$ para um dado polímero; entretanto, são inferiores as propriedades de resistência ao impacto, elongação na ruptura e ótica (FLEESON et al., 2017).

Os materiais poliméricos possuem diferentes características mecânicas, sendo assim classificados em termoplásticos ou termofixos. Os termoplásticos são caracterizados por possuir ligações químicas fracas (Van der Waals) entre as cadeias, que podem ser facilmente rompidas com a introdução de energia; são solúveis e podem ser fundidos em solventes comuns. Possuem fácil controle de qualidade, são recicláveis, tornando-os relevantes quanto ao aspecto socioeconômico, em prol da redução de utilização dos recursos naturais. Os polímeros termofixos, por sua vez, são insolúveis e não fundem em solventes 
orgânicos comuns; após submetidos ao aquecimento, assumem estrutura tridimensional, reticulada, com ligações cruzadas (COMPTON et al., 2012; FLEESON et al., 2017).

\subsection{Embalagem para Alimentos}

Materiais que possuem a capacidade de envolver e armazenar produtos, protegendo o material acondicionado, de modo este possa ser comercializado com segurança até chegar ao consumidor final são conhecidos como embalagens. Estas que são fundamentais para a acessibilidade a produtos frágeis, perecíveis, atender as necessidades de alimentação, saúde e conveniência. As embalagens para alimentos se destacam por se adequarem a quantidade de produto a ser acondicionado (relação entre a massa da embalagem versus massa do produto), sendo altamente flexíveis.

Atualmente, os materiais mais utilizados para embalagem de alimentos consistem de uma variedade de polímeros derivados do petróleo (plástico). Estes materiais são usados em várias combinações no preparo de embalagens com propriedades que assegurem a segurança e a qualidade dos produtos alimentícios, desde o processamento, manuseio e armazenamento, até o consumidor final.

As embalagens plásticas não são diferenciadas somente pelo material que às compõem, mas também pelos métodos de fabricação e uso. Os métodos de fabricação de plásticos para embalagens estão cada vez mais difundidos, como a extrusão plana ou balão para filmes, a coextrusão, a injeção e co-injeção em moldes, entre outros.

Vários fatores precisam ser considerados para a seleção da embalagem adequada para um determinado produto alimentício. As embalagens plásticas flexíveis e semirrígidas (potes, bandejas) vem substituindo gradativamente as tradicionais latas e frascos de vidro usados no acondicionamento de alimentos. Neste segmento, as embalagens plásticas flexíveis multicamadas, compostas por diferentes camadas de materiais poliméricos, tais como polietileno (PE), polipropileno (PP), poliamida (PA), poli(tereftalato de etileno) (PET) e poli(etileno-co-álcool vinílico) (EVOH), são mais utilizadas do que as embalagens 
plásticas monocamadas, as rígidas ou as embalagens de metal, vidro, papel e cartão.

Embalagens flexíveis são aquelas cujo formato depende da forma física do produto acondicionado, com espessura inferior a 250 micrometros. Nessa categoria estão incluídos: filmes plásticos flexíveis, papéis, folhas, alguns tipos de fibras vegetais e tecidos que podem ser usados para fazer invólucros, sacos selados ou sacos não selados para o acondicionamento do produto, pouches que ficam em pé (stand-up-pouches), envoltórios fechados por torção e/ou grampos, tripas, bandejas flexíveis que se conformam ao produto, filmes encolhíveis (filmes shrink), filmes esticáveis (filmes stretch), sacos de ráfia etc. Os materiais flexíveis incluem ainda selos de fechamento, rótulos e etiquetas plásticas.

As embalagens flexíveis se destacam pela relação otimizada entre a massa da embalagem e a quantidade de produto acondicionado, e pela flexibilidade no dimensionamento de suas propriedades. É possível combinar diferentes tipos de polímeros visando a obtenção das propriedades necessárias, que atendam aos requisitos econômicos, ambientais e de conservação e comercialização de produtos (RAHEEM, 2013; ABRE, 2018).

Do ponto de vista da sustentabilidade, as embalagens flexíveis oferecem vantagens para o acondicionamento de alimentos. Por exemplo, num pacote de plástico flexível é utilizado aproximadamente 50 a $75 \%$ menos material em comparação a um recipiente plástico rígido ou garrafa, para a mesma aplicação. O menor impacto ambiental associado à produção responsável são aspectos relevantes considerados pelas empresas quando do desenvolvimento de novas embalagens; é fundamental que a sustentabilidade seja mantida em toda cadeia produtiva, em novos desenvolvimentos, em conformidade com a Associação Brasileira da Indústria de Embalagens Plásticas Flexíveis (ABIEF, 2017).

A embalagem flexível pode se constituir numa solução para o combate do desperdício de frutas e hortaliças que, no Brasil, gira em torno de $40 \%$, segundo a Organização das Nações Unidas para Alimentação e Agricultura (FAO). São $40 \%$ de frutas e hortaliças que não chegaram à mesa do consumidor, porque foram acondicionadas em embalagens inadequadas, que não preservaram a integridade desses produtos. O mercado de embalagens flexíveis para alimentos 
vem apresentando grande expansão; segundo a Associação Brasileira da Indústria de Embalagens Plásticas Flexíveis (ABIEF), a indústria brasileira para estas embalagens vem acompanhando a tendência mundial. Em 2017, este mercado apresentou uma alta relevância, com $47 \%$ do total de produção, sendo o principal consumidor para o setor (ABIEF, 2018).

Segundo publicações da Agência de pesquisa internacional Canadean, o crescimento na escolha por embalagens flexíveis se fundamentará na busca por embalagens cada vez mais e mais inovadoras, com design que evidenciem o produto, agregando valor à sustentabilidade, destacando as reutilizáveis, com alta barreira e facilidade na abertura e refechamento (ABIEF,2017).

\subsection{Filmes Flexíveis}

Filmes poliméricos flexíveis constituem a estrutura básica de uma embalagem plástica flexível, capaz de garantir ao produto embalado a qualidade e a segurança do alimento, durante o armazenamento e transporte; e, também, aumentar a vida de prateleira, conferir proteção contra intempéries, tais como, fatores ambientais ou condições desfavoráveis, contra a presença de microrganismos que causam deterioração, contaminantes químicos, oxigênio, umidade e luz.

Para garantir a qualidade e a segurança do produto acondicionado podem ser utilizadas as embalagens denominadas multicamadas, para a qual camadas de filmes flexíveis produzidos a partir de diferentes materiais poliméricos são utilizados na sua composição, conferindo assim características específicas (ALLAHVAISI, 2017).

As embalagens multicamadas para alimentos são produzidas, afim de utilizar as melhores propriedades de cada material, protegendo o alimento de agentes externos como: umidade, luz, oxigênio, transporte entre outros. Como a utilização por exemplo do PP e PE para proteção contra vapor d'água; multicamadas de PP (possui ótima resistência térmica e ao impacto) na camada externa, e EVOH (excelentes propriedades de barreira aos gases) atuando como barreira ao oxigênio; multicamada para contato com alimentos, a partir do PET (excelente transparência e resistência ao impacto) usado como material de base, 
$\mathrm{EVOH}$ (excelentes propriedades de barreira aos gases) atuando como barreira, e PE (boa capacidade de vedação e barreira ao vapor de água) utilizado em camadas externas (COLOMBI, 2017; SEGUNDO; VILAR, 2016).

Uma descrição sucinta dos principais polímeros utilizados na produção de filmes flexíveis utilizados na composição de embalagens flexíveis multicamadas para alimentos é apresentada a seguir.

\subsubsection{Polietileno}

O polietileno (PE) é uma das poliolefinas mais abundantes, constituído por uma longa cadeia semicristalina de átomos de carbono, com átomos de hidrogênio unidos a cada átomo de carbono. O PE é um termoplástico formado de longas cadeias a partir do monômero etileno $\left(-\mathrm{CH}_{2}-\right)$; apresenta características de grande resistência a agentes químicos e mecânica, flexibilidade e boa barreira ao vapor d'água. O PE possui diferentes estruturas moleculares, o que influência a sua densidade e fluidez. Por exemplo, a densidade interfere na estrutura do PE, ramificações longas do PE diminuem a densidade, e as ramificações curtas aumentam a cristalinidade. A partir das ramificações das cadeias moleculares, pode ser classificado em: polietileno de alta densidade (HDPE), polietileno de baixa densidade (LDPE) e polietileno linear de baixa densidade (LLDPE) (JAIME et al., 2014; APRELINI, 2016).

O polietileno de baixa densidade (LDPE) é um polímero termoplástico, com estrutura cristalina, indicado para a fabricação de embalagens; durante sua utilização, o polímero é submetido a sucessivas compressões, por possuir maior flexibilidade e menor tendência à fratura da embalagem pela combinação entre ação química e tensão (BARBOSA et al., 2016).

O polietileno de alta densidade (HDPE) é um termoplástico mais resistente, com alto peso molecular, boas propriedades mecânicas, fácil processabilidade e melhor propriedade de barreira ao vapor d'água, em comparação ao LDPE (APRELINI, 2016).

O polietileno linear de baixa densidade (LLDPE) vem sendo utilizado em embalagens de alimentos, substituindo LDPE, em filmes industriais, fraldas descartáveis, brinquedos, artigos hospitalares, revestimentos para cabos, etc. $O$ 
LLDPE possui menor custo de fabricação quando comparado ao LDPE (APRELINI, 2016). Dentre as diversas aplicações para o LLDPE, a indústria de embalagens flexíveis se destaca, pelo consumo de aproximadamente $80 \%$ de todo LLDPE consumido no país, sendo $35 \%$ do consumo total das embalagens produzidas destinada à indústria de alimentos (ABIEF, 2018).

\subsubsection{Polipropileno}

O polipropileno (PP) é um polímero derivado do propileno, e uma poliolefina obtida via fracionamento do petróleo, com fórmula molecular $\left(\mathrm{C}_{3} \mathrm{H}_{6}\right)$ n. O PP é um termoplástico, empregado na fabricação de frascos, tampas de garrafa PET ou de vidro, com alta barreira ao vapor d'água, resistência mecânica e alto brilho. A utilização do PP corresponde significativamente ao consumo mundial do setor de embalagens, sendo um plástico translúcido, com alta rigidez, atóxico e reciclável, sendo muito utilizado para embalagens de destaque nas prateleiras e que não precisam de refrigeração (JAIME et al.; 2014).

O filme plástico de polipropileno biorientado (BOPP), é um tipo de filme plástico muito utilizado em embalagens de salgadinhos, biscoitos, sopas instantâneas, barrinhas de cereais, rótulos de garrafas PET, entre outros. Sendo muito usado pela indústria devido a sua fácil coloração, fácil impressão, baixo custo, elevada resistência química a solventes, resistência a quebras por flexão ou fadiga, boa resistência a temperatura e ótima estabilidade térmica, e totalmente impermeável. Porém, vem sendo utilizado em filmes multicamadas, laminado com outros polímeros quando se faz necessário de barreira a umidade e gases.

\subsubsection{Poliamida}

A poliamida ( $\mathrm{PA}$ ) é um polímero formado a partir de monômeros dos grupos amida (-CONH-) conectados por ligações peptídicas, e pertence também, ao grupo dos termoplásticos. Dentre os grupos da PA, as poliamidas aromáticas ou poliaramidas possuem um grande interesse industrial devido as suas características de boa estabilidade térmica, resistência à tração e elevada resistência ao impacto, além de apresentar barreira a aromas e gases. Sendo 
utilizada como camada de adesivo em embalagens multicamadas devido a sua resistência a perfuração e barreira ao oxigênio (COLOMBI, 2017).

\subsubsection{Poli(tereftalato de etileno)}

O Poli(tereftalato de etileno) (PET) é um polímero de condensação, termoplástico, constituído por átomos de carbono, oxigênio e hidrogênio. O PET é produzido industrialmente por transesterificação do etilenoglicol (glicol etilênico) com o tereftalato de dimetila, ou por esterificação direta, a formação ocorre entre o etilenoglicol e o ácido tereftálico (ácido p-benzenodioico), muito utilizado na indústria têxtil e indústria de embalagens. A estrutura molecular do monômero do PET apresenta anel aromático e é composta basicamente por ligações entre carbono e oxigênio. O PET é uma resina tradicional para barreira na produção de embalagens multicamadas, sendo usado também como camada de adesivo, devido a sua resistência mecânica, química, boa transparência e barreira contra gases e odores (FIGUEIREDO et al., 2015;CHENG et al.; 2009).

\subsubsection{Poli(etileno-co-álcool vinílico) - EVOH}

O poli(etileno-co-álcool vinílico) (EVOH) pertence à família de materiais poliméricos semicristalinos, com excelentes propriedades de barreira a gases, solventes e aromas e boa resistência química. Apresenta uma grande versatilidade de aplicação, podendo ser usado para embalagens no acondicionamento a vácuo, solventes e produtos químicos, e até mesmo em tanques de gasolina.

$\mathrm{O} E \mathrm{EOH}$, em razão do seu alto custo de produção, geralmente é usado em aplicações de embalagens que requerem materiais com altíssima barreira a gás, resistência à permeação de óleos, gorduras, solventes orgânicos, associado a uma boa resistência mecânica, elasticidade e alta resistência à abrasão (MATEO et al., 2017; MOKWENA; TANG, 2012). Como pode ser visto na Fig. 1, o EVOH apresenta na sua cadeia principal dois meros, sendo um de etileno e outro de álcool vinílico, distribuídos de maneira aleatória, que dão origem ao copolímero. É preparado comercialmente via processo de transesterificação do copolímero 
de etileno e do acetato vinílico (EVA) (NOGUEIRA et al., 2012; MACHADO et al., 2016).

Figura 1- Estrutura do Poli(etileno-co-álcool vinílico) (EVOH)

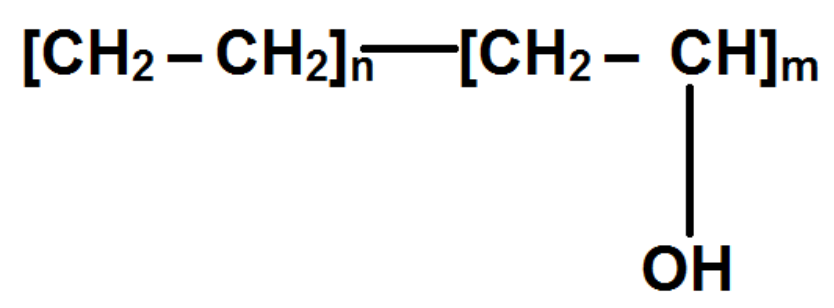

Fonte: Autor da dissertação.

$\mathrm{O}$ EVOH pode ser processado pelo processo de extrusão ou injeção, podendo também ser processado por coextrusão ou laminação, em combinação com PE, PP, PET, PA, e outras resinas para a produção de embalagens multicamadas. Todavia, a laminação e coextrusão de filmes barreira aumentam os custos de fabricação, dificultando a reciclagem e a reutilização das embalagens (KWON, et al., 2013).

\subsubsection{Propriedades de barreira}

Ao contrário de latas e frascos de vidro, os materiais plásticos são relativamente permeáveis aos gases, vapor d'água, e outras moléculas pequenas penetrantes. Portanto, as embalagens plásticas flexíveis para acondicionamento de alimentos sensíveis ao oxigênio devem possuir baixa permeabilidade ao oxigênio (ou seja, possuir alta barreira ao oxigênio). Além de várias outras características, tais como barreira à umidade, resistência mecânica, química, ao calor, à perfuração, transparência, brilho, capacidade de impressão, e estar em conformidade com a legislação em contato com alimentos vigente.

As propriedades de barreira se constituem num dos requisitos que devem ser considerados na seleção de embalagens flexíveis para alimentos. Para manter o alimento fresco e crocante, a embalagem deve possuir barreira à umidade. A rancidez do alimento pode ser minimizada pelo uso de materiais de embalagem que apresentem uma boa barreira ao oxigênio e à luz. $O$ contato do oxigênio com alimentos pode causar uma série de alterações indesejáveis tais 
como, a rancificação de óleos e gorduras presente nos alimentos, alterações da cor, aromas e sabores (BIJl et al., 2015). Por outro lado, o sabor original de um determinado alimento pode ser mantido pelo uso de uma embalagem que ofereça uma boa barreira a um aroma específico. Sendo assim, sistemas de embalagens flexíveis bem projetados são fundamentais para manter o alimento embalado em condições de uso e estender a sua vida útil.

No atual mercado de produção para embalagens, diversas tecnologias são encontradas com o objetivo de melhorar as propriedades de barreira, desde a incorporação de uma embalagem plástica, por adição de camadas de materiais de barreira, e também por misturas de materiais poliméricos, formando blendas e compósitos.

Nas primeiras embalagens flexíveis com barreira (a umidade e oxigênio) eram utilizadas uma camada de alumínio, inicialmente, camadas finas com espessuras micrométricas e, mais recentemente são utilizados revestimentos (coating) que conta com a adição de materiais em tamanhos nanométricos, podendo estes serem líquidos ou sólidos, que quando aplicados a embalagem atuam como barreira conferindo assim características especiais a embalagem e uma melhor proteção ao produto acondicionado. Outros métodos usados para melhorar as propriedades de barreira (à umidade, oxigênio e barreira a gás) são a laminação, a coextrusão e extrusão com polímeros de alta barreira a gás como o poli(cloreto de vinilideno) (PVDC), poli(etileno-co-álcool vinílico) (EVOH), poli(álcool vinílico) (PVA) e a poliamida (PA) (LANGE \& WYSER, 2003).

O poli(etileno-co-álcool vinílico) (EVOH) representa um interessante sistema polimérico para aplicação no segmento de embalagens flexíveis, destacando-se entre os filmes barreira a gás mais utilizados em embalagens flexíveis para alimentos. Entre os materiais poliméricos utilizados como barreira para embalagens de alimentos, $\mathrm{O} E \mathrm{EVH}$ possui melhor transparência, resistência a óleos, e propriedades de alta barreira contra permeação de gases, oxigênio e solventes.

Muito embora, o EVOH seja considerado um dos melhores materiais barreira ao oxigênio para alimentos e outras aplicações de embalagens que requerem alta proteção ao oxigênio, em condições de alta umidade relativa este apresenta uma redução na sua propriedade de alta barreira ao oxigênio (MATEO 
et al., 2017; MOKWENA; TANG; LABORIE, 2011). Os grupos hidroxila (-OH) tornam o polímero hidrofílico, atraindo moléculas de água. A presença de água no EVOH diminui sua temperatura de transição vítrea e reduz drasticamente as propriedades de barreira ao oxigênio do material. A presença do grupo $\mathrm{OH}$ na cadeia do $\mathrm{EVOH}$ aumenta as forças intermoleculares entre a cadeia polimérica da ligação hidrogênio e o rendimento proeminente de barreira para os permeantes, causando sorção de umidade devido à natureza hidrofílica, resultando na deterioração das propriedades de barreira do gás (CHIN, 2010).

A permeabilidade do EVOH a gases é dependente da taxa de copolimerização de etileno e álcool vinílico. As composições do EVOH normalmente variam de 27 a $48 \% \mathrm{~mol} /$ etileno. $\mathrm{O} \mathrm{EVOH} \mathrm{com} \mathrm{alto} \mathrm{teor} \mathrm{de} \mathrm{etileno}$ (acima de $27 \%$ ) e é geralmente utilizado como camada barreira a gás para embalagens flexíveis e semirrígidas de alimentos, onde a altíssima barreira a oxigênio se constitui num requisito fundamental.

Os danos causados pela absorção de água nas propriedades do EVOH associados ao alto custo de produção de uma embalagem contendo EVOH tem incentivado a pesquisa por materiais que possam ser incorporados a esse polímero e que resultem em melhorias e ganhos em suas propriedades finais, associado a um menor custo de produção.

A incorporação em materiais de embalagens plásticas flexíveis, de micro ou nanocargas, pode melhorar as propriedades mecânicas, propriedades de barreira a gás, conferir maior estabilidade às variações de temperatura, e também aumentar a preservação do produto final e reduzir o custo de sua produção, pois diminuem a quantidade de polímero inicial. Pode ainda contribuir para a sustentabilidade do planeta, uma vez que a população mundial cresce exponencialmente e de forma desorganizada; consequentemente, a indústria de embalagem necessita produzir mais e mais embalagens para 0 acondicionamento de alimentos que irão suprir as necessidades de alimentação desta população em grande expansão (KIM; CHA, 2014; SHANKAR \& RHIM, 2016).

De acordo com Yang, et al. (2013), a adição de diferentes nanocargas, tais como, argila, nanotubos de carbono, nanofolhas de grafeno e seus derivados, ou seja, materiais em tamanho nanométricos, com alta razão de aspecto podem 
melhorar significativamente as propriedades de barreira a gás do $E V O H$ (KASHYAP et al., 2016). Uma vez que a interação entre estas nanocargas e a matriz de EVOH ocorra de forma homogênea, origina-se então um nanocompósito o qual pode dar origem a embalagens flexíveis com melhores propriedades de barreira a gás, resistência mecânica, estabilidade térmica, ópticas, elétricas e maior flexibilidade, quando comparado as embalagens contendo a matriz de EVOH puro (CERISUELO et al., 2012; RAHEEM, 2013).

\subsection{Nanocompósito}

Um nanocompósito é um material no qual um de seus componentes possui uma das dimensões em tamanho nanométrico, ou seja, menor que 10-9 nm. Acredita-se que o termo "nanocompósito" foi utilizado inicialmente em 1986 e desde então os trabalhos nesta área vem crescendo exponencialmente. A ciência dos nanocompósitos está presente em todas as áreas de materiais como: metais, plásticos, cerâmicos, biomateriais, materiais elétricos e outros.

A incorporação de nanocargas em matrizes poliméricas fornece muitos benefícios, como melhores propriedades de barreira, maior resistência mecânica e melhor resistência ao calor, quando comparado aos polímeros puros e compósitos poliméricos convencionais (GABOR \& NAIARETTI, 2012).

A propriedade de barreira a gás dos nanocompósitos poliméricos pode ser determinada por três fatores: capacidade de resistência à difusão de gases das nanocargas, propriedade de barreira específica da matriz polimérica e interação entre a matriz polimérica e a qualidade da dispersão (aglomeração, interface específica) (CUI et al., 2016).

\subsection{Processamento de Nanocompósitos de Matriz Polimérica}

Os nanocompósitos poliméricos têm sido sintetizados por diversos, entre esses métodos destacam-se a intercalação do polímero a partir da solução, polimerização in situ; processo sol-gel e processo de mistura direta do polímero e das nanocargas (porque podem ser nanopartículas ou nanofolhas como é o 
caso do GO), o qual ocorre geralmente através da mistura mecânica no estado fundido em extrusora.

Para a mistura por solução, as nanocargas (porque podem ser nanopartículas ou nanofolhas como é o caso do GO) são dispersas numa solução orgânica, até a evaporação do solvente ou precipitação do polímero. Um fator importante que deve ser considerado para a realização da mistura por solução é a escolha do solvente a ser utilizado: este deve ser solúvel no polímero e apresentar uma boa interação com a nanocarga, para que ocorra uma boa dispersão desse reforço na matriz (CUI et al., 2016).

Na polimerização in situ, a nanocarga é dispersa em solventes, podem ser misturados com uma solução de monómero com um iniciador (foto iniciadores e iniciadores térmicos); após a dispersão, o iniciador de polimerização/catalisador e o monómero são colocados diretamente no reator de polimerização. A polimerização in situ é um método que utiliza unidades monoméricas e uma grande quantidade de reagentes no processo de polimerização (DAS et al., 2011; CUl et al., 2016).

3.5.1 Processamento de nanocompósitos por mistura mecânica no estado fundido (extrusão)

No processamento por mistura mecânica no estado fundido, ou seja, processamento por extrusão, nenhum solvente é utilizado para a preparação do nanocompósito, e o reforço nanométrico é misturado ao termoplástico fundido. Os nanocompósitos obtidos são considerados esfoliados quando há compatibilidade entre a nanocarga e a matriz polimérica, sendo obtidos através de adequadas condições de processamento, como temperatura e rotação da rosca da extrusora.

Processamento por extrusão é uma técnica de produção de materiais poliméricos (plásticos), considerado um método econômico por sua alta produtividade, alta eficiência na fusão do plástico (devido ao cisalhamento na rosca), matérias primas reutilizáveis em diferentes formas (pellets, cargas em pó), sendo assim ambientalmente amigável, quando se trata de produção em 
larga escala de nanocompósitos para aplicações industriais. (PARK, 2015; CUI et al., 2016; MA et al., 2013).

Nos últimos anos, o processamento de materiais compósitos, nanocompósitos e filmes via técnica de extrusão foi popularizado, devido à alta capacidade de produção, satisfazendo altas demandas a um custo baixo. A extrusão é o processo mais utilizado na indústria de plásticos, devido à operação a baixas a altas temperaturas, em curtos períodos, e funcionamento simples (VERMA et al., 2014; YEPES et al., 2018).

\subsection{Grafeno e Óxido de Grafeno}

Pesquisas com grafeno vem sendo efetuadas desde 1947, quando o físico Philip Russel Wallace observou uma folha do carbono de um átomo de espessura, enquanto estudava as propriedades eletrônicas da grafite. Em 2010 o prêmio Nobel da Física foi conquistado pelos russos Andre Geim e Konstantin Novoselov, ambos da Universidade de Manchester, na Inglaterra, que a partir da esfoliação mecânica da grafite foi descoberto o grafeno (YOUNG et al., 2012).

O grafeno é um material bidimensional (2D), sem defeitos, formado por átomos de carbono com hibridização $\mathrm{sp}^{2}$ : cada átomo de carbono se liga a outros três átomos de carbono, formando uma estrutura hexagonal (Fig. 2), que permite a obtenção de propriedades físico-químicas totalmente diferenciadas (GARCIA, 2016; HUANG et al., 2011; YOO et al., 2014). 
Figura 2 - Representação da estrutura do Grafeno

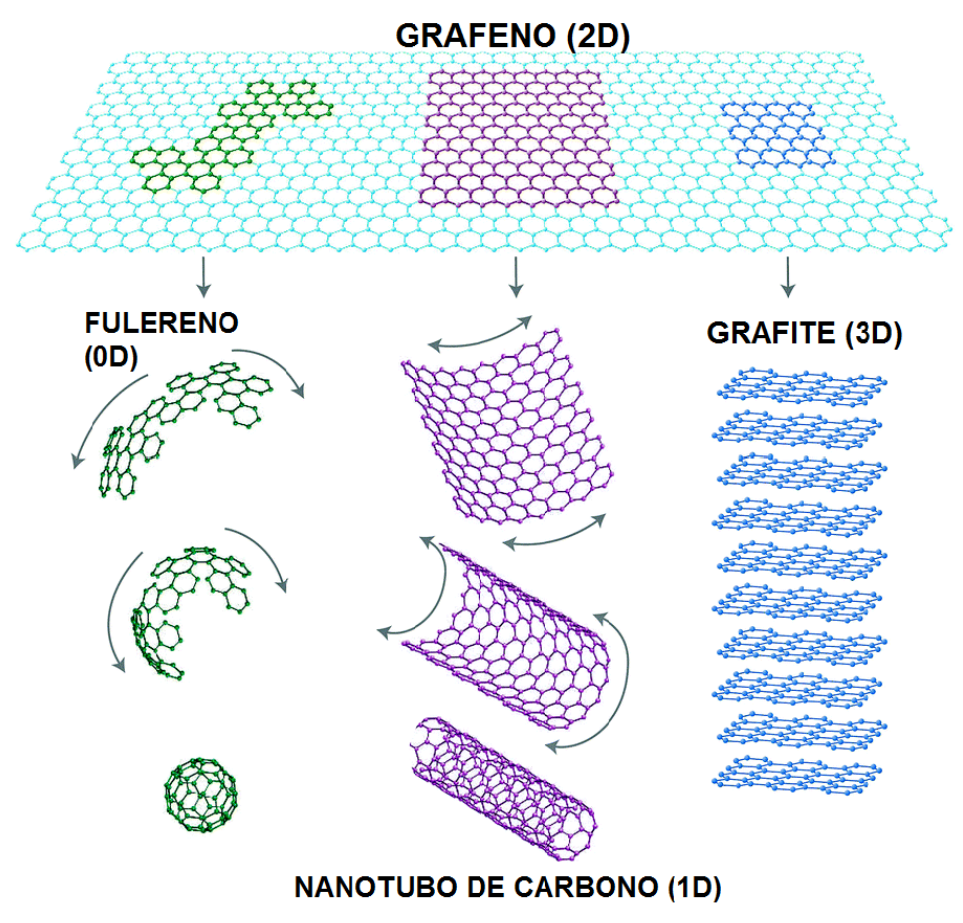

Fonte: adaptado autor da dissertação, Mother of all graphitic allotropes (GEIM; NOVOSELOV, 2007).

De acordo com Geim \& Novoselov (2007), a forma alotrópica do carbono, conhecida como grafeno, consiste num bloco básico para a arquitetura das estruturas nanométricas do carbono, exceto para o diamante. Como pode ser observado na figura 2 o carbono possui diversas formas alotrópicas e formas de estrutura organizadas, como fulereno (OD), nanotubos de carbono (1D) e grafite e diamante (3D).

O grafeno é um dos alótropos de carbono com maior interesse, devido às suas potenciais aplicações. Assim, a pesquisa a partir do grafeno atraiu atenção, devido ao interesse em explorar outras propriedades físicas interessantes e estimulantes, como: altos níveis de rigidez e resistência, condutividade térmica e elétrica, e impermeabilidade aos gases (YOO et al., 2014; CUI et al., 2016).

As propriedades notáveis do grafeno estão associadas à sua única camada. Diferentes métodos têm sido propostos para produzir uma monocamada de grafeno isenta de defeitos. $O$ grafeno pode ser sintetizado por deposição química a vapor (CVD), clivagem mecânica da grafite e esfoliação 
química da grafite (HIELSCHER \& GMBH, 2011; CUI et al., 2016; AZARNIYA et al., 2016).

\subsubsection{Processos de Obtenção do Grafeno}

Como o grafeno apresenta propriedades únicas, devido a sua alta mobilidade eletrônica, ótimo condutor térmico, um dos materiais mais resistentes e duros da atualidade, possui também excelentes propriedades óticas entre outras; podendo ser sintetizado através de vários métodos. A qualidade, o grau de esfoliação, a pureza, e a quantidade de defeitos estruturais do grafeno sintetizado dependerá da técnica escolhida para a sua síntese (GARCIA, 2016).

O grafeno pode ser obtido por meio das seguintes sínteses:

- método de deposição química em fase vapor ou (chemical vapour deposition) CVD, leva a obtenção de grafeno com um baixo número de defeitos estruturais da ordem de 1 a $15 \mathrm{~nm}$ de tamanho. Contudo, o custo da síntese é considerado elevado em relação as demais técnicas (CUI et al., 2011; YOO et al., 2014);

- outra técnica é a usada primeiramente por Geim \& Novoselov (2007), a qual rendeu o prêmio Nobel para eles, com a separação mecânica da grafite em camadas individuais, realizada com o uso de uma fita adesiva, a partir da descamação das camadas da grafite. Nesta técnica o grafeno obtido possui uma pequena quantidade de defeitos estruturais (SEGUNDO \& VILAR, 2016);

- a esfoliação química, é realizada a partir da modificação na estrutura da grafite através de tratamentos químicos, utilizando ácido nítrico ou sulfúrico concentrado e compostos oxidantes (SHAHRIARY \& ATHAWALE, 2014);

- o grafeno pode ser sintetizado também, por meio de síntese química a partir da grafite, pela qual obtém-se o óxido de grafeno (GO) que posteriormente é reduzido a grafeno. Está técnica é considerada a mais econômica e eficiente (SOLTANI; KYU LEE, 2017).

A síntese de obtenção do óxido de grafeno e sua redução, devido a sua importância neste trabalho será apresentada a seguir com maior detalhamento. 


\subsubsection{Síntese de Obtenção do Óxido e Grafeno}

Neste processo, a grafite é oxidada com uso de ácidos e agentes oxidantes fortes, aumentando o espaçamento interlamelar, ou seja, o espaçamento entre as camadas da grafite (GUPTA, 2011). A síntese de oxidação da grafite para a produção do GO surgiu em 1859, quando Brodie usou ácido nítrico fumegante e clorato de potássio $\left(\mathrm{KClO}_{3}\right)$ para oxidar a grafite. Depois de anos de pesquisa, Hummers e Offeman descobriram um método de síntese para a oxidação da grafite com permanganato de potássio $\left(\mathrm{KMnO}_{4}\right)$ e ácido sulfúrico $\left(\mathrm{H}_{2} \mathrm{SO}_{4}\right)$ como agentes oxidantes (Fig.3).

Figura 3 - Esquema do processo de produção do GO e RGO a partir da oxidação da grafite

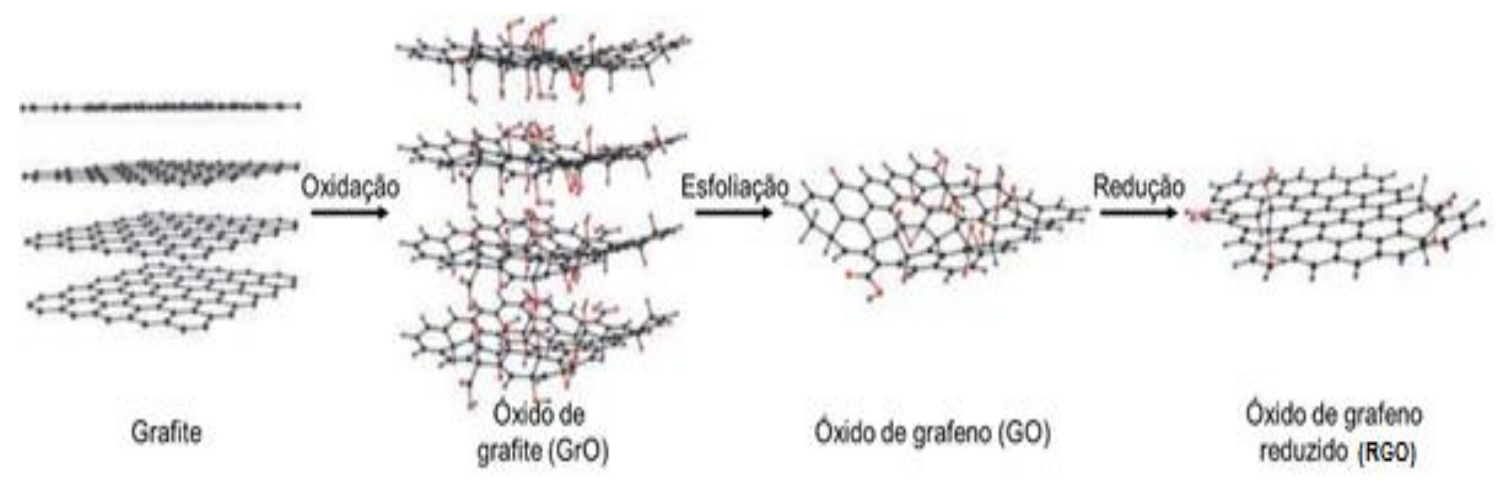

Fonte: SOLTANI \& KYU LEE, 2017.

Atualmente o método de Hummers original e modificado por diversos autores estão entre os mais pesquisados e aplicados para a síntese do GO (CHENG-AN et al., 2017). Alguns métodos desenvolvidos para a síntese do GO são resumidos na tabela 1 . 
Tabela 1 - Métodos de síntese de GO

\begin{tabular}{c|c|c|c}
\hline Métodos & Ano & Oxidantes & Solventes \\
\hline BRODIE & 1859 & $\mathrm{KClO}_{3}$ & $\mathrm{HNO}_{3}$ \\
\hline STAUDENMAIER & 1898 & $\mathrm{KClO}_{3}$ & $\mathrm{HNO}_{3} / \mathrm{H}_{2} \mathrm{SO}_{4}$ \\
\hline HOFMANN & 1937 & $\mathrm{KClO}_{3}$ & $\mathrm{HNO}_{3} / \mathrm{H}_{2} \mathrm{SO}_{4}$ \\
\hline HUMMERS & 1958 & $\mathrm{NaNO}_{3} / \mathrm{KMnO}_{4}$ & $\mathrm{H}_{2} \mathrm{SO}_{4}$ \\
\hline $\begin{array}{c}\text { HUMMERS } \\
\text { (Modificado) }\end{array}$ & 1999 & $\begin{array}{c}\mathrm{K}_{2} \mathrm{~S}_{2} \mathrm{O}_{8} / \mathrm{P}_{2} \mathrm{O}_{5} / \\
\mathrm{KMnO}_{4}\end{array}$ & $\mathrm{H}_{2} \mathrm{SO}_{4}$ \\
\cline { 2 - 4 } & 2010 & $\mathrm{KMnO}_{4}$ & $\mathrm{H}_{2} \mathrm{SO}_{4} / \mathrm{H}_{3} \mathrm{PO}_{4}$ \\
\hline
\end{tabular}

Fonte: DAUD, et al., 2017.

O óxido de grafeno (GO), que é esfoliado a partir do óxido da grafite, contém uma série de grupos funcionais de oxigênio reativos, como: hidroxila, carboxila e epóxi em seu plano basal, o que o faz promissor para a incorporação em matrizes poliméricas polares, como é o caso do EVOH (HE, et al., 1998; COMPTON et al., 2012). Devido à maior adesão interfacial entre o $\mathrm{GO}$ e a matriz polimérica polar, uma estrutura altamente esfoliada e com dispersão homogênea pode ser atingida. No entanto, se as nanofolhas de GO não estiverem bem separadas umas das outras, tendem a formar agregados irreversíveis durante os processos de preparação e aplicação, devido às forças de atração de Van der Waals.

De acordo com Gao (2015), a redução de parte dos grupos funcionais de oxigênio presentes no GO pode melhorar a sua dispersão na matriz polimérica. Observa-se também na literatura deferentes trabalhos sobre a incorporação do $\mathrm{GO}$ e o GO reduzido em polímeros termoplásticos como, polietileno (PE), poli(vinil álcool) (PVA), poli(tereftalato de etileno) (PET), poli(etileno-co-álcool vinílico) (EVOH). De acordo com estes trabalhos, os materiais compósitos obtidos, têm apresentado ganhos nas propriedades de barreira a gás, nas propriedades térmicas e mecânicas (X. HUANG et al., 2012; CUl et al., 2016).

\subsection{Redução do óxido de grafeno (GO)}

Atualmente, observa-se na literatura vários métodos de reduções do GO, tais como, a redução térmica em altas temperaturas, redução química a baixa 
temperatura, e redução induzida por radiação gama (MOON, et al., 2010; GAO et al., 2010). A redução térmica é geralmente realizada à temperaturas acima de 200 C, à vácuo ou em atmosfera inerte (STANKOVICH et al., 2007; HÉCTOR et al., 2008). Métodos solvotérmicos que requerem altas temperaturas acima de $100 \stackrel{\circ}{\circ}$ e altas pressões também são usados para a redução do GO (SALAVAGIONE et al., 2009; MOHANTY et al., 2010; MOON et al., 2010; GARCIA, 2016). A redução química pode ser realizada nas fases líquida e gasosa, com uso de agentes redutores como: hidrazina, boro-hidreto de sódio $\left(\mathrm{NaH}, \mathrm{NaBH}_{4}\right)$, ácido ascórbico, iodeto de hidrogênio $(\mathrm{HI})$, e hidroquinina.

São conhecidos vários métodos de redução química como os de Brodie, Staudenmaier. Contudo são perigosos, com alto risco durante o processo e tóxicos, devido a utilização do dióxido de cloro $\left(\mathrm{ClO}_{2}\right)$, do óxido nítrico $\left(\mathrm{NO}_{2}\right)$ e de agentes redutores, tais como, a hidrazina, boro-hidreto de sódio $\left(\mathrm{NaH}, \mathrm{NaBH}_{4}\right)$, iodeto de hidrogênio (HI), e hidroquinona (EMIRU \& AYELE, 2017).

A obtenção do $G O$ reduzido pode ser também realizada termodinamicamente por aquecimento do $\mathrm{GO}$ em um forno. A partir do aquecimento o gás de alta temperatura cria uma pressão dentro das camadas empilhadas e a esfoliação da estrutura empilhada ocorre através da extrusão de dióxido de carbono a uma temperatura de $1050^{\circ} \mathrm{C}$. Porém o tratamento térmico tem demonstrado um dano estrutural às plaquetas pela liberação de dióxido de carbono, reduzindo aproximadamente $30 \%$ da massa do GO durante a esfoliação, e afetando também as propriedades mecânicas do produto (GAO, 2015).

Atualmente, métodos ecologicamente mais amigáveis para a redução do GO vem sendo propostos, a fim de evitar o uso de produtos químicos agressivos, altas temperaturas e pressão. Entre os métodos amigáveis mais eficazes para a redução do $G O(R G O)$ e para uma produção segura de grafeno, pode-se citar a redução eletroquímica, a desoxigenação fototérmica e o uso de diferentes fontes de irradiação como a radiação ultravioleta, laser de excimer $\mathrm{KrF}$ e a radiação ionizante (feixe de elétrons e raios gama) (P. CUI et al., 2011; ESWARAIAH et al., 2011; DUMÉE et al., 2014; EMIRU \& AYELE, 2017).

A redução do $\mathrm{GO}$ induzida por radiação ionizante tem sido reportada pela literatura científica nos últimos anos. A redução do GO pode ser induzida por 
raios gama ou feixe de elétrons na presença de solução de água/álcool. A redução do GO induzida por radiação ionizante é considerada um dos métodos ecologicamente mais adequados e promissores para uma produção em larga escala de grafeno e apresenta muitas vantagens, em comparação aos outros métodos. A redução é realizada à temperatura ambiente, é livre de redutores químicos agressivos, é rentável e facilmente escalável (DUMÉE et al., 2014; KIM et al., 2015; EMIRU \& AYELE, 2017; AZARNIYA et al., 2016).

Nos trabalhos de Hareesh et al, (2015), tem apresentado uma outra maneira fácil e sem a utilização de agentes tóxicos e ácidos para a obtenção do RGO a partir da redução induzida por raios gama em uma solução de GO em dimetilformamida (DMF) à temperatura ambiente, e também a funcionalização do GO usando radicais livres formados a partir da redução induzida por radiação gama, em atmosfera controlada de $\mathrm{N}_{2}$ ou $\mathrm{H}_{2}$ (HAREESH et al., 2015).

Comparado com a redução química, a redução do $\mathrm{GO}$ induzida por raios gama ou feixe de elétrons apresenta vantagens significativas, tais como, o processo é isento da adição de agentes redutores químico agressivos e da geração de subprodutos óxidos indesejáveis; os radicais redutores que atuam como agentes redutores químicos são criados de forma homogênea na solução; e o processo de redução é simples, ambientalmente seguro e econômico.

De acordo com a radiólise da água, a água, quando exposta à radiação de alta energia, pode ser decomposta em espécies oxidativas $(\cdot \mathrm{OH})$, espécies redutoras $(\bullet \mathrm{H})$ e elétron hidratado ( $\left.\mathrm{e}^{-} \mathrm{aq}\right)$. Quando o álcool, um capturador de radicais livre é adicionado ao sistema, ele pode capturar $\mathrm{o} \cdot \mathrm{OH}$ oxidativo e convertê-lo em radicais redutores, o que pode transformar os precursores oxidativos em espécies reduzidas (DUMÉE et al., 2014; EMIRU \& AYELE, 2017).

\subsection{Sonicação}

A Sonicação é um procedimento que utiliza a energia das ondas sonoras, mais comumente conhecido como ultrassom, e vem sendo usado na indústria de processos e reações químicas, preparação de emulsão e suspensão, intensificando o processo de dispersão do solvente e nanocargas, contribuindo para aumentar a superfície de contato entre a fase orgânica e a fase aquosa. Em laboratórios, a sonicação é geralmente aplicada através de um sonicado, um 
recipiente de água pelo qual é transmitido ondas sonoras. Dependendo da potência deste, podem alcançar-se altas temperaturas. Os efeitos sonoquímicos podem ser observados em reações químicas com o aumento da velocidade de reação; melhoria da síntese de partículas; revestimento de nanopartículas. Fenômenos físicos e químicos no processo sonoquímico é a cavitação, que é a formação, crescimento e colapso implosivo de bolhas na solução (CIESIELSKI \& SAMORì, 2014;SOLTANI \& KYU LEE, 2017).

Durante a sonicação, as forças de cisalhamento e cavitação atuam no material induzindo a esfoliação. Existe uma relação entre o tempo de sonicação a ser usado, com a concentração e tamanho das partículas a serem produzidas.

O tratamento com ultrassom ou sonicação do óxido de grafeno (GO) e grafeno podem ser realizados a partir da esfoliação da grafite em solventes orgânicos. A sonicação da grafite e seus derivados, como o GO e RGO é considerada como um tratamento não destrutivo; muito embora o material sonicado possa ainda apresentar alguns defeitos estruturais (CIESIELSKI \& SAMORì, 2014).

A modificação de nanomateriais tais como as nanocargas de óxidos metálicos, argila, grafeno, GO entre outros, através da sonicação vem se tornando mais comum, devido à alta eficiência, menor tempo de reação e facilidade (CIESIELSKI \& SAMORì, 2014).

\subsection{Radiação lonizante}

A radiação ionizante é a radiação que possui energia suficiente para ionizar átomos e moléculas, capaz de arrancar um elétron de um átomo ou molécula produzindo íons (PRZYBYTNIAK, 1968). A radiação ionizante vem sendo utilizada há mais de quarenta anos para a modificação de polímeros, fibras, macromoléculas naturais, e, mais recentemente para a produção de novos materiais compósitos. As modificações induzidas pela radiação ionizante nos materiais são resultados dos processos de reticulação e cisão (degradação) que ocorrem simultaneamente durante a irradiação, e da compatibilização e estabilização da morfologia do material. Os processos de reticulação occorem preferencialmente na região amorfa do polímero. Estes processos ocorrem 
quando durante a irradiação, os raios gama ou feixe de elétrons interagem com a estrutura polimérica, causando excitações e ionizações nas moléculas provocando reações de decomposição e adição das cadeias (DRISCOLL et al., 2009; GARCIA, 2016).

A interação da radiação ionizante com a matéria promove eventos físicos, químicos e físico-químicos, assim polímeros e materiais derivados, quando submetidos à radiação ionizante podem sofrer modificações físicas e químicas induzidas pela radiação no polímero. Os efeitos da interação da radiação ionizante com o EVOH são reportados pela literatura. Polímeros como o EVOH quando submetidos a radiação de alta energia, ou seja, radiação ionizante, sofrem preferencialmente 0 processo de reticulação (CHUAQUIOFFERMANNS, 1989; GÜVEN et al., 2016).

A interação da radiação ionizante com a matéria também pode ocorrer através de mecanismos como o "efeito fotoelétrico", o "efeito Compton" e a "produção de pares". A prevalência de um mecanismo sobre o outro depende da energia incidente do fóton ou da partícula e do número atômico dos elementos químicos que constituem as moléculas da matéria (F.-W. SHEN, 1994; BHATTACHARYA, 2000).

\subsubsection{Efeito fotoelétrico}

No efeito fotoelétrico, um fóton incidente transfere a energia da radiação a um único elétron orbital, que é expelido com uma energia cinética $\left(E_{c}\right)$ bem definida (Fig. 4). O efeito fotoelétrico geralmente ocorre em baixas energias e em elementos químicos de elevado número atômico do átomo, i.e., quanto maior o número atômico, maior a probabilidade, decrescendo rapidamente com 0 aumento da energia (F.-W. SHEN, 1994; TAUAHATA et al., 2014). 
Figura 4 - Efeito fotoelétrico

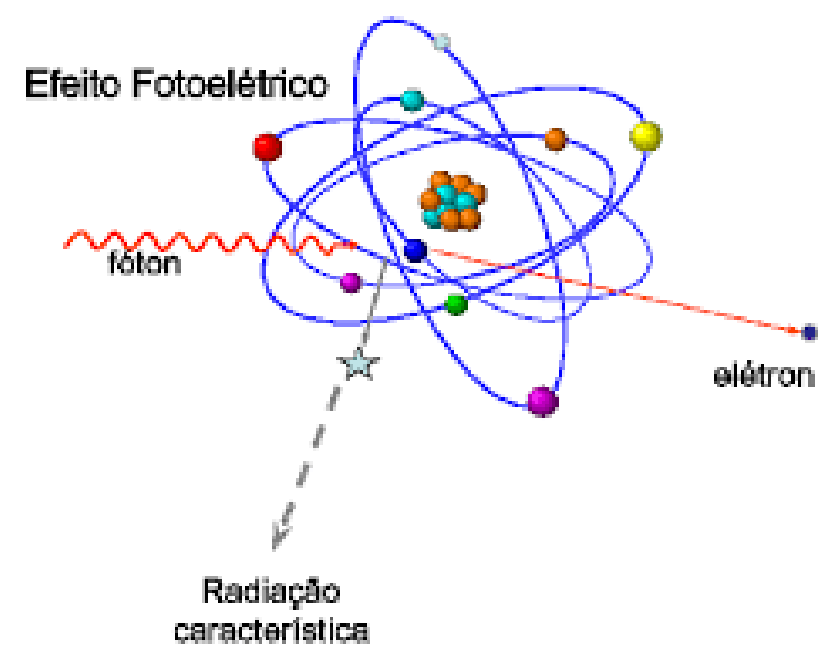

Fonte: TAUAHATA et al., 2014.

\subsubsection{Efeito Compton}

No efeito Compton, o fóton é emitido e transfere sua energia à matéria principalmente através de eventos de espalhamento de elétrons dos orbitais dos átomos alvo (Fig. 5). A distribuição no espectro de contagem é aleatória, a energia do fóton espalhado $E^{\prime} \gamma$ depende da energia do fóton incidente $E \gamma$ e do ângulo de espalhamento $\theta$, em relação à direção do fóton incidente. Assim, a ocorrência do efeito Compton é maior quando a energia da radiação gama aumenta de valor, ou quando a energia de ligação do elétron que sofre a incidência possui um valor menor, ou mínimo, em relação à da radiação incidente (TAUAHATA et al., 2014).

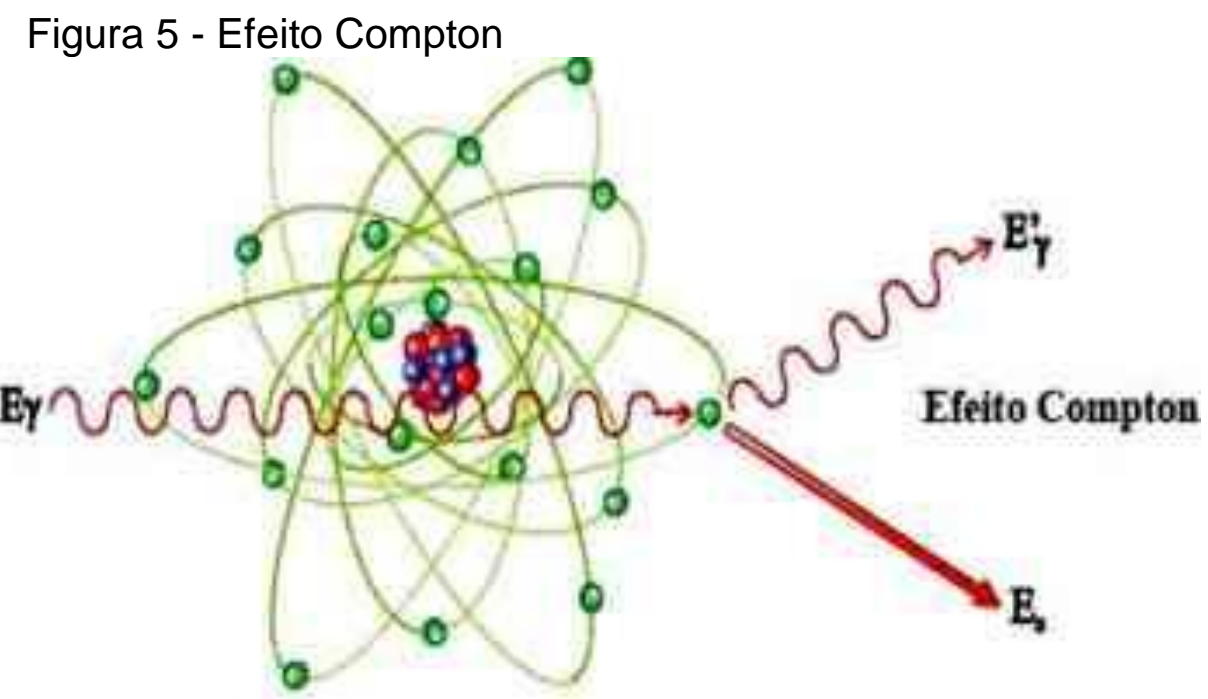

Fonte: TAUAHATA et al., 2014. 


\subsubsection{Produção de pares}

Na produção de pares, um fóton perde toda a sua energia em uma colisão, que é convertida em massa de repouso e energia cinética de uma partícula/antipartícula - elétron/pósitron (Fig. 6) (CHUAQUI-OFFERMANNS, 1989).

Segundo Heitler W (1953), na produção de pares a transição de um elétron de um estado de energia total negativa para um estado positivo; a diferença de energia entre os dois estados é a energia do fóton incidente, que é absorvido; a presença de um elétron no conjunto de estados de energia negativa é considerada como um pósitron.

Figura 6 - Produção de pares

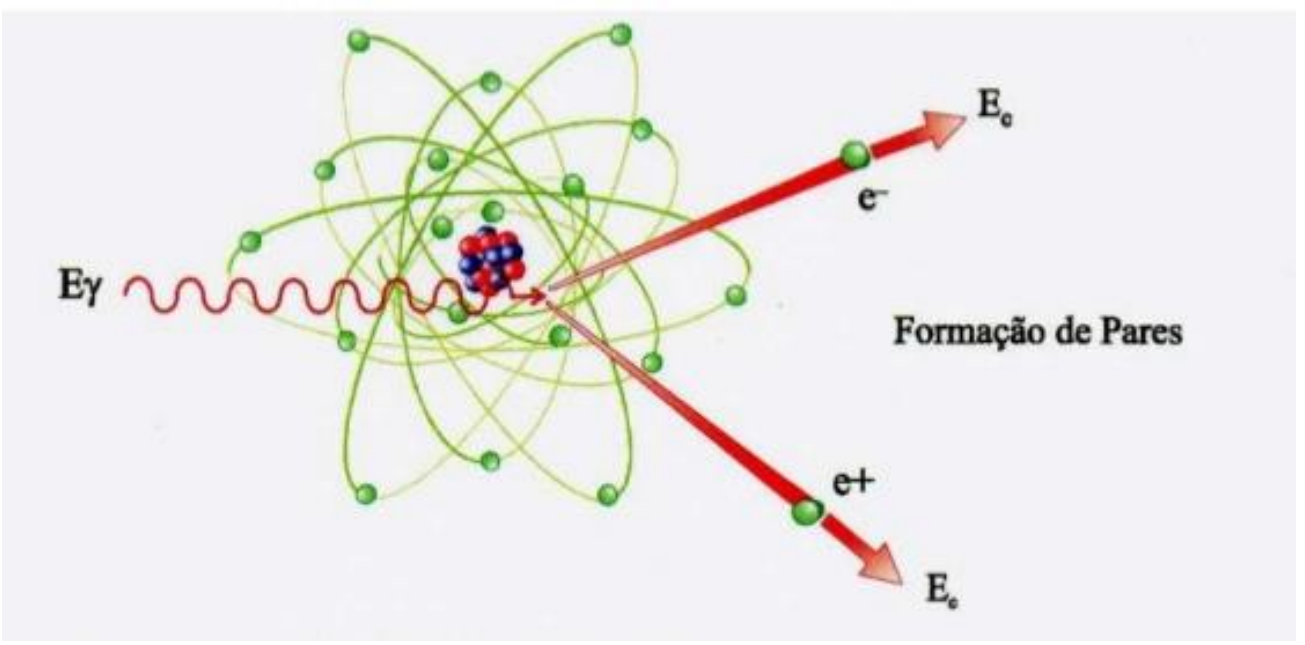

Fonte: TAUAHATA et al., 2014.

\subsection{Acelerador de Elétrons}

Aceleradores são máquinas capazes de acelerar feixes de partículas carregadas, fazendo com que estes alcancem velocidades altíssimas gerando energia capaz de produzir matéria em grande quantidade, íons com velocidade e energia cinética alta com o feixe bem controlado. Os aceleradores de elétrons podem ser divididos de acordo com a energia do feixe produzido, sendo aceleradores de baixa e de alta energia (MEHNERT, 1995). 
Os aceleradores de elétrons são muito utilizados para modificação de polímeros, uso em hospitais e processos de esterilização (alimentos, produtos de ortodontia) (SPINKS \& WOODS, 1964). São muito versáteis, pois, a partir do feixe de elétrons pode-se produzir feixes de radiação de freamento (radiação eletromagnética de alta energia e espectro contínuo), ou feixe de nêutrons, utilizando reações nucleares, para certas faixas de energia.

A radiação por feixe de elétrons pode causar mudanças estruturais nos materiais de embalagens, esterilização, modificação de polímeros, alterando suas propriedades mecânicas, químicas e de barreiras originais, e a polimerização de camadas finas de monômeros em superfícies de papel, plástico, madeira e metais (TAUAHATA et al., 2014).

\subsection{Irradiador Gama}

A radiação gama $(\gamma)$ são radiações eletromagnéticas de alta energia e curto comprimento de onda. Sendo bastante utilizada para a esterilização de produtos médicos, material de laboratório, embalagens, cosméticos, entre outros (ANSÓN-CASAOS et al., 2014).

A radiação gama é considerado um método limpo, seguro e fácil para modificação de nanoestrutura e das propriedades dos materiais de carbono, e para promover reações químicas em suas superfícies. Recentemente, os efeitos positivos associados a mudanças estruturais nos nanotubos dos nanotubos de carbono, grafeno e GO induzidos pela radiação gama vem sendo apresentados e discutidos pela literatura (LEILA SHAHRIARY \& ATHAWALE, 2015; HAREESH et al., 2016).

\subsection{Efeitos da radiação em polímeros}

A interação da radiação ionizante com os polímeros depende do tipo de radiação, das condições de processo: presença de oxigênio, diferentes atmosferas, temperatura, o grau de cristalinidade e homogeneidade do polímero, pode ocorrer a reticulação e cisão/degradação das cadeias poliméricas, e alterações das propriedades mecânicas, térmicas originais. Os resultados destas reações podem ser de formação de produtos oxidados, a quebra da cadeia 
principal (degradação), ou a reticulação nas regiões amorfas dos polímeros (DRISCOLL et al., 2009; FERREIRA et al., 2014).

Quando um polímero é submetido a radiação ionizante, pode ocorrer simultaneamente os processos de reticulação e cisão/degradação das cadeias poliméricas, os quais podem promover alterações nas propriedades originais do polímero. A prevalência do processo de reticulação sobre a degradação do polímero depende também do polímero que está sendo tratado, alguns polímeros, como é o caso do $\mathrm{EVOH}$, quando submetidos ao tratamento por radiação ionizante, sofrem preferencialmente a reticulação

O processo de degradação também conhecido como cisão (Fig. 7), pode ser definido como uma série de reações químicas que podem levar a ruptura das ligações da cadeia principal da macromolécula, quebra de ligações covalentes e formação de novas ligações, a produção de compostos voláteis em alguns polímeros (o qual reduz a massa molar) e redução das propriedades físicomecânicas (JAE BYUN et al., 2007; CANEVAROLO S., 2012).

Figura 7- Processo de degradação por radiação

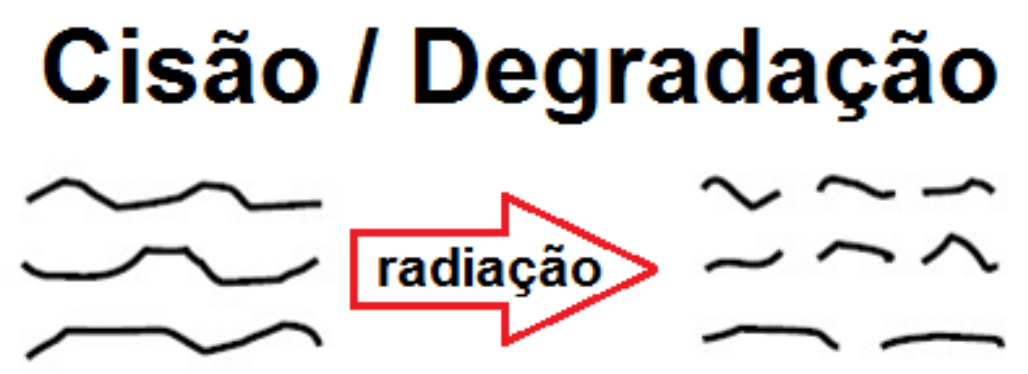

Fonte: Adaptado autor da dissertação (YOO et al., 2014).

A reticulação (crosslinking) é a formação de ligações intermoleculares na cadeia polimérica formando redes tridimensionais que aumentam o peso da massa molar do polímero (Fig. 8).

A reticulação induzida por radiação vem sendo utilizado na produção de materiais compósitos, devido ao ganho de propriedades originais, e melhor adesão interfacial entre a fase dispersa e a matriz polimérica após a irradiação (FERREIRA et al., 2014). A reticulação dos polímeros termoplásticos induzida por radiação ionizante, pode alterar a estrutura química do polímero, o que pode 
promover ganhos nas propriedades mecânicas, química, aumento da sua temperatura de degradação térmica e melhores propriedades de barreira a gases (MARSH \& BUGUSU, 2007; CHIN, 2010).

Figura 8 - Processo de reticulação por radiação

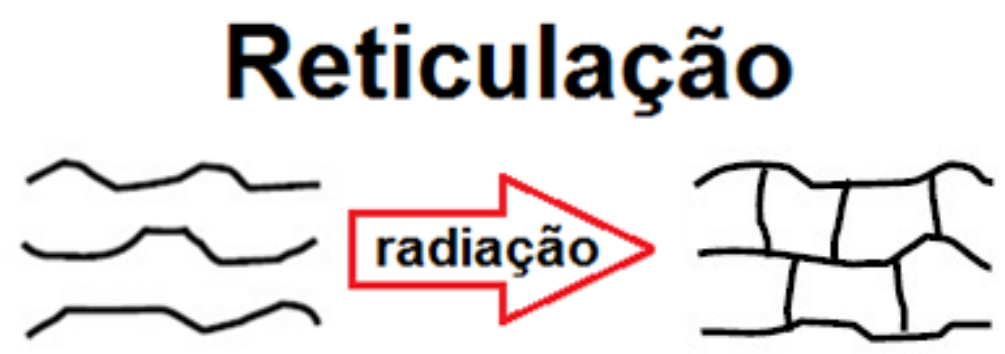

Fonte: Adaptado autor da dissertação (YOO et al., 2014).

Processamento de misturas por fusão, como os processos de extrusão são as técnicas mais utilizados para fabricação de compósitos termoplásticos, contudo estes processos muitas vezes levam a obtenção de compósitos com pobre adesão interfacial entre o polímero e a fase dispersa. Assim, quando estas técnicas convencionais são associadas ao uso da radiação de alta energia como por exemplo, o feixe de elétrons, um grau de reticulação uniforme pode ser produzido no material, levando-o a excelentes propriedades de resistência térmicas mecânica, e propriedades de barreira, entre outras. A irradiação pode também promover ligações entre a fase dispersa e a matriz polimérica, melhorando a adesão interfacial, e, consequentemente as propriedades do material compósito termoplástico tratado (CHIN, 2010; NOGUEIRA et al., 2012).

\subsection{Técnicas de caracterização}

3.13.1 Difração de Raios X (DRX)

A técnica de difração de raios $X$ permite quantificar o espaçamento basal (do01) entre as lamelas do GO (CHIN, 2010).

Quando um feixe de raios $X$ incide sobre cristal, estes é espalhado pelos elétrons, percorrendo uma distância interplanar é $d$, e com o ângulo de incidência é $\theta$. Em certas direções os feixes espalhados se somam construtivamente e 
produzem picos de difração (CHIN, 2010), conforme esquema representado na Fig. 9.

Figura 9 - Difração de Raios X

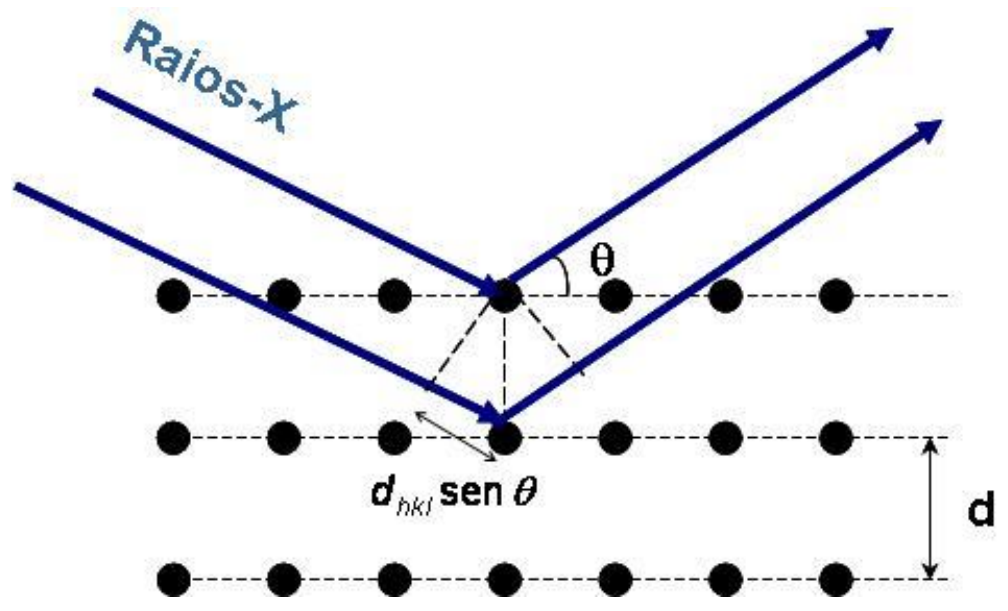

Fonte: SALAVAGIONE et al., 2009.

A equação 1 representa lei de Bragg:

$$
n \lambda=2 \mathrm{~d} \operatorname{sen} \theta
$$

Onde:

$\boldsymbol{n}=$ representa a ordem de difração,

$\lambda=$ comprimento de onda da radiação incidente,

$\boldsymbol{d}=$ distância interlamelar

$\theta$ = ângulo de difração.

3.13.2 Microscopia eletrônica de varredura com fonte de emissão de campo (MEV-FEG)

A microscopia eletrônica de varredura com fonte de emissão de campo (MEV-FEG) é uma técnica para caracterizações microestruturais, que pode ser aplicada em diversas áreas, como a engenharia e ciências dos materiais, ciências biológicas dentre outros. A incidência de um feixe de elétrons sobre uma determinada área a ser analisada, apresentam sinais (imagens) a serem 
utilizados para as caracterizações da amostra, como: sua composição, morfologia, cristalografia e outros (DENARI, 2012; BENNETT, 2014).

O equipamento utilizado para o MEV-FEG apresentado na fig.10, é dividido em duas partes principais: a coluna e a câmara de amostras. A coluna trabalha mantida sob vácuo e contém em sua parte superior um canhão de elétrons, abaixo deste canhão existem lentes magnéticas usadas para focar o feixe de elétrons sob a amostra. Na câmara de amostras diferentes detetores são usados para captar os sinais gerados pela interação da amostra com elétrons incidentes e o suporte (CANEVAROLO S., 2012).

Figura 10 - Representação esquemática do MEV-FEG

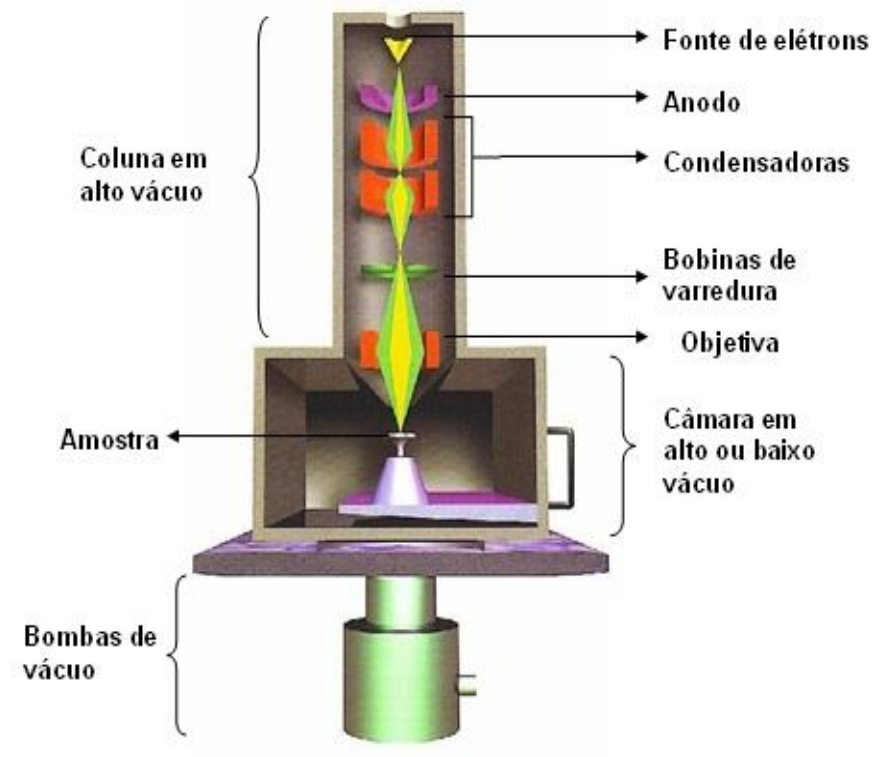

Fonte:CANEVAROLO, 2006.

\subsubsection{Microscopia Eletrônica de Transmissão (MET)}

A microscopia eletrônica de transmissão é uma técnica que apresenta uma alta resolução. Dentre as suas aplicações estão: a análise de nanopartículas, de defeitos; avaliação de filmes; identificação de composição de fases (por exemplo, nanocompósitos), e outros.

Na parte experimental, a interação do feixe eletrônico de alta energia com a matéria promove diversos efeitos tais como radiação (raios-X característicos), 
elétrons secundários, elétrons retroespalhados e elétrons transmitidos, utilizados na formação das imagens.

3.13.4 Espectroscopia vibracional de absorção no infravermelho com transformada de Fourier (FTIR)

A espectrofotometria de infravermelho, é uma técnica muito utilizada para conhecer as informações a respeito da identidade, pureza e presença de grupos funcionais, tendo assim as características estruturais do material de pesquisa.

No espectro eletromagnético a radiação infravermelha está situada em comprimentos de onda específicos, a região correspondente ao infravermelho médio (MIR), estende de 2,5 $\mu \mathrm{m}$ a $25 \mu \mathrm{m}$, que são as frequências vibracionais mais utilizadas na caracterização de materiais plásticos (CANEVAROLO, 2006; LEE et al., 2008; BARSBAY et al., 2016).

\subsubsection{Espectroscopia Raman}

A espectroscopia Raman, fornece informações relacionadas às propriedades eletrônicas e estruturais do grafeno, usada também para determinar a ordem de empilhamento em várias camadas do grafeno, GO e RGO (quando estas sobrepostas, com a formação do empilhamento das nanofolhas).

Características do espectro Raman para o grafeno e seus derivados são chamadas banda $\mathrm{G}$ (a vibração no plano de átomos de carbono $\mathrm{sp}^{2}$, grau de grafitização), banda $D$ (fornece informações sobre a estrutura eletrônica) atribuída ao grau de desordem/defeitos e a banda 2D ou G', que é segunda ordem da banda D (H. YANG et al., 2014;.LEILA SHAHRIARY \& ATHAWALE, 2015).

\subsubsection{Análise Termogravimétrica (TG)}

As análises por termogravimetria são baseadas no estudo da variação de massa de uma amostra (perda ou ganho) resultante de uma transformação física ou química em função do tempo ou da temperatura. Pode-se conhecer o 
comportamento térmico da amostra, como sua estabilidade térmica, e acompanhar processos com variação de massa, como degradação, desidratação, oxidação e desintegração (MATOS, J.R. \& MACHADO, 2004). Os resultados deste tipo de análise são as curvas de variação de massa e temperatura, chamadas de curvas termogravimétricas (TG), e suas derivadas (DTG), estas curvas apresentam informações sobre estabilidade térmica e composição da amostra (Fig. 11) (CANEVAROLO, 2006).

Figura 11- Curvas TG e DTG

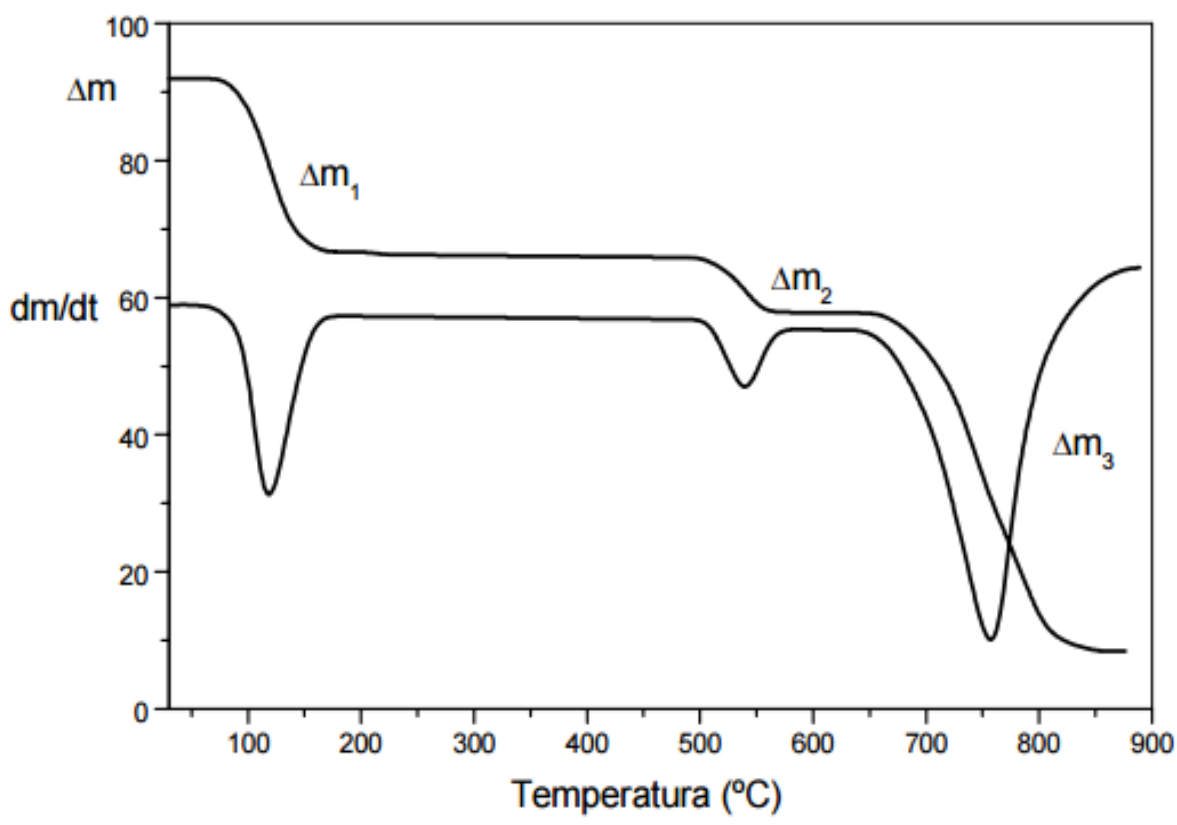

Fonte: PRZYBYTNIAK, 1968.

\subsubsection{Calorimetria Exploratória Diferencial (DSC)}

A Calorimetria Exploratória Diferencial (DSC) é uma técnica que mede a quantidade de calor envolvido com as correspondentes temperaturas das transições físico-químicas. O DSC mede a diferença de energia fornecida à substância e ao material de referência, ambos submetidos à mesma programação controlada de temperatura, de modo que a amostra e a referência sejam mantidas em condições isotérmicas uma em relação à outra. Como resultado, obtêm-se curvas DSC, geralmente apresentadas como fluxo de calor em função do tempo ou da temperatura. Por meio delas, é possível observar as 
transições associadas à variação de calor específico, como transição vítrea, e variação de entalpia $\triangle \mathrm{H}$ associada às transições de primeira ordem, como fusão e cristalização (MATOS, J.R. \& MACHADO, 2004).

Como evento térmico de materiais poliméricos pode-se citar:

- Temperatura de transição vítrea $\left(T_{g}\right)$ : é a temperatura abaixo da qual a cadeia principal do polímero não possui mobilidade;

- Temperatura de fusão $\left(T_{m}\right)$ : ocorre em materiais com um mínimo de cristalinidade, uma vez que em materiais totalmente amorfos este evento não ocorre;

- Grau de cristalinidade $\left(X_{c}\right)$ : as propriedades físicas como dureza, resistência mecânica, densidade, entre outras, variam consideravelmente com o percentual de cristalinidade, que relaciona a quantidade de material cristalino e material amorfo de uma amostra (SEGUNDO \& VILAR, 2016).

\subsubsection{Ensaios Mecânicos de Tração}

Propriedades de tração incluem resistência à tração, alongamento e módulo de elasticidade. Estas propriedades são determinadas por meio de um ensaio padrão das amostras submetidas a uma taxa constante de estiramento, usando um equipamento de tração. A resistência à tração é a força, ou a tensão, expressa em $\mathrm{MPa}$ ou $\mathrm{N} / \mathrm{mm}^{2}$, necessária para romper uma amostra em teste padrão pelo estiramento, com uma taxa de velocidade constante. $O$ alongamento é definido como uma expansão produzida pela força de tração aplicada para uma amostra e é expressa como uma porcentagem do comprimento inicial. O módulo de elasticidade é definido como a força, expressa em $\mathrm{N} / \mathrm{mm}^{2}$, necessária para produzir certo alongamento (CHOUDHARY et al., 2012).

Nos ensaios de tração um corpo de prova com dimensões padrão é preso em duas garras na direção vertical do equipamento de ensaio. Uma das garras é fixa e a outra é deslocada para cima por um mecanismo de tração acoplado a software no computador que controla a velocidade de deslocamento do travessão. Nesta mesma garra superior é fixado um sensor de força, que também é conectado ao mesmo computador. O computador registra a força 
necessária para tracionar o corpo de prova em função do deslocamento (GUBBELS et al., 1994; ZHU et al., 2010).

\subsubsection{Espectroscopia de tempos de vida de aniquilação de pósitrons (PALS)}

A Espectroscopia de tempos de vida de aniquilação de pósitrons (PALS) é comumente utilizada para investigações de porosidade, volumes livres dos materiais poliméricos (SÖYLEMEZ et al., 2018).

O tempo de vida do $\mathrm{e}^{+}$, tempo desde a sua formação até à sua aniquilação pode ser analisado através de um sistema PALS. Após entrar na matéria condensada, o pósitron eletricamente carregado $\left(\mathrm{e}^{+}\right)$torna-se termalizado em um tempo curto (alguns ps), aniquilando-se em um elétron diretamente ou através da formação de um estado intermediário, positrônio (com o símbolo químico Ps) (FERREIRA MARQUES et al., 2007; NORTON et al., 2015). Apesar da tendência do $\mathrm{e}^{+} \mathrm{e}$ do $\mathrm{e}^{-}$se aniquilarem quando se encontram, eles podem, em certas condições, formar um estado ligado antes de ocorrer a aniquilação. A formação do estado ligado entre $0 \mathrm{e}^{+}$e $0 \mathrm{e}^{-}$pode ocorrer se $0 \mathrm{e}^{+}$termalizado estiver na vizinhança de um $\mathrm{e}^{-}$. $\mathrm{O} \mathrm{e}^{+}$e $\mathrm{o} \mathrm{e}^{-}$são então atraídos pelas suas cargas eletrostáticas e, em vez de se aniquilarem, formam um átomo "exótico" designado positrônio (Ps) (SÖYLEMEZ \& GÜVEN, 2018; SÖYLEMEZ et al., 2018).

Este sistema oferece uma grande variedade de informações sobre as propriedades estruturais do material uma vez que o tempo de vida do $\mathrm{e}^{+}$contém informação sobre a densidade eletrônica da matéria e no caso da formação de pósitrons o seu tempo de vida contém informação sobre a distribuição do volume livre. O tamanho das cavidades (volumes livres) é uma das propriedades mais diretas que podem ser identificadas por meio deste sistema. A Fig.12 mostra o princípio básico de todos os sistemas tradicionais de medida de tempos de vida do positrão, é a medida do tempo de vida individual dos vários $\mathrm{e}^{+}$registando os sinais, desde o seu nascimento até à sua eventual aniquilação com os e- do meio onde os e $e^{+}$são implantados. 
Figura 12 - Esquema princípio PALS

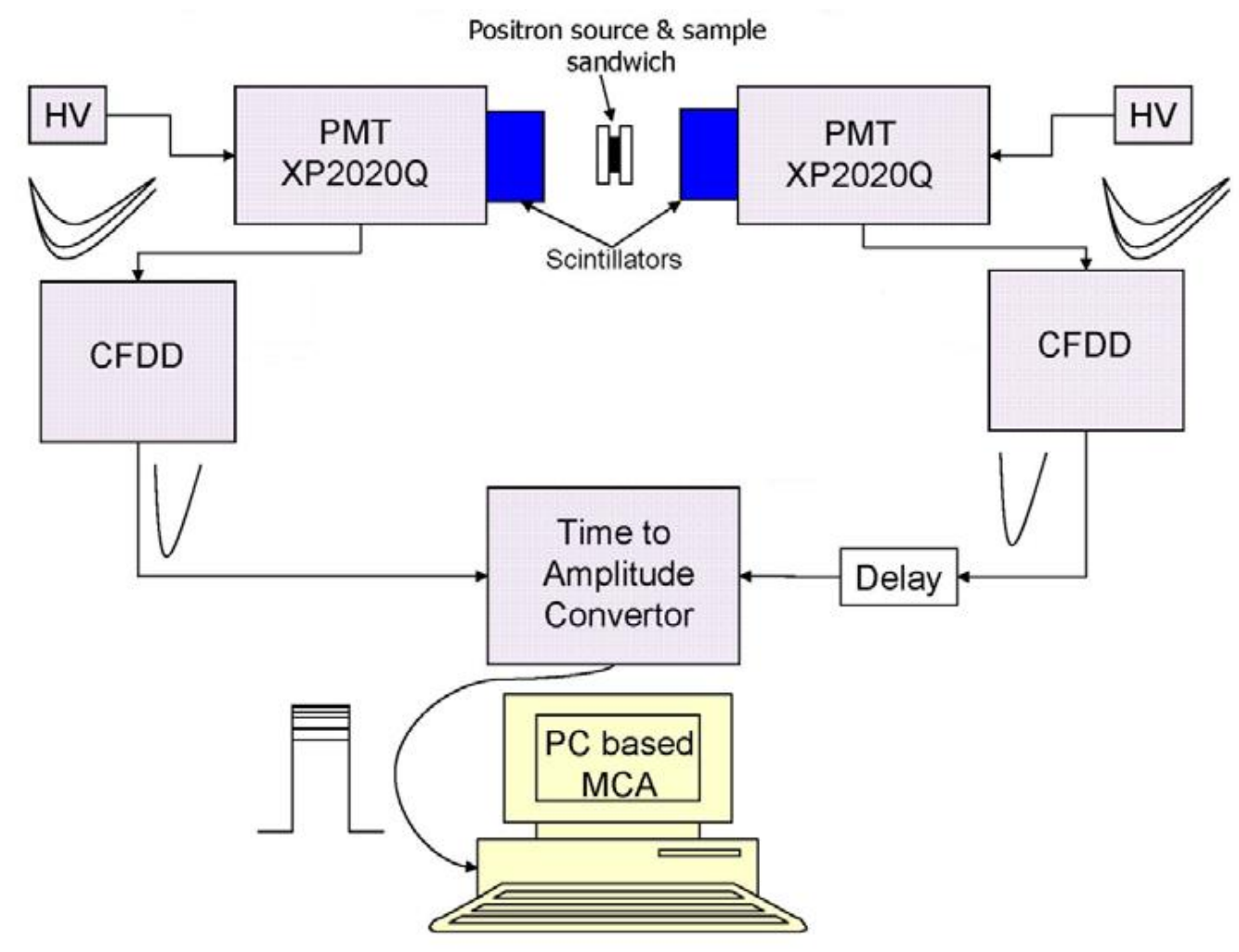

Fonte: HANDELSBLATT, 2010.

3.13.10 Taxa de permeabilidade ao oxigênio $\left(\mathrm{TPO}_{2}\right)$

A taxa de permeabilidade ao oxigênio $\left(\mathrm{TPO}_{2}\right)$ permite a determinação do coeficiente de permeabilidade ao oxigênio dos filmes. A $\mathrm{TPO}_{2}$ é uma característica importante e determinante dos materiais flexíveis com propriedade de barreira a gás, principalmente se relacionada à proteção de produtos sensíveis ao oxigênio (CRIPPA, 2006; BENNETT, 2014).

A eficácia da barreira ao oxigênio aumenta com a diminuição do coeficiente de permeação ao oxigênio, isto é, o produto da constante de difusão com o coeficiente de solubilidade. Um parâmetro experimental que permite quantificar a eficácia da barreira contra a penetração do oxigênio, sob condições definidas de temperatura e umidade (geralmente $23^{\circ} \mathrm{C}$ e $0 / 90 \%$ de umidade relativa) é a taxa de transmissão de oxigênio, geralmente expressa em termos de $\mathrm{cm}^{3} / \mathrm{m}^{2}$.dia (SPINKS \& WOODS, 1964).

Para a realização do ensaio, o filme é fixado como divisória entre duas câmaras. Em uma das câmaras a atmosfera é de nitrogênio, na outra é oxigênio, 
ambas à pressão atmosférica ambiente. Na saída de nitrogênio há um sensor que mensura quantidade de oxigênio presente conforme pode ser observado na figura 13. O teste termina quando a concentração de oxigênio na atmosfera de nitrogênio é constante (NOGUEIRA, 2012).

Figura 13 - Funcionamento de um equipamento de avaliação da $\mathrm{TPO}_{2}$

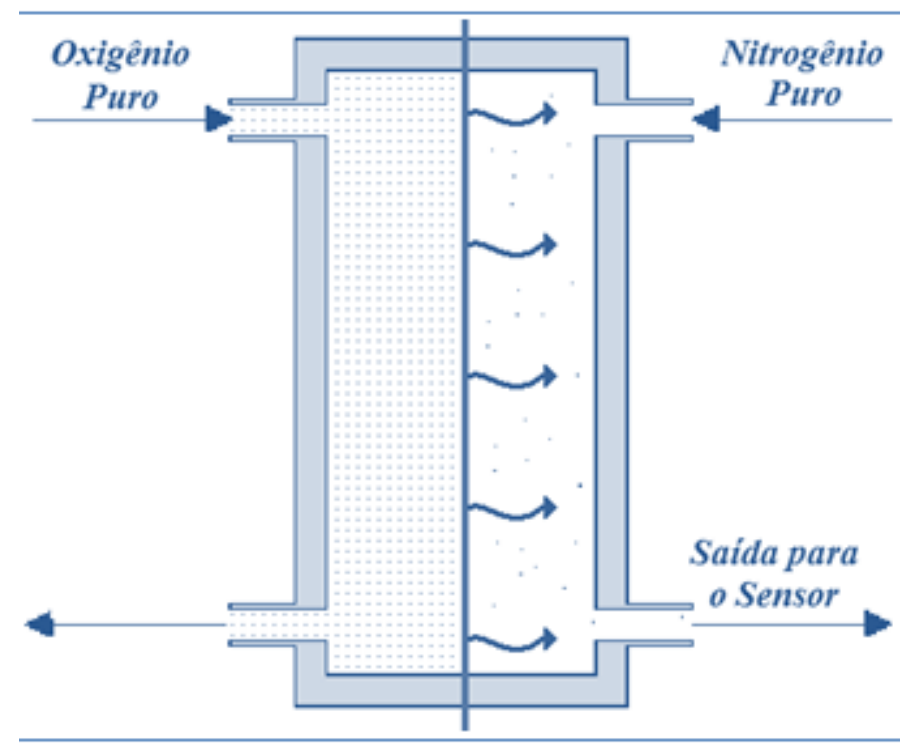

Fonte: NOGUEIRA, 2012. 


\section{MATERIAIS E MÉTODOS}

4.1 Materiais

Para a obtenção e desenvolvimento deste trabalho foram utilizados os seguintes materiais:

> Poli(Etileno-co-álcool Vinílico)(EVOH) $32 \%$ mol/etileno - comercial EVAL.

> Grafite - Química Ltda. (São Paulo, Brasil);

> Ácido Sulfúrico - $\left(\mathrm{H}_{2} \mathrm{SO}_{4}, 98 \%\right)$;

> Permanganato de Potássio $\left(\mathrm{KMnO}_{4}, 99.9 \%\right)$;

$>$ Peróxido de hidrogênio $\left(\mathrm{H}_{2} \mathrm{O}_{2}, 30 \%\right)$;

$>$ Dimetilformamida (DMF);

> Água Destilada;

> Ácido clorídrico $(\mathrm{HCl}, 37 \%)$;

> Álcool etílico absoluto - (Etanol - $\mathrm{C}_{2} \mathrm{H}_{6} \mathrm{O}-99.5 \%$ Synth).

\subsection{Métodos}

\subsubsection{Síntese do óxido de grafeno}

O óxido de grafeno (GO) foi produzido seguindo o método de Hummers (W.S. HUMMERS JR., 1958) modificado. Em primeiro lugar, grafite (5 g) e permanganato de potássio (15 g) foram homogeneizados a seco, depois ácido sulfúrico concentrado (100 mL - 98 \%) foram adicionados continuamente misturados num banho de gelo. Em seguida foi adicionado água destilada (400 $\mathrm{mL}$ ) a mistura, e esta foi colocada num banho maria a $90^{\circ} \mathrm{C}$ durante $60 \mathrm{~min}$. Ao final foi adicionado à solução de $30 \mathrm{~mL}$ de peroxido de hidrogênio $\left(\mathrm{H}_{2} \mathrm{O}_{2}\right)$ e 70 $\mathrm{mL}$ de agua destilada, seguidos por agitação mecânica por mais 4h. A figura 14 mostra o fluxograma da metodologia utilizada. 
Figura 14 - Fluxograma da metodologia de obtenção do GO

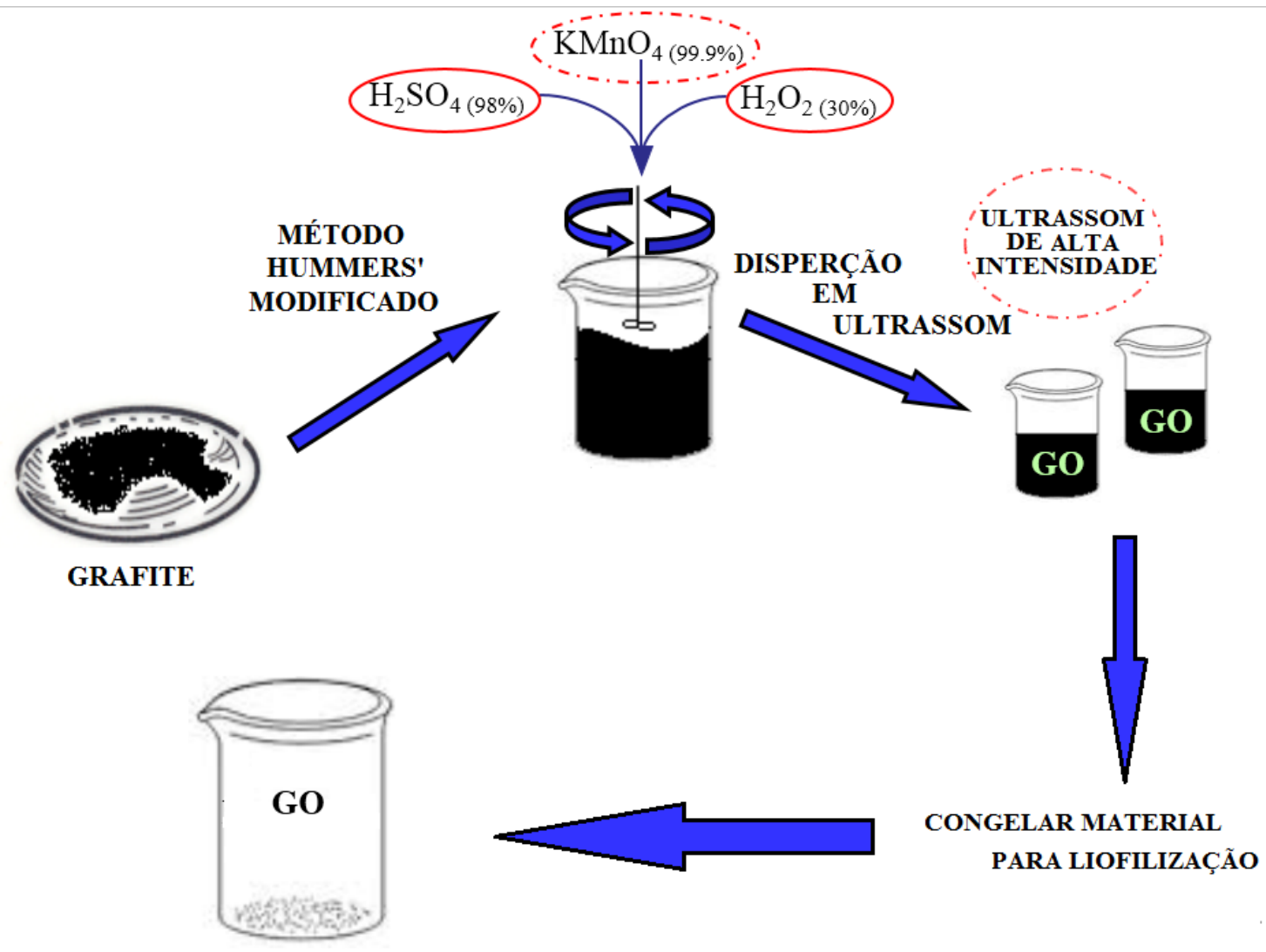

Fonte: Autor da dissertação.

\subsubsection{Centrifugação}

A solução resultante $(600 \mathrm{~mL})$ foi lavada com ácido clorídrico, álcool etílico e agua destilada respectivamente, até chegar a um $\mathrm{pH} \sim 6$ com o uso e uma centrífuga (fig. 15), modelo Q222T204 a 10.000rpm.

Figura 15- Centrífuga modelo Q222T204

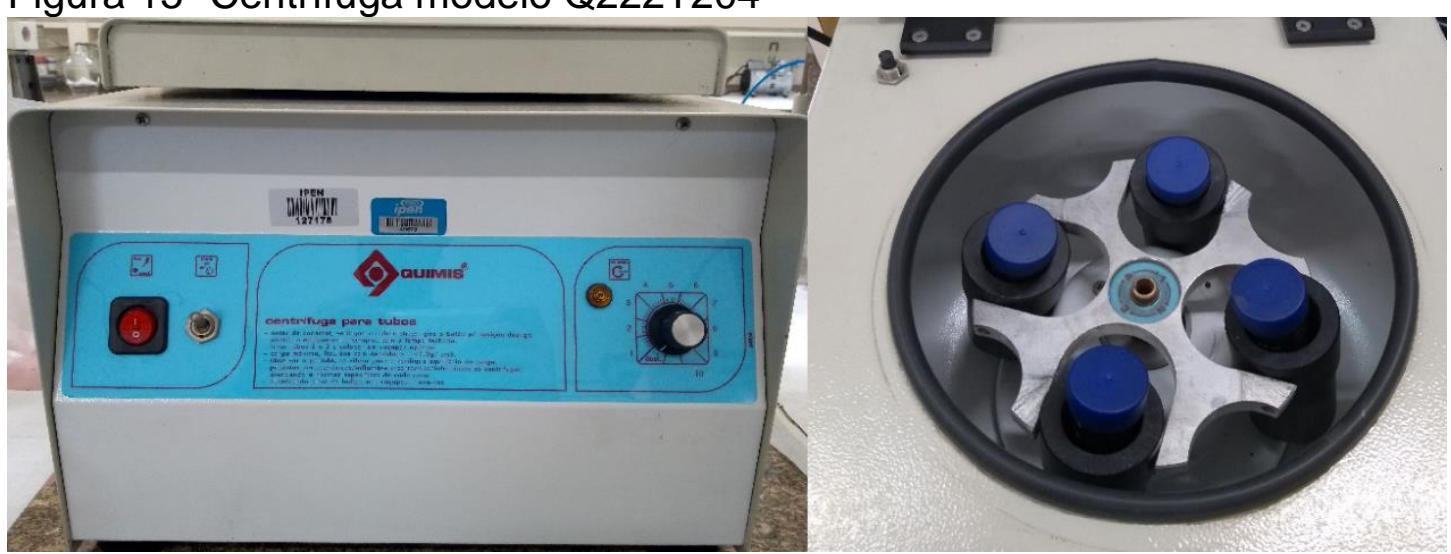

Fonte: Autor da dissertação. 


\subsubsection{Ultrassom}

Após a lavagem, o sólido obtido foi disperso em dimetilformamida (DMF) (30 mL) e água destilada $(70 \mathrm{~mL}$ ) e sonicado utilizando um Desruptor de Célula Ultrassônico - Modelo: DES500 (Fig. 16) de alta intensidade (20 kHz e 450 W/ $\mathrm{cm} 2$ ) durante 2 horas.

Figura 16 - Desruptor de Célula Ultrassônico

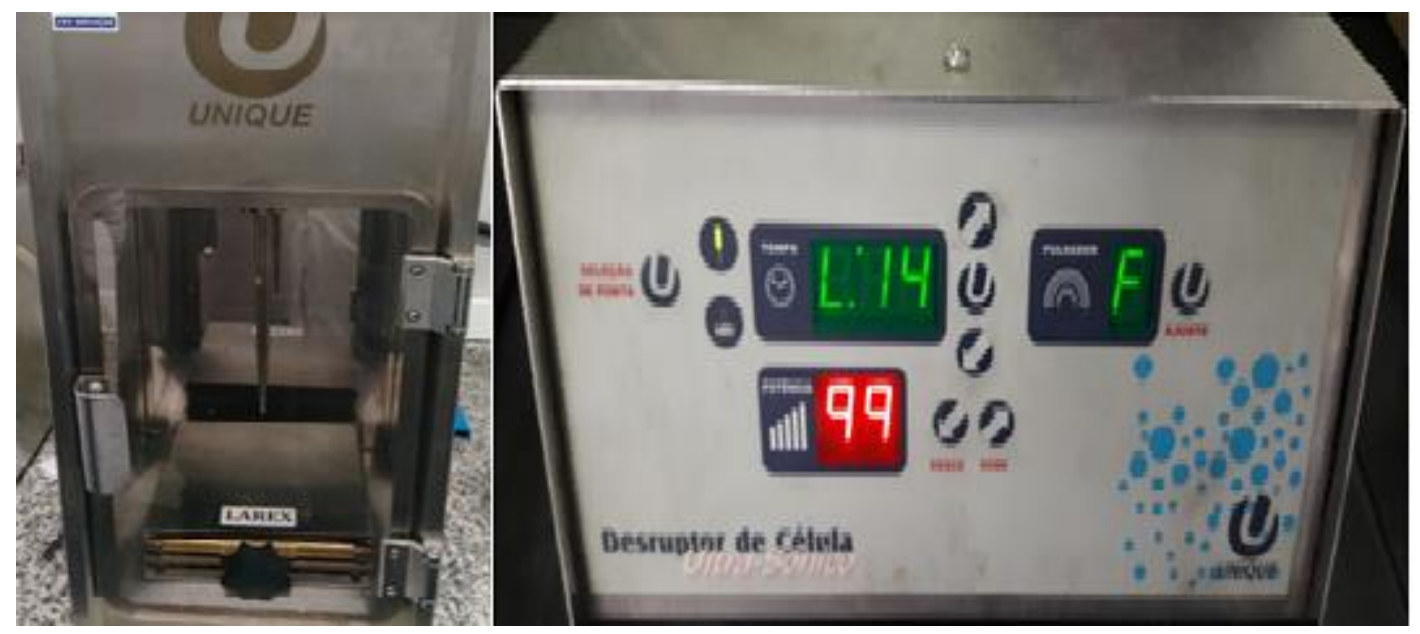

Fonte: Autor da dissertação.

\subsubsection{Liofilizador}

Após sonicado o material foi congelado e levado ao liofilizador - Liofilizador De Bancada (L101) (Fig. 17) por 48h para a liofilização do óxido de grafeno.

Figura 17- Liofilizador De Bancada (L101)

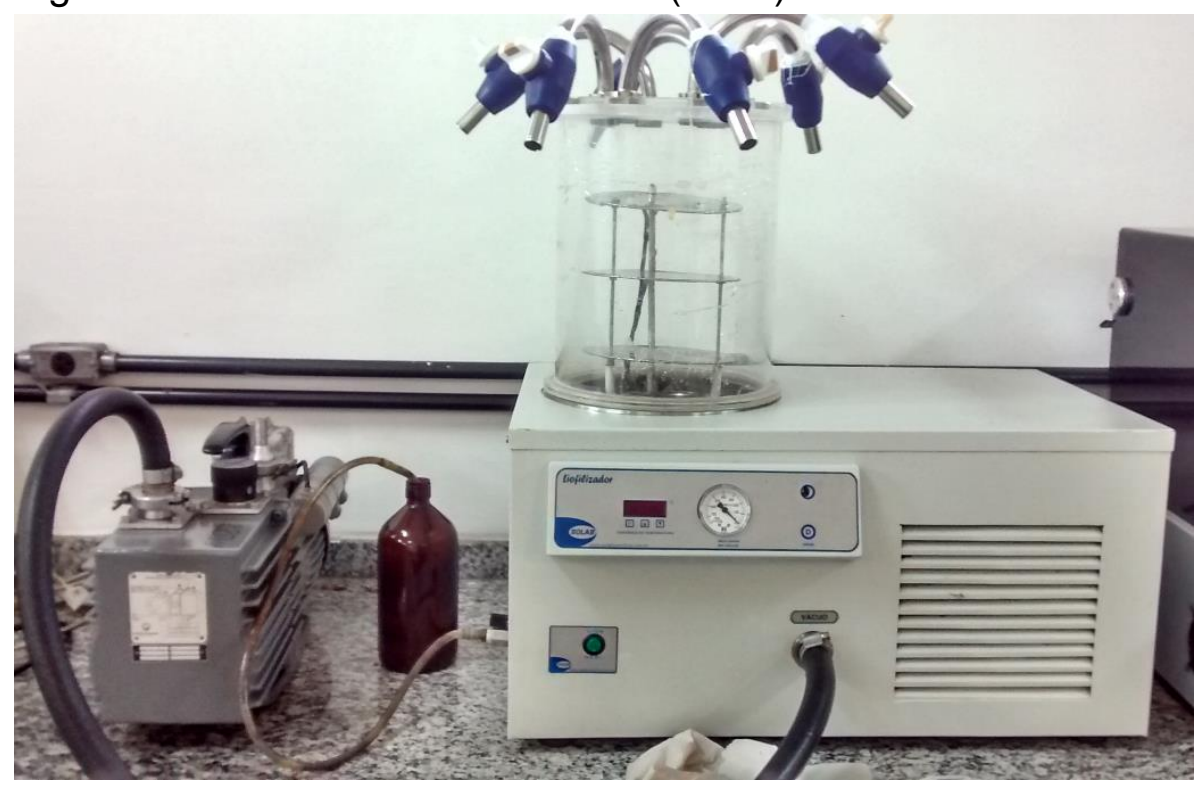

Fonte: Autor da dissertação. 


\subsubsection{Redução do GO}

Para a redução do GO sintetizado, foi preparada uma solução de (50/50 \%) de água destilada e álcool etílico absoluto colocados em balão de fundo redondo, selado na presença de ar e levado para ser irradiado por radiação gama $\left({ }^{60} \mathrm{Co}\right)$ na dose de radiação de $100 \mathrm{kGy}$ (RGO100). A irradiação foi realizada a taxa de dose de radiação de $6 \mathrm{kGy} / \mathrm{h}$ e temperatura ambiente utilizando o Irradiador Gama Multipropósito do IPEN, localizado no Centro de Tecnologia de Radiação (CTR/IPEN-CNEN/SP). Após a irradiação, a solução aquosa contendo RGO foi congelada durante 24 horas e liofilizada por 48 horas para a liofilização das nanofolhas de RGO. A Fig.18 apresenta um fluxograma da metodologia usada para a síntese e redução do GO/RGO.

Figura 18- Fluxograma da metodologia de obtenção do GO

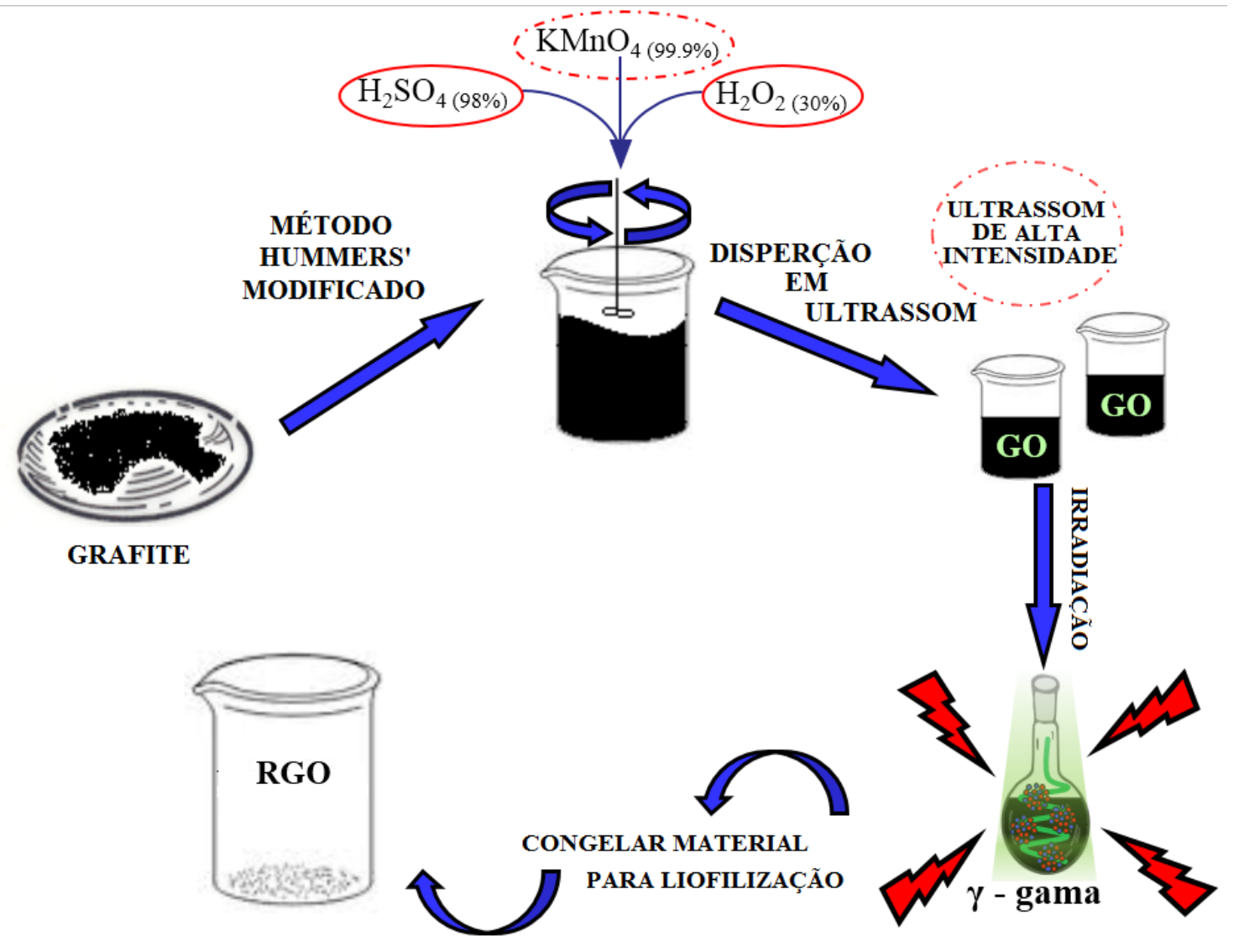

Fonte: Autor da dissertação. 


\subsection{Caracterização das nanofolhas de GO e RGO}

Afim de avaliar as características do GO e RGO, foram realizados os ensaios de DRX, MEV-FEG, MET, FTIR, espectroscopia de Raman e TG.

\subsubsection{Difração de Raios X (DRX)}

Os espectros de difração de raios $X$ do GO/RGO foram determinados em um difratômetro modelo Rigaku DMAX 2200, modelo Multiflex (Fig. 19) com radiação CuKa $(\lambda=1.54 \mathrm{~nm})$ operado em $40 \mathrm{kV}$ e $40 \mathrm{~mA}$, com $2 \theta$ variando entre $2^{\circ}$ e $70^{\circ}$.

Figura 19- Equipamento de Difração de Raios X (DRX)

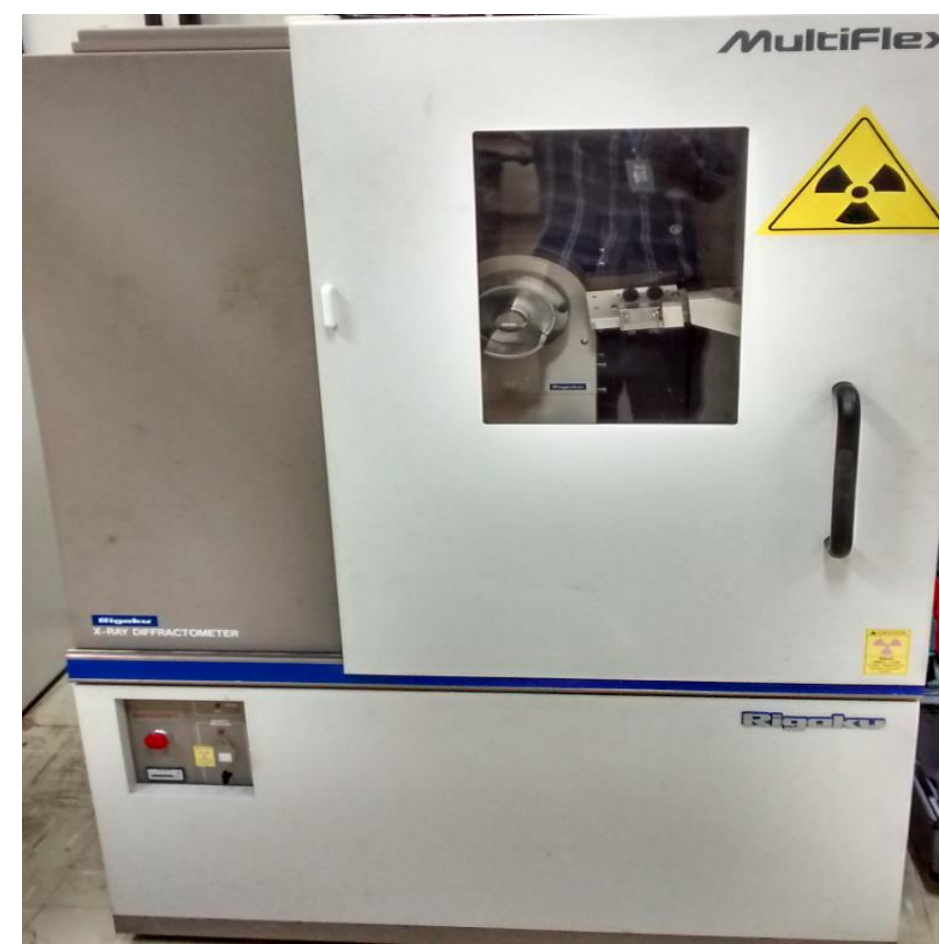

Fonte: Autor da dissertação.

4.3.2 Microscopia Eletrônica de Varredura com fonte de emissão de campo (MEV-FEG).

As amostras de GO e RGO foram recobertas com carbono e analisadas no microscópio JEOL-JSM-6701F (Fig. 20) com tensão de aceleração de 1- 30 kV e EDS Thermo-Scientific modelo Noran System Six. 
Figura 20 - Microscópio JEOL-JSM-6701F

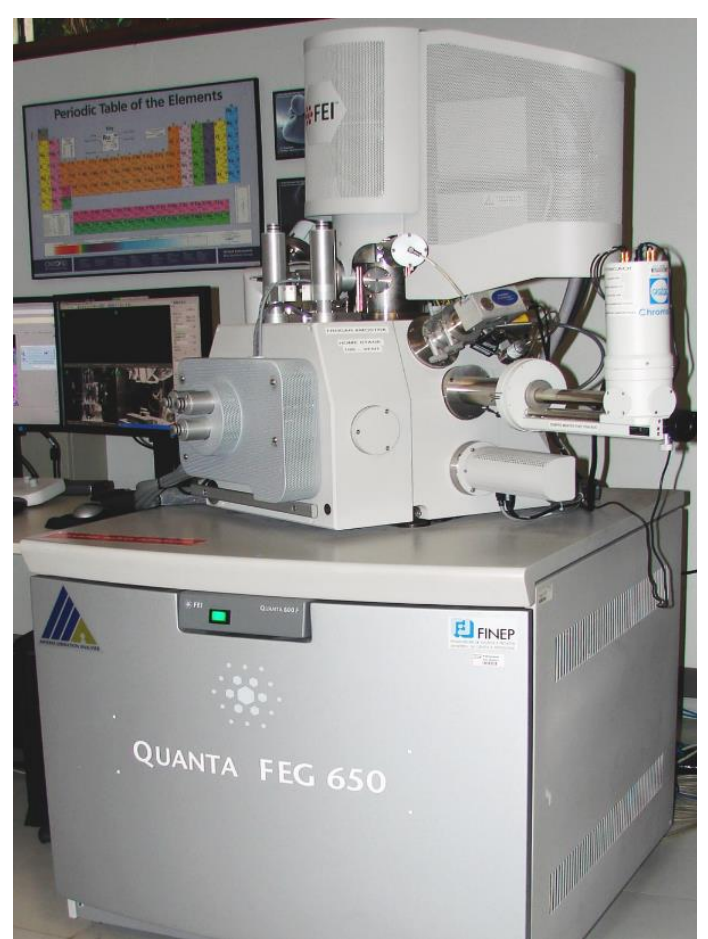

Fonte: Autor da dissertação.

\subsubsection{Microscopia Eletrônica de Transmissão (MET)}

As imagens foram obtidas no equipamento JEOL JEM-1200. Amostras foram preparadas adicionando uma gota da dispersão de GO sobre grades de cobre cobertas com filme fino de carbono. A tensão da fonte utilizada foi de 110120 kV (Fig.21). 
Figura 21 - Microscópio Eletrônico de Transmissão JEOL JEM-1200

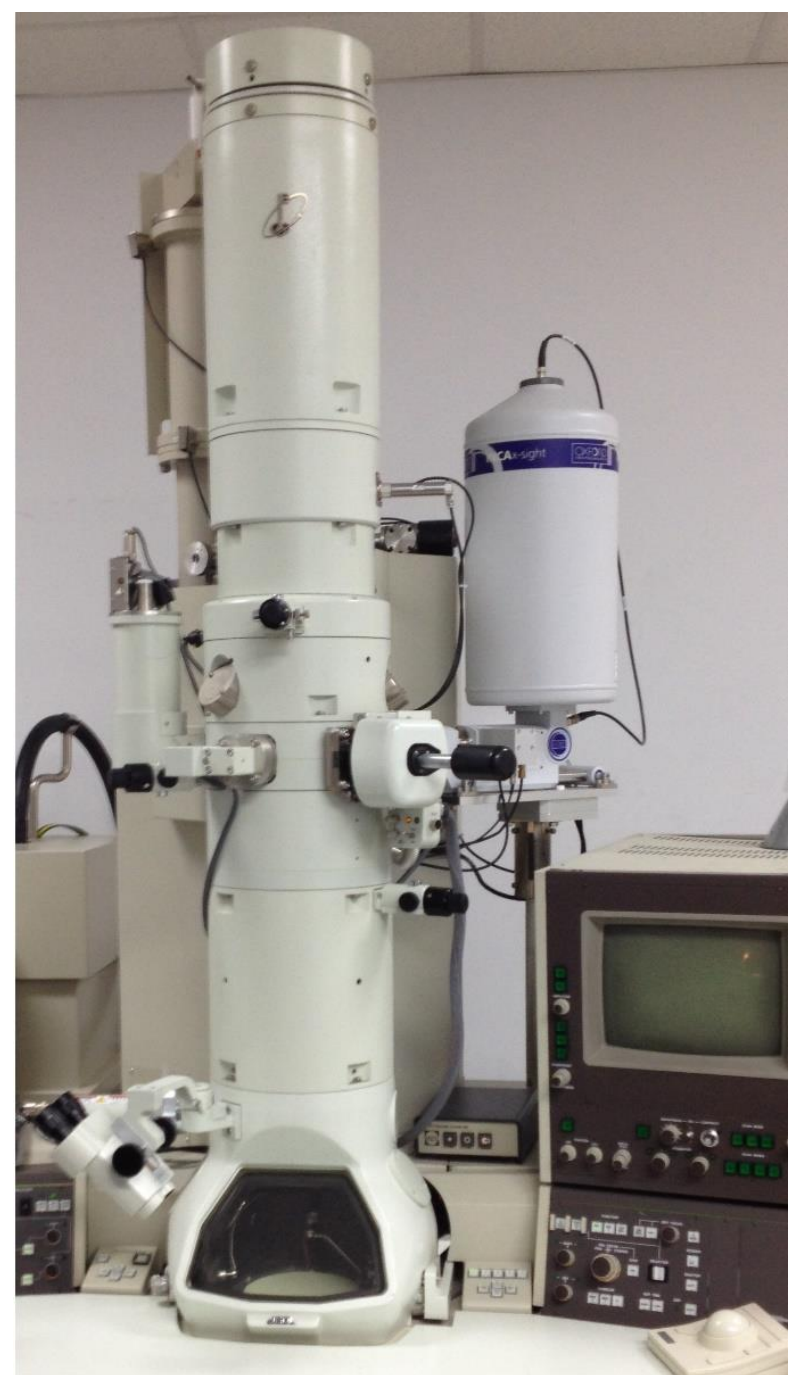

Fonte: Autor da dissertação.

4.3.4 Espectroscopia vibracional de absorção no infravermelho com transformada de Fourier (FTIR)

As análises de FTIR das amostras de GO e RGO, foram realizadas no modo de transmitância, utilizando um espectrômetro Nicolet Magna-IR 750 (Fig. 22) equipado com um detector DGTS. 
Figura 22- Espectrômetro Nicolet Magna-IR 750

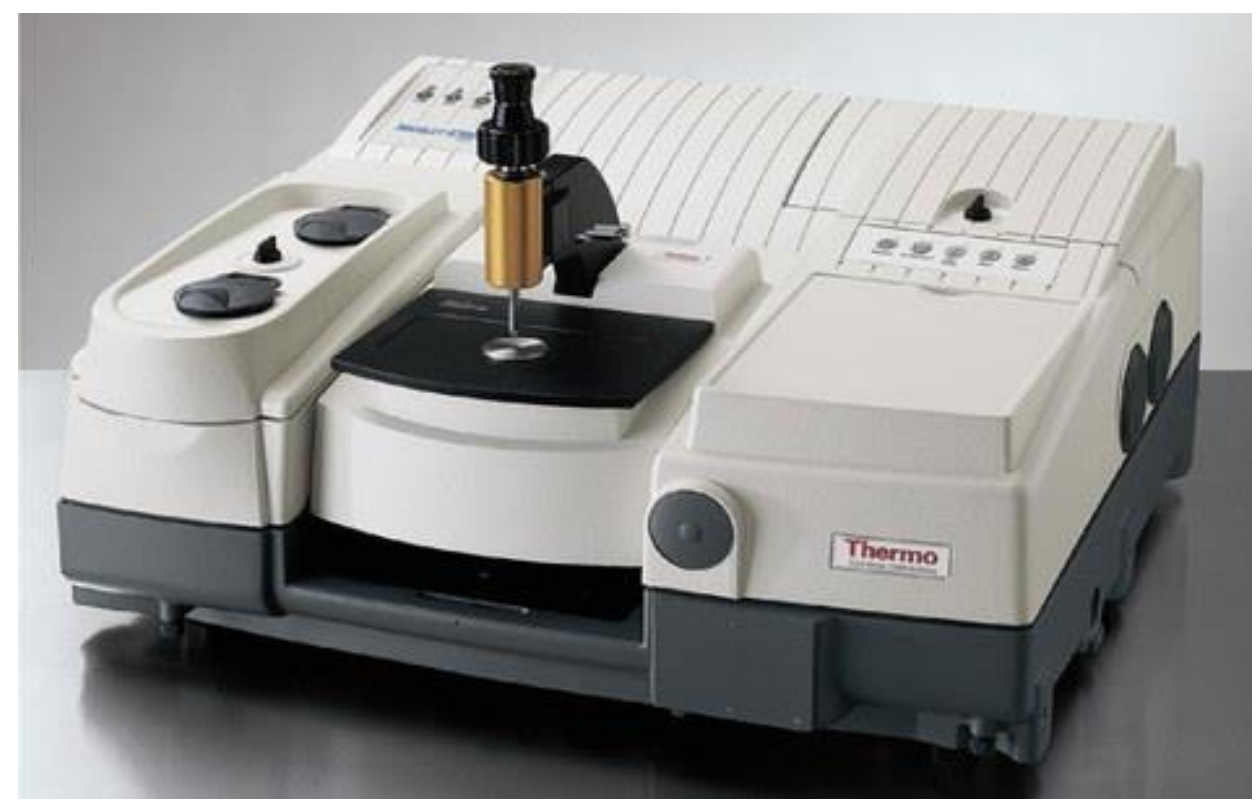

Fonte: Autor da dissertação.

\subsubsection{Espectroscopia Raman}

Os espectros Raman das amostras de GO e RGO foram realizadas usando o equipamento HORIBA Jobin Yvon, França (Fig. 23), equipado com um microscópio confocal com um laser de cristal de estado sólido ( $\lambda=532 \mathrm{~nm}$ ) como fonte de excitação. $O$ espectro obtido foi ajustado pelo software de aquisição de imagens LabSpec 5.1; HORIBA JobinYvon.

Figura 23 - Equipamento HORIBA Jobin Yvon

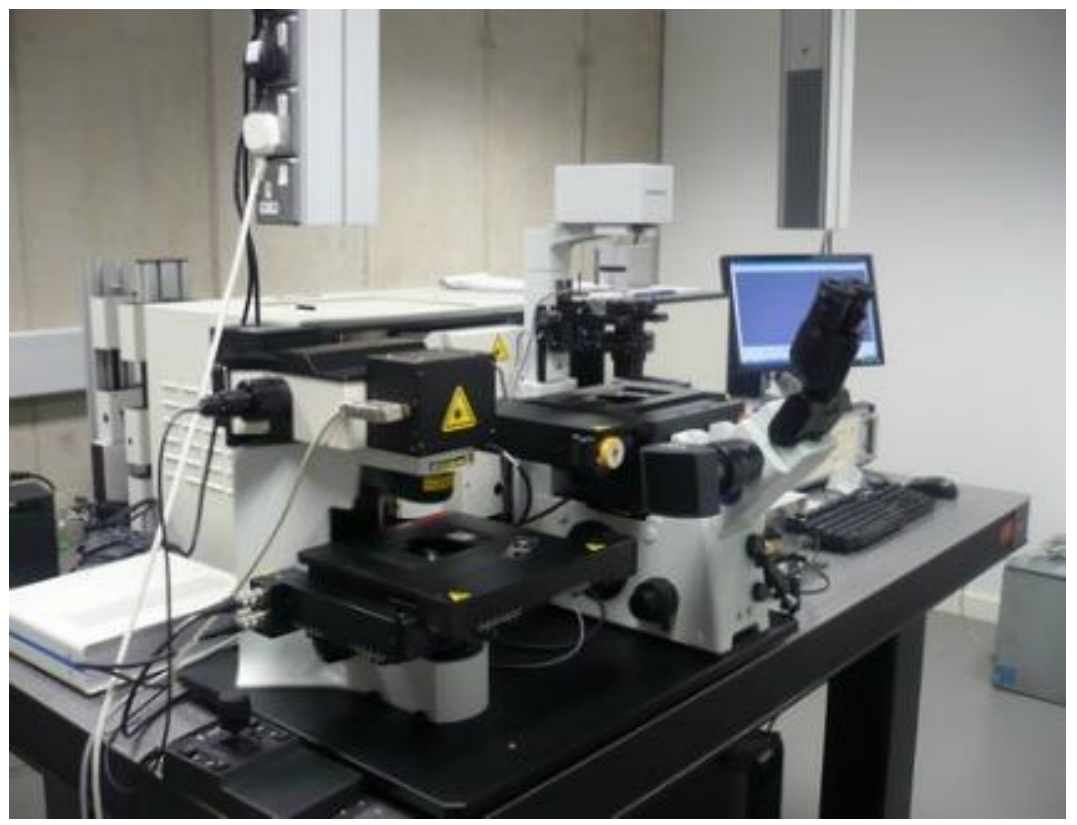

Fonte: Autor da dissertação. 


\subsubsection{Análise Termogravimétrica (TG)}

As análises por termogravimetria das amostras de GO e RGO foram realizadas no equipamento Mettler Toledo TGA modulo "TGA/SDTA851e" (Fig. 24) com temperatura inicial de $30{ }^{\circ} \mathrm{C}$ elevada a até $1000{ }^{\circ} \mathrm{C}$ com taxa de aquecimento de $10{ }^{\circ} \mathrm{C} / \mathrm{min}$ em atmosfera inerte de nitrogênio com fluxo de 50 $\mathrm{ml} / \mathrm{min}$.

Figura 24- Mettler Toledo TGA modulo "TGA/SDTA851E"

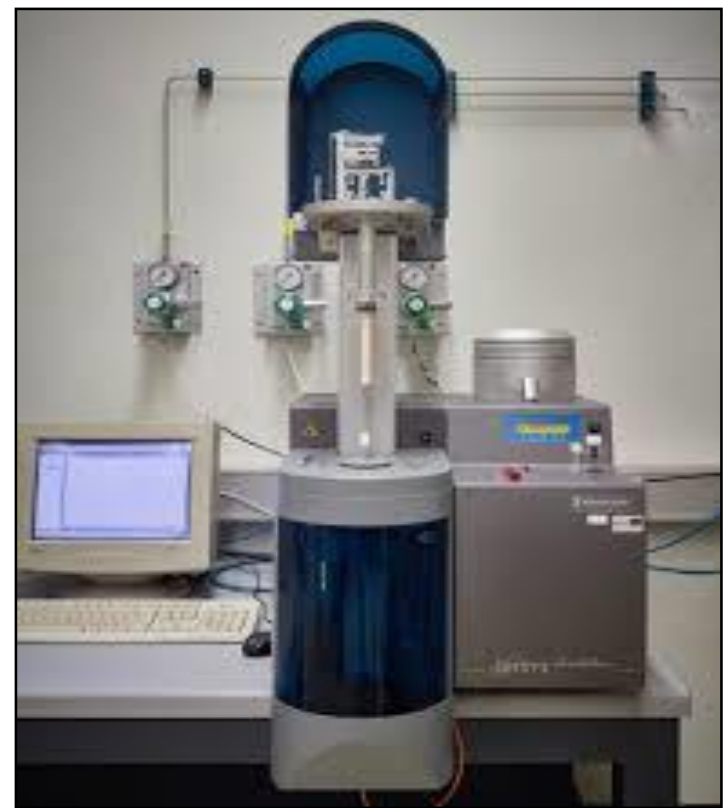

Fonte: Autor da dissertação.

4.4 Preparação dos filmes flexíveis de EVOH e seus nanocompósitos

A incorporação das nanofolhas de GO e RGO na matriz polimérica do EVOH (EVOH/GO) e (EVOH/RGO) foram realizadas em duas etapas:

\subsubsection{Obtenção dos nanocompósitos}

Os nanocompósitos de EVOH/GO e EVOH/RGO foram preparados de acordo com as formulações apresentadas na Tabela 2 com a utilização de uma extrusora co-rotante dupla-rosca HAAKE, modelo Rheomex 332p (Fig. 25), roscas com $16 \mathrm{~mm}$ de diâmetro e $\mathrm{L} / \mathrm{D}=25$ da Thermo Scientific pertencente ao laboratório de processamento de materiais compósitos do Centro de Química e Meio Ambiente (CQMA) do IPEN/CNEN -SP. A extrusão foi realizada na faixa de temperatura de $200 / 205 / 210 / 215 / 220 / 225{ }^{\circ} \mathrm{C}$, velocidade de rotação das 
roscas de $30 \mathrm{rpm}$. O material extrusado foi resfriado com jatos de ar seco para uma melhor estabilidade dimensional do material e submetido ao processo de granulação contínua. Posteriormente os materiais nanocompósitos preparados foram colocados em estufa com circulação de ar à temperatura de $60 \pm 2 \stackrel{\circ}{\circ}$ por 4 horas.

Os nanocompósitos de EVOH reforçados com o GO reduzido (EVOH/RGO) foram preparados com o objetivo de avaliar se a incorporação de $\mathrm{GO}$ reduzido no EVOH impactaria ganhos significativos nas propriedades mecânicas dos filmes quando comparado aos filmes de EVOH reforçado com o $\mathrm{GO}$ não reduzido $(\mathrm{EVOH} / \mathrm{GO})$.

\begin{tabular}{|c|c|c|c|c|}
\hline \multicolumn{2}{|c|}{ Materiais } & $\begin{array}{l}\text { EVOH } \\
\text { (\%, em } \\
\text { massa) }\end{array}$ & $\begin{array}{c}\mathrm{GO} \\
(\%, \text { em } \\
\text { massa) }\end{array}$ & $\begin{array}{c}\text { RGO } \\
\text { (\%, em } \\
\text { massa) }\end{array}$ \\
\hline \multirow{4}{*}{ EVOH/GO } & EVOH puro & 100 & - & - \\
\hline & EVOH/GO 0,1 \% & 99,9 & 0,1 & - \\
\hline & EVOH/GO 0,2 \% & 99,8 & 0,2 & - \\
\hline & EVOH/GO 0,3\% & 99,7 & 0,3 & - \\
\hline \multirow{3}{*}{ EVOH/RGO } & EVOH/RGO 0,1 \% & 99,9 & - & 0,1 \\
\hline & EVOH/RGO 0,2 \% & 99,8 & - & 0,2 \\
\hline & EVOH/RGO 0,3 \% & 99,7 & - & 0,3 \\
\hline
\end{tabular}

Fonte: Autor da dissertação. 
Figura 25 - Extrusora dupla rosca HAAKE Rheomex, Thermo Scientific

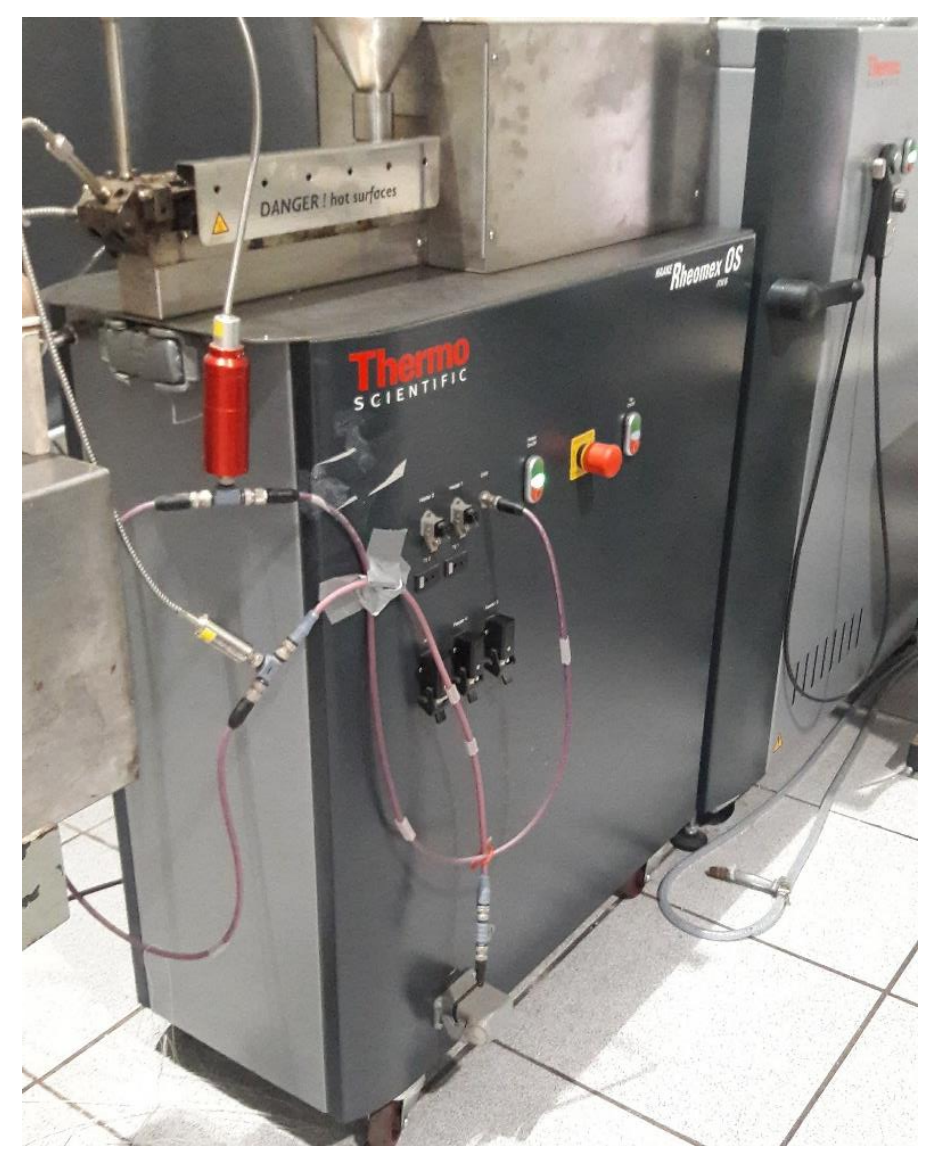

Fonte: Autor da dissertação.

\subsubsection{Obtenção do filme flexível}

Para a obtenção dos filmes flexíveis, as amostras do EVOH puro, e dos nanocompósitos EVOH/GO e EVOH/RGO preparados foram alimentados a uma extrusora monorosca de laboratório HAAKE Rheomex P332 (Fig. 26), Thermo Scientific com uma matriz plana acoplada $A$ extrusão dos filmes foi realizada na faixa de temperatura de 200/210/215/220/225 ${ }^{\circ} \mathrm{C}$, velocidade de rotação da rosca de $20 \mathrm{rpm}$. 
Figura 26 - Extrusora monorosca de laboratório HAAKE Rheomex, Thermo Scientific

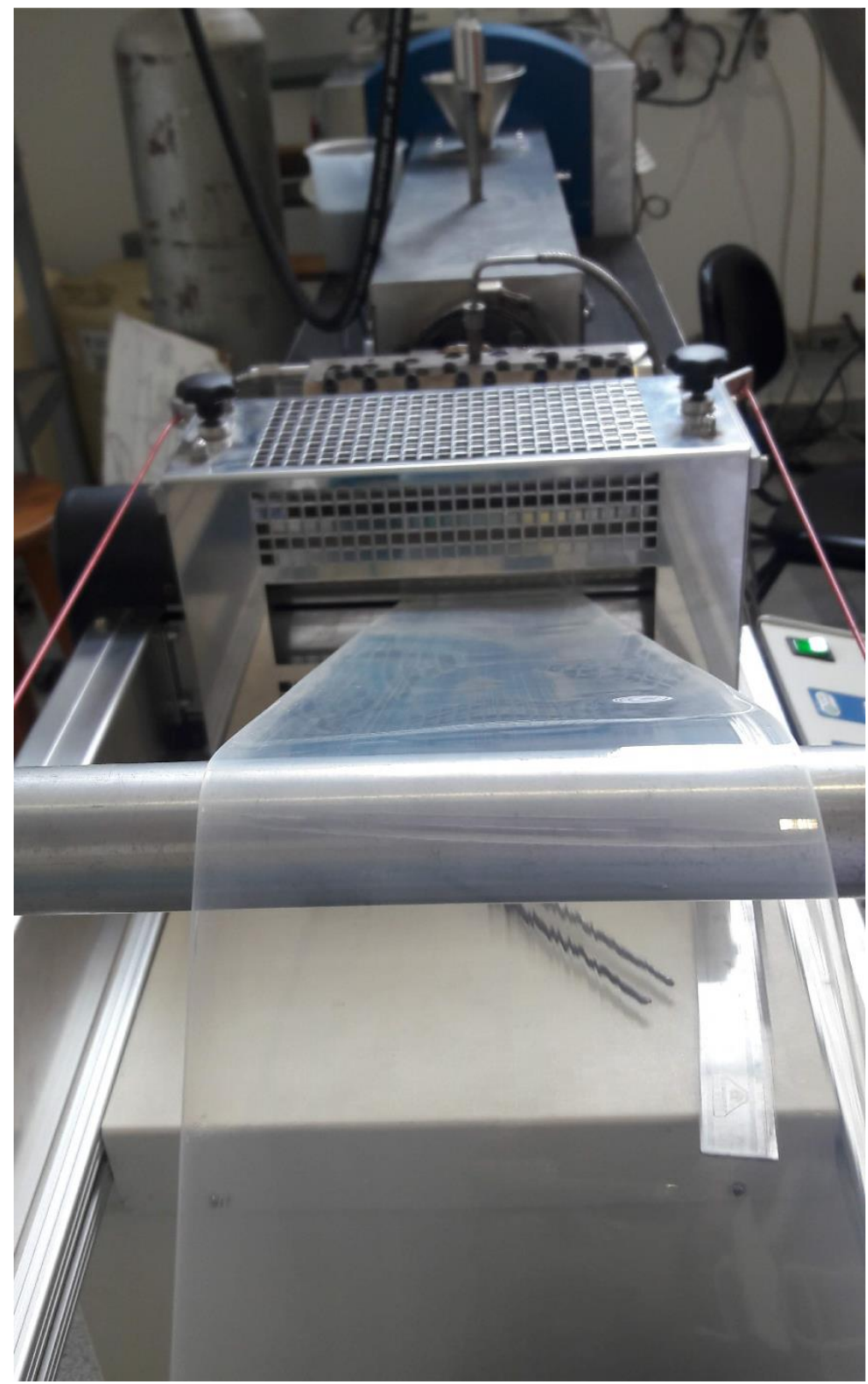

Fonte: Autor da dissertação.

\subsection{Irradiação dos filmes flexíveis}

Parte das amostras dos filmes flexíveis de $\mathrm{EVOH}$ e seus nanocompósitos foram irradiadas com feixe de elétrons, utilizando o acelerador de elétrons modelo "Dynamitron II" com energia de 1,5 MeV e corrente de 2,81 mA, localizado no Centro de Tecnologia de Radiação CTR do IPEN CNEN/SP. As irradiações foram realizadas nas doses de radiação de 100, 150, 200 e 250 kGy, 
taxa de dose de 22,3 kGy/s, à temperatura ambiente e na presença de ar (Fig. 27).

Figura 27 - Acelerador de elétrons modelo "Dynamitron II"

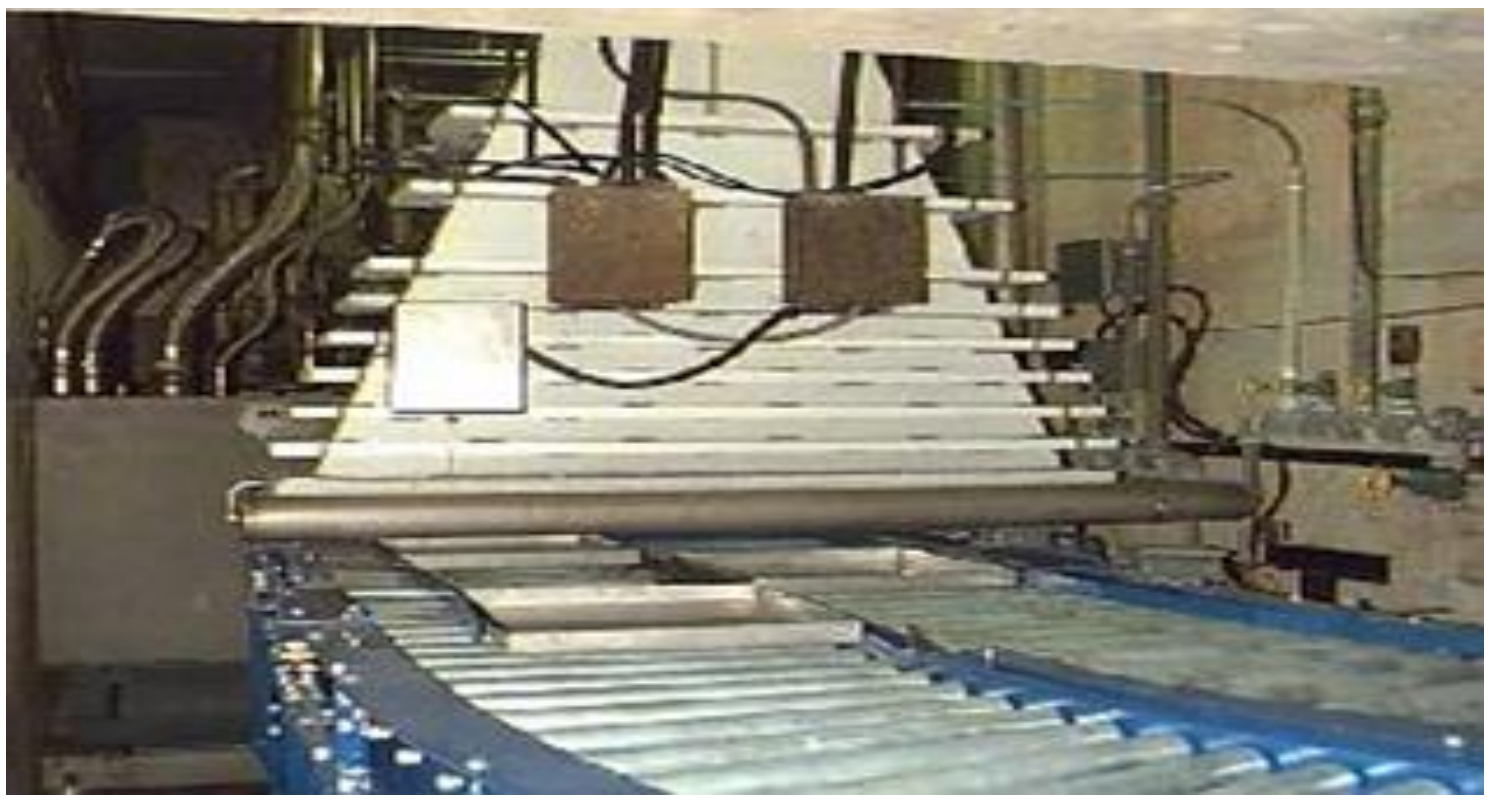

Fonte: Autor da dissertação.

\subsection{Caracterização do EVOH puro e seus nanocompósitos}

\subsubsection{Difração de Raios X (DRX)}

Os espectros de difração de raios $\mathrm{X}$ das amostras dos filmes flexíveis foram determinados em um difratômetro modelo Rigaku DMAX 2200, modelo Multiflex com radiação CuKa ( $\lambda=1.54 \mathrm{~nm}$ ) operado em $40 \mathrm{kV}$ e $40 \mathrm{~mA}$, com $2 \theta$ variando entre $2^{\circ} \mathrm{C}$ e $70^{\circ} \mathrm{C}$.

4.6.2 Microscopia Eletrônica de Varredura com fonte de emissão de campo (MEV-FEG).

As análises de MEV-FEG foram realizadas nas amostras dos nanocompósitos crio-fraturados em nitrogênio líquido e recobertas com carbono. Para estas análises foi utilizado o microscópio JEOL-JSM-6701F com tensão de aceleração de 1- 30 kV e EDS Thermo-Scientific modelo Noran System Six para avaliar a superfície do EVOH e dos nanocompósitos. 


\subsubsection{Análise Termogravimétrica (TG)}

As análises por termogravimetria foram realizadas no equipamento Mettler Toledo TGA modulo "TGA/SDTA851e" com temperatura inicial de $30^{\circ} \mathrm{C}$ elevada a até $600^{\circ} \mathrm{C} \mathrm{com}$ taxa de aquecimento de $10{ }^{\circ} \mathrm{C} / \mathrm{min}$ em atmosfera inerte de nitrogênio com fluxo de $50 \mathrm{ml} / \mathrm{min}$.

\subsubsection{Calorimetria Exploratória Diferencial (DSC)}

As análises de DSC foram realizadas utilizando um Mettler Toledo DSC 822 e de 25 a $250{ }^{\circ} \mathrm{C}$ a uma taxa de aquecimento de $10^{\circ} \mathrm{C} / \mathrm{min}$ sob atmosfera de azoto (50 ml/min), em 3 ciclos de aquecimento/resfriamento.

4.6.5 Espectroscopia vibracional de absorção do infravermelho por transformada de Fourier (FTIR)

As analise de FTIR das amostras foram realizadas em modo de transmitância, utilizando um espectrômetro Nicolet Magna-IR 750 equipado com um detector DGTS.

\subsubsection{Ensaios mecânicos de tração}

Os ensaios mecânicos de resistência à tração foram realizados de acordo com a norma ASTM D 882-91, utilizando-se uma máquina universal de ensaios modelo Instron 5567 (Fig. 28). Os ensaios foram realizados em amostras dos filmes flexíveis, na direção de máquina, com velocidade de deslocamento de 500 $\mathrm{mm} / \mathrm{min}$, em temperatura ambiente. 
Figura 28- Máquina universal de ensaios modelo Instron 5567

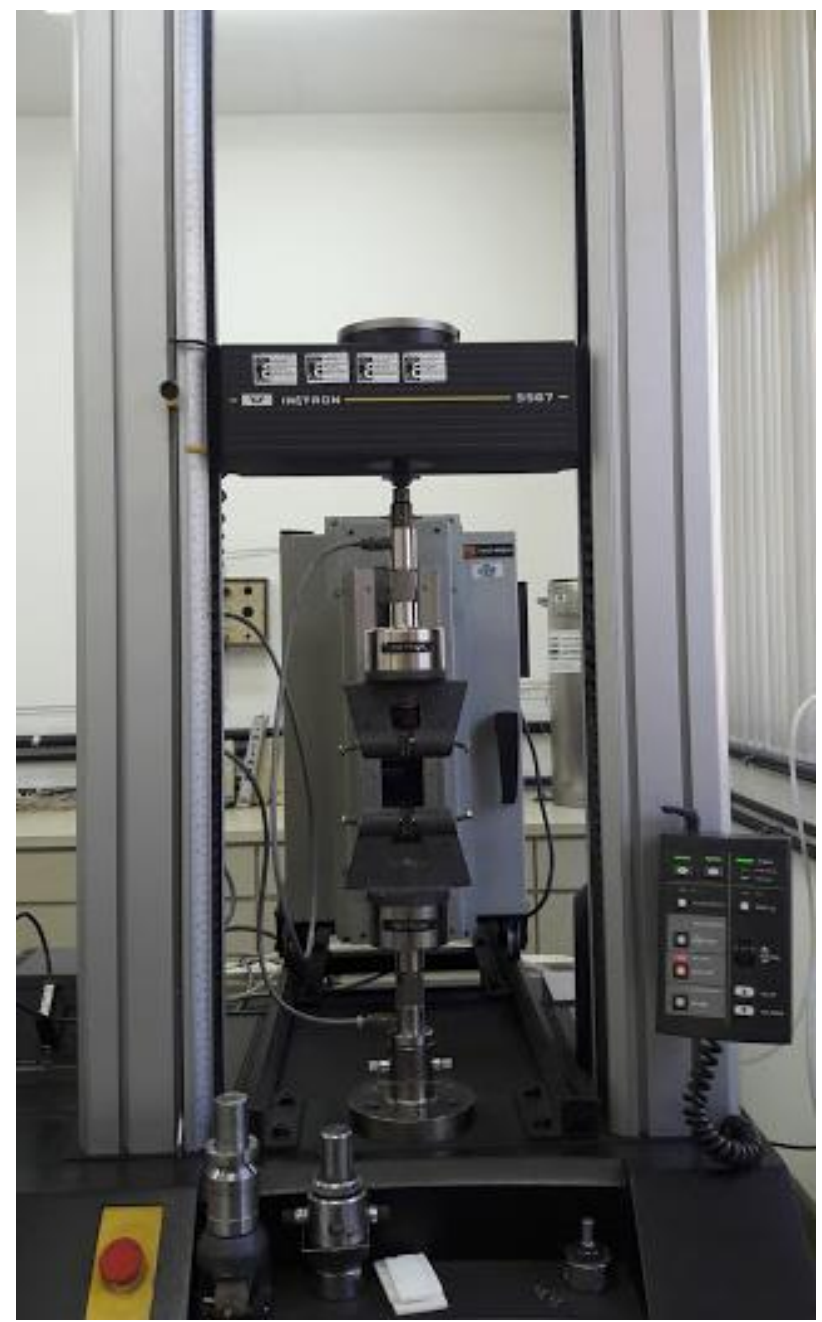

Fonte: Autor da dissertação.

4.6.7 Espectroscopia de tempos de vida de aniquilação de pósitrons (PALS)

A fonte do pósitron utilizado neste trabalho foi ${ }^{22} \mathrm{Na}$, um filme flexível $(50 \mu)$, a fonte foi colocada entre 2 tecidos não tecidos enxertados MIP ou NIP idênticos em uma configuração típica de "sanduíche" em temperatura ambiente. Os espectros foram obtidos usando um sistema convencional de coincidência ORTEC com resolução de tempo de aproximadamente 248 ps. As medidas foram conduzidas no ar à temperatura ambiente. Os espectros foram registrados a cada 2,8 horas. Posteriormente, foram resumidos 10 espectros de cada amostra em conjunto, resultando em uma representação estatística de 2,36 ×107. Os espectros obtidos foram avaliados usando os programas LT e MELT (SÖYLEMEZ \& GÜVEN, 2018). A contribuição da fonte foi determinada como 0.393 ns com $9 \%$. 
4.6.8 Taxa de permeabilidade ao oxigênio $\left(\mathrm{TPO}_{2}\right)$

A análise $\mathrm{TPO}_{2}$ das amostras dos filmes foi realizada de acordo com a norma ASTM D 3985-81, em condições de umidade relativa de $0 \%$ e $95 \%$, utilizando o equipamento OX-TRAN 2/20, da Modern Controls Inc. 


\section{RESULTADOS E DISCUSSÃO}

\subsection{Análises do óxido de Grafeno}

\subsubsection{Difração de Raios X (DRX)}

O difratograma de DRX para a grafite, o GO e RGO são mostrados na Fig. 29. $O$ espectro de $D R X$ da grafite apresenta um pico característico em $2 \theta=26^{\circ}$, correspondente ao espaçamento $d=3,35 \AA$, de acordo com a equação de Bragg. Os espectros do GO e do RGO mostram o pico característico da grafite em $2 \theta=$ $26{ }^{\circ}$ (espaçamento $d=3,35 \AA$ ) com intensidade reduzida e um novo pico de reflexão acentuado, característico das nanofolhas de $\mathrm{GO}$, em $2 \theta=10^{\circ}$ (d $\left.\mathrm{d}_{001}\right)$, correspondente ao espaçamento $d=8,84 \AA$. O método de produção de GO parte da geração de grupos contendo oxigênio em sua superfície, desde o processo de oxidação, os grupos hidroxila, carbonila, epóxi ou peróxi foram ligados às bordas dos planos basais da estrutura da grafite, ocorrendo assim hidrólise do carbono e as ligações $\mathrm{sp}^{2}$ mudaram para ligações $\mathrm{sp}^{3}$ (ANSÓN-CASAOS et al., 2014; BLANTON \& MAJUMDAR, 2013).

Figura 29 - Difratograma de DRX da Grafite, GO e RGO 100 kGy

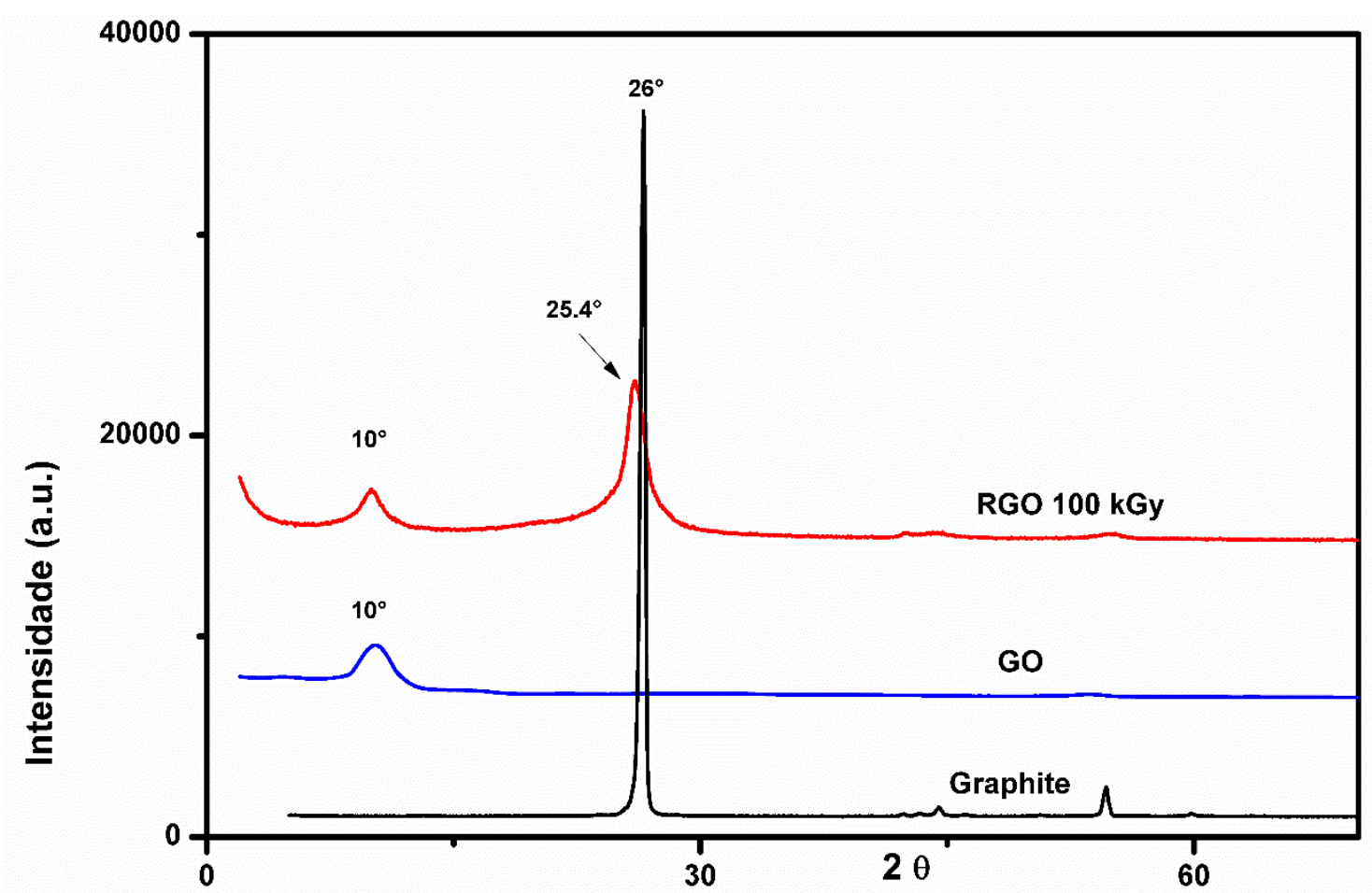

Fonte: Autor da dissertação. 
A intensidade reduzida do pico da grafite em $2 \theta=26^{\circ}$ no espectro do RGO, sugere que a grafite foi parcialmente convertida em óxido de grafeno reduzido. $O$ aparecimento do pico característico do $\mathrm{GO}$ em $2 \theta=10^{\circ}$, com espaçamento "d" do pico do $G O(d=8,84 \AA)$ sugerem que a grafite foi quase totalmente convertida em GO. O espaçamento entre camadas da GO "d" do pico do GO (d= $8,84 \AA$ ) é maior que o da grafite $(d=3,35 \AA)$, devido à presença de grupos funcionais formados após a esfoliação química (LERF et al., 2006). O padrão de DRX do RGO revelou um pico agudo (do02) a $2 \theta=25,32^{\circ}$ correspondendo ao espaçamento $d=3,51 \AA$, que pode estar relacionado com um empilhamento irregular do GO quando da sua reorganização no estado sólido, após o processo de redução.

5.1.2 Microscopia Eletrônica de Varredura com fonte de emissão de campo (MEV-FEG).

A micrografia da superfície do GO nas figuras 30 e 31 mostram uma superfície relativamente rugosa, com empilhamento de folhas e alguns domínios agregados. A micrografia do GO na fig. 30 mostra uma expansão das camadas e as bordas mais finas e lisas devido ao processo de oxidação. O GO preparado neste estudo apresenta regiões com folhas dobradas nas bordas com larguras médias de 171 - 997 nm medidas por alta resolução no MEV-FEG. 
Figura 30-Micrografias obtidas por MEV- FEG do GO (19.000x)

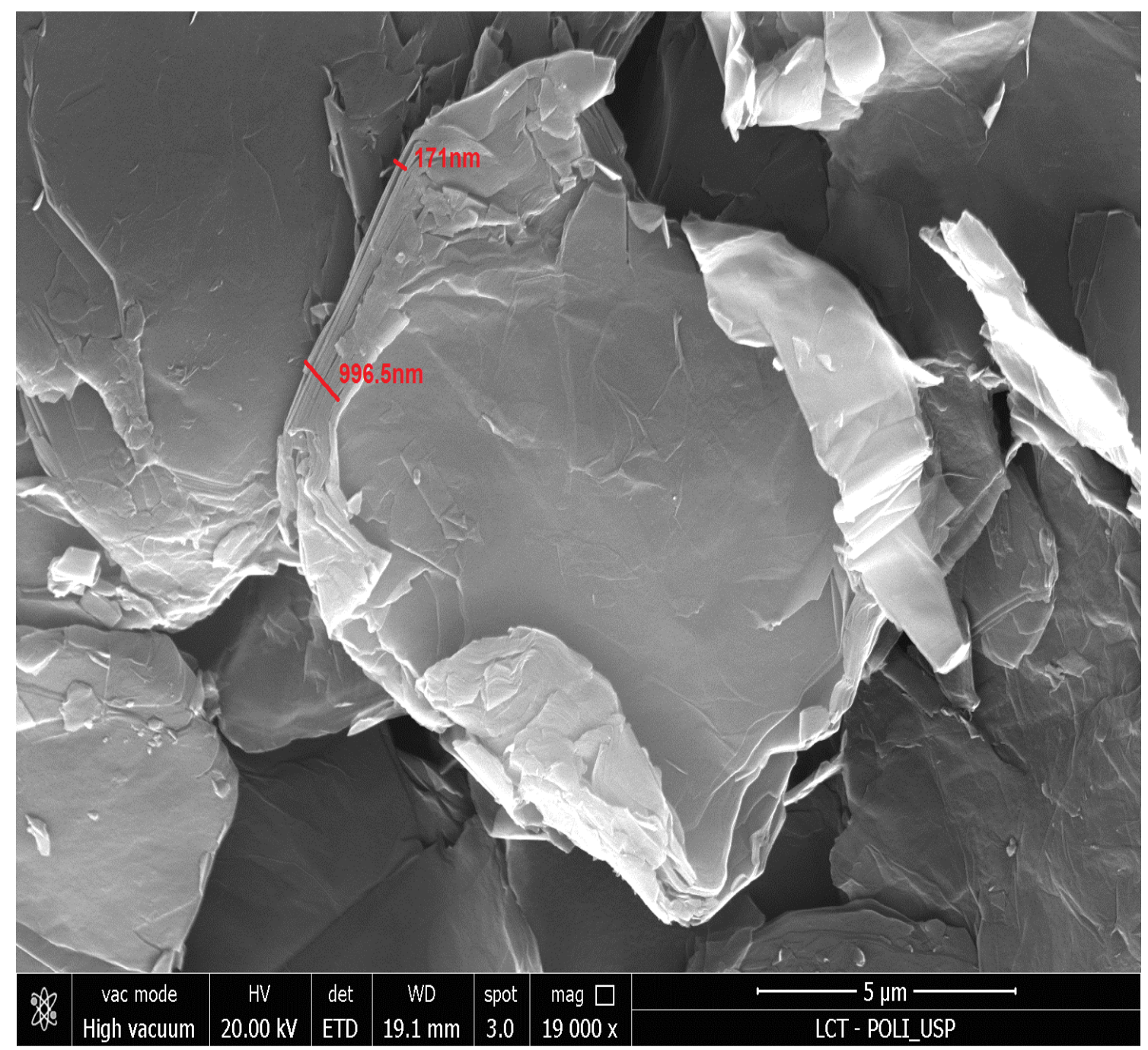

Fonte: Autor da dissertação.

No entanto, na maior ampliação da imagem (Fig. 31) pode-se observar a presença de algumas folhas separadas umas das outras, porém devido as forças de van der Waals na estrutura laminada da grafite, que após o processo de oxidação/esfoliação, resulta em uma reorganização das camadas; formando folhas finas e empilhadas para o GO (YANG et al., 2013a). 
Figura 31- Micrografias obtidas por MEV- FEG do GO (100.000x)

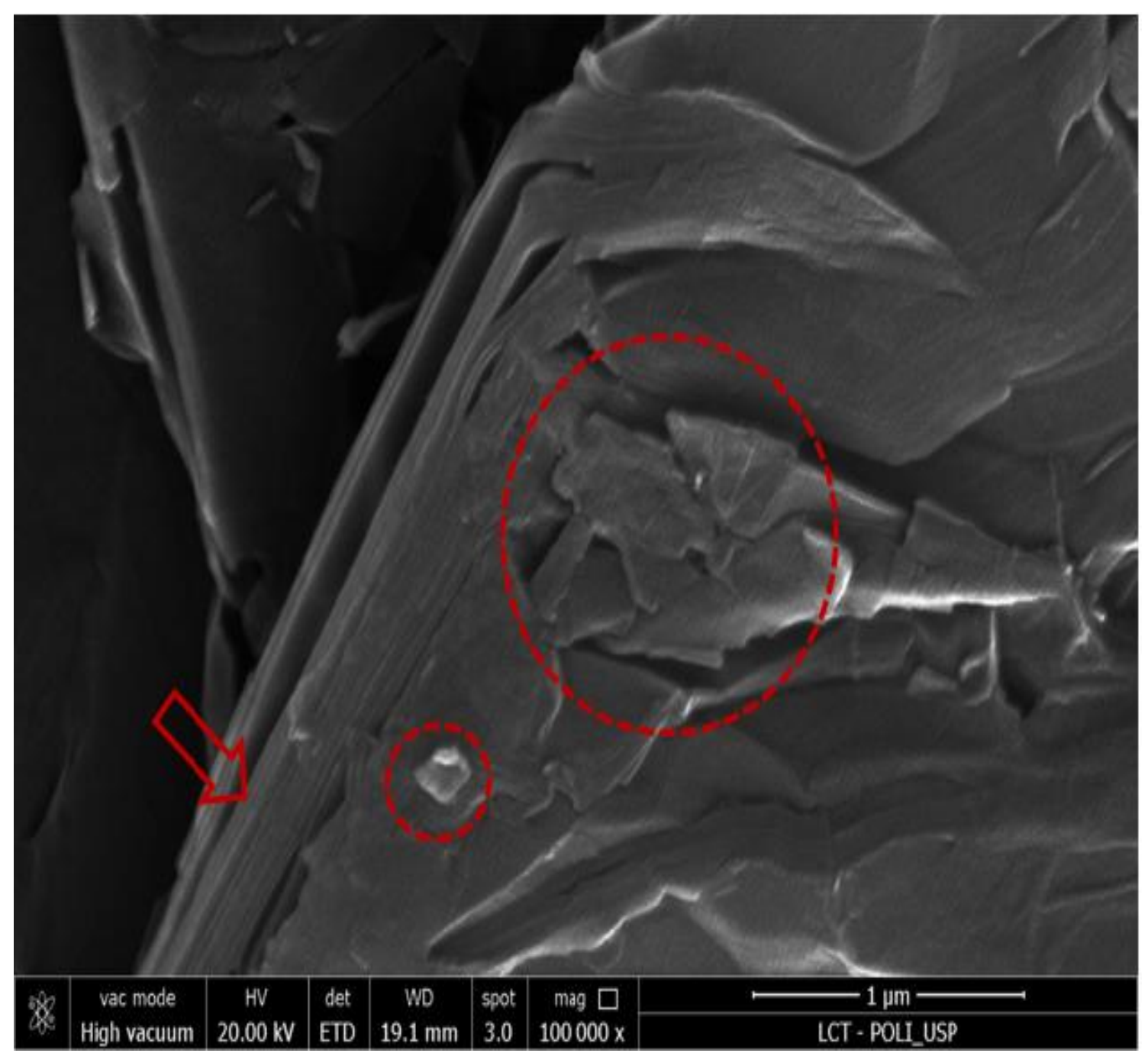

Fonte: Autor da dissertação.

Após a redução induzida por radiação gama, a morfologia das nanofolhas de GO foi fortemente modificada, assim como o tamanho das nanofolhas, modificação na superfície, como mostrado na Figura 32 e 33. A micrografia do RGO (Fig. 32) mostra algumas regiões dobradas, bordas com algumas folhas sobrepostas, porém camadas finas nas bordas, sem domínios agregados (RATHNAYAKE et al., 2017). 
Figura 32- Micrografias obtidas por MEV- FEG do RGO (19.000x)

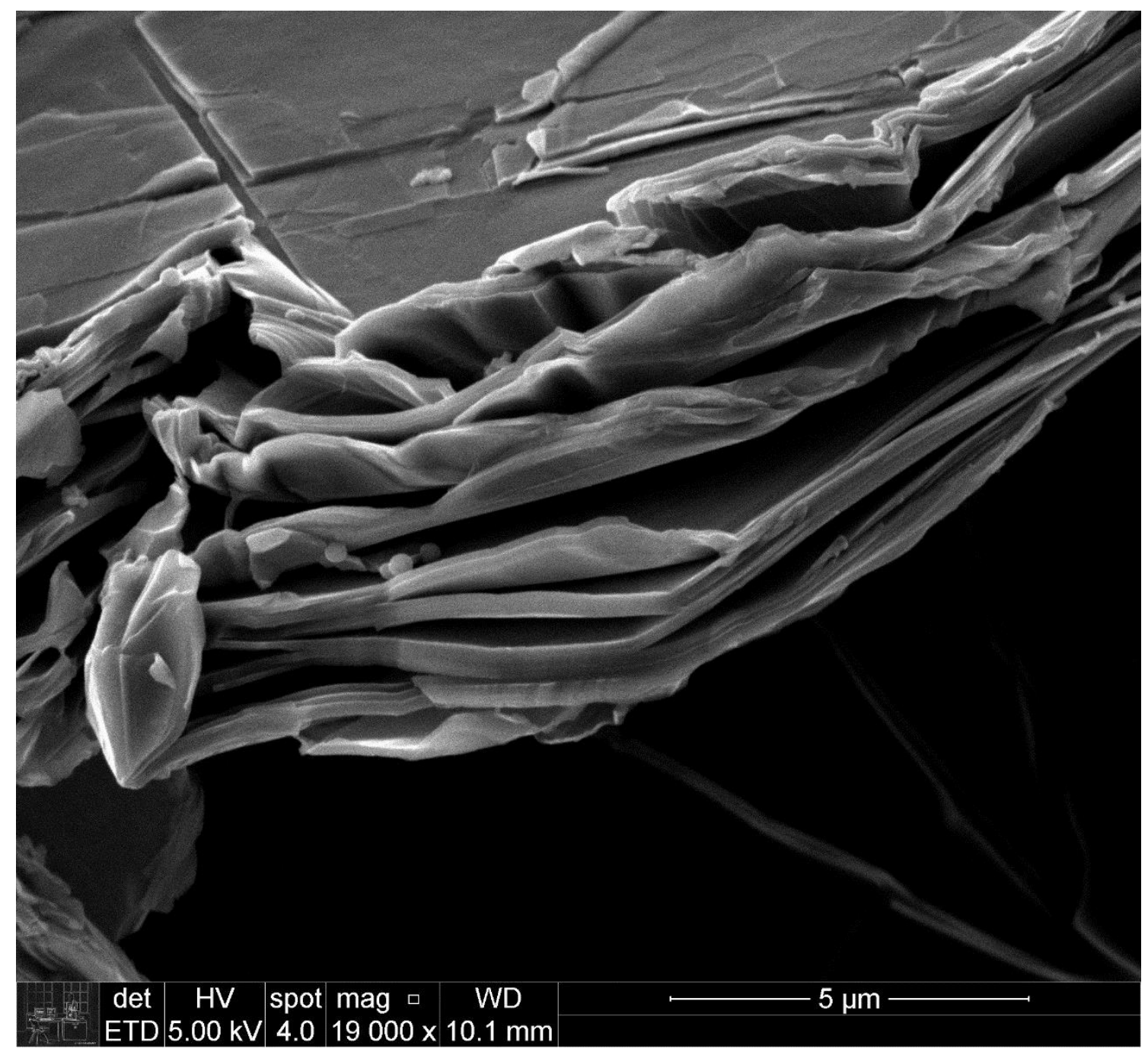

Fonte: Autor da dissertação.

A superfície da micrografia do RGO (Fig. 33) apresenta uma superfície bastante plana e lisa, com folhas mais separadas, algumas regiões dobradas, mas sem domínios agregados. 
Figura 33- Micrografias obtidas por MEV- FEG do RGO (100.000x)

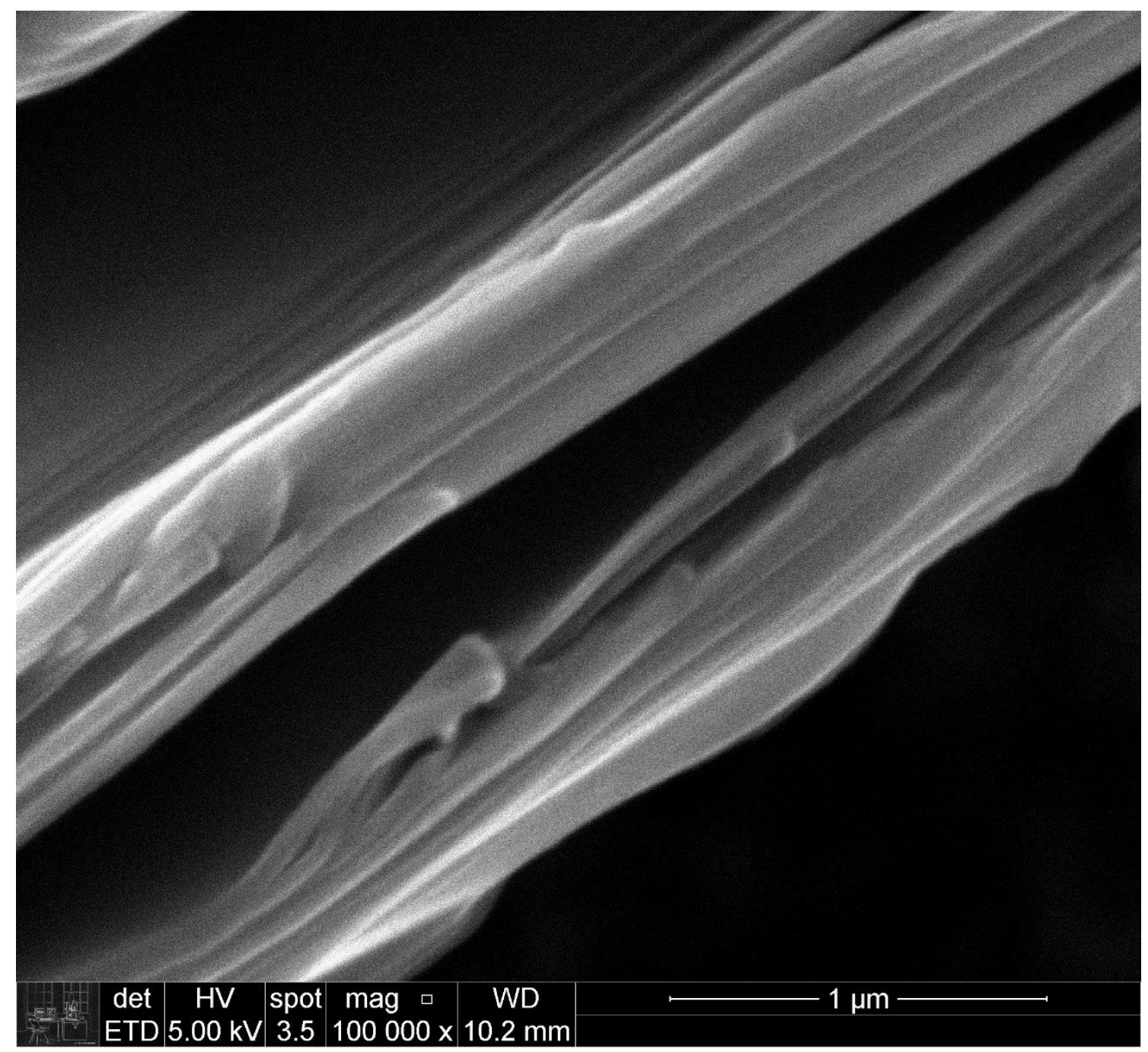

Fonte: Autor da dissertação.

Estes resultados sugerem que a redução do GO induzida pela radiação gama na presença de solução de etanol / água é um processo simples e seguro para obter RGO com um reduzido número de defeitos e com excelente esfoliação para posterior incorporação na matriz polimérica.

\subsubsection{Microscopia Eletrônica de Transmissão (MET)}

A morfologia das nanofolhas de GO e RGO foram também caracterizadas por microscopia eletrônica de transmissão (MET). A morfologia estrutural do GO apresentada na figura 34 mostra uma superfície plana e lisa com domínios agregados e regiões transparentes que provavelmente são monocamadas de GO (HARRIS, 2018; ROY et al., 2017; LIU et al., 2017). 
Figura 34 - Imagem obtida por microscopia eletrônica de transmissão do GO $(200 \mathrm{~nm})$

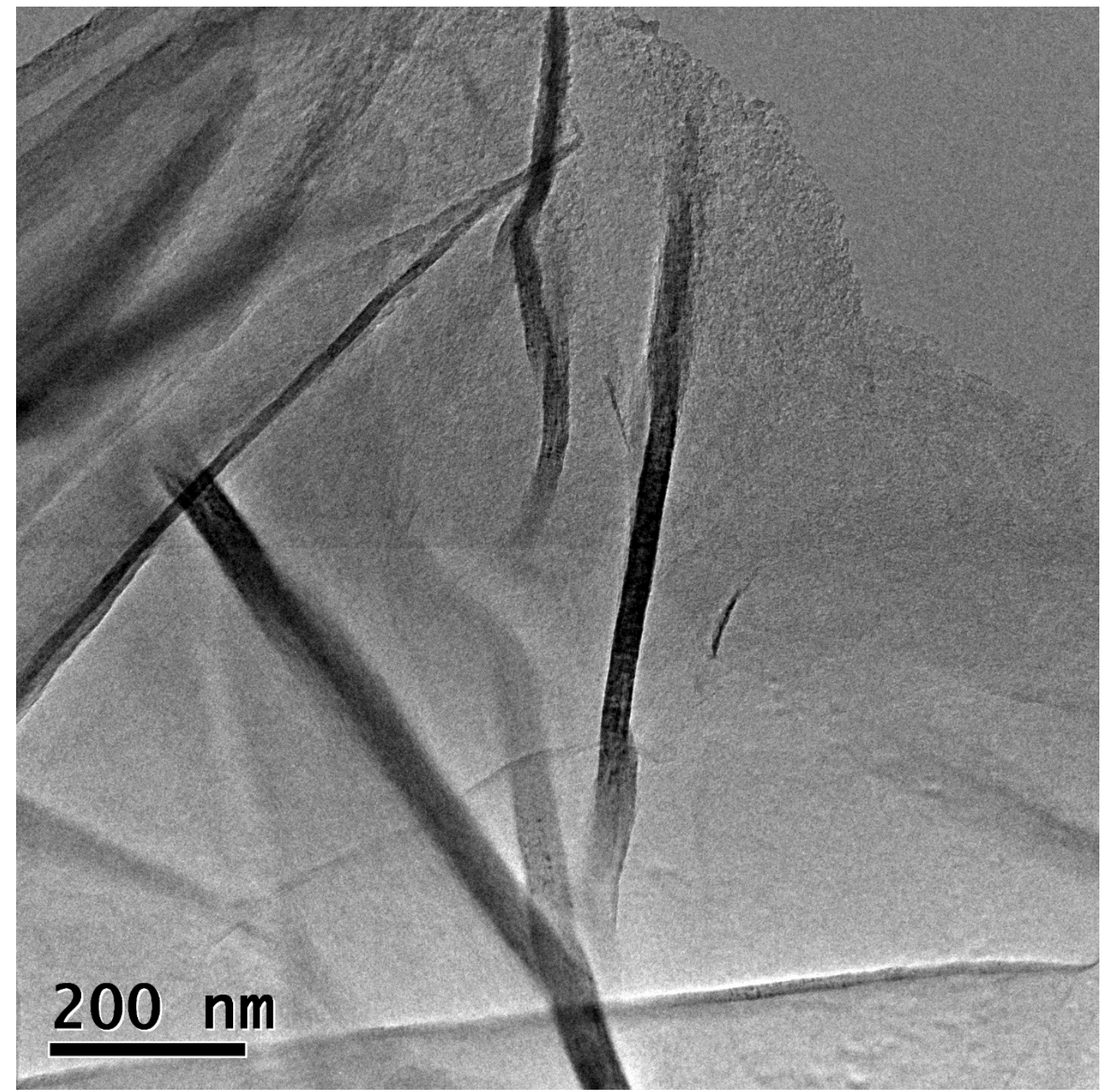

Fonte: Autor da dissertação.

A imagem de MET (Fig. 35) apresenta uma desordem para as folhas de GO, contudo pode ser observada uma boa esfoliação química, uma vez que as folhas observadas são translúcidas, indicando a existência de poucos domínios agregados. 
Figura 35 - Imagem obtida por microscopia eletrônica de transmissão do GO $(50 \mathrm{~nm})$

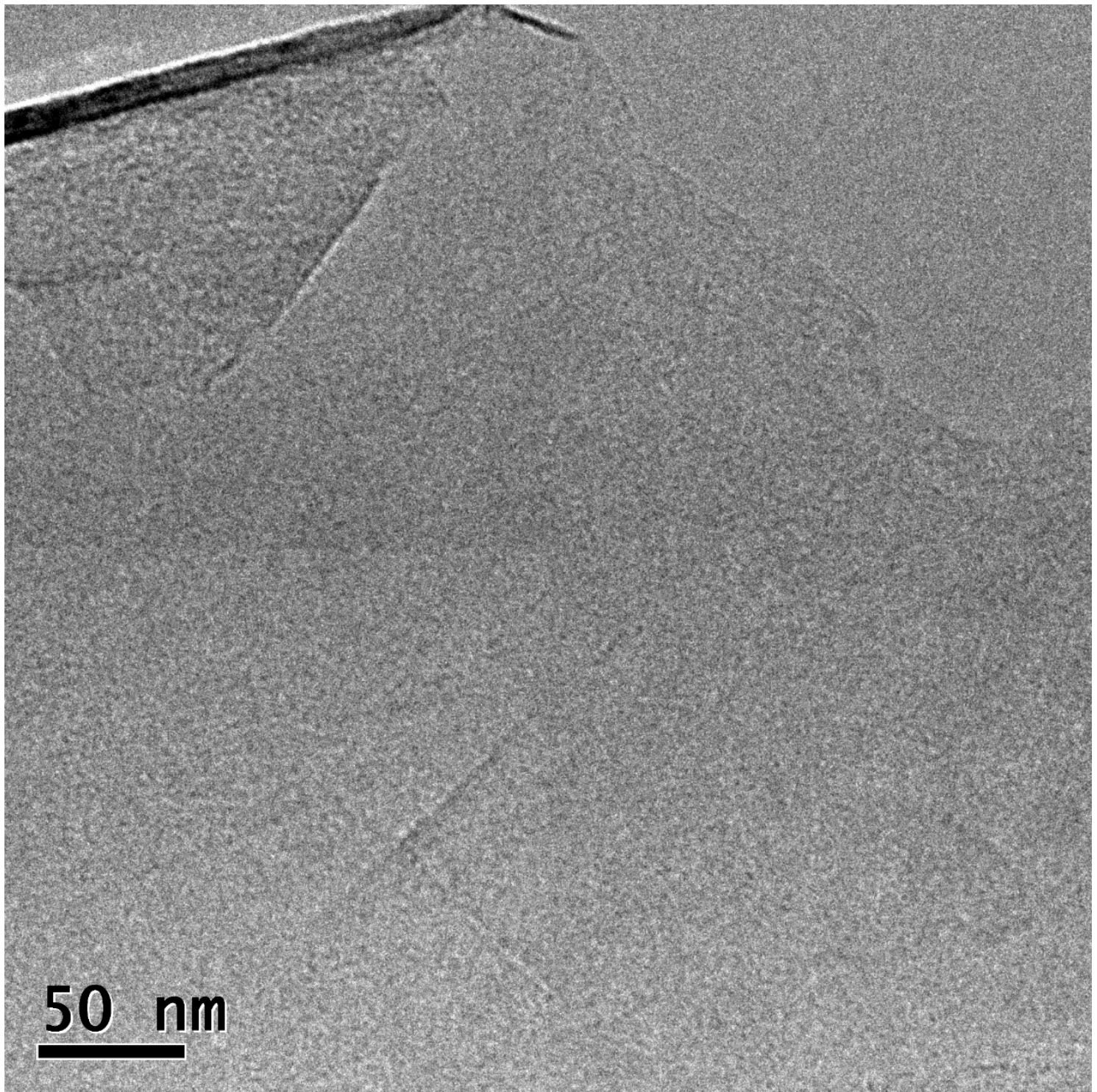

Fonte: Autor da dissertação.

O padrão apresentado através das imagens indicam que domínios grafíticos cristalinos agregados foram bem esfoliados (MATTEVI et al., 2009; FATHY et al., 2016).

5.1.4 Espectroscopia vibracional de absorção no infravermelho com transformada de Fourier (FTIR)

Os espectros de FTIR-ATR das nanopartículas GO e RGO são apresentados ou são mostrados na Fig. 36. Nos espectros de FTIR de GO / RGO 
pode- se observar a presença de picos típicos, como o pico a $1741 \mathrm{~cm}^{-1}$ atribuído a grupos carbonila $(\mathrm{C}=\mathrm{O})$ e os picos a $1045-958 \mathrm{~cm}^{-1}$ atribuídos a grupos epóxi (C-C-O). As bandas mais intensas foram identificadas em aproximadamente $2921 \mathrm{~cm}^{-1}$ e $2851 \mathrm{~cm}^{-1}$ e correspondem aos modos de vibração assimétrica do alongamento $\mathrm{C}-\mathrm{H}$, e estiramento do $\mathrm{C}-\mathrm{H}$ simétrico $\left(\mathrm{CH}_{2}\right)$, respectivamente. A partir do espectro do RG0100 (na Fig.36) pode-se observar o efeito da descarboxilação após a redução do GO por radiação gama, tais como a redução de grupos epóxi em $1045-958 \mathrm{~cm}^{-1}$ e do grupo carbonila em $1741 \mathrm{~cm}^{-1}$, e o aparecimento de alguns novos picos como o pico em $1523 \mathrm{~cm}^{-1}(\mathrm{C}=\mathrm{C})$, mostrando que o $\mathrm{C}=\mathrm{C}$ aromático foi formado (ZHANG et al., 2012; HE et al., 2016; DAUD et al., 2017; LIU et al., 2017).

Figura 36 - Espectros obtidos por FTIR para o GO e RGO

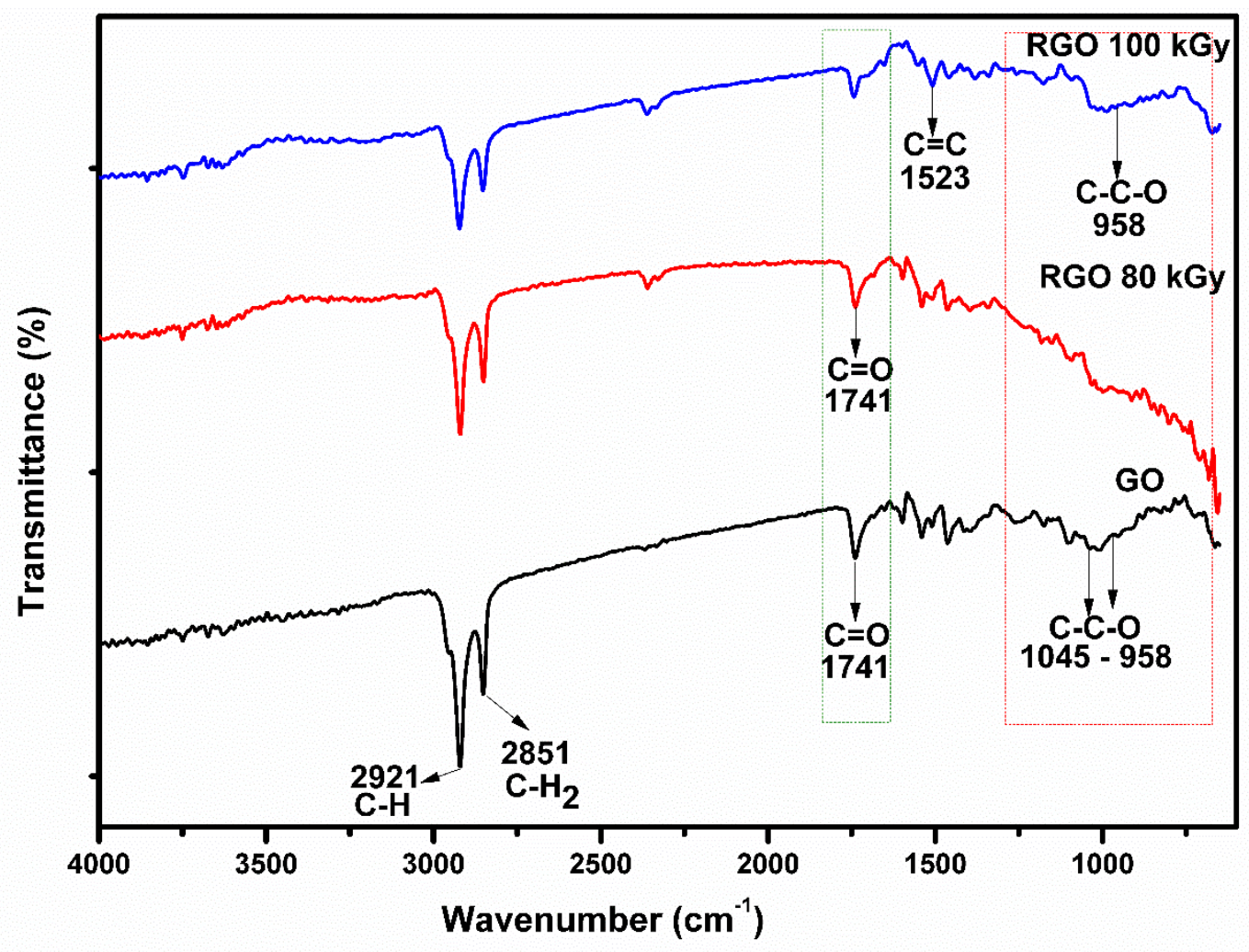

Fonte: Autor da dissertação.

\subsubsection{Espectroscopia Raman}

A Figura 37 mostra os espectros obtidos por Raman para o GO e RGO. Estes espectros são constituídos pelas bandas $D$ atribuída à presença de 
estruturas desordenadas e defeitos, a banda G devido à oxigenação dos planos da grafite, e sugere a formação de novos átomos de carbono $\mathrm{sp}^{3}$, e a banda 2D, a qual está relacionada com o número de camadas de nanofolhas de GO.

Figura 37- Bandas do espectro de RAMAN para o GO e RGO

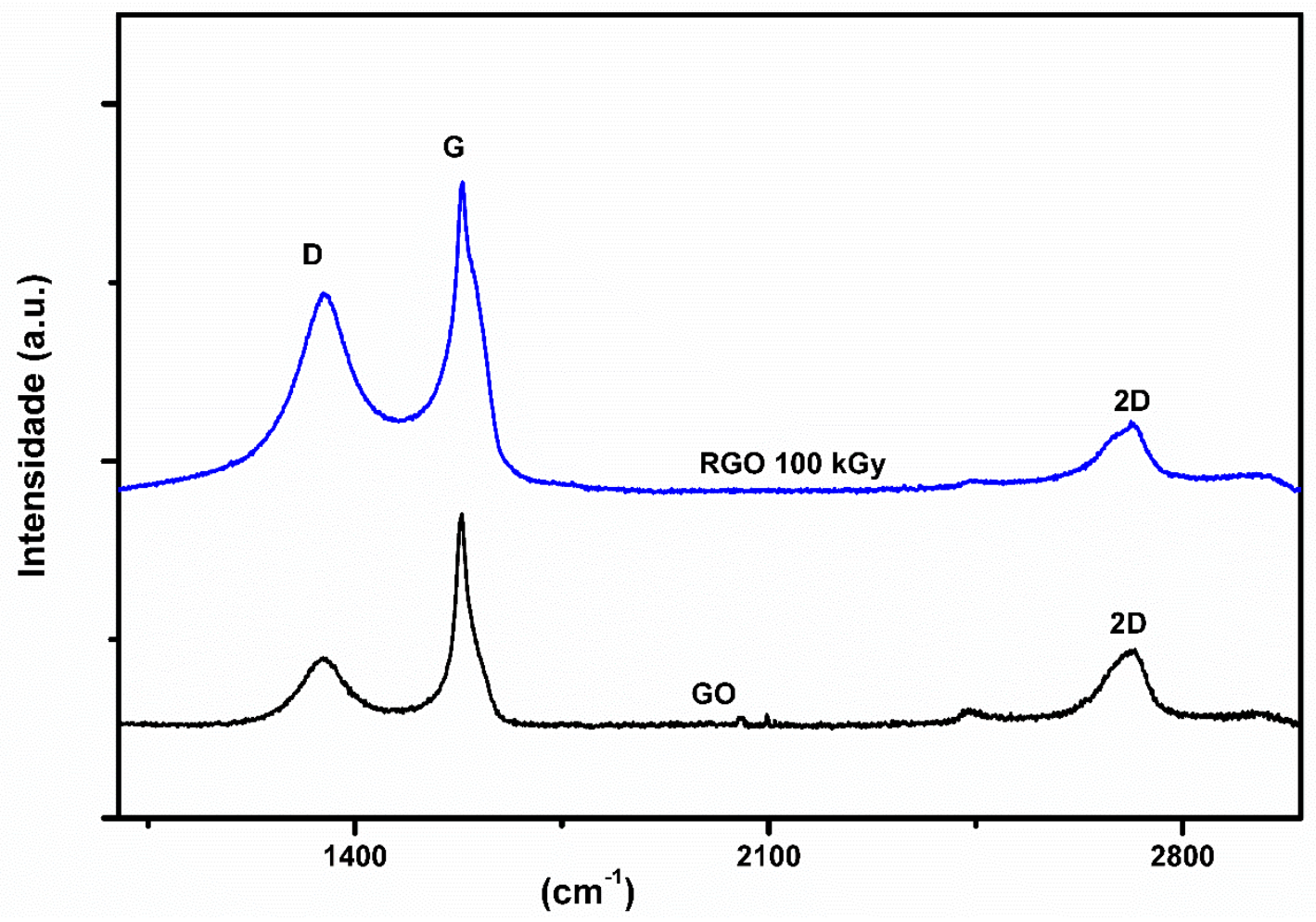

Fonte: Autor da dissertação.

O espectro do GO revela um pico proeminente na banda $G$ em $1581 \mathrm{~cm}^{-1}$, um pico alargado e com baixa intensidade na banda $D$ em $1347 \mathrm{~cm}^{-1}$ e um pico 2D alargado em $2709 \mathrm{~cm}^{-1}$. A presença da banda $\mathrm{D} \mathrm{em} 1347 \mathrm{~cm}^{-1}$ é devido à redução no tamanho dos domínios $\mathrm{sp}^{2}$ no plano da grafite, induzida pela criação de defeitos, vacâncias e distorções dos domínios $\mathrm{sp}^{2}$ após a oxidação. $\mathrm{O}$ espectro do RGO acima mostra um pico alargado e de maior intensidade na banda $D$ deslocado para $1340 \mathrm{~cm}^{-1}$, um pico com alta intensidade na banda $G$ deslocado para $1573 \mathrm{~cm}^{-1}$ e um pico alargado em 2D centrado em $2720 \mathrm{~cm}^{-1}$. Pode-se observar no espectro do RGO quando comparado com o espectro do GO um aumento de intensidade das bandas $D$ e $G$ e redução da intensidade da banda $2 \mathrm{D}$. 
A razão da intensidade das bandas $D / G$ fornece informações sobre a estrutura do grafeno. A razão da intensidade $\mathrm{I} / \mathrm{I}_{\mathrm{G}}$ representa os defeitos

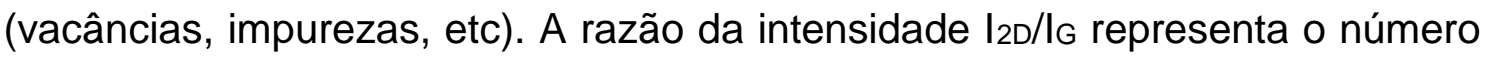
de camadas presentes no GO (KUDIN et al., 2007; G. WANG et al., 2009; KHAN et al., 2017). A intensidade das bandas $D, 2 D, G$ e as razões da intensidade $I_{D} / l_{G}$ e I2D/lg são listados na Tabela 3.

Tabela 3 - Intensidade das bandas D, 2D e G e as taxas de intensidade de ID/IG e I $\mathrm{I}_{2 \mathrm{D}} / \mathrm{I}_{\mathrm{G}}$ obtidas por espectroscopia Raman

\begin{tabular}{c|c|c|c|c|c}
\hline Amostras & D (a.u.) & G (a.u.) & 2D (a. u.) & $\mathrm{I}_{\mathrm{D}} / \mathrm{IG}_{\mathrm{G}}$ & $\mathrm{I}_{2 \mathrm{D} / \mathrm{IG}_{\mathrm{G}}}$ \\
\hline GO & 5543 & 13569 & 5981 & 0.41 & 0.44 \\
\hline RGO 100 kGy & 32783 & 38640 & 5310 & 0.85 & 0.14 \\
\hline
\end{tabular}

Fonte: Autor da dissertação.

De acordo com a literatura, o valor de ID/IG próximo a zero indica a característica de um material grafítico cristalino, e quanto maior este valor, menor será a cristalinidade do material. Conforme é apresentado na tabela 3, a razão $\mathrm{ID} / \mathrm{lg}$ aumentou cerca de $100 \%$ quando o GO foi reduzido a RGO por radiação gama na dose de $100 \mathrm{kGy}$, indicando uma maior quantidade de defeitos estruturais no RGO 100 kGy devido à quebra da estrutura grafítica e maior incorporação de grupos oxigenados pela oxidação da grafite no processo de esfoliação química. $O$ aumento da razão $\mathrm{ID} / \mathrm{IG}_{\mathrm{G}}$ também pode ser atribuído a uma diminuição no tamanho médio dos domínios $\mathrm{sp}^{2}$ após a redução do $\mathrm{GO}$ devido à criação de vários novos domínios grafíticos no RGO que possuem tamanho menor que aqueles encontrados no GO antes da redução, mas são maiores em quantidade.

Também pode-se observar, a partir da Tabela 3, uma diminuição na razão $\mathrm{I}_{2 D} / \mathrm{lg}_{\mathrm{G}}$ do $\mathrm{RGO}$ em relação ao $\mathrm{GO}$. Considerando que a razão $\mathrm{I}_{2 \mathrm{D}} / \mathrm{IG}_{\mathrm{G}}$ representa 0 número de camadas de nanofolhas de GO na amostra, estes resultados sugerem que a amostra de RGO apresenta um número muito menor de camadas comparado ao GO não reduzido. Estes resultados podem ser confirmados pelas imagens de MEV-FEG apresentadas. Portanto, é possível inferir que o RGO 
apresentou um baixo número de camadas empilhadas e defeitos e, consequentemente, pode ser considerado um material com melhor qualidade que o GO não reduzido. De acordo com estes resultados, pode-se concluir que a redução do GO induzida por radiação gama na presença de solução de etanol/água e dose de radiação de 100 kGy é uma técnica segura, simples e eficiente para a obtenção de GO reduzido (RGO). A eficiência da redução do GO induzida por radiação gama também tem sido reportada por outros autores na literatura (GAO, 2015; STANKOVICH et al., 2007; KHAN et al., 2017).

\subsubsection{Análise Termogravimétrica (TG)}

As Figs. 38 e 39 apresentam os resultados da análise termogravimétrica para o GO e RGO. Como pode ser visto nos termogramas das amostras de GO e RGO, Fig. 38 e nos termogramas DTG Fig. 39, o GO apresentou uma maior perda de massa que o RGO, indicando menor estabilidade térmica. Este comportamento era esperado, uma vez que, devido a abundância de grupos oxigenados presentes na estrutura do GO este tende a ficar mais sensível à degradação térmica em atmosfera de nitrogênio.

A partir das Fgs. 38 e 39, podem ser observados três estágios de degradação para o GO. O primeiro estágio, na faixa de temperatura de 42 - 229 @C é devido à perda de umidade e também corresponde à decomposição de grupos funcionais contendo oxigênio, o segundo a partir de $236-539{ }^{\circ} \mathrm{C}$ correspondem a remoção de grupos funcionais contendo oxigênio mais estáveis, o terceiro e último estágio, na faixa de temperatura de 543 - $978{ }^{\circ} \mathrm{C}$, apresenta uma grande perda de massa, de cerca de $55 \%$ da massa total do GO que está associada à pirólise de alta temperatura do esqueleto do carbono (ZHANG et al., 2012; J. YANG et al., 2013; X. YANG et al., 2013). 
Figura 38- Curvas de TG para o GO e RGO

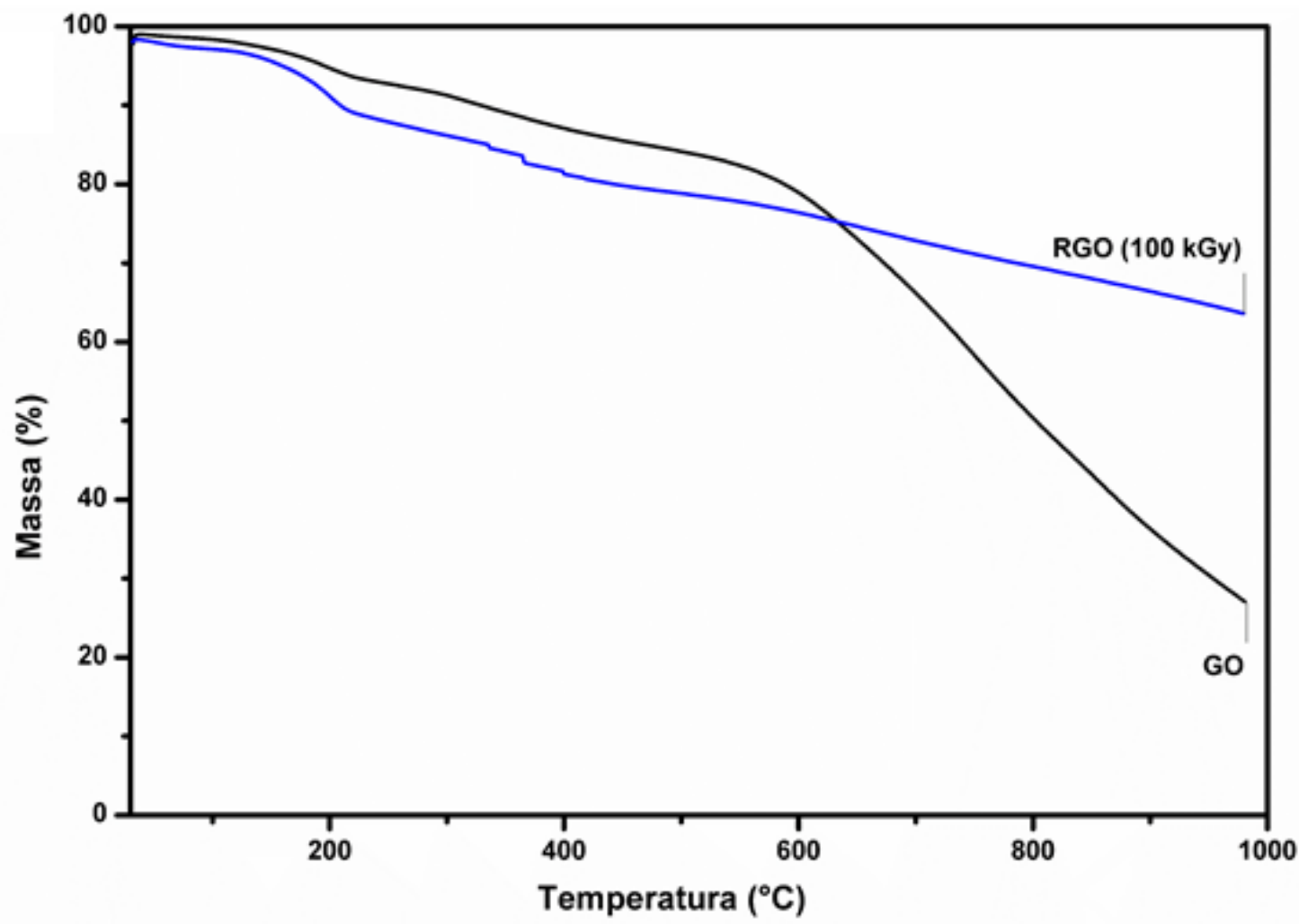

Fonte: Autor da dissertação.

Figura 39- Curvas de DTG para o GO e RGO

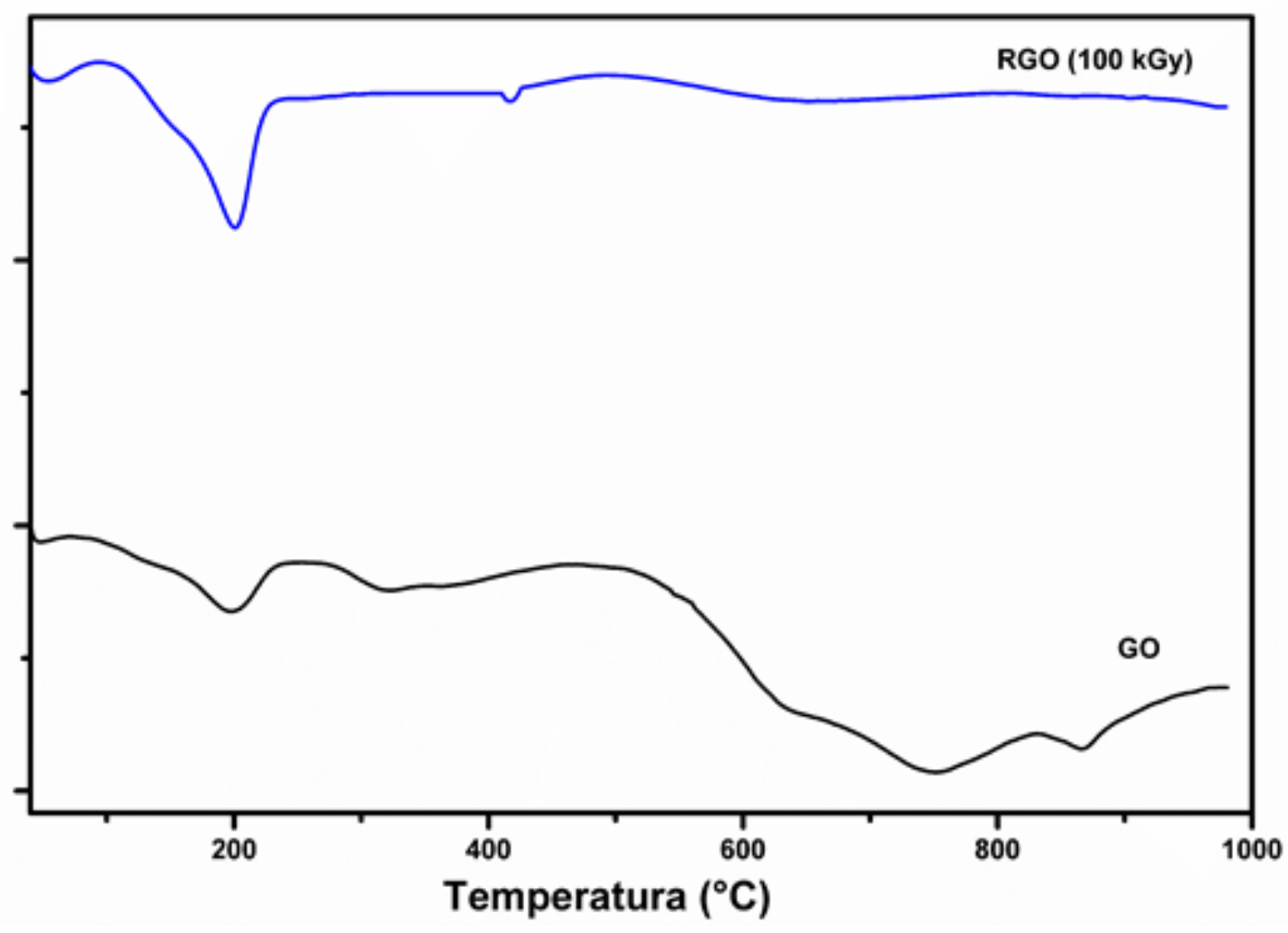

Fonte: Autor da dissertação. 
As temperaturas de decomposição térmica e perda de massa das nanofolhas de GO e RGO são apresentadas na Tabela 4.

Tabela 4 - Temperaturas de decomposição e perda de massa das nanofolhas de GO / RGO

\begin{tabular}{|c|c|c|c|c|c|c|c|}
\hline \multicolumn{3}{|c|}{ Zona 1} & \multicolumn{2}{|c|}{ Zona 2} & \multicolumn{2}{|c|}{ Zona 3} & $\begin{array}{l}T_{\max } \\
1000 \\
\left({ }^{\circ} \mathrm{C}\right)\end{array}$ \\
\hline Amostras & $\begin{array}{l}\text { T.D. } \\
\left({ }^{\circ} \mathrm{C}\right)\end{array}$ & $\begin{array}{c}\text { Perda } \\
\text { de } \\
\text { massa } \\
(\%)\end{array}$ & $\begin{array}{l}\text { T.D. } \\
(\stackrel{\circ}{ } \mathrm{C})\end{array}$ & $\begin{array}{c}\text { Perda } \\
\text { de } \\
\text { massa } \\
(\%)\end{array}$ & $\begin{array}{l}\text { T.D. } \\
(\stackrel{\circ}{ } \mathrm{C})\end{array}$ & $\begin{array}{c}\text { Perda } \\
\text { de } \\
\text { massa } \\
(\%)\end{array}$ & $\begin{array}{c}\text { Perda de } \\
\text { massa total } \\
(\%)\end{array}$ \\
\hline $\mathrm{GO}$ & $42-229$ & 5,7 & $236-539$ & 10,2 & 543- 978 & 55,4 & 72 \\
\hline $\mathrm{RGO}$ & $41-124$ & 1,5 & $126-221$ & 7,6 & $220-470$ & 9,7 & 35 \\
\hline
\end{tabular}

Fonte: Autor da dissertação.

Como pode ser visto nesta tabela, após a redução induzida por raios gama, o GO reduzido (RGO) apresentou uma taxa de degradação lenta, a qual pode ser descrita como uma maior estabilidade térmica, devido à remoção de grupos contendo oxigênio. Pode-se observar que a perda de massa de RGO é perceptivelmente menor do que aquela do GO, apresentando uma perda de massa total de apenas $35 \%$ enquanto a perda de massa total para o GO foi de 72 \%. Esta pequena perda de massa do RGO pode ser atribuída à ausência da maioria dos grupos funcionais de oxigênio presentes no GO. Isto indica que a maioria dos grupos funcionais contendo oxigênio do GO foram reduzidos durante o processo de irradiação com raios gama, o que resultou no aumento da estabilidade térmica do RGO (DUBIN et al., 2010; ZHU et al., 2010; WANG et al., 2010).

\subsection{Análise do EVOH puro e seus nanocompósitos}

\subsubsection{Difração de Raios X (DRX)}

A Figura 40 mostra os espectros de DRX no intervalo de $2 \theta=2-70^{\circ}$ para os filmes flexíveis de EVOH e EVOH/GO. 
O espectro de DRX mostra picos característicos do $\mathrm{EVOH}$, apresentando um pico com um ombro em $2 \theta=20,3^{\circ}$, que é a característico do EVOH (KIM \& LEE, 2014; KIM \& CHOI, 2015). O espectro de DRX para o EVOH/GO 0,1\% também apresenta um ombro em $2 \theta=20,3^{\circ}$. O pico característico do $\mathrm{GO}$ em $2 \theta=10^{\circ}$ está ausente para os nanocompósitos de EVOH/GO, indicando assim que as nanofolhas do GO foram intercaladas entre as cadeias moleculares do EVOH (KWON et al., 2013). Há um pequeno deslocamento e formação de um pico agudo em $2 \theta=20,1^{\circ}$ para os nanocompósitos, indicando a cristalização do EVOH (KIM \& LEE, 2014).

Figura 40 - Difratograma do EVOH e EVOH/GO

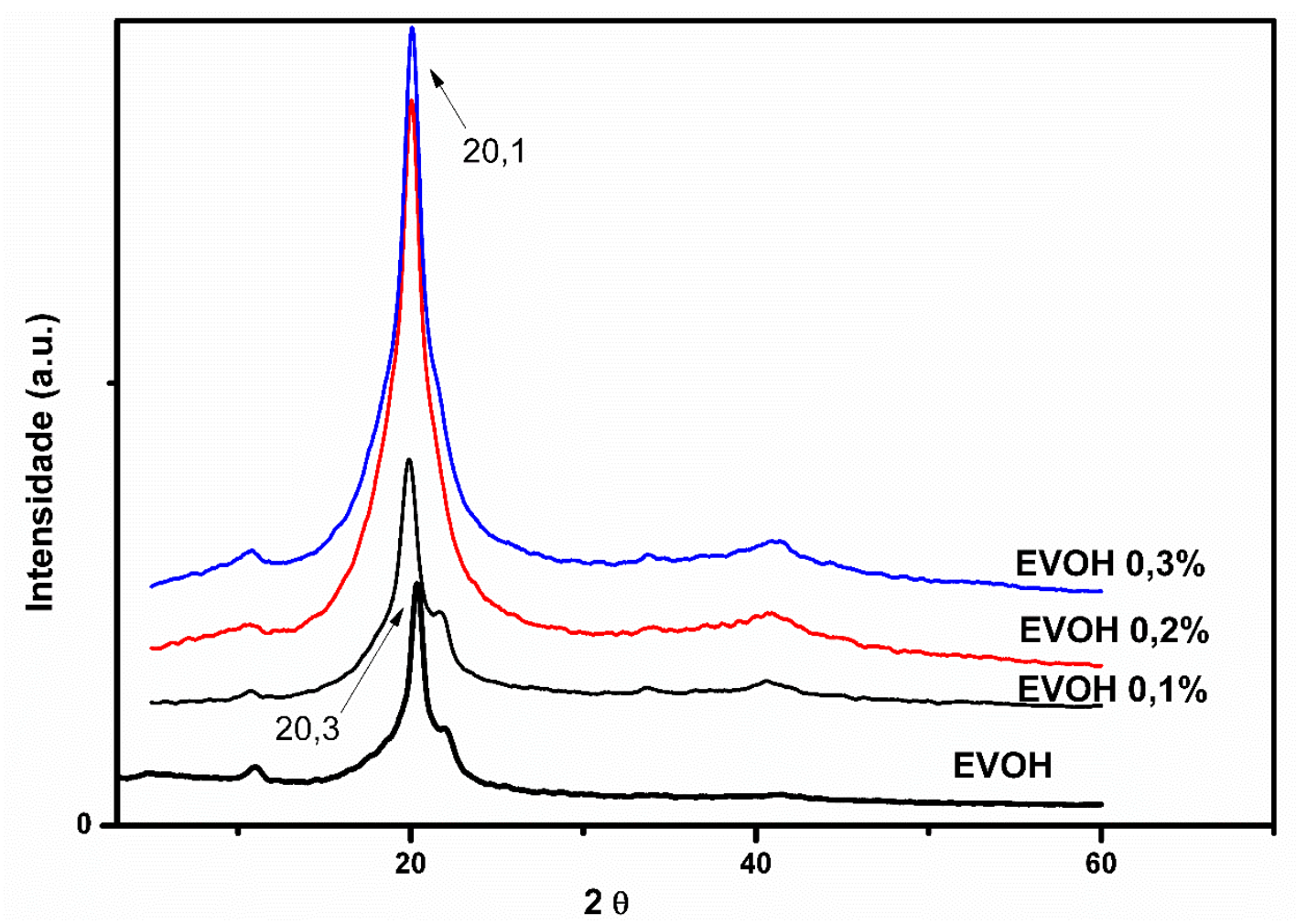

Fonte: Autor da dissertação.

Observa-se também nestes espectros o pico em $2 \theta=20,3^{\circ}$ característico do EVOH com um aumento de intensidade de acordo com a adição das nanofolhas de GO $(0,1-0,3 \%)$.

Nas figuras de 41 a 44 são apresentados os difratogramas dos materiais estudados nas doses de radiação de 100 - 250 kGy. 
Figura 41 - Difratograma comparativo do EVOH em função da dose de radiação aplicada

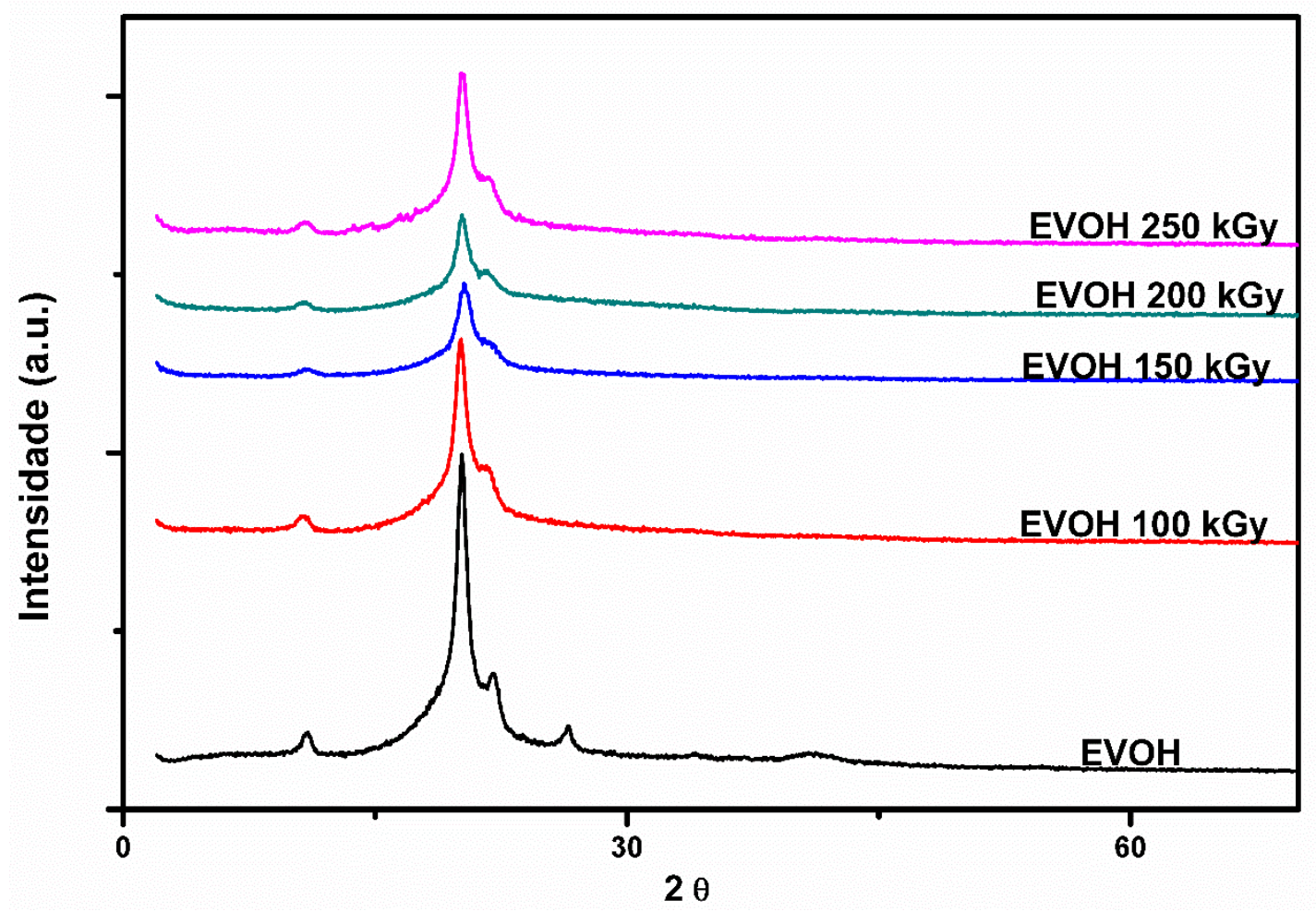

Fonte: Autor da dissertação.

Figura 42 - Difratograma comparativo do $\mathrm{EVOH} / \mathrm{GO}$ 0,1 \% em função da dose de radiação aplicada

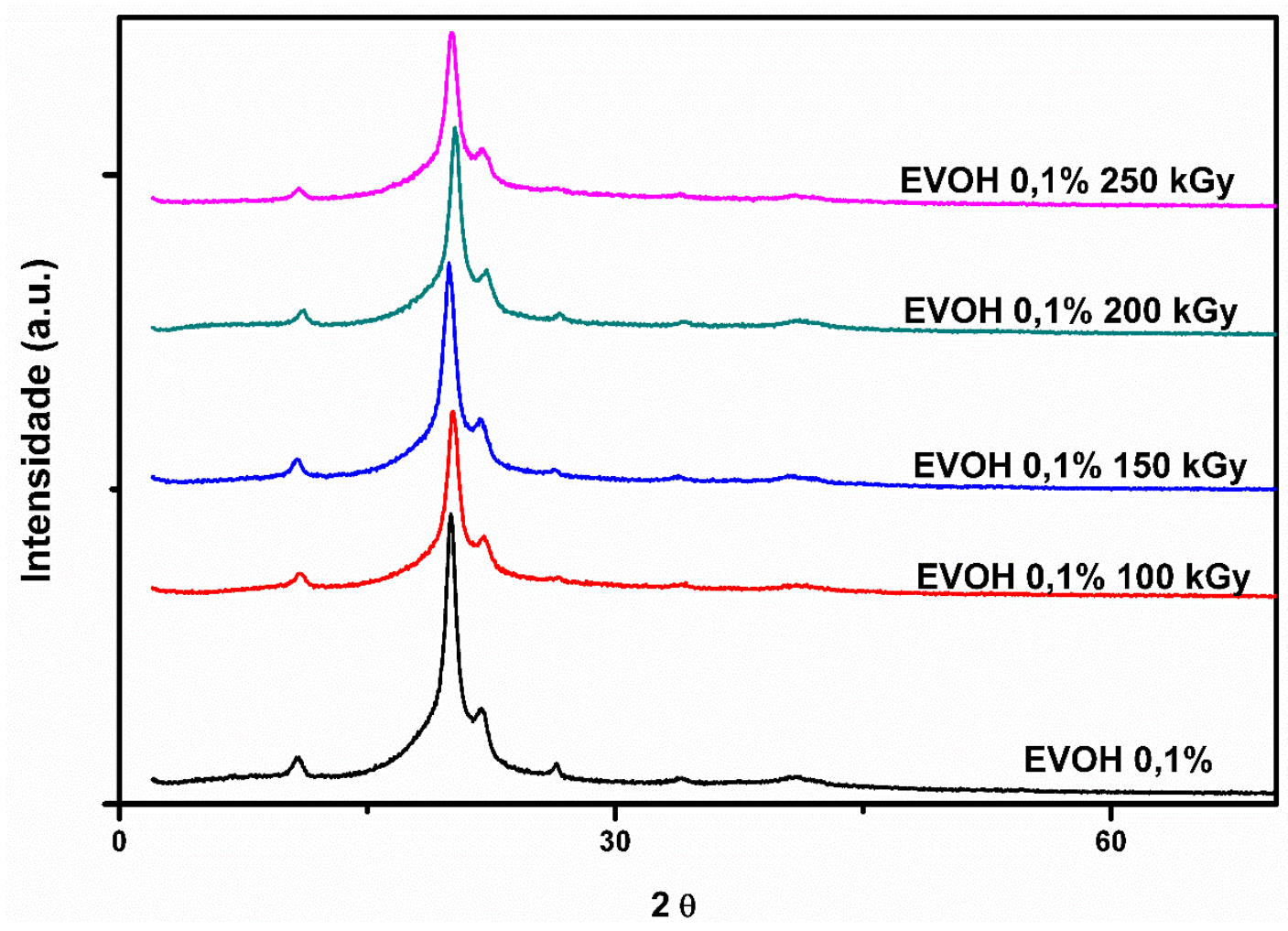

Fonte: Autor da dissertação. 
Figura 43 - Difratograma comparativo do EVOH/GO 0,2 \% em função da dose de radiação aplicada

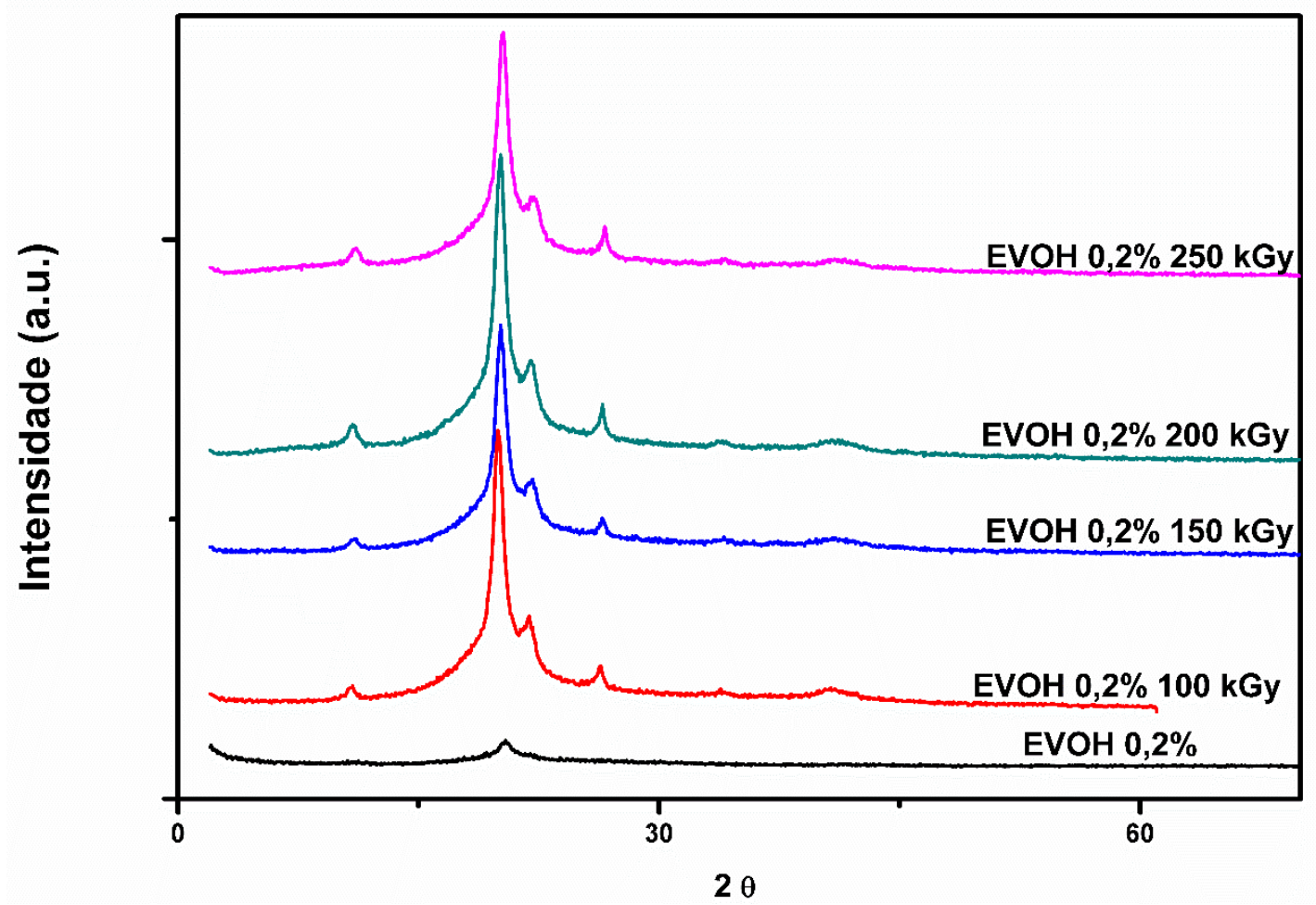

Fonte: Autor da dissertação.

Figura 44 - Difratograma comparativo do $\mathrm{EVOH} / \mathrm{GO}$ 0,3 \% em função da dose de radiação aplicada

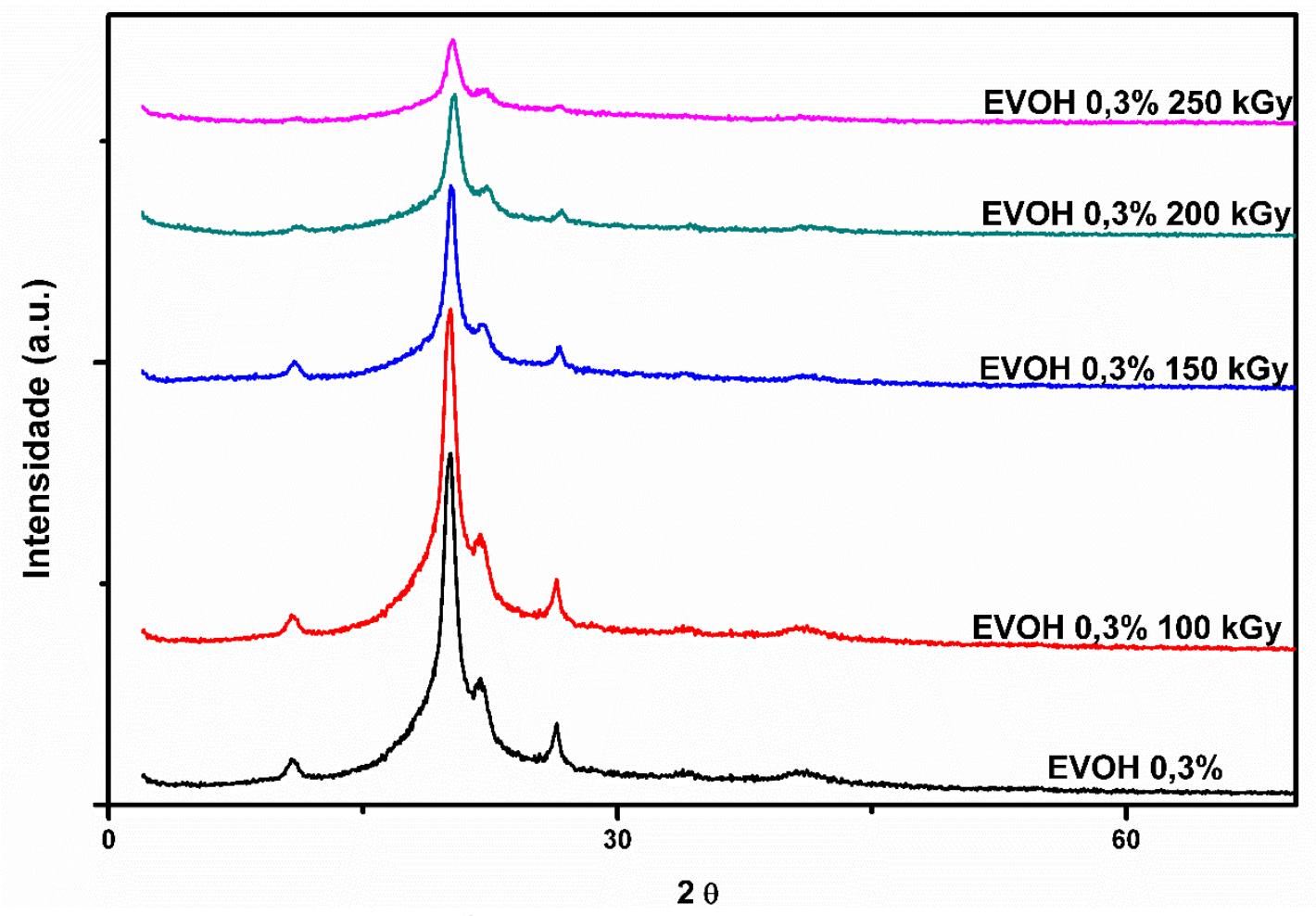

Fonte: Autor da dissertação. 
Nos difratogramas apresentados pode ser observado, a presença de dois picos característicos do EVOH em $2 \theta=20,3$ e 22,3 ${ }^{\circ}$ indicando a esfoliação das nanofolhas de $\mathrm{GO}$ e também uma grande variação no aumento e redução de intensidade no pico em $2 \theta=20,3^{\circ}$ dos nanocompósitos de acordo com a dose de radiação aplicada.

5.2.2 Microscopia Eletrônica de Varredura com fonte de emissão de campo (MEV-FEG)

As imagens obtidas por microscopia eletrônica de varredura com fonte de emissão de campo (MEV-FEG) das superfícies criofraturadas em nitrogênio líquido para as amostras não irradiadas do $\mathrm{EVOH}$ puro e dos nanocompósitos EVOH/GO 0,1- 0,3 \%, com 5000 X e 10000X de ampliações, são mostradas a seguir nas figuras de 45 a 52 .

As micrografias da superfície criofraturada do $\mathrm{EVOH}$ puro apresentado nas figuras 45 e 46 mostram uma superfície rugosa, relativamente irregular característica da matriz polimérica de $\mathrm{EVOH}$.

Figura 45 - Micrografias obtidas por MEV-FEG das superfícies criofraturadas do EVOH (5000 X)

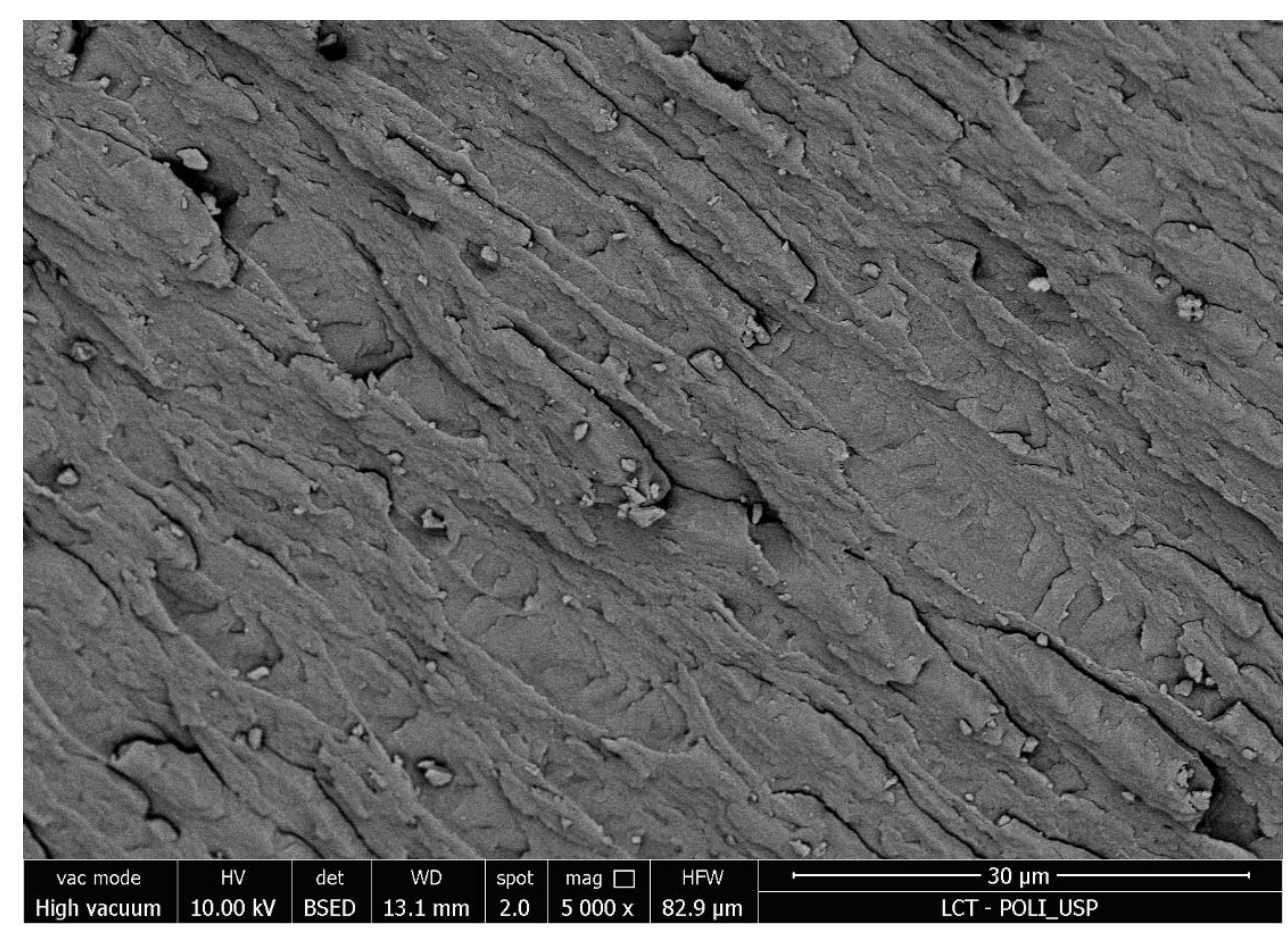

Fonte: Autor da dissertação. 
Figura 46 - Micrografias obtidas por MEV- FEG das superfícies criofraturadas do $\mathrm{EVOH}(10.000 \mathrm{X})$

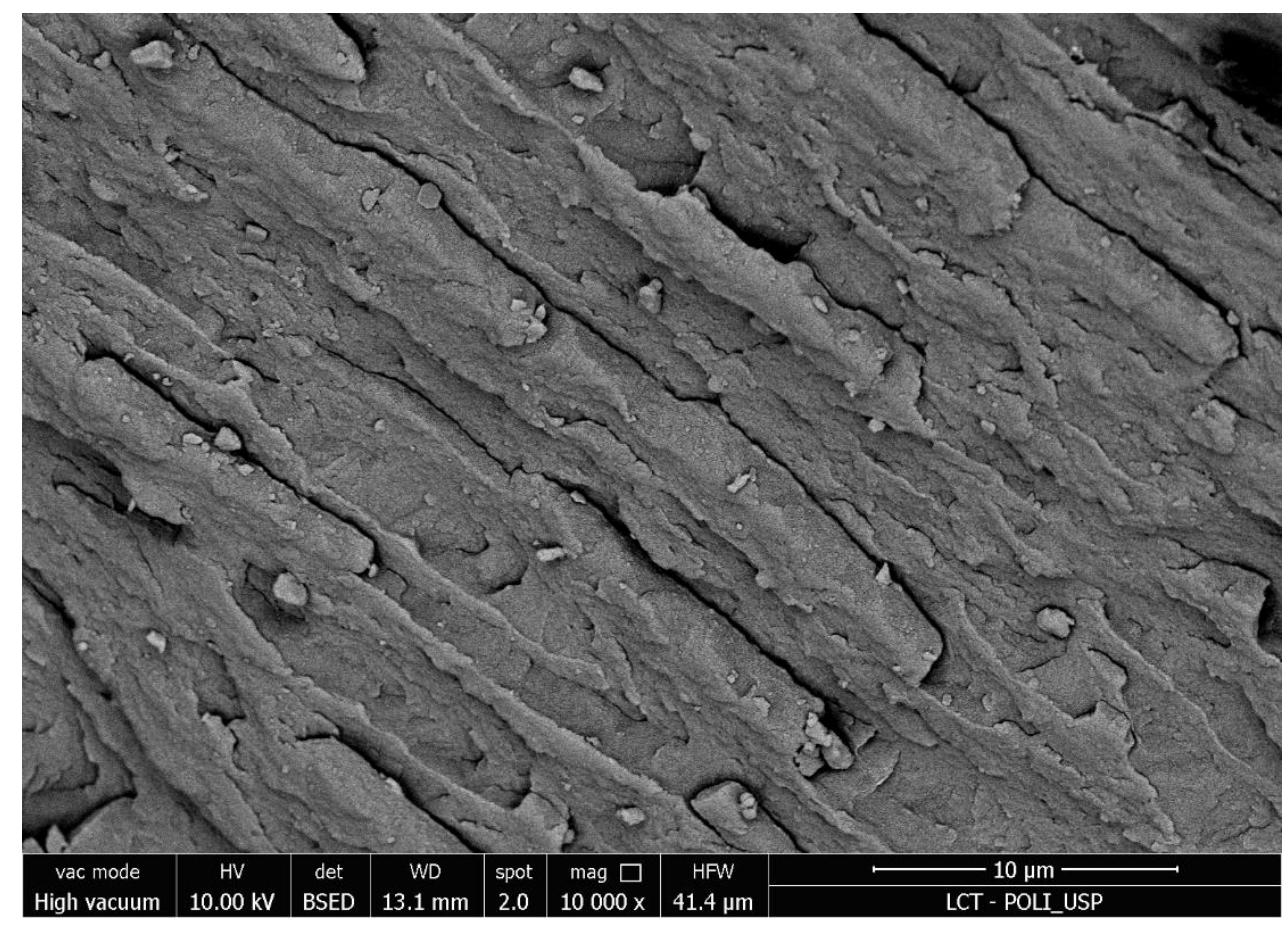

Fonte: Autor da dissertação.

As Figuras 47 e 48 mostram as micrografias EVOH/GO contendo $0,1 \%$ em peso de GO. Pode-se observar nestas figuras uma superfície criofraturada lisa e sem a presença de aglomerados. 
Figura 47 - Micrografias obtidas por MEV-FEG das superfícies criofraturadas do $\mathrm{EVOH} / \mathrm{GO} 0,1 \%(5000 \mathrm{X})$

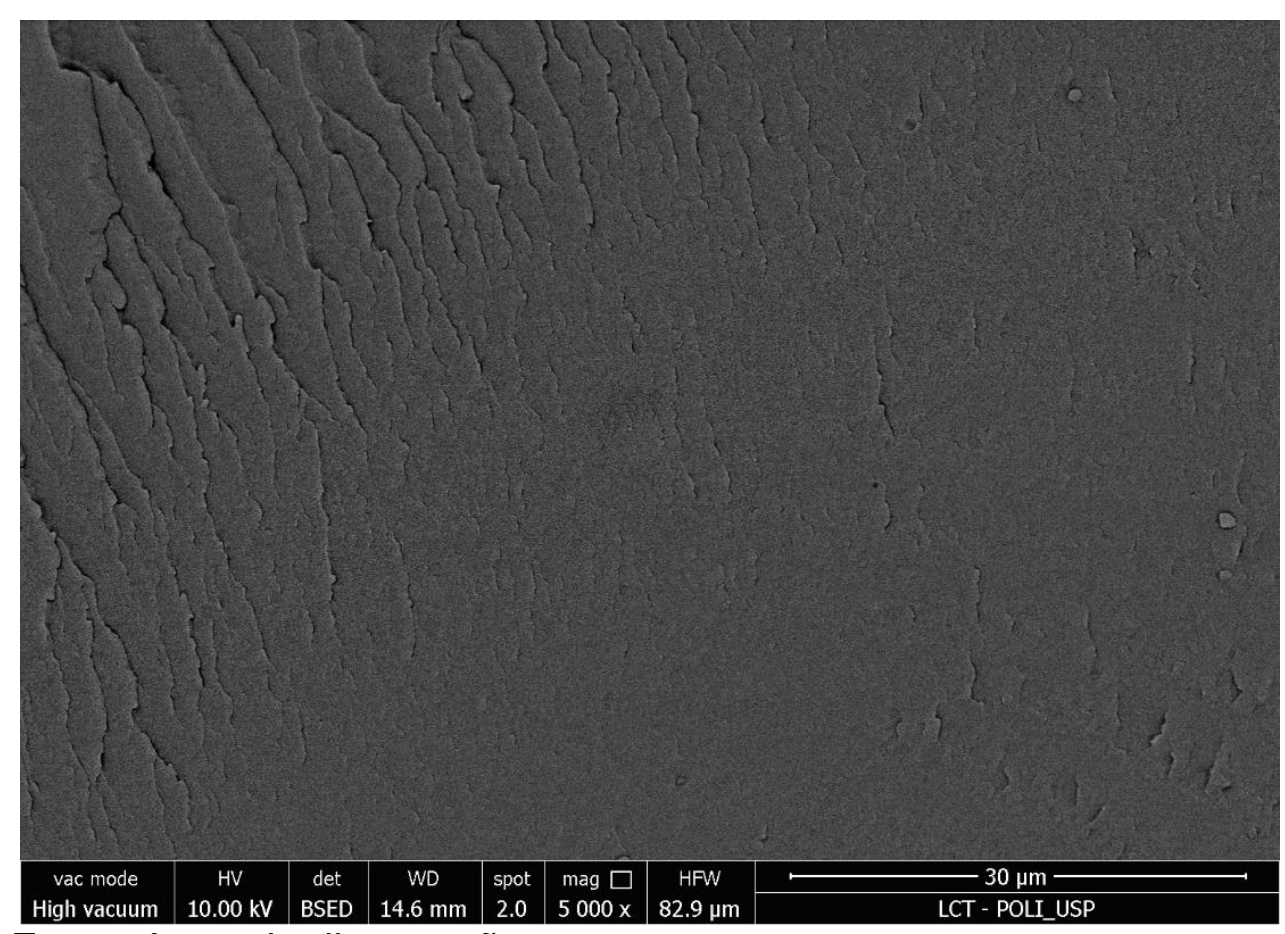

Fonte: Autor da dissertação.

Figura 48 - Micrografias obtidas por MEV- FEG das superfícies criofraturadas do $\mathrm{EVOH} / \mathrm{GO} 0,1 \%(10.000 \mathrm{X})$

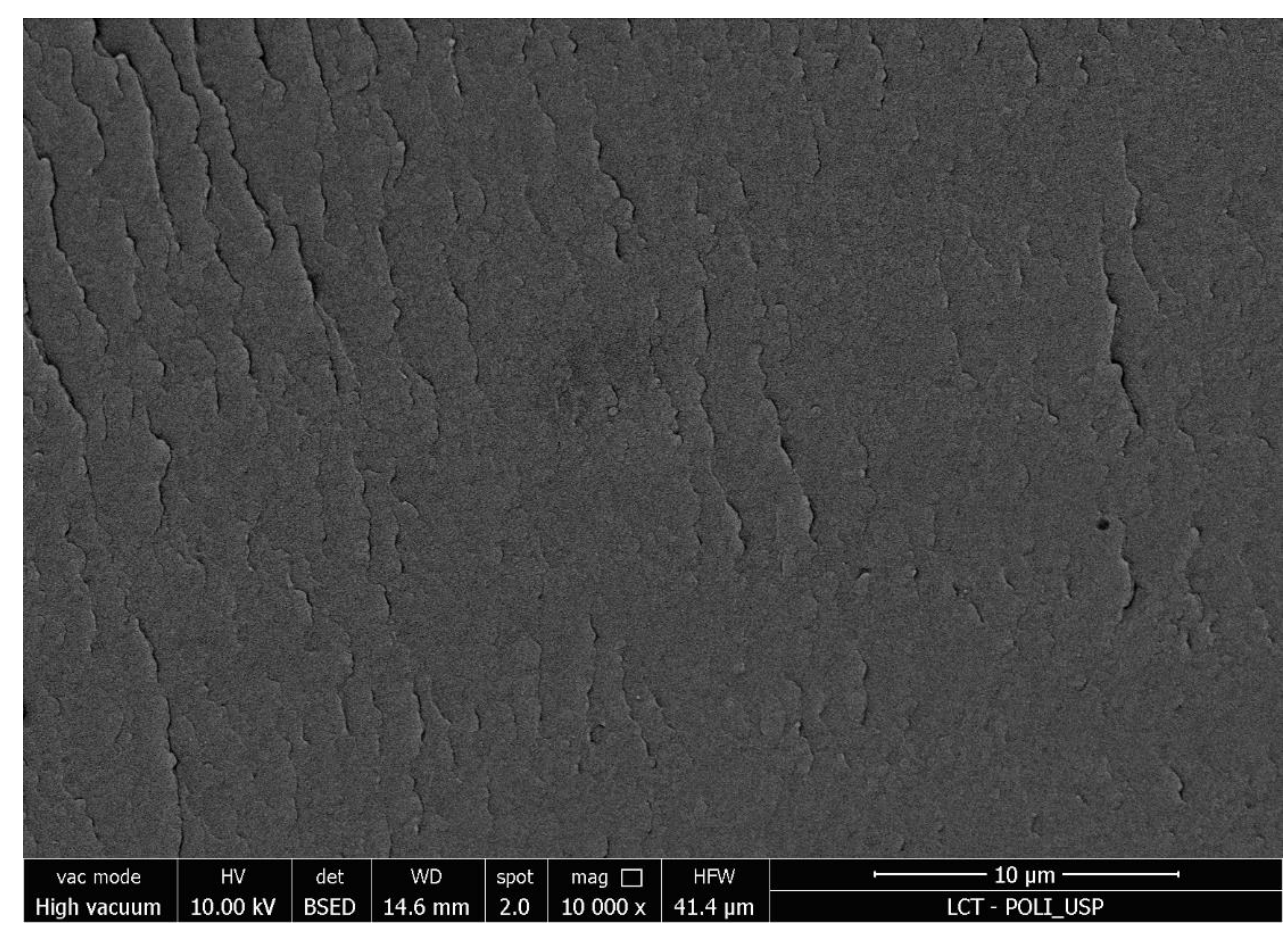

Fonte: Autor da dissertação. 
No entanto, para o $\mathrm{EVOH} / \mathrm{GO}$ contendo $0,2 \%$ em peso de GO, como mostram as Figs. 49 e 50, pode-se observar uma superfície irregular, com presença de pequenos agregados de GO dispersos por toda a superfície da amostra.

Figura 49 - Micrografias obtidas por MEV-FEG das superfícies criofraturadas do $\mathrm{EVOH} / \mathrm{GO} 0,2 \%(5000 \mathrm{X})$

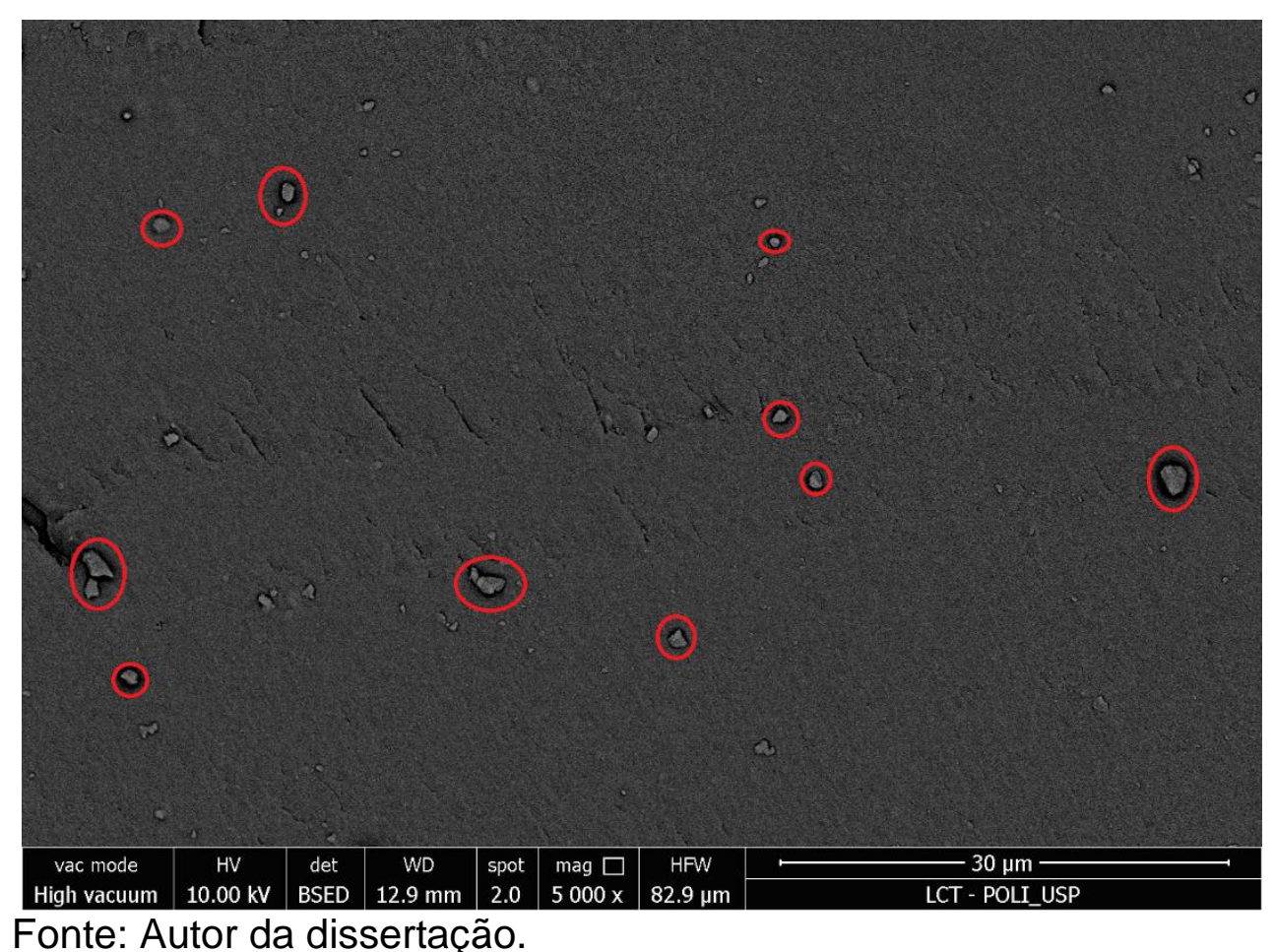


Figura 50 - Micrografias obtidas por MEV- FEG das superfícies criofraturadas do $\mathrm{EVOH} / \mathrm{GO} 0,2 \%(10.000 \mathrm{X})$

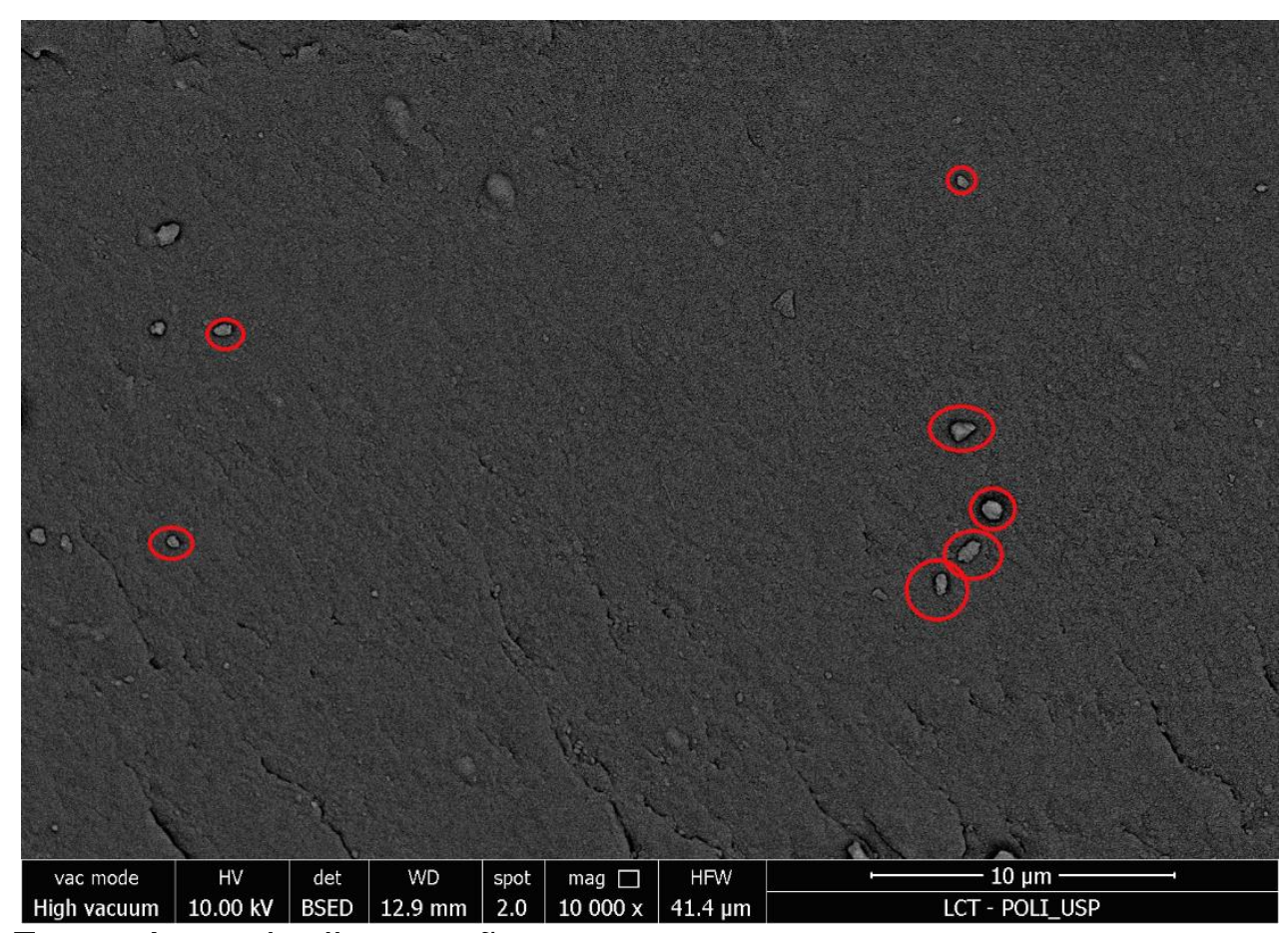

Fonte: Autor da dissertação.

As Figs. 51 e 52 mostram as micrografias de superfície do EVOH/GO contendo 0,3\% em peso de GO. Pode-se observar também nestas figuras uma superfície lisa sem a presença de aglomerados, indicando uma distribuição homogênea das nanofolhas de GO na superfície da matriz EVOH. 
Figura 51 - Micrografias obtidas por MEV- FEG das superfícies criofraturadas do $\mathrm{EVOH} / \mathrm{GO} 0,3 \%(5000 \mathrm{X})$

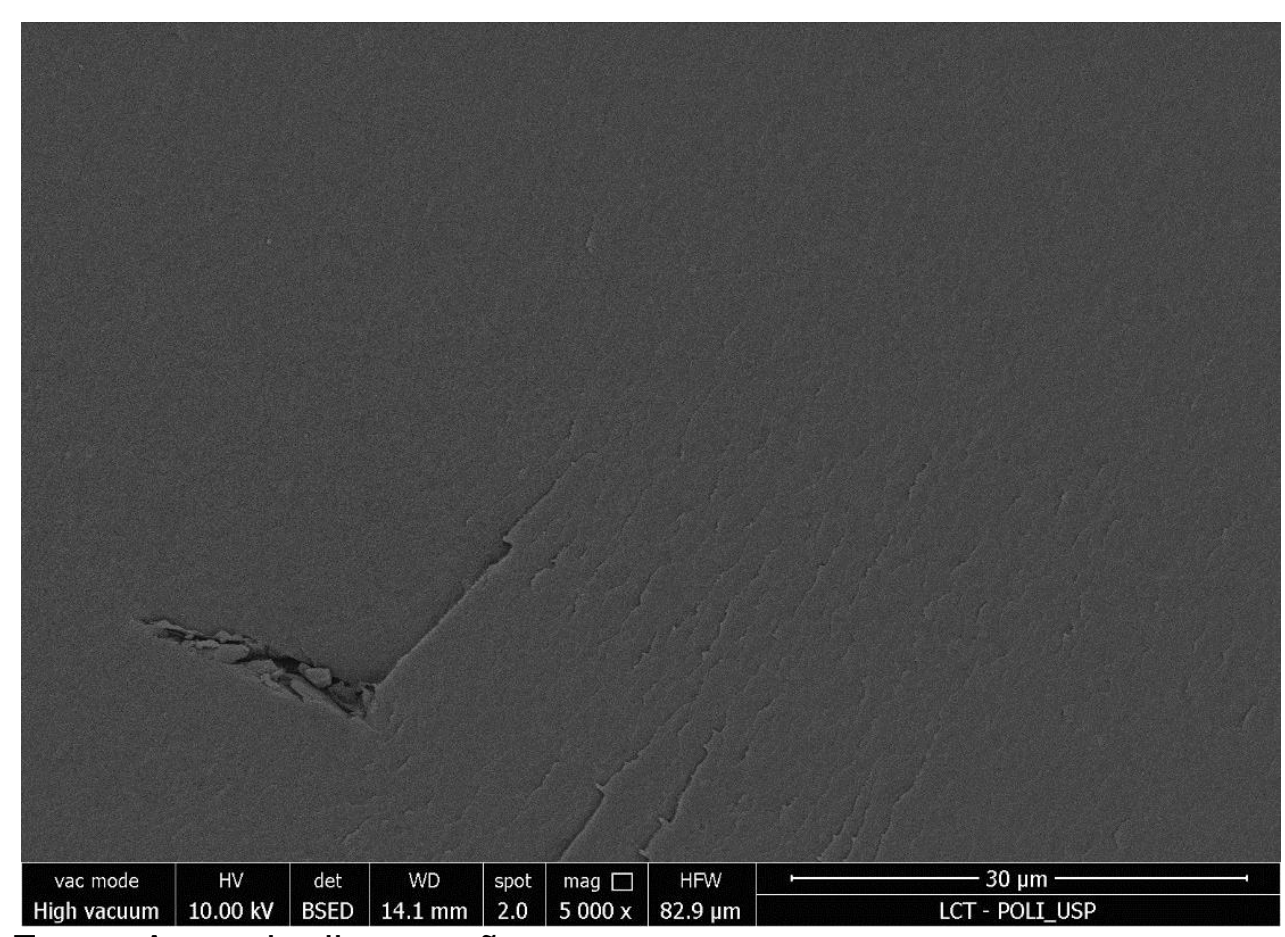

Fonte: Autor da dissertação.

Figura 52 - Micrografias obtidas por MEV- FEG das superfícies criofraturadas do $\mathrm{EVOH} / \mathrm{GO} 0,3 \%(10.000 \mathrm{X})$

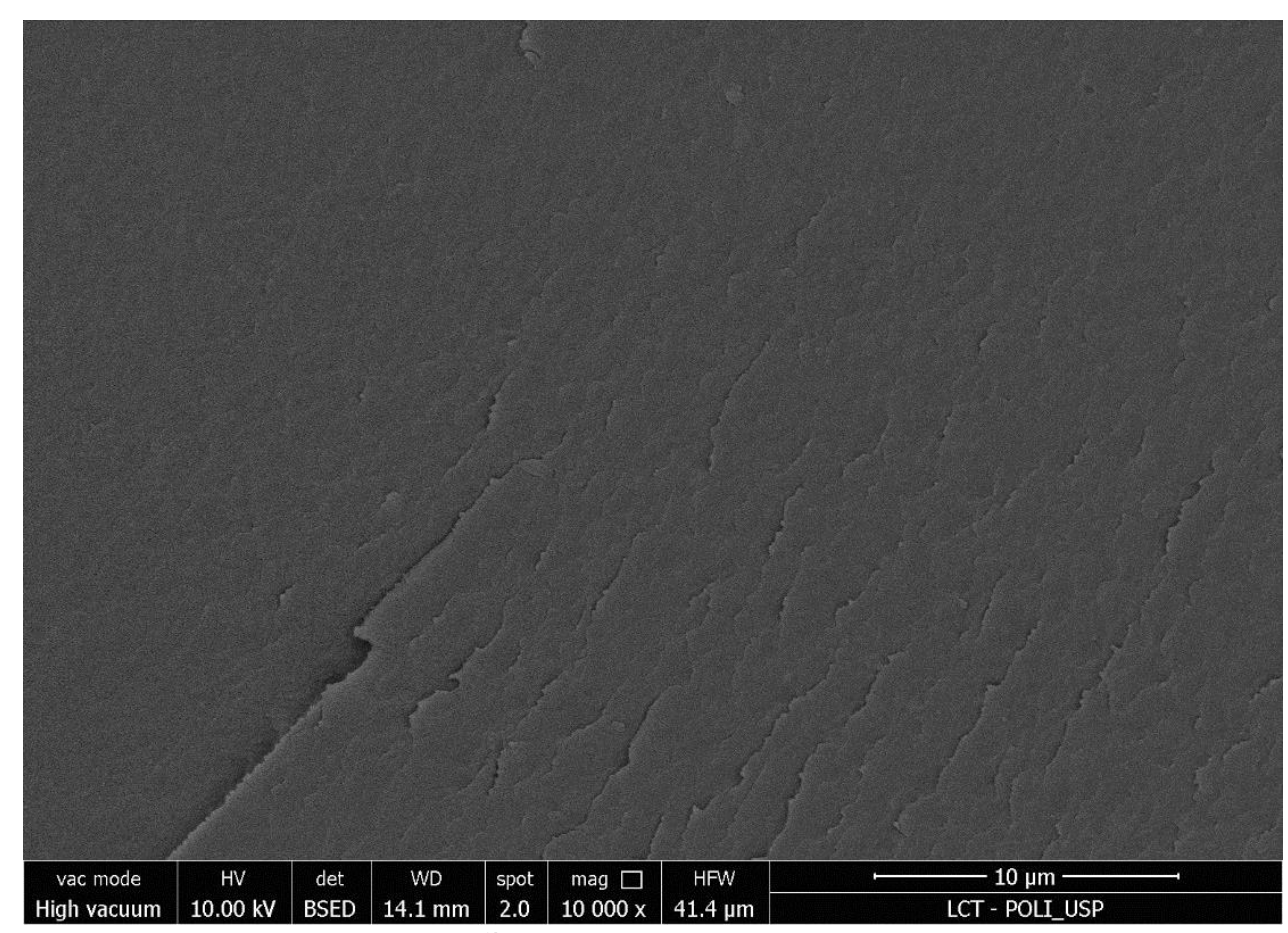

Fonte: Autor da dissertação. 
Os nanocompósitos $\mathrm{EVOH} / \mathrm{GO}$ com $0,1 \%$ e 0,3\% em peso de GO exibiram uma superfície lisa similar sem a presença visual de aglomerados. Estes resultados sugerem uma boa dispersão do GO na matriz de EVOH e uma boa adesão interfacial entre o GO e a matriz.

\subsubsection{Análise Termogravimetrica (TG)}

A análise termogravimetrica do EVOH e seus nanocompósitos foi realizada para avaliar os efeitos da adição do GO na estabilidade térmica dos nanocompósitos, avaliando a estabilidade térmica e massa residual até $600{ }^{\circ} \mathrm{C}$.

$\mathrm{Na}$ figura 53 pode-se observar que a adição de GO reduziu levemente a temperatura inicial de degradação térmica do $\mathrm{EVOH}$, mas aumentou em aproximadamente $42{ }^{\circ} \mathrm{C}$ a temperatura máxima de degradação térmica, o que pode indicar um ganho de estabilidade térmica para os filmes de EVOH/GO quando comparados aos filmes de EVOH puro. $O$ aumento da temperatura pode ser devido à interação da ligação de hidrogênio entre GO e o EVOH (KIM \& LEE, 2014).

Figura 53 - Curva de TG do EVOH e EVOH/GO 0,1 - 0,3\%

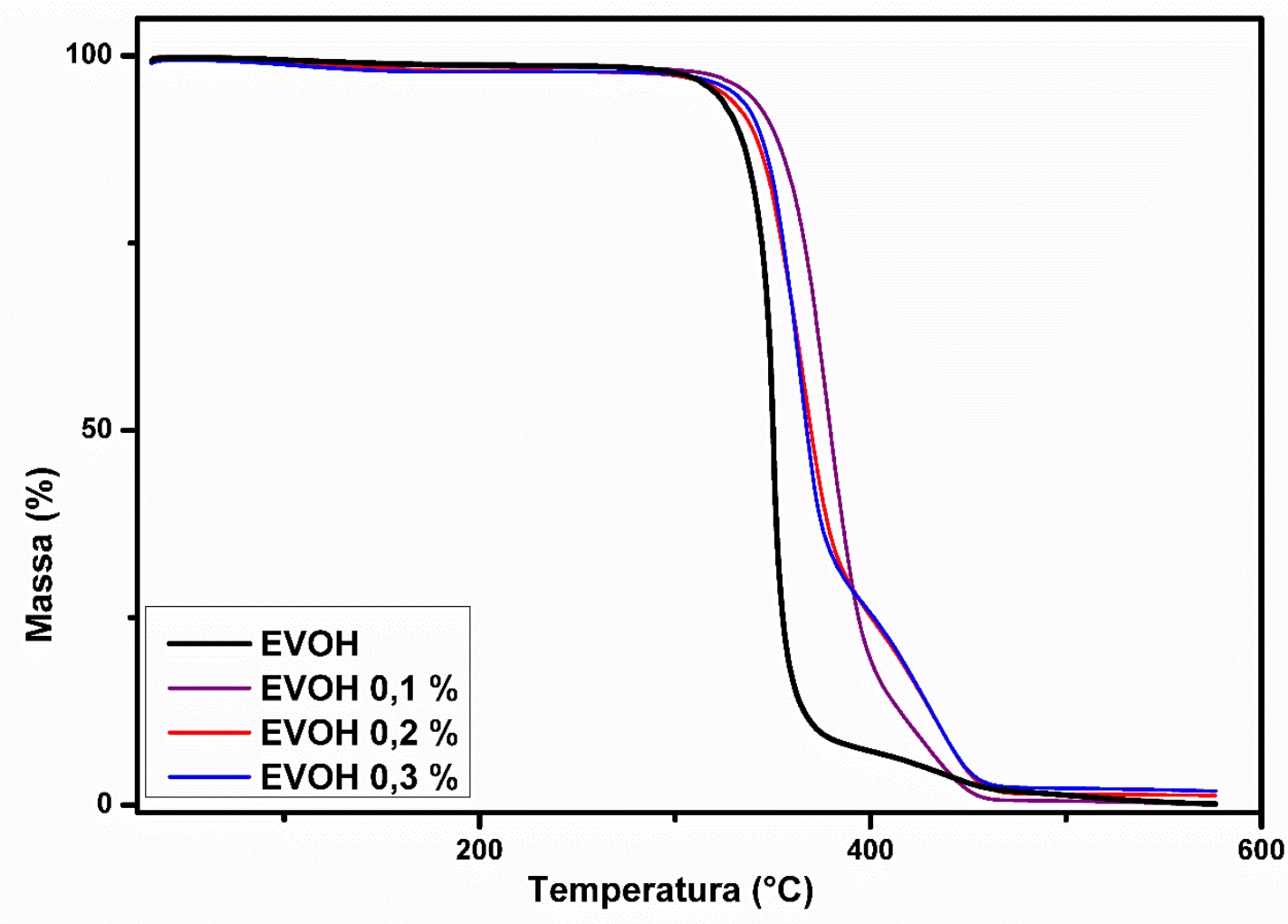

Fonte: Autor da dissertação. 
As amostras de EVOH e seus nanocompósitos quando expostos a doses de radiação de 100 a 250 kGy apresentaram algumas mudanças na temperatura de degradação térmica em função da dose de radiação aplicada.

Nas figuras de 54 a 57 são apresentados os graficos de TG para as amostras de $\mathrm{EVOH} / \mathrm{GO} 0,1-0,3 \%$ nas doses de radiação de 100 a 250 kGy, respectivamente.

Figura 54 - Curva de TG do EVOH/GO 0,1 - 0,3 \% (100 kGy)

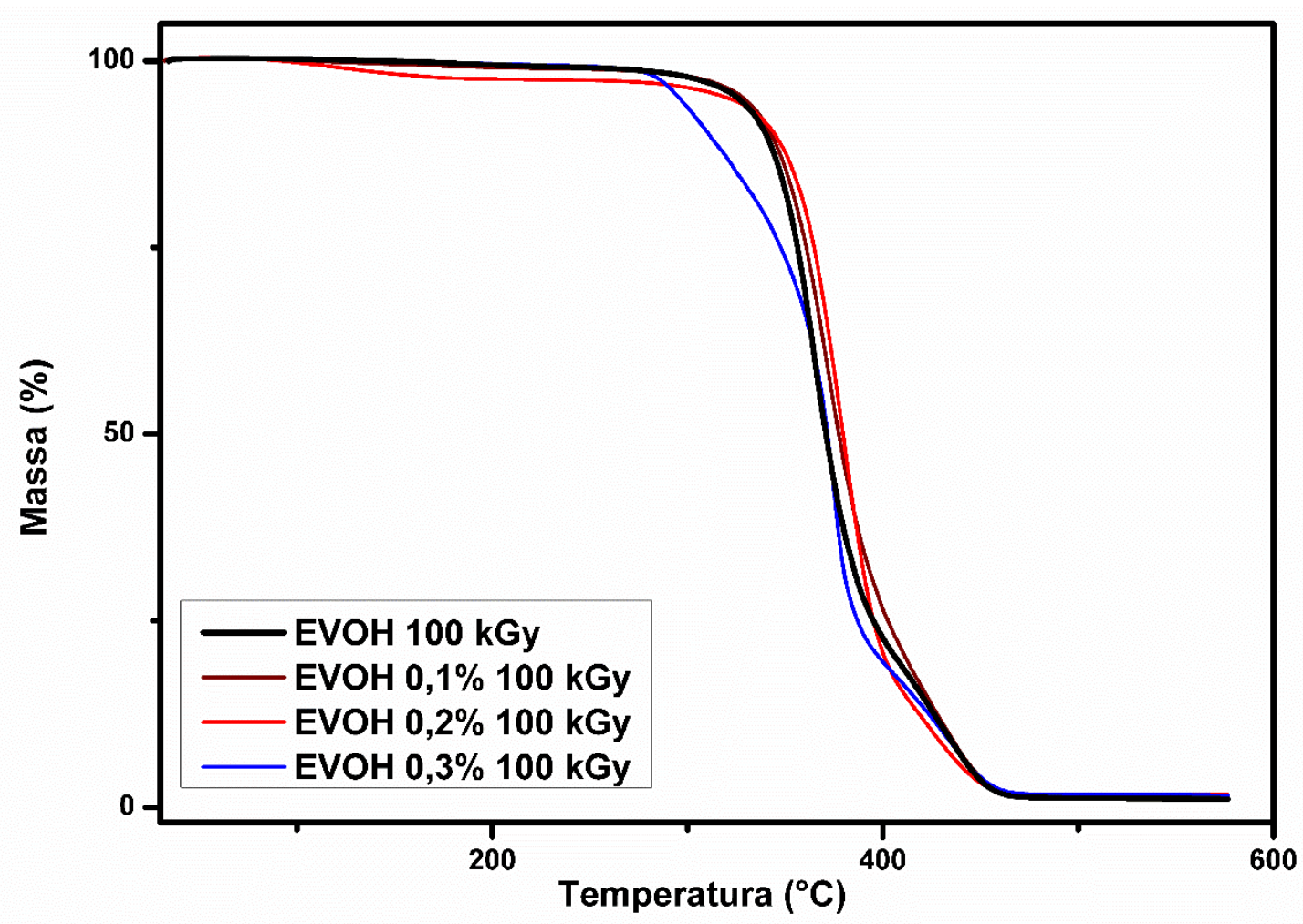

Fonte: Autor da dissertação. 
Figura 55 - Curva de TG do EVOH/GO 0,1 - 0,3 \% (150 kGy)

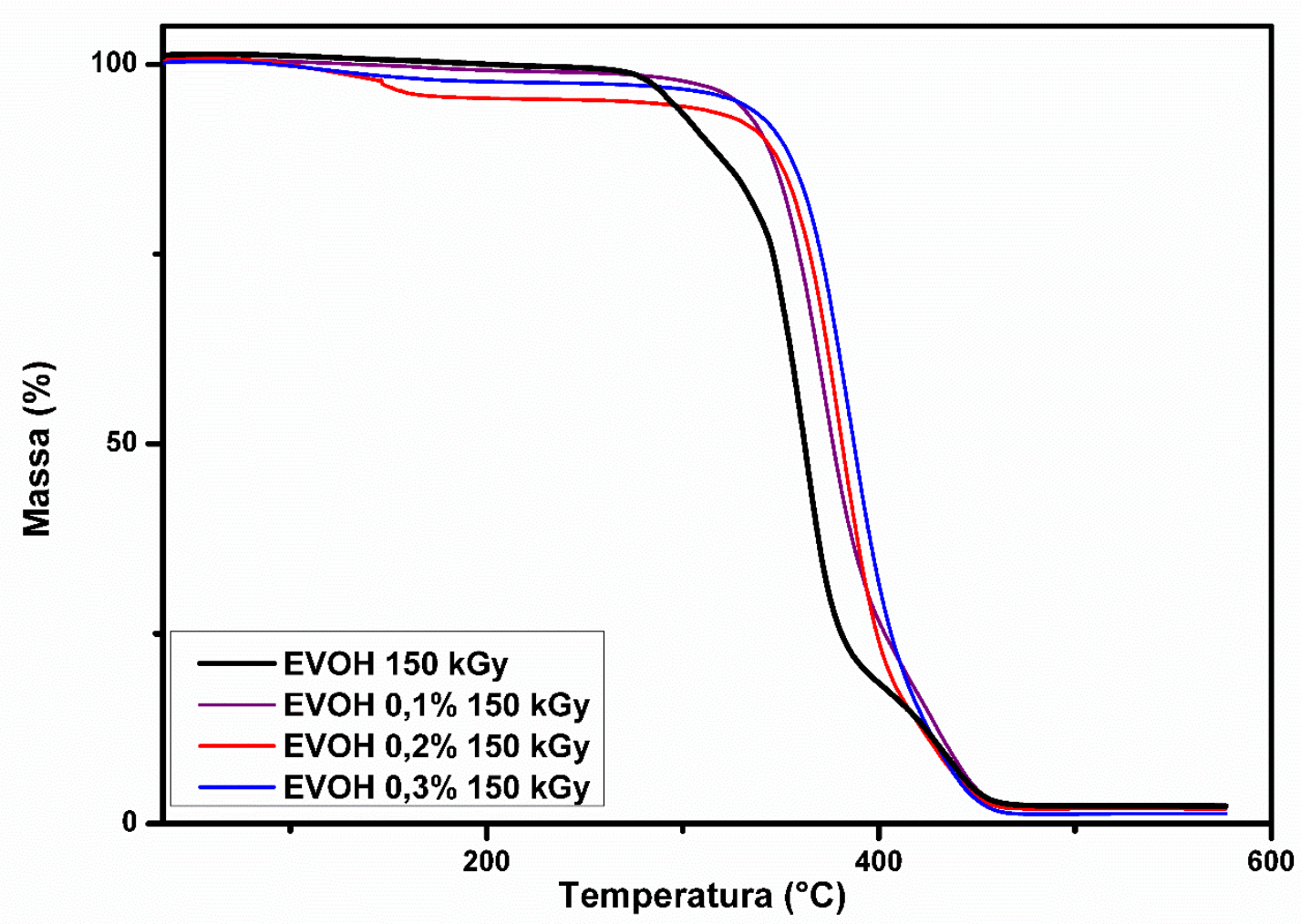

Fonte: Autor da dissertação.

Figura 56 - Curva de TG do EVOH/GO 0,1 - 0,3 \% (200 kGy)

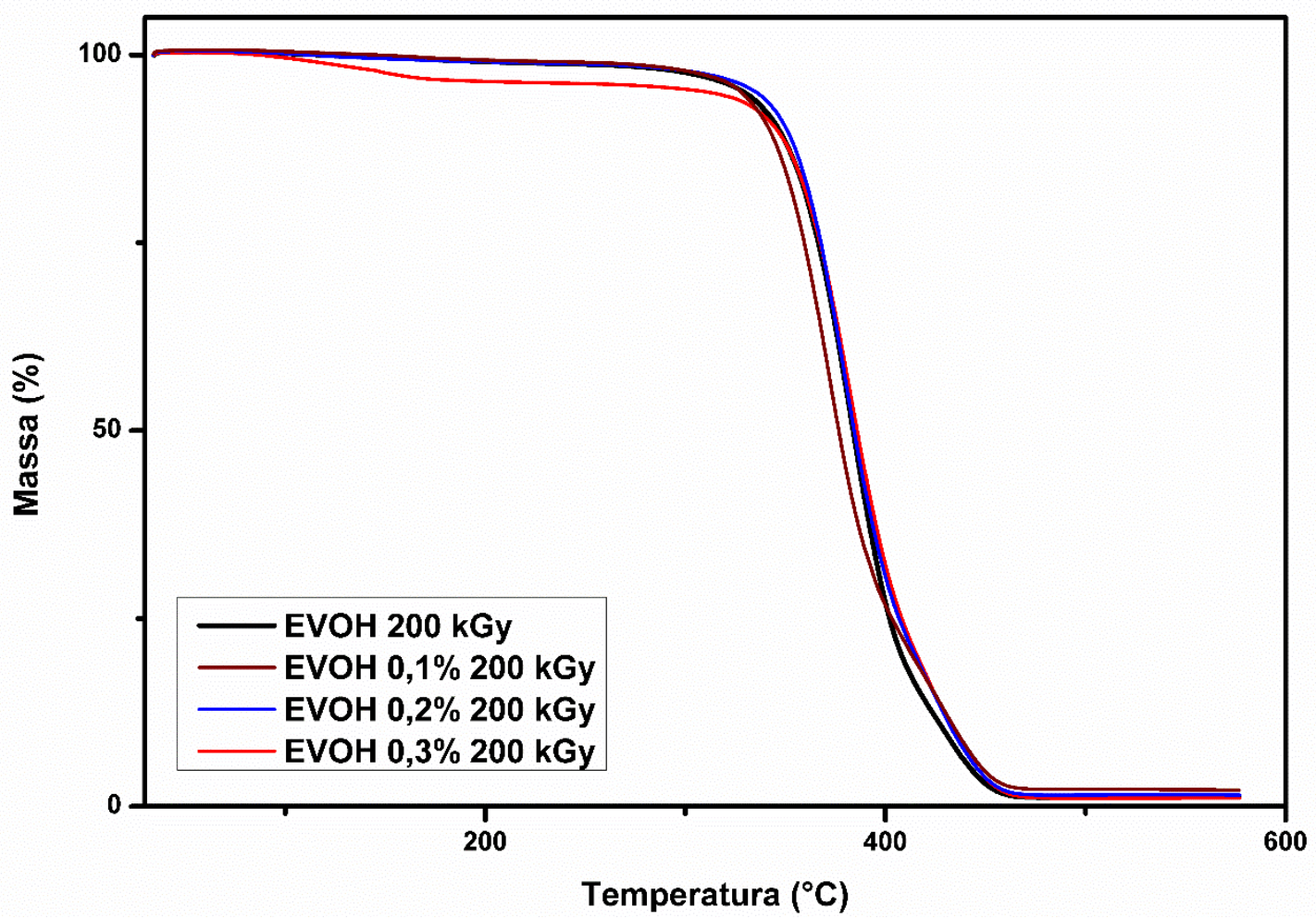

Fonte: Autor da dissertação. 
Figura 57 - Curva de TG do EVOH/GO 0,1 - 0,3 \% (250 kGy)

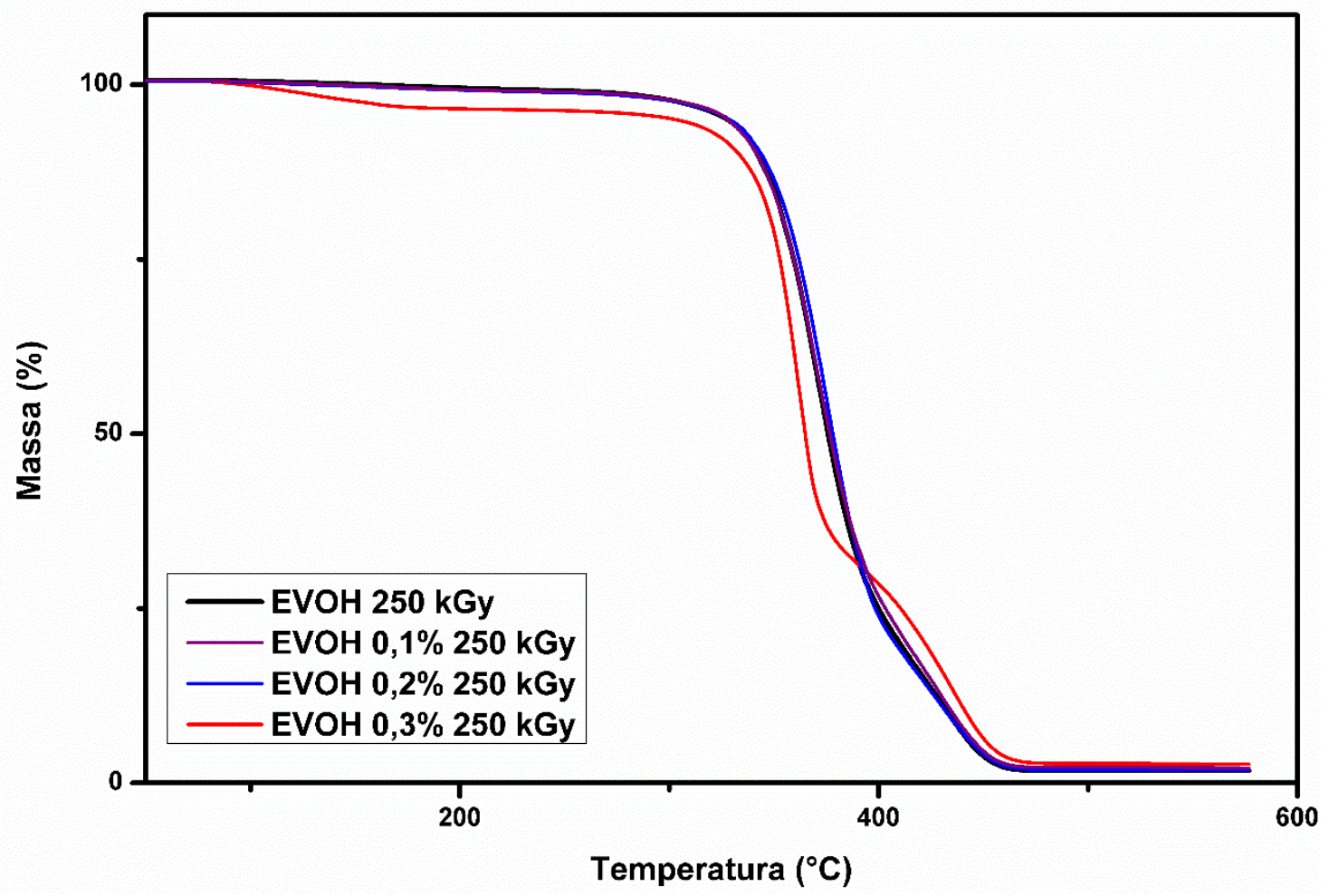

Fonte: Autor da dissertação.

A Tabela 5 apresenta a temperatura de degradação para os filmes de EVOH/GO contendo de 0,1 - 0,3\% em peso de GO para as amostras irradiadas e não irradiadas. Observa-se nesta tabela, um aumento da ordem de $20{ }^{\circ} \mathrm{C}$ na temperatura máxima de degradação térmica original dos filmes de $\mathrm{EVOH}$ puro após o tratamento por radiação e adição de GO, sendo estas temperaturas ainda maiores após o tratamento por radiação com feixe de elétrons. Observa se também nesta tabela uma redução na temperatura inicial de degradação térmica do EVOH com o aumento da dose de radiação aplicada. Esse resultado pode ser atribuído à mobilidade mais restrita dos segmentos da cadeia EVOH nos nanocompósitos, resultante da forte ligação de hidrogênio entre os grupos funcionais contendo oxigênio na superfície do $\mathrm{GO}$ e os grupos hidroxila das moléculas de EVOH (KIM \& CHOI, 2015). 
Tabela 5 - Temperatura inicial de degradação térmica e perda de massa do EVOH e nanocompósitos

\begin{tabular}{c|c|c|c}
\hline Amostras & $\begin{array}{c}T_{\text {inicial }} \\
\left({ }^{\circ} \mathrm{C}\right)\end{array}$ & $\begin{array}{c}T_{\max } \\
\left({ }^{\circ} \mathrm{c}\right)\end{array}$ & $\begin{array}{c}\text { Perda de } \\
\text { Massa } \\
(\%)\end{array}$ \\
\hline EVOH & 330 & 555 & 100 \\
EVOH/GO 0,1\% & 273,1 & 598 & 98 \\
EVOH/GO 0,2\% & 288,9 & 598 & 98,5 \\
EVOH 100KGy & 301,6 & 598 & 95,5 \\
EVOH/GO 0,1\% 100KGy & 296,2 & 574 & 100 \\
EVOH/GO 0,2\% 100KGy & 257,1 & 584 & 97,6 \\
EVOH/GO 0,3\% 100KGy & 264,1 & 580 & 96,1 \\
EVOH 150KGy & 254,7 & 580 & 97,5 \\
EVOH/GO 0,1\% 150KGy & 324,6 & 585 & 100 \\
EVOH/GO 0,2\% 150KGy & 225,5 & 585 & 99,1 \\
EVOH/GO 0,3\% 150KGy & 301,1 & 585 & 95,8 \\
EVOH 200KGy & 274,4 & 570 & 100 \\
EVOH/GO 0,1\% 200KGy & 287,6 & 579 & 96,5 \\
EVOH/GO 0,2\% 200KGy & 294,1 & 583 & 97,1 \\
EVOH/GO 0,3\% 200KGy & 308,2 & 587 & 94,5 \\
EVOH 250KGy & 278,1 & 576 & 100 \\
EVOH/GO 0,1\% 250KGy & 286,5 & 580 & 96,5 \\
EVOH/GO 0,2\% 250KGy & 277,3 & 580 & 96,5 \\
EVOH/GO 0,3\% 250KGy & 274,4 & 580 & 93,3 \\
\hline Autor da dissertacão.
\end{tabular}

Fonte: Autor da dissertação.

A tabela apresenta uma redução na temperatura inicial de degradação para todos os nanocompósitos, quando comparado ao EVOH puro. As amostras de $\mathrm{EVOH} / \mathrm{GO}$ com 0,1\% apresentaram um aumento em sua temperatura inicial de degradação, com exceção da amostra irradiada a 100 kGy, e redução das temperaturas máximas de degradação após tratamento por radiação com feixe de elétrons. Para as amostras de EVOH/GO com 0,2 e 0,3 \%, uma redução na temperatura inicial de degradação ocorreu, com exceção das amostras irradiadas a 200 kGy, e também redução na temperatura máxima de degradação de todas as amostras após tratamento por radiação com feixe de elétrons. 


\subsubsection{Calorimetria Exploratória Diferencial (DSC)}

Neste estudo, portanto, a análise de DSC foi realizada para examinar a influência da incorporação do GO, e sua interação física quando disperso na matriz polimérica do EVOH. As Figuras de 58 a 61 mostram o primeiro e segundo ciclo de aquecimento de DSC para o EVOH e EVOH/GO irradiados e não irradiados.

Figura 58 - Curvas de DSC para o EVOH, EVOH/GO 0,1, 0,2, e 0,3\%

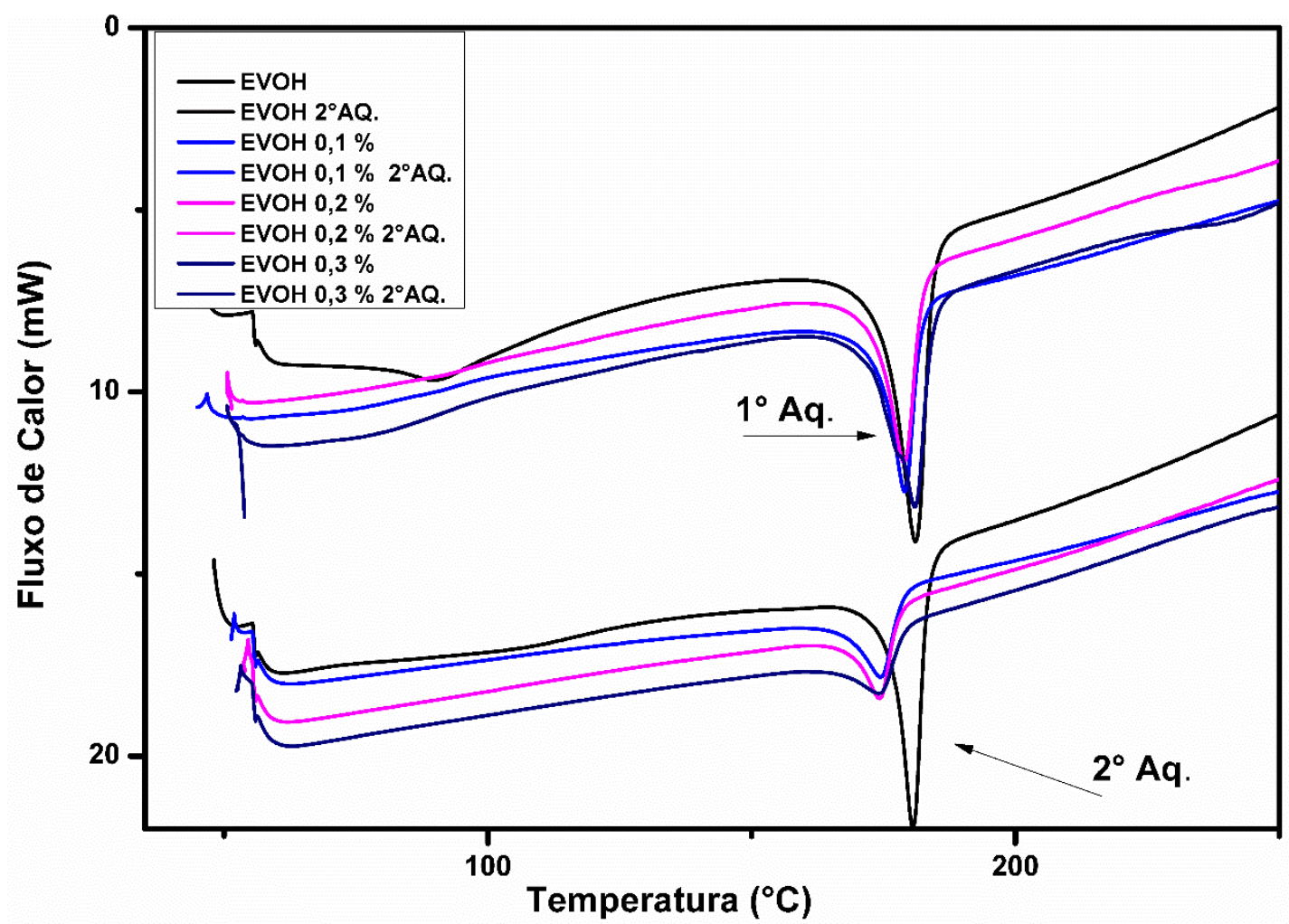

Fonte: Autor da dissertação. 
Figura 59 - Curvas de DSC para EVOH/GO 0,1 \% 100 a 250 kGy

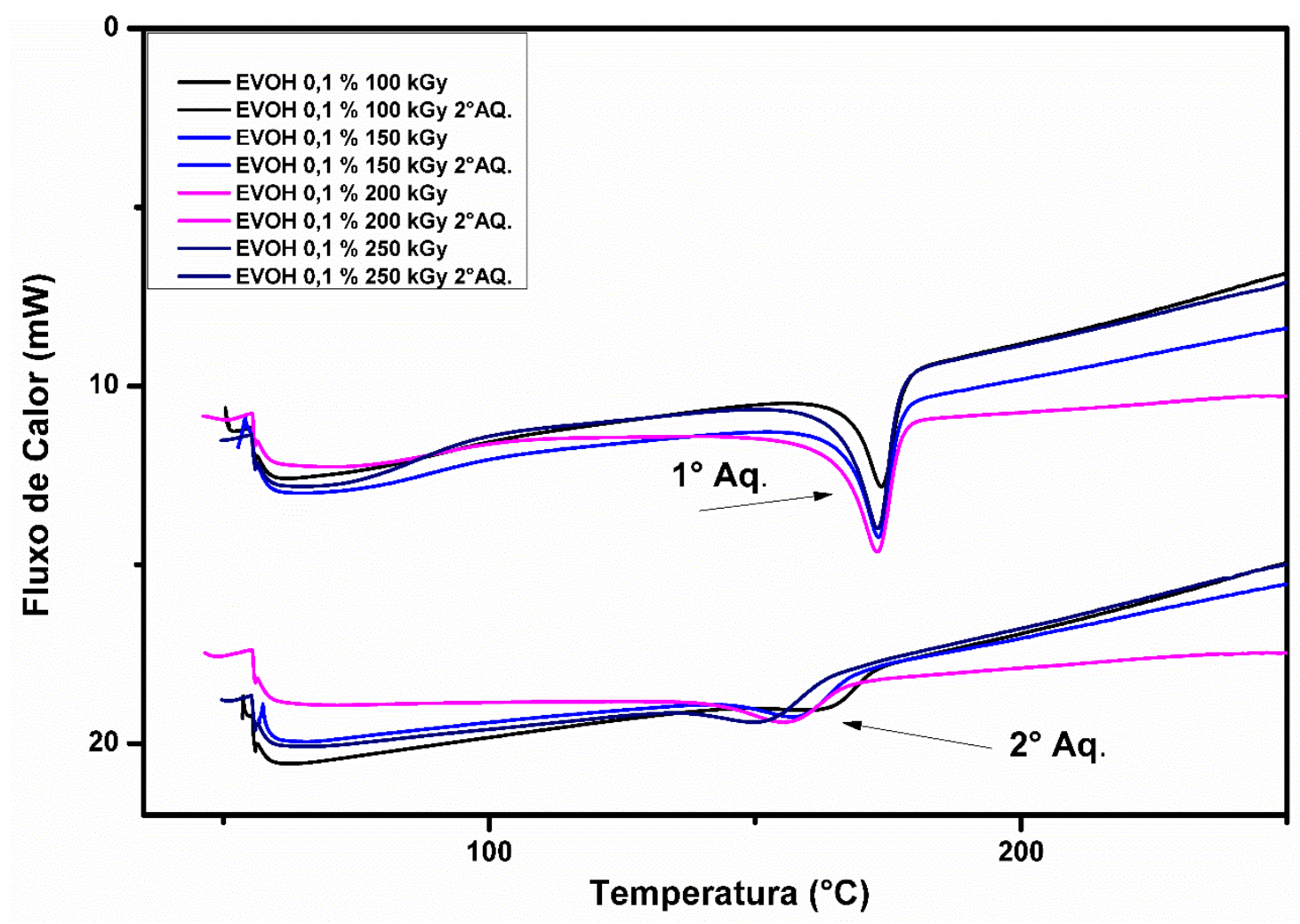

Fonte: Autor da dissertação.

Figura 60 - Curvas de DSC para EVOH/GO 0,2 \% 100 a 250 kGy

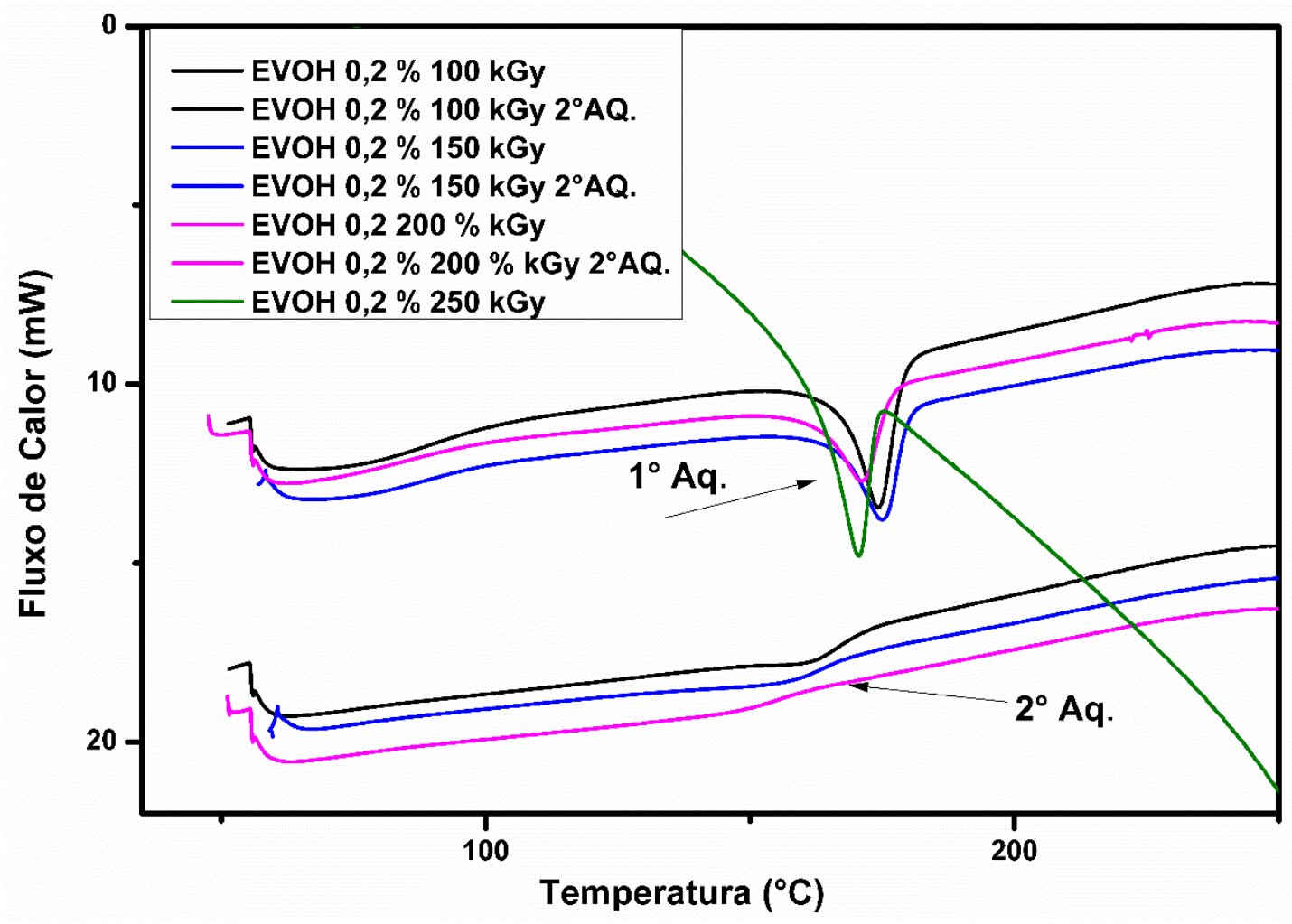

Fonte: Autor da dissertação. 
Figura 61 - Curvas de DSC para EVOH/GO 0,3 \% 100 a 250 kGy

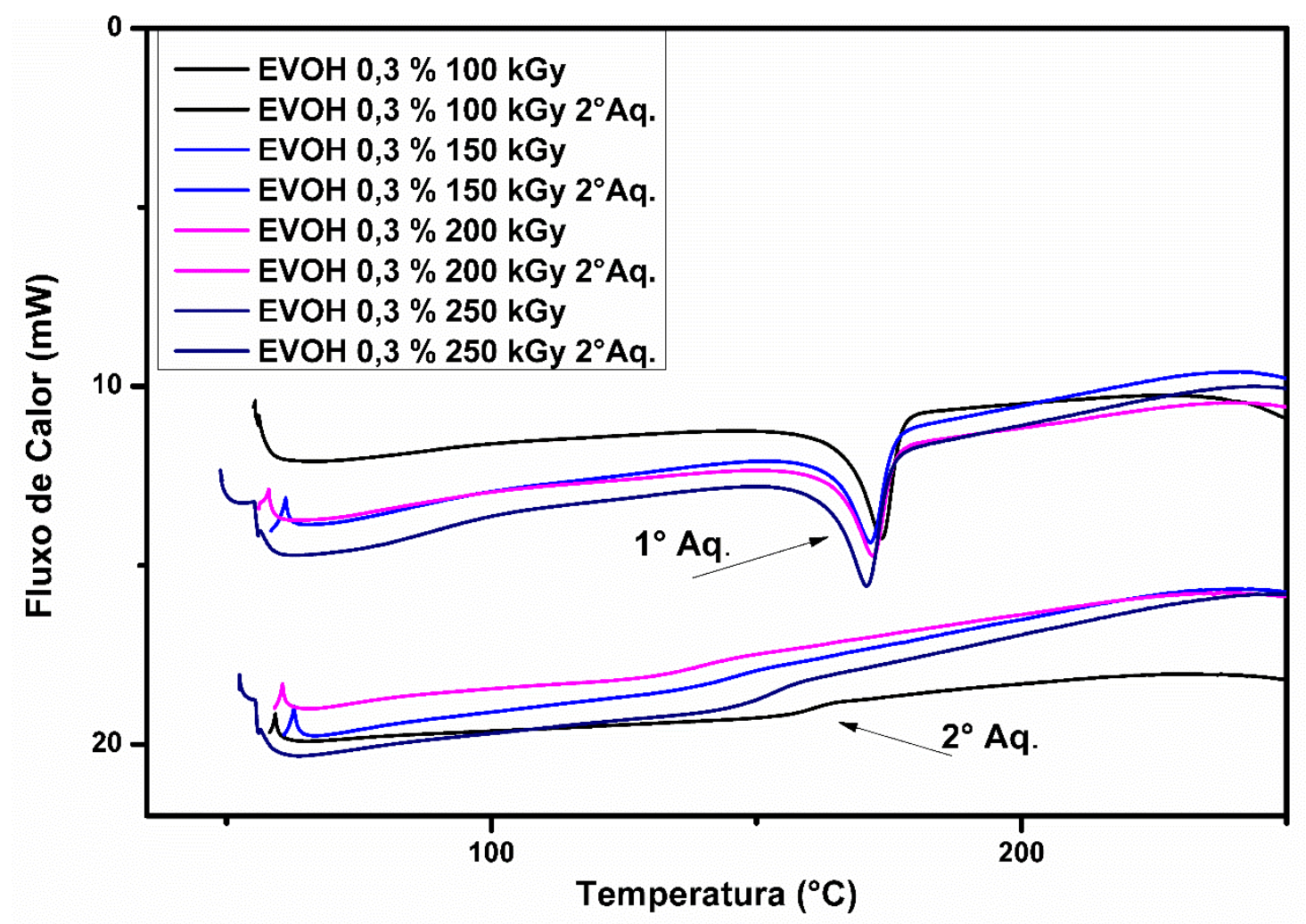

Fonte: Autor da dissertação.

A Tabela 6 apresenta os resultados do primeiro aquecimento e do segundo aquecimento para a entalpia de fusão $(\Delta \mathrm{H})$ e temperatura de fusão $\left({ }^{\circ} \mathrm{C}\right)$ dos filmes de EVOH puro e EVOH/GO. Pode-se observar nesta tabela uma redução na entalpia e temperatura de fusão do $\mathrm{EVOH}$ devido a incorporação de $\mathrm{GO}$ e 0 tratamento por radiação com feixe de elétrons. Estes resultados podem ser atribuídos a mobilidade restrita dos segmentos da cadeia das moléculas do $\mathrm{EVOH}$, resultantes da forte ligação dos grupos funcionais de hidrogênio dos grupos funcionais de oxigênio e grupos hidroxila $(\mathrm{O}-\mathrm{H})$ presentes na superfície do GO, bem como também pela reticulação induzida por radiação por feixe de elétrons no $\mathrm{EVOH}$, a qual ocorre preferencialmente na região amorfa do $\mathrm{EVOH}$ (YOO et al., 2014; PINTO, 2013). 
Tabela 6 - Entalpia e Temperatura de Fusão para o EVOH puro e EVOH/GO

\begin{tabular}{|c|c|c|c|c|}
\hline & \multicolumn{2}{|c|}{$1^{\circ}$ Aquecimento } & \multicolumn{2}{|c|}{$2^{\circ}$ Aquecimento } \\
\hline & $\begin{array}{l}\Delta H_{m} \\
(\mathrm{~J} / \mathrm{g})\end{array}$ & $\begin{array}{c}\mathrm{T}_{\mathrm{m}} \\
\left({ }^{\circ} \mathrm{C}\right)\end{array}$ & $\begin{array}{l}\Delta H_{m} \\
(\mathrm{~J} / \mathrm{g})\end{array}$ & $\begin{array}{c}\mathrm{T}_{\mathrm{m}} \\
\left({ }^{\circ} \mathrm{C}\right)\end{array}$ \\
\hline $\mathrm{EVOH}$ & 53,1 & 181.0 & 51,6 & 180,5 \\
\hline EVOH/GO 0,1 & 53,8 & 178,9 & 33,1 & 174,5 \\
\hline EVOH/GO 0,1 100 kGy & 51,6 & 173,7 & 36,0 & 163,1 \\
\hline $\mathrm{EVOH} / \mathrm{GO} 0,1150 \mathrm{kGy}$ & 53,7 & 173,2 & 30,3 & 158,1 \\
\hline EVOH/GO 0,1200 kGy & 66,6 & 172,8 & 32,1 & 156,0 \\
\hline EVOH/GO 0,1250 kGy & 57,0 & 173,0 & 25,1 & 151,5 \\
\hline $\mathrm{EVOH} / \mathrm{GO} 0,2$ & 55,7 & 178,8 & 28,4 & 174,3 \\
\hline EVOH/GO 0,2 100 kGy & 55,6 & 174,3 & 17,5 & 160,6 \\
\hline EVOH/GO 0,2 150 kGy & 56,7 & 175,5 & 37,6 & 154,0 \\
\hline EVOH/GO 0,2 200 kGy & 52,5 & 171,1 & 30,8 & 144,3 \\
\hline EVOH/GO 0,2 250 kGy & 57,8 & 170,3 & 3,7 & 148,3 \\
\hline $\mathrm{EVOH} / \mathrm{GO} 0,3$ & 58,5 & 180,9 & 24,1 & 174,0 \\
\hline EVOH/GO 0,3 100 kGy & 53,3 & 173,6 & 21,1 & 148,9 \\
\hline EVOH/GO 0,3 150 kGy & 54,1 & 171,4 & ---- & ----- \\
\hline EVOH/GO 0,3 200 kGy & 56,1 & 172,0 & ---- & ----- \\
\hline EVOH/GO 0,3 250 kGy & 52,9 & 170,7 & ---- & ----- \\
\hline
\end{tabular}

Fonte: Autor da dissertação.

Os resultados da temperatura de fusão do EVOH puro comparado aos filmes de $\mathrm{EVOH} / \mathrm{GO}$ não irradiados mostraram que houve uma redução de $6^{\circ} \mathrm{C}$, que permanece constante. Para EVOH/GO 0,1 \% irradiado até $250 \mathrm{kGy}$ quando comparado com o não irradiado também apresenta uma redução de $13 \%$, o mesmo ocorre com EVOH/GO 0,2 \% com $15 \%$ de redução, enquanto que para amostras de $\mathrm{EVOH} / \mathrm{GO}$ 0,3 \% a $250 \mathrm{kGy}$ durante seu segundo aquecimento a entalpia e temperatura de fusão vão diminuindo até não serem mais medidas.

A temperatura de fusão, está associada à mobilidade das cadeias poliméricas. O confinamento físico e as fortes interações entre as cadeias poliméricas e a superfície de preenchimento são duas contribuições dominantes que afetam a mobilidade da cadeia do EVOH. Conforme a tabela, todos os nanocompósitos mostraram uma redução padrão na entalpia e temperatura de fusão de acordo com as doses recebidas no tratamento por radiação com feixe de elétrons. No entanto, com a redução da entalpia e temperatura de fusão dos nanocompósitos, a cristalinidade também é reduzida (JIHUI et al., 2017; PAPAGEORGIOU, KINLOCH, \& YOUNG, 2017; PINTO, 2013; ROY et al., 2017). 
5.2.5 Espectroscopia vibracional de absorção no infravermelho com transformada de Fourier (FTIR)

A análise de FTIR foi utilizada para investigar as interações entre o EVOH e o GO. A Figura 62 mostra os espectros de FTIR do EVOH puro e para o EVOH/GO contendo de 0,1 - 0,3 \% em massa de GO. Os espectros do EVOH/GO mostram os picos de absorção característicos do EVOH em $2800-3000 \mathrm{~cm}^{-1}$ e $1300-1500 \mathrm{~cm}^{-1}$, identificados pelas cadeias simétricas de alongamento $\left(\mathrm{CH}_{2}\right)$ e bandas de deformação $\left(\mathrm{CH}_{3}\right)$, respectivamente (JAE BYUN et al., 2007).

A presença das bandas de absorção entre $3100-3600 \mathrm{~cm}^{-1}$ indicam que os grupos $\mathrm{O}-\mathrm{H}$ estão presentes. Pode-se observar que não ocorreram mudanças significativas na intensidade ou posição dos picos características do EVOH nos espectros do EVOH/GO quando comparado ao EVOH puro (KWON et al., 2013).

Não são observados nesta figura os picos característicos do GO, uma vez que os picos do GO possuem baixa intensidade, os picos característicos do EVOH se sobrepõem aos do GO.

Figura 62 - Espectro de infravermelho para o EVOH puro e EVOH/GO

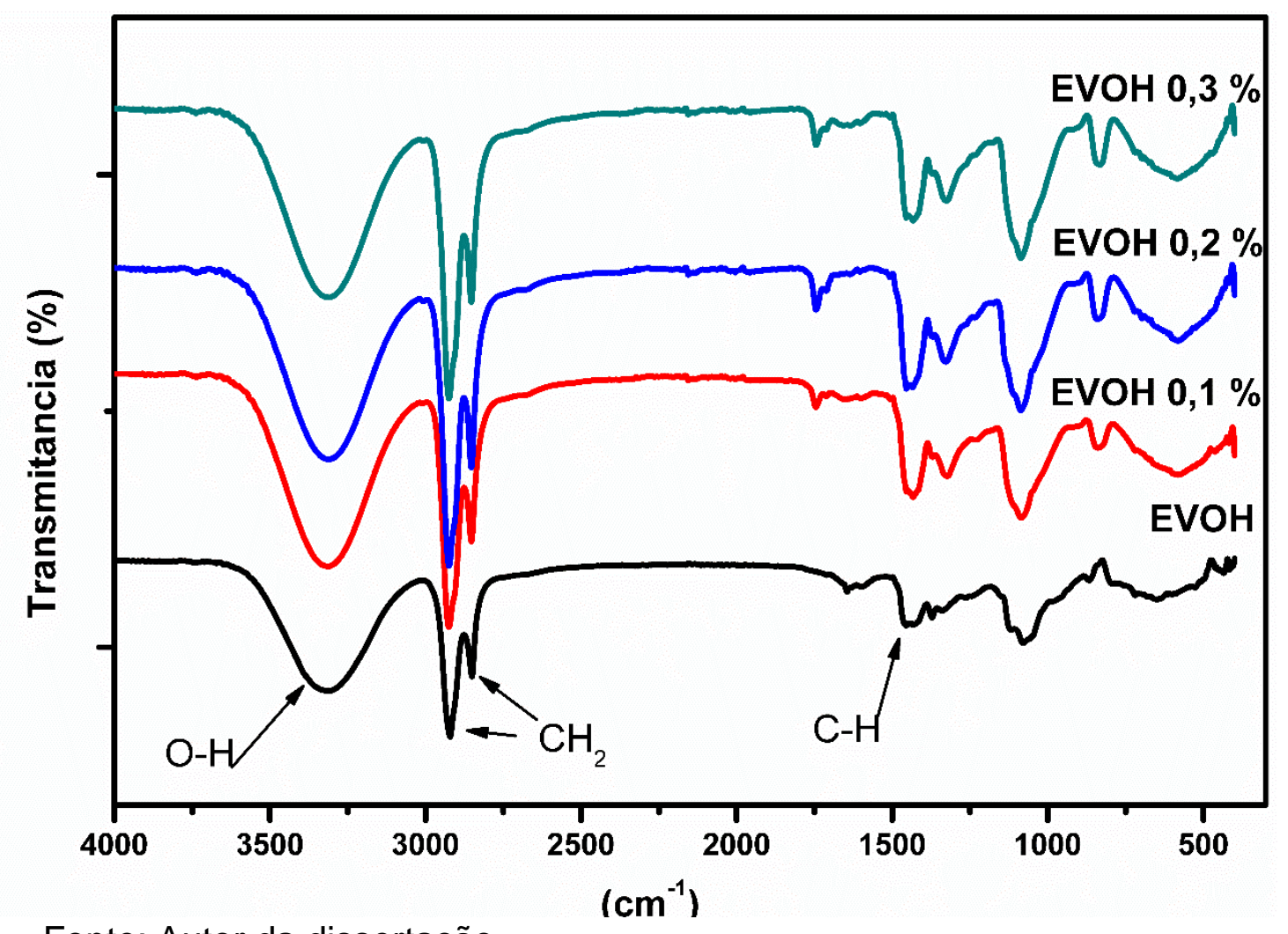

Fonte: Autor da dissertação. 


\subsubsection{Espectroscopia de aniquilação de pósitrons (PALS)}

O tempo de vida dos pósitrons que aniquilam como orto-positronium (o-Ps), T3, varia de acordo com o tamanho da cavidade de volume livre em que estão localizados, relacionado ao tamanho de elementos de volume livre ( $r 3$ ) na amostra, conforme apresenta a tabela 7 (MARSH \& BUGUSU, 2007).

Tabela 7 - Volume livre (r3) determinado por PALS

\begin{tabular}{ccccc}
\hline \multicolumn{5}{c}{ Go , \% } \\
kGy & EVOH32 & EVOH 0,1 & EVOH 0,2 & EVOH 0,3 \\
\hline 0 & $0,258 \pm 0,004$ & $0,272 \pm 0,090$ & $0,239 \pm 0,003$ & $0,240 \pm 0,003$ \\
100 & $0,252 \pm 0,004$ & $0,216 \pm 0,001$ & $0,221 \pm 0,001$ & $0,220 \pm 0,001$ \\
150 & $0,247 \pm 0,003$ & $0,217 \pm 0,001$ & $0,217 \pm 0,001$ & $0,217 \pm 0,001$ \\
200 & $0,230 \pm 0,008$ & $0,217 \pm 0,001$ & $0,221 \pm 0,001$ & $0,223 \pm 0,001$ \\
250 & $0,225 \pm 0,005$ & $0,217 \pm 0,001$ & $0,221 \pm 0,001$ & $0,220 \pm 0,002$ \\
\hline
\end{tabular}

Fonte: Autor da dissertação.

Como pode ser visto na tabela 7 os filmes de EVOH e EVOH/GO não irradiados apresentaram uma diminuição do raio (r3) do volume livre, com exceção do $\mathrm{EVOH} 0,1 \%$, enquanto que para o $\mathrm{EVOH}$ puro houve uma redução constante do raio (r3) do volume livre com o aumento da dose de radiação recebida. Os filmes de EVOH com 0,1, 0,2 e 0,3 \% de GO também apresentaram uma redução linear do raio ( $r$ ) do seu volume livre, com o aumento da dose de radiação aplicada. Segundo Yeh \& Chen (2007), o tamanho e a distribuição das cavidades do volume livre de polímeros estão relacionados à sua estrutura molecular e à interação molecular presentes nas suas fases amorfas. Como o EVOH apresenta uma interação molecular forte, como as ligações de hidrogênio inter e intramoleculares, estas podem atrair e manter as moléculas de polímero de forma mais condensadas e, portanto, apresentar um raio $(r 3)$ das cavidades de volume livre relativamente pequeno.

Pode-se observar também, a partir da tabela 7, que a adição de GO seguida da irradiação reduziu ainda mais o raio (r3) do volume livre. Esta redução pode 
dificultar ainda mais a passagem de moléculas e, portanto, melhorar a barreira a gás dos filmes de EVOH/GO (JAE BYUN et al., 2007). De acordo com estes resultados, pode-se concluir que o tamanho do raio ( $r 3$ ) do volume livre dos poros foi reduzido com o aumento da dose de radiação recebida

\subsubsection{Taxa de permeabilidade ao oxigênio $\left(\mathrm{TPO}_{2}\right)$}

A Tabela 8 apresenta a taxa de transmissão de oxigênio (OTR) para os filmes flexíveis de $\mathrm{EVOH}$ puro e $\mathrm{EVOH} / \mathrm{GO}$ medidos à temperatura de $23^{\circ} \mathrm{C}$ em duas condições diferentes de teste, com relação a umidade relativa (0 e $90 \%$ ). Como pode ser observado na tabela, as propriedades de barreira ao oxigênio dos filmes de $\mathrm{EVOH} / \mathrm{GO}$ contendo 0,1 e $0,3 \%$ de GO, na condição de $0 \%$ de umidade relativa apresentaram um importante ganho quando comparadas ao filme flexível de EVOH puro. Para o filme flexível de EVOH/GO com 0,2 \% de GO, o fator de aumento de OTR nas condições de teste de $90 \%$ de umidade relativa foi menor que para o filme de EVOH puro. O filme flexível de EVOH/GO com $0,3 \%$ de GO apresentou melhores propriedades de barreira ao oxigênio tanto nas condições de teste de 0 como de $90 \%$ de umidade relativa. Demonstrando assim uma correlação linear entre os resultados da taxa de transmissão de oxigênio e o volume livre determinado por PALS.

Tabela 8 - Taxa de permeabilidade ao oxigênio $\left(\mathrm{TPO}_{2}\right)$

\begin{tabular}{|c|c|c|c|c|}
\hline \multirow{2}{*}{ Amostras } & \multirow{2}{*}{$\begin{array}{l}\text { Espessura } \\
\qquad(\mu \mathrm{m})\end{array}$} & \multicolumn{2}{|c|}{$\begin{array}{c}23^{\circ} \mathrm{C} \text { Condições de umidade } \\
\text { relativa }(\mathrm{RH})\end{array}$} & \multirow{2}{*}{$\begin{array}{l}\text { OTR } \\
(\%)\end{array}$} \\
\hline & & $\begin{array}{c}0 \\
(\%)\end{array}$ & $\begin{array}{c}90 \\
(\%)\end{array}$ & \\
\hline $\mathrm{EVOH}$ & $27 \pm 4$ & $0,42 \mathrm{cc} / \mathrm{m}^{2} \cdot \mathrm{dia}$ & $2,09 \mathrm{c} / \mathrm{m}^{2} \cdot \mathrm{dia}$ & 4,9 \\
\hline $\mathrm{EVOH} / \mathrm{GO} 0,1 \%$ & $35 \pm 7$ & $0,24 \mathrm{cc} / \mathrm{m}^{2} \cdot \mathrm{dia}$ & $3,5 \mathrm{cc} / \mathrm{m}^{2} \cdot \mathrm{dia}$ & 14,5 \\
\hline $\mathrm{EVOH} / \mathrm{GO} 0,2 \%$ & $30 \pm 1,7$ & $0,48 \mathrm{cc} / \mathrm{m}^{2} \cdot \mathrm{dia}$ & $1,8 \mathrm{cc} / \mathrm{m}^{2} . \mathrm{dia}$ & 3,8 \\
\hline $\mathrm{EVOH} / \mathrm{GO} 0,3 \%$ & $35 \pm 1,3$ & $0,38 \mathrm{cc} / \mathrm{m}^{2} \cdot \mathrm{dia}$ & $2,06 \mathrm{c} / \mathrm{m}^{2} . \mathrm{dia}$ & 5,4 \\
\hline
\end{tabular}

Fonte: Autor da dissertação. 


\subsubsection{Ensaios mecânicos de tração}

A partir dos ensaios mecânicos de tração é esperado que o desempenho mecânico dos nanocompósitos seja aumentado devido a grande razão de aspecto das nanofolhas de GO e RGO, e também pela interação interfacial através das ligações de hidrogênio entre GO e RGO na matriz de EVOH.

A tabela 9 apresenta os resultados para a resistência à tração e elongação no ponto de ruptura obtidos para os filmes flexíveis de $\mathrm{EVOH}$ e $\mathrm{EVOH} / \mathrm{GO}$. Os resultados apresentam os valores médios calculados a partir dos dados obtidos nos testes para cinco corpos de prova, com desvio padrão menor que $10 \%$ para todas as amostras testadas.

Tabela 9 - Resistência à tração e Elongação no ponto de ruptura para os filmes de EVOH e EVOH/GO

\begin{tabular}{ccccc}
\hline Amostras & $\begin{array}{c}\text { Espessura } \\
(\mu \mathrm{m})\end{array}$ & $\begin{array}{c}\text { Resistência } \\
\text { à tração } \\
(\mathrm{MPa})\end{array}$ & $\begin{array}{c}\text { Elongação no } \\
\text { ponto de } \\
\text { ruptura } \\
(\%)\end{array}$ & $\begin{array}{c}\text { Módulo } \\
\text { Young } \\
(\mathrm{MPa})\end{array}$ \\
\hline $\mathrm{EVOH}$ & $40 \pm 2$ & $6 \pm 0,3$ & $117 \pm 12$ & $5 \pm 0,6$ \\
$\mathrm{EVOH} / \mathrm{GO} 0.1 \%$ & $40 \pm 2$ & $16 \pm 1$ & $120 \pm 13$ & $4 \pm 0,5$ \\
$\mathrm{EVOH} / \mathrm{GO} 0.2 \%$ & $30 \pm 2$ & $17 \pm 2$ & $170 \pm 14$ & $5 \pm 0,2$ \\
$\mathrm{EVOH} / \mathrm{GO} 0.3 \%$ & $35 \pm 1$ & $14 \pm 1$ & $110 \pm 8$ & $4 \pm 0,3$ \\
\hline
\end{tabular}

Fonte: Autor da dissertação.

A partir da tabela é possível observar que a adição de 0,1-0,3\% de nanofolhas de GO contribuiu para um aumento significativo de mais de $100 \%$ na resistência à tração quando comparados ao filme de EVOH puro. Observa-se também que a propriedade de elongação dos filmes não foi significativamente alterada após a incorporação do GO, com exceção da adição de 0,2 \% de GO que aumentou em cerca de $40 \%$ a elongação máxima na ruptura dos filmes sem 
perda da resistência à tração, o que é bastante interessante, uma vez que tratase de um material para aplicação em embalagens flexíveis.

As figuras de 63 a 66 mostram os diagramas tensão $x$ deformação obtidos para os ensaios de resistência à tração do EVOH e EVOH/RGO irradiados e não irradiados.

Figura 63 - Diagrama tensão x deformação para o EVOH e EVOH 100 - 250 kGy

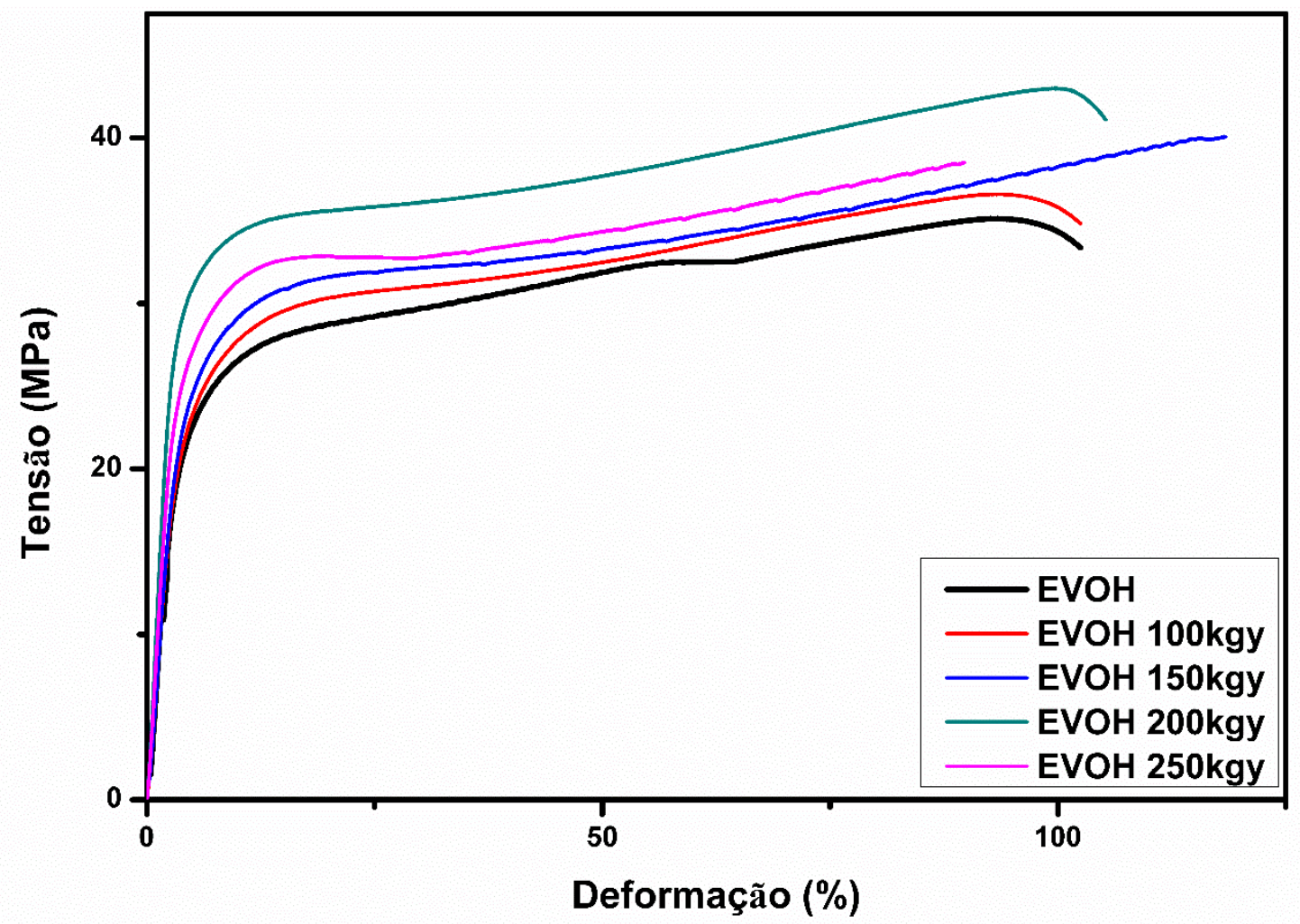

Fonte: Autor da dissertação. 
Figura 64 - Diagrama tensão x deformação para o EVOH/RGO 0,1 \% e EVOH/RGO 0,1 \% $100-250$ kGy

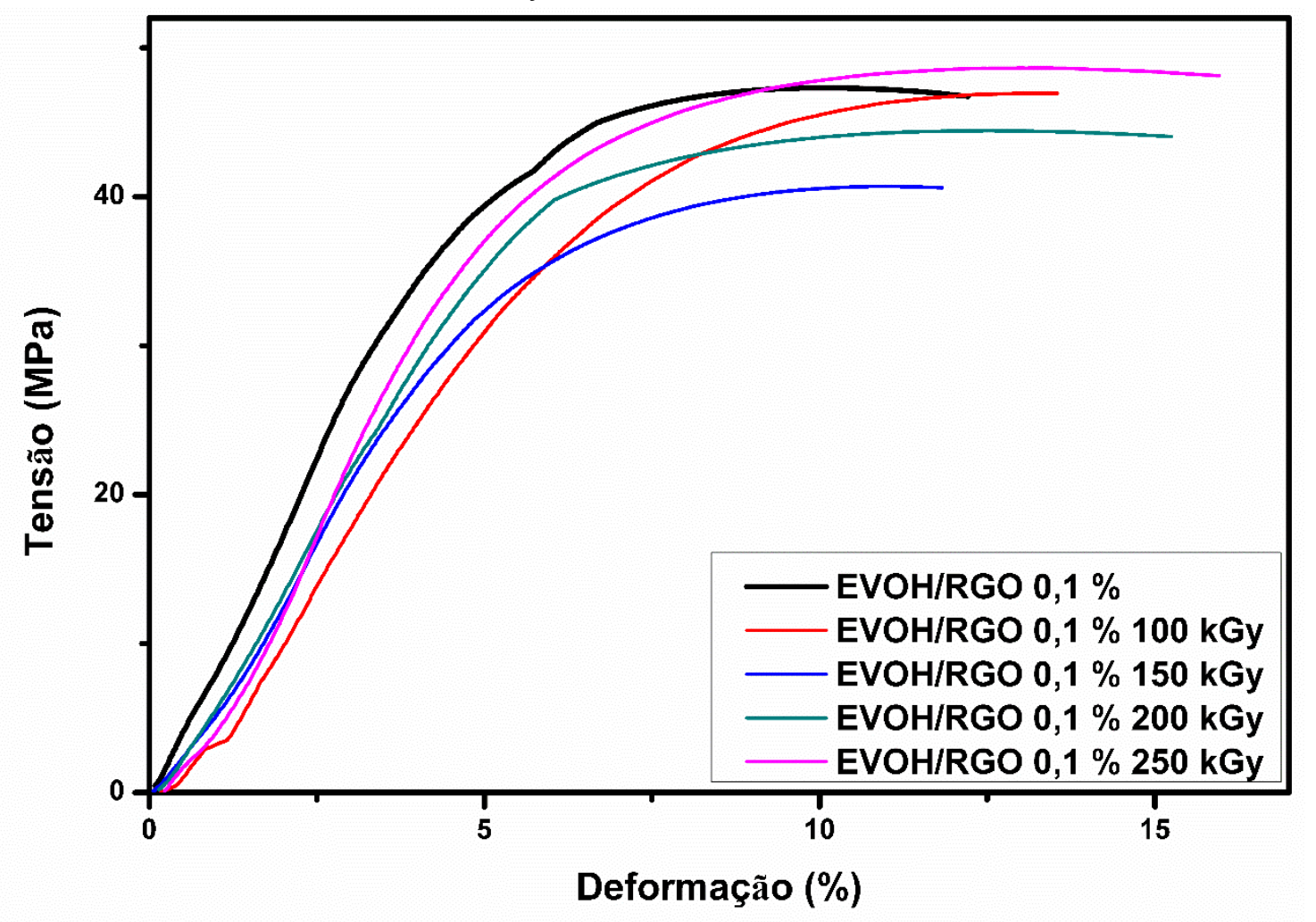

Fonte: Autor da dissertação. 
Figura 65 - Diagrama tensão x deformação para o EVOH/RGO 0,2 \% e EVOH/RGO 0,2\% $100-250$ kGy

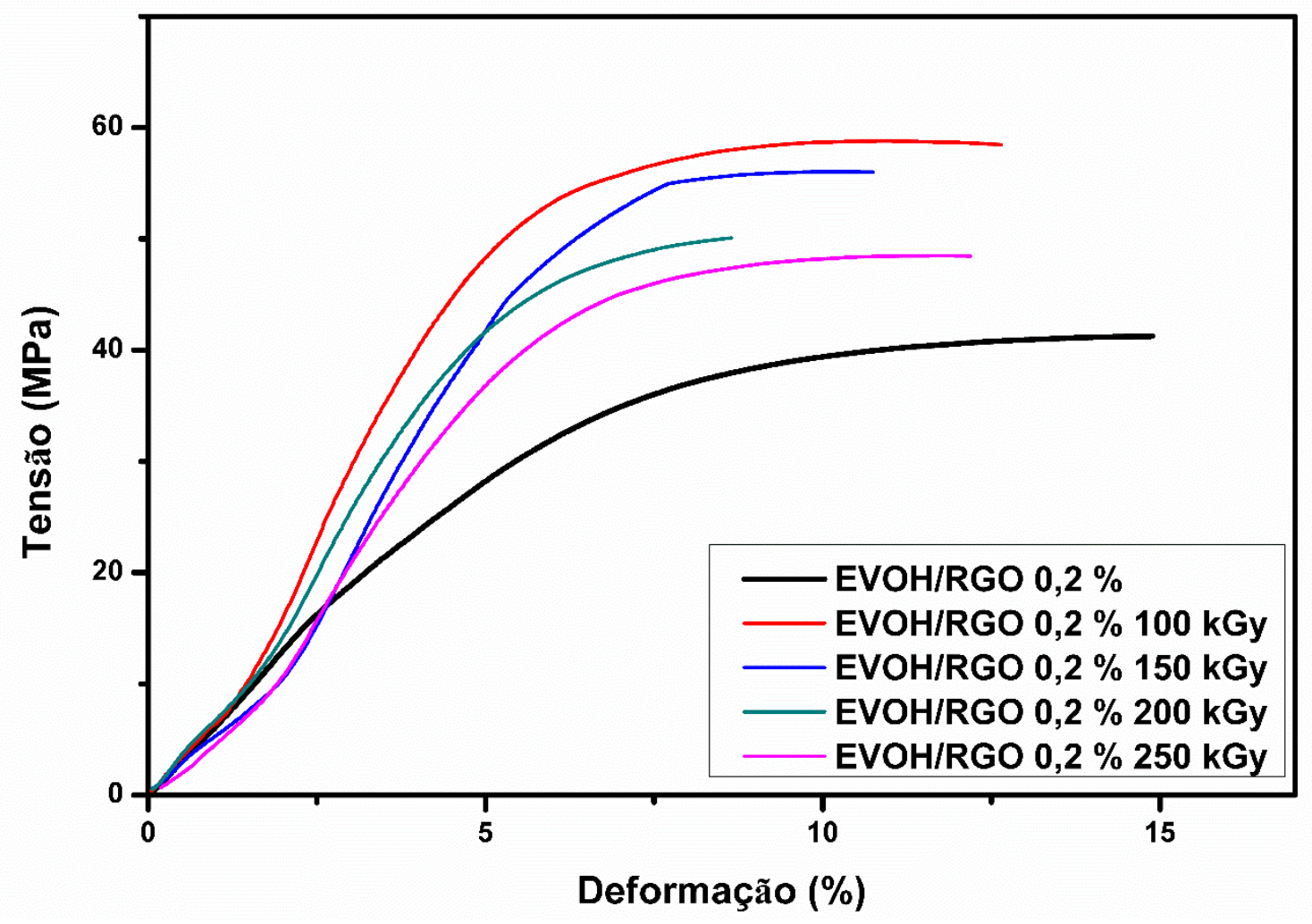

Fonte: Autor da dissertação.

Figura 66 - Diagrama tensão x deformação para o EVOH/RGO $0,3 \%$ e $\mathrm{EVOH} / \mathrm{RGO} 0,3 \% 100-250 \mathrm{kGy}$

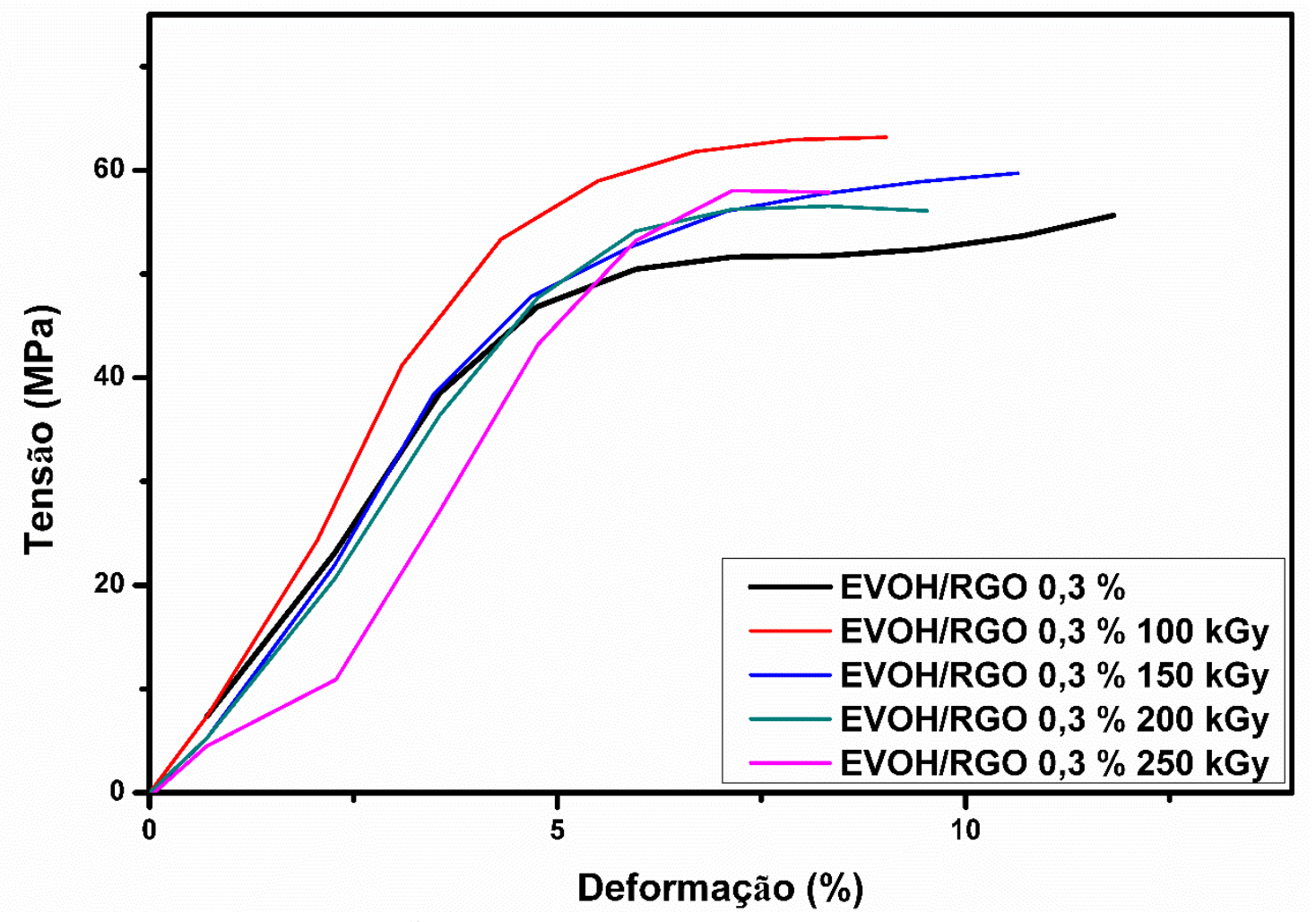

Fonte: Autor da dissertação. 
A figura 63 mostrou que os filmes de $\mathrm{EVOH}$ irradiados e não irradiados exibiram maior deformação quando comparados com os filmes de EVOH após a adição das nanofolhas de RGO (fig. 64 a 66), com uma redução de 90 \% no alongamento. Redução esta que pode ser atribuída à interação entre o RGO e a matriz de $\mathrm{EVOH}$, que restringe o movimento das cadeias poliméricas (ZHAO; ZHANG; CHEN; LU, 2010), e pode indicar também um enrijecimento do filme de $\mathrm{EVOH} / \mathrm{RGO}$.

Os valores de resistência à tração, elongação no ponto de ruptura, e módulo Young para o EVOH e nanocompósitos de EVOH/RGO estão representadas na tabela 10. Segundo a tabela, pode-se observar em geral que após a adição das nanofolhas de RGO no $\mathrm{EVOH}$, este apresentou superior resistência a tração de 30 \% e ganhos em módulo Young para todos os filmes, resultante de uma eficiente adesão das nanofolhas de RGO no EVOH, como também foi comparado por Kim e Choi (2015). 
Tabela 10 - Resistência à tração e Elongação no ponto de ruptura e Módulo Young para os filmes de EVOH e EVOH/RGO

\begin{tabular}{|c|c|c|c|c|}
\hline Amostras & $\begin{array}{c}\text { Espessura } \\
(\mu \mathrm{m})\end{array}$ & $\begin{array}{l}\text { Resistência } \\
\text { à tração no } \\
\text { ponto de } \\
\text { ruptura } \\
(\mathrm{MPa})\end{array}$ & $\begin{array}{c}\text { Elongação } \\
\text { no ponto de } \\
\text { ruptura } \\
(\%)\end{array}$ & $\begin{array}{l}\text { Módulo } \\
\text { Young } \\
\text { (MPa) }\end{array}$ \\
\hline $\mathrm{EVOH}$ & $40 \pm 2$ & $36 \pm 2$ & $100 \pm 6$ & $7 \pm 0,2$ \\
\hline $\mathrm{EVOH} / \mathrm{RGO} 0,1 \%$ & $50 \pm 1$ & $46 \pm 1$ & $11 \pm 1$ & $9 \pm 0,1$ \\
\hline $\mathrm{EVOH} / \mathrm{RGO} 0,2 \%$ & $50 \pm 1$ & $41 \pm 2$ & $15 \pm 1$ & $7 \pm 0,1$ \\
\hline $\mathrm{EVOH} / \mathrm{RGO} 0,3 \%$ & $50 \pm 1$ & $50 \pm 4$ & $9 \pm 0,3$ & $12 \pm 0,5$ \\
\hline EVOH 100KGy & $40 \pm 2$ & $32 \pm 1$ & $100 \pm 1$ & $4 \pm 0,1$ \\
\hline EVOH/RGO 0,1 \% 100KGy & $50 \pm 1$ & $47 \pm 2$ & $13 \pm 1$ & $7 \pm 0,1$ \\
\hline EVOH/RGO 0,2 \% 100KGy & $50 \pm 1$ & $59 \pm 2$ & $12 \pm 1$ & $10 \pm 0,2$ \\
\hline EVOH/RGO 0,3 \% 100KGy & $50 \pm 1$ & $63 \pm 2$ & $9 \pm 0,4$ & $13 \pm 0,2$ \\
\hline EVOH 150KGy & $40 \pm 2$ & $40 \pm 2$ & $130 \pm 10$ & $4 \pm 0,1$ \\
\hline EVOH/RGO 0,1 \% 150KGy & $50 \pm 1$ & $40 \pm 3$ & $11 \pm 1$ & $7 \pm 0,2$ \\
\hline EVOH/RGO 0,2 \% 150KGy & $50 \pm 1$ & $55 \pm 5$ & $11 \pm 1$ & $9 \pm 0,3$ \\
\hline EVOH/RGO 0,3 \% 150KGy & $50 \pm 1$ & $60 \pm 3$ & $11 \pm 0,2$ & $10 \pm 0,6$ \\
\hline EVOH 200KGy & $40 \pm 2$ & $43 \pm 3$ & $102 \pm 4$ & $7 \pm 0,2$ \\
\hline EVOH/RGO 0,1 \% 200KGy & $50 \pm 1$ & $44 \pm 4$ & $15 \pm 1$ & $7 \pm 0,3$ \\
\hline EVOH/RGO 0,2 \% 200KGy & $50 \pm 1$ & $50 \pm 2$ & $9 \pm 0,3$ & $9 \pm 0,2$ \\
\hline EVOH/RGO 0,3 \% 200KGy & $50 \pm 1$ & $56 \pm 3$ & $8 \pm 1$ & $10 \pm 0,1$ \\
\hline EVOH 250KGy & $40 \pm 2$ & $30 \pm 1$ & $100 \pm 1$ & $7 \pm 0,2$ \\
\hline EVOH/RGO 0,1 \% 250KGy & $50 \pm 1$ & $49 \pm 4$ & $15 \pm 1$ & $8 \pm 0,2$ \\
\hline EVOH/RGO 0,2 \% 250KGy & $50 \pm 1$ & $49 \pm 3$ & $10 \pm 1$ & $8 \pm 0,4$ \\
\hline EVOH/RGO 0,3 \% 250KGy & $50 \pm 1$ & $60 \pm 2$ & $7 \pm 1$ & $12 \pm 0,6$ \\
\hline
\end{tabular}

Fonte: Autor da dissertação.

Os filmes de EVOH não apresentaram ganhos em módulo Young após o tratamento por radiação, e verificou-se que os filmes de EVOH irradiados com100 e 150 kGy apresentaram uma redução de 42 \% no módulo elástico (módulo Young), o qual pode estar relacionado com a redução da cristalinidade. 
Pode-se observar nesta tabela que os filmes de EVOH/RGO irradiados e não irradiados apresentaram maior resistência à tração e módulo Young, quando comparados aos filmes de EVOH e EVOH 100-250 kGy.

A partir da Tabela 10 observa-se também que os filmes de EVOH/RGO contendo 0,2 e $0,3 \%$ de RGO apresentaram ganhos tanto em resistência à tração quanto em módulo para todos as amostras dos filmes irradiadas e não irradiadas. Contudo, para o filme de $\mathrm{EVOH} / \mathrm{RGO}$ com $0,1 \%$ de $\mathrm{RGO}$ foram observados ganhos de resistência à tração apenas para as amostras irradiadas à 250 kGy, porém acompanhado de uma pequena redução no módulo. Estes ganhos de resistência à tração e módulo dos filmes de nanocompósitos de $\mathrm{EVOH} / \mathrm{RGO}$ podem ser atribuídos à dispersão homogênea das nanofolhas de RGO na matriz polimérica. Resultados similares foram citados para nanocompósitos com nanotubos de carbono (XIAOMING YANG et al., 2010; YOUNG et al., 2012). Os ganhos em módulo Young apresentados, representam a relação do grau de rigidez e flexibilidade dos nanocompósitos, uma vez que as nanofolhas foram incorporadas na matriz de EVOH.

Quando comparado os resultados obtidos para os nanocompósitos de $\mathrm{EVOH} / \mathrm{GO}$ e EVOH/RGO, observou-se maiores aumentos no módulo elástico para os filmes $\mathrm{EVOH} / \mathrm{RGO}$ do que para os filmes de $\mathrm{EVOH} / \mathrm{GO}$, em razão da melhor e mais homogênea dispersão das nanofolhas de RGO altamente esfoliadas após processo de redução induzido por radiação, e devido a maior interação interfacial entre as nanofolhas de RGO e a matriz de EVOH.

Os resultados obtidos nestes ensaios, mostram a importância da redução do GO para as propriedades mecânicas de tração dos filmes. Os ganhos nas propriedades mecânicas dos filmes produzidos foram diretamente dependentes do grau de esfoliação das nanofolhas de GO na matriz polimérica. As amostras de RGO apresentaram uma melhor esfoliação, ou seja, um número bem menor de nanofolhas empilhadas do que as amostras de GO, de acordo com os resultados da espectroscopia Raman. Consequentemente, quando as amostras de RGO foram incorporadas à matriz de EVOH resultaram na obtenção de filmes flexíveis com superiores propriedades mecânicas que os filmes preparados com o EVOH contendo o GO não reduzido. Resultados semelhantes vêm sendo relatado por diversas referências bibliográficas (ZHAO et al., 2010;LI et al., 2014b). 


\section{CONCLUSÃO}

Neste trabalho estudou-se a síntese do óxido de grafeno (GO) usando a grafite como precursor, um processo com alto potencial para uma larga produção do GO, e sua subsequente redução induzida por radiação gama e a seguido da incorporação na matriz de EVOH para a produção de filmes flexíveis.

Com base nos resultados dos ensaios realizados pode-se concluir em relação a síntese do $\mathrm{GO}$ e sua redução a $\mathrm{RGO}$ que:

As micrografias do RGO apresentaram uma superfície bastante plana e lisa, com um baixo número de camadas empilhadas, e menor número de defeitos quando comparado ao GO não reduzido. O padrão das imagens indicou que o GO e RGO obtidos foram bem esfoliados através da obtenção pelo método de Hummer's modificado.

A partir dos resultados da espectroscopia Raman pode-se identificar a eficácia da síntese realizada neste trabalho através quantificação do número de camadas de nanofolhas do GO / RGO produzidas, tendo o RGO apresentado um menor número de camadas e defeitos; sendo o RGO considerado um material com melhor qualidade que o GO não reduzido.

O RGO apresentou maior estabilidade térmica que o GO, devido à remoção de grupos funcionais contendo oxigênio após a redução induzida por radiação gama.

Com relação aos nanocompósitos, filmes de EVOH puro, EVOH/GO e EVOH/RGO pode-se concluir:

Os resultados apresentados nos difratogramas dos nanocompósitos, foi obtida uma boa dispersão, adesão interfacial das nanofolhas de GO/RGO na matriz de EVOH, assim como através das micrografias do MEV-FEG mostraram uma uma superfície lisa sem a presença de aglomerados, indicando uma boa adesão interfacial entre o GO e a matriz.

Os filmes EVOH apresentaram superiores propriedades de estabilidade térmica após a adição do GO, e tratamento por radiação.

O tratamento por radiação promoveu a reticulação das cadeias moleculares do $\mathrm{EVOH}$, um fator muito importante, pois através dos resultados obtidos por 
PALS, verificou-se uma redução linear do volume livre para os filmes de EVOH e os nanocompósitos com o aumento das doses de radiação recebidas.

Os resultados entre a taxa de permeabilidade ao oxigênio e o volume livre tiveram uma relação linear com o tamanho dos poros dos filmes, como o filme de $\mathrm{EVOH}$ com $0,3 \%$ de $\mathrm{GO}$ que apresentou a melhor propriedade de barreira ao oxigênio nas condições de 0 - 90 \% de umidade relativa estudadas.

Os resultados de resistência à tração e módulo Young para os filmes de EVOH e nanocompósito de EVOH/GO e EVOH/RGO apresentaram superiores propriedades que as originais, com ganhos de $38 \%$ e $29 \%$ respectivamente, somados ao tratamento por radiação em diferentes doses 100 a 250 kGy, conferindo assim excelentes resultados as propriedades mecânicas dos filmes de EVOH e nanocompósitos.

Os resultados obtidos mostram a importância da redução do GO para as propriedades mecânicas de tração dos filmes, que dependem do nível de esfoliação das nanofolhas de GO na matriz polimérica. As amostras de RGO apresentaram uma melhor esfoliação, que as amostras de GO, e após incorporadas à matriz de $\mathrm{EVOH}$ resultaram na obtenção de filmes flexíveis com superiores propriedades mecânicas que os filmes preparados com o EVOH/GO. 


\section{SUGESTÕES PARA TRABALHOS FUTUROS}

Para melhor analisar os resultados obtidos dos nanocompósitos de $\mathrm{EVOH} / \mathrm{GO}$ e $\mathrm{EVOH} / \mathrm{RGO}$, sugere-se os seguintes pontos para trabalhos futuros:

- Analisar o Volume livre ( $r 3$ ) determinado por PALS para todos os filmes de $E V O H / G O$ e EVOH/RGO, não irradiados e irradiados a 100, 150, 200 e 250 kGy.

- Realizar os ensaios de barreira ao oxigênio $\left(\mathrm{TPO}_{2}\right)$ para todos os filmes de EVOH/GO e EVOH/RGO, não irradiados e irradiados a 100, 150, 200 e 250 kGy. 


\section{REFERÊNCIAS BIBLIOGRÁFICAS}

ABIEF - Associação Brasileira da Indústria de Embalagens Plásticas Flexíveis, "Indústria 4.0 chega ao setor de plástico 2017". Disponível em http://stage.momm.com.br/abief/publicacoes/novidade/1; acesso em janeiro de 2019.

ABIEF - Associação Brasileira da Indústria de Embalagens Plásticas Flexíveis, "ABIEF - Flex Tendência Abril 2018 - Cenário é positivo para indústria de embalagens flexíveis em 2018". Disponível em https://www.simplas.com.br/imprensa/noticias-setor/abief-flex-tendencia-abril2018.html; acesso em janeiro de 2019.

ABRE - Associação Brasileira de Embalagem. "Cenário é positivo para indústria de embalagens flexíveis em 2018". Disponível em http://www.abre.org.br/noticias/cenario-e-positivo-para-industria-deembalagens-flexiveis-em-2018/; acesso em janeiro de 2019.

AMERICAN SOCIETY FOR TESTING AND MATERIALS (ASTM) Standard Test Method for Tensile Properties of Thin Plastics Sheeting: D 882 -9. ASTM, 1996.

AMERICAN SOCIETY FOR TESTING AND MATERIALS (ASTM) Standard Test Method for Oxigen Gas Transmission Rate Through Plastic Film and Sheeting Using a Coulometric Sensor. Filadélfia. D 3985 - 81. ASTM, 2002.

AL-JABAREEN, A.; AL-BUSTAMI, H.; HAREL, H.; MAROM, G. Improving the oxygen barrier properties of polyethylene terephthalate by graphite nanoplatelets. Journal of Applied Polymer Science, v. 128, n. 3, p. 1534-1539, 2013.

ALLAHVAISI, S. Polypropylene in the industry of Food Packaging. Advances in Polypropylene, p. 3-22, 2017.

ALVES, A. L. ALVES, Abraão Leal. Síntese e caracterização de poliamida a partir do produto natural norbixina e o fármaco dapsona. Dissertação de Mestrado. Programa de Pós-Graduação em Engenharia Materiais, Instituto Federal de Educação, Ciência e Tecnologia do Piauí. [s.l: s.n.].

ANSÓN-CASAOS, A.; PUÉRTOLAS, J. A.; PASCUAL, F. J.; HERNÁNDEZ- 
FERRER, J.; CASTELL, P.; BENITO, A. M.; MASER, W. K.; MARTíNEZ, M. T. The effect of gamma-irradiation on few-layered graphene materials. Applied Surface Science, v. 301, n. February, p. 264-272, 2014.

APRELINI, L. O. Caracterização térmica, mecânica e morfológica de compósitos de polietileno de alta densidade com fibras da casca da semente da Moringa oleífera. 2016. 69. - Universidade Federal de Ouro Preto, Ouro Preto, 2016. [s.l: s.n.].

AZARNIYA, A.; ESLAHI, N.; MAHMOUDI, N.; SIMCHI, A. Effect of graphene oxide nanosheets on the physico-mechanical properties of chitosan/bacterial cellulose nanofibrous composites. Composites Part A: Applied Science and Manufacturing, v. 85, p. 113-122, 2016.

BAI, S.; SHEN, X.; ZHU, G.; XU, Z.; LIU, Y. Reversible phase transfer of graphene oxide and its use in the synthesis of graphene-based hybrid materials. Carbon, v. 49, n. 13, p. 4563-4570, 2011.

BARBOSA, L. A.; DREGER, A. A.; SCHNEIDER, E. L.; MORISSO, F. D. P.; SANTANA, R. M. C. Polietileno de baixa densidade -PEBD: mercado, produção, principais propriedades e aplicações. Revista Espacios, v. 38, n. 17, p. 10, 2016.

BARSBAY, M.; GÜVEN, O.; KODAMA, Y. Amine functionalization of cellulose surface grafted with glycidyl methacrylate by $\mathrm{Y}$-initiated RAFT polymerization. Radiation Physics and Chemistry, v. 124, p. 140-144, 2016.

BHATTACHARYA, A. Radiation and industrial polymers. Progress in Polymer Science (Oxford), v. 25, n. 3, p. 371-401, 2000.

BIJI, K. B.; RAVISHANKAR, C. N.; MOHAN, C. O.; SRINIVASA GOPAL, T. K. Smart packaging systems for food applications: a review. Journal of Food Science and Technology, v. 52, n. 10, p. 6125-6135, 2015.

BLANTON, T. N.; MAJUMDAR, D. Characterization of X-ray irradiated graphene oxide coatings using $\mathrm{X}$-ray diffraction, $\mathrm{X}$-ray photoelectron spectroscopy, and atomic force microscopy. Powder Diffraction, v. 28, n. 2, p. 68-71, 2013.

BROCKGREITENS, J.; ABBAS, A. Responsive Food Packaging: Recent 
Progress and Technological Prospects. Comprehensive Reviews in Food Science and Food Safety, v. 15, n. 1, p. 3-15, 2016.

CALLISTER JR., W. D. Ciência e engenharia de materiais: uma introdução. [s.l: s.n.].

CANEVAROLO S. Técnicas de Caracterização de Polímeros. 1 ed. ed. São Paulo: [s.n.].

CANEVAROLO, S. J. CIENCIA DOS POLIMEROS: um texto básico para tecnólogos e engenheiros. 1 ed. ed. São Paulo: [s.n.].

CERISUELO, J.P.; ALONSO, J.; AUCEJO, S.; GAVARA, R. HERNANDEZMUÑOZ, P. Modifications induced by the addition of a nanoclay in the functional and active properties of an EVOH film containing carvacrol for food packaging. Journal of Membrane Science, v. 423/424, p. 247/256, 2012.

CHENG-AN, T.; HAO, Z.; FANG, W.; HUI, Z.; XIAORONG, Z.; JIANFANG, W. Mechanical properties of Graphene Oxide/Polyvinyl Alcohol Composite Film. Polymers and Polymer Composites, v. 25, n. 1, p. 11-16, 2017.

CHENG, Y.; DENG, S.; CHEN, P.; RUAN, R. Polylactic acid (PLA) synthesis and modifications: A review. Frontiers of Chemistry in China, v. 4, n. 3, p. 259-264, 2009.

CHIN, A. W. Polymers for Innovative Food Packaging An Interactive Qualifying Project Report. Worcester Polytechnic Institute, p. 55, 2010.

CHOUDHARY, S.; MUNGSE, H. P.; KHATRI, O. P. Dispersion of alkylated graphene in organic solvents and its potential for lubrication applications. Journal of Materials Chemistry, v. 22, n. 39, p. 21032-21039, 2012.

CHUAQUI-OFFERMANNS, N. Food packaging materials and radiation processing of food: A brief review. International Journal of Radiation Applications and Instrumentation. Part, v. 34, n. 6, p. 1005-1007, 1989.

CIESIELSKI, A.; SAMORÌ, P. Graphene via sonication assisted liquid-phase exfoliation. Chemical Society Reviews, v. 43, n. 1, p. 381-398, 2014.

COBOS, M.; FERNÁNDEZ, M. Graphene Based Poly(Vinyl Alcohol) 
Nanocomposites Prepared by In Situ Green Reduction of Graphene Oxide by Ascorbic Acid: Influence of Graphene Content and Glycerol Plasticizer on Properties. Nanomaterials, v. 8, n. 12, p. 1013, 2018.

COLOMBI, B. L. Polimerização da Poliamida 6 , 6 : Uma Breve Revisão. Revista Eletrônica de Materiais e Processos, v. 3, n. 2016, p. 121-129, 2017.

COMPTON, O. C.; CRANFORD, S. W.; PUTZ, K. W.; AN, Z.; BRINSON, L. C.; BUEHLER, M. J.; NGUYEN, S. T. Tuning the \{Mechanical\} \{Properties\} of \{Graphene\} \{Oxide\} \{Paper\} and $\{\mathrm{Its}\}$ \{Associated\} \{Polymer\} \{Nanocomposites\} by \{Controlling\} \{Cooperative $\}$ Intersheet $\}$ Hydrogen\} \{Bonding\}. ACS Nano, v. 6, n. 3, p. 2008-2019, 2012.

CRIPPA, A. Estudo Do Desempenho De Filmes Multicamadas. 2006, Engenharia e Ciência dos Materiais, Universidade Federal do Paraná. [s.l: s.n.].

CUI, P.; LEE, J.; HWANG, E.; LEE, H. One-pot reduction of graphene oxide at subzero temperatures. Chemical Communications, v. 47, n. 45 , p. $12370-$ 12372, 2011.

CUI, Y.; KUNDALWAL, S. I.; KUMAR, S. Gas barrier performance of graphene/polymer nanocomposites. Carbon, v. 98, p. 313-333, 2016.

DANIEL R. DREYER, SUNGJIN PARK, C. W. B. AND R. S. R. The chemistry of graphene oxide. Chemical Society Reviews, v. 39, p. 228-240, 2009.

DANIELA GABOR (NAIARETTI), O. T. Biopolymers Used in Food Packaging : a Review. Acta Universitatis Cibiniensis Series E: FOOD TECHNOLOGY, v. XVI, n. 2, p. 3-19, 2012.

DAS, S.; WAJID, A. S.; SHELBURNE, J. L.; LIAO, Y. C.; GREEN, M. J. Localized in situ polymerization on graphene surfaces for stabilized graphene dispersions. ACS Applied Materials and Interfaces, 2011.

DAUD, N. A.; CHIENG, B. W.; TALIB, N. A. I.; ABIDIN, Z. Synthesis and Characterisation of Functionalised Graphene Oxide by Gamma Ray Irradiation. Journal of Engineering Science, v. 13, p. 1-17, 2017.

DENARI, G. B. Denari, Gabriela Bueno Princípios e aplicações de análise 
térmica /org. por Gabriela Bueno Denari e Eder Tadeu Gomes Cavalheiro. -- São Carlos: IQSC, 2012. 40 p. 1. p. 40, 2012.

DESIGN, F. Transcrito pela Food Design*. v. 2003, n. 11, p. 1997-1999, 1997.

DRISCOLL, M.; STIPANOVIC, A.; WINTER, W.; CHENG, K.; MANNING, M.; SPIESE, J.; GALLOWAY, R. A.; CLELAND, M. R. Electron beam irradiation of cellulose. Radiation Physics and Chemistry, v. 78, n. 7-8, p. 539-542, 2009.

DUBIN, S. et al. A one-step, solvothermal reduction method for producing reduced graphene oxide dispersions in organic solvents. ACS Nano, v. 4, n. 7, p. 3845-3852, 2010.

DUMÉE, L. F. et al. Single step preparation of meso-porous and reduced graphene oxide by gamma-ray irradiation in gaseous phase. Carbon, v. 70, p. 313-318, 2014.

EMIRU, T. F.; AYELE, D. W. Controlled synthesis, characterization and reduction of graphene oxide: A convenient method for large scale production. Egyptian Journal of Basic and Applied Sciences, v. 4, n. 1, p. 74-79, 2017.

ESWARAIAH, V.; JYOTHIRMAYEE ARAVIND, S. S.; RAMAPRABHU, S. Top down method for synthesis of highly conducting graphene by exfoliation of graphite oxide using focused solar radiation. Journal of Materials Chemistry, v. 21, n. 19, p. 6800-6803, 2011.

F.-W. SHEN, H. A. M. AND R. S. Effect of irradiation on chemically crosslinked ultrahigh molecular weight polyethylene. p. 1063-1077, 1994.

FATHY, M.; GOMAA, A.; TAHER, F. A.; EL-FASS, M. M.; KASHYOUT, A. E. H. B. Optimizing the preparation parameters of $\mathrm{GO}$ and $\mathrm{rGO}$ for large-scale production. Journal of Materials Science, v. 51, n. 12, p. 5664-5675, 2016.

FERREIRA, M. S.; SARTORI, M. N.; OLIVEIRA, R. R.; GUVEN, O.; MOURA, E. A. B. Short vegetal-fiber reinforced HDPE - A study of electron-beam radiation treatment effects on mechanical and morphological properties. Applied Surface Science, v. 310, p. 325-330, 2014.

FERREIRA MARQUES, M. F.; GORDO, P. M.; KAJCSOS, Z.; LOPES GIL, C.; DE LIMA, A. P.; QUEIROZ, D. P.; DE PINHO, M. N. Positron studies of the 
temperature-dependence

of

free

volumes

in

Polydimethylsiloxane/poly(propylene oxide) urethane/urea membranes.

Radiation Physics and Chemistry, v. 76, n. 2, p. 129-133, 2007.

FIGUEIREDO, A. L.; AlVES, A. P. M.; FERnANDES, V. J.; ARAUJO, A. S. Reciclagem Terciária do Poli(etileno tereftalato) Visando a Obtenção de Produtos Químicos e Combustível: Uma Revisão. Revista Virtual de Quimica, v. 7, n. 4 , p. $1145-1162,2015$.

GAO, X.; JANG, J.; NAGASE, S. Hydrazine and thermal reduction of graphene oxide: Reaction mechanisms, product structures, and reaction design. Journal of Physical Chemistry C, v. 114, n. 2, p. 832-842, 2010.

GARCIA, M. T. Preparação De Óxido De Grafeno E Óxido De Grafeno Reduzido E Dispersão Em Matriz Polimérica Biodegradável. [s.I: s.n.].

GEIM, A. K.; NOVOSELOV, K. S. The rise of graphene. Nature Materials, v. 6, n. 3, p. 183-191, 2007.

GÓMEZ, I.; MEJÍA, E.; CABANZO, R. SYNTHESIS OF GRAPHENE OXIDE AND CHEMICALLY REDUCED GRAPHENE NANOSHEETS Synthesis of grapheme oxide and chemically reduced grapheme nanosheets. Revista Colombiana de Materiales N, 2013.

GUBBElS, F.; JÉRÔME, R.; TEYSSIÉ, P.; VANLATHEM, E.; DELTOUR, R.; CALDERONE, A.; PARENTÉ, V.; BRÉDAS, J. L. Selective Localization of Carbon Black in Immiscible Polymer Blends: A Useful Tool To Design Electrical Conductive Composites. Macromolecules, v. 27, n. 7, p. 1972-1974, 1994.

GÜVEN, O.; MONTEIRO, S. N.; MOURA, E. A. B.; DRELICH, J. W. Re-Emerging Field of Lignocellulosic Fiber - Polymer Composites and Ionizing Radiation Technology in their Formulation. Polymer Reviews, v. 56, n. 4, p. 702-736, 2016.

HAREESH, K. et al. Reduction of graphene oxide by $100 \mathrm{MeV}$ Au ion irradiation and its application as H2O2sensor. Journal of Physics D: Applied Physics, v. 48, n. 36, p. 365105, 2015.

HAREESH, K.; JOSHI, R. P.; DAHIWALE, S. S.; BHORASKAR, V. N.; DHOLE, 
S. D. Synthesis of Ag-reduced graphene oxide nanocomposite by gamma radiation assisted method and its photocatalytic activity. Vacuum, v. 124, n. December, p. 40-45, 2016.

HARRIS, P. Transmission Electron Microscopy of Carbon: A Brief History. Journal of Carbon Research, v. 4, n. 1, p. 4, 2018.

HE, H.; KLINOWSKI, J.; FORSTER, M.; LERF, A. E1998.Pdf. n. April, p. 98-101, 1998.

HE, Y.; LI, J.; LI, L.; LI, J. Gamma-ray irradiation-induced reduction and selfassembly of graphene oxide into three-dimensional graphene aerogel. Materials Letters, v. 177, p. 76-79, 2016.

HÉCTOR, A. B. et al. Evaluation of Solution-Processed Reduced Graphene Oxide Films as as Transparent Conductors. ACS Nano, v. 2, n. 3, p. 463-470, 2008.

HEITLER W. The Quantum Theory of Radiation. New York: Dover Publication; 1953. 3. ed. New York: [s.n.].

HIELSCHER, K.; GMBH, H. U. Ultrasonically-assisted-preparation-of-graphene. n. Suslick 1998, 2011.

HU, K.; KULKARNI, D. D.; CHOI, I.; TSUKRUK, V. V. Graphene-polymer nanocomposites for structural and functional applications. Progress in Polymer Science, v. 39, n. 11, p. 1934-1972, 2014.

HUANG, H. D.; REN, P. G.; CHEN, J.; ZHANG, W. Q.; JI, X.; LI, Z. M. High barrier graphene oxide nanosheet/poly(vinyl alcohol) nanocomposite films. Journal of Membrane Science, v. 409-410, p. 156-163, 2012.

HUANG, P. Y. et al. Grains and grain boundaries in single-layer graphene atomic patchwork quilts. Nature, v. 469, n. 7330, p. 389-392, 2011.

HUANG, X.; QI, X.; BOEY, F.; ZHANG, H. Graphene-based composites. Chemical Society Reviews, v. 41, n. 2, p. 666-686, 2012.

JAE BYUN, Y.; HONG, S. I.; KIM, K. B.; JEON, D. H.; KIM, J. M.; WHITESIDE, W. S.; JIN PARK, H. Physical and chemical properties of $\gamma$-irradiated EVOH film. 
Radiation Physics and Chemistry, v. 76, n. 6, p. 974-981, 2007.

JAIME, S. B. M.; GOZA DE CAMPOS, A. C. M.; LEMOS, A. B.; ALVES, R. M. V. Propriedade de barreira à umidade de embalagens plásticas para produtos oftálmicos. Revista de Ciencias Farmaceuticas Basica e Aplicada, v. 35, n. 1, p. 133-139, 2014.

JORGE, N. Embalagens para alimentos / Neuza Jorge. - São Paulo : Cultura Acadêmica: Universidade Estadual Paulista, Pró-Reitoria de Graduação, 2013. [s.l: s.n.].

JOSÉ MANUEL MARQUES LUÍS. Espectroscopia de tempos de vida de aniquilação do positrão no estudo dos processos de relaxação e absorção de humidade num polímero comercial. José Manuel Marques Luís Coimbra,2010. p. 7-9, 2010.

KASHYAP, S.; PRATIHAR, S. K.; BEHERA, S. K. Strong and ductile graphene oxide reinforced PVA nanocomposites. Journal of Alloys and Compounds, v. 684, p. 254-260, 2016.

KHAN, Q. A.; SHAUR, A.; KHAN, T. A.; JOYA, Y. F.; AWAN, M. S. Characterization of reduced graphene oxide produced through a modified Hoffman method. Cogent Chemistry, v. 3, n. 1, 2017.

KHOLMANOV, I. N. et al. Reduced graphene oxide/copper nanowire hybrid films as high-performance transparent electrodes. ACS Nano, v. 7, n. 2, p. 1811-1816, 2013.

KIM, H. M.; LEE, H. S. Water and oxygen permeation through transparent ethylene vinyl alcohol/(graphene oxide) membranes. Carbon letters, v. 15, n. 1 , p. 50-56, 2014.

KIM, S. H.; NOH, Y. J.; KWON, S. N.; KIM, B. N.; LEE, B. C.; YANG, S. Y.; JUNG, C. H.; NA, S. I. Efficient modification of transparent graphene electrodes by electron beam irradiation for organic solar cells. Journal of Industrial and Engineering Chemistry, v. 26, p. 210-213, 2015.

KIM, S. W.; CHA, S. H. Thermal, mechanical, and gas barrier properties of ethylene-vinyl alcohol copolymer-based nanocomposites for food packaging 
films: Effects of nanoclay loading. Journal of Applied Polymer Science, 2014.

KIM, S. W.; CHOI, H. M. Enhancement of thermal, mechanical, and barrier properties of ethylene vinyl alcohol copolymer by incorporation of graphene nanosheets. High Performance Polymers, v. 27, n. 6, p. 694-704, 2015.

KUDIN, K. N. et al. Raman Spectra of Graphite Oxide and Functionalized Graphene Sheets. Nano Letters, v. 8, n. 1, p. 36-41, 2007.

KWON, H.; KIM, D.; SEO, J.; HAN, H. Enhanced moisture barrier films based on EVOH/exfoliated graphite (EGn) nanocomposite films by solution blending. Macromolecular Research, v. 21, n. 9, p. 987-994, 2013.

LANGE, J.; WYSER, Y. Recent Innovations in Barrier Technologies for Plastic Packaging - A Review. Packaging Technology and Science, v. 16, n. 4, p. 149158, 2003.

LEE, C.; WEI, X.; KYSAR, J. W.; HONE, J. Measurement of the elastic properties and intrinsic strength of monolayer graphene. Science, v. 321, n. 5887, p. 385388, 2008.

LERF, A.; BUCHSTEINER, A.; PIEPER, J.; SCHÖTTL, S.; DEKANY, I.; SZABO, T.; BOEHM, H. P. Hydration behavior and dynamics of water molecules in graphite oxide. Journal of Physics and Chemistry of Solids, v. 67, n. 5-6, p. 1106-1110, 2006.

LI, J.; LI, Y.; NIU, S.; LI, N. Ultrasonic-assisted synthesis of phosphorus graphene oxide/poly (vinyl alcohol) polymer and surface resistivity research of phosphorus graphene oxide/poly (vinyl alcohol) film. Ultrasonics Sonochemistry, v. 36, p. 277-285, 2017.

LI, J.; SHAO, L.; YUAN, L.; WANG, Y. A novel strategy for making poly(vinyl alcohol)/reduced graphite oxide nanocomposites by solvothermal reduction. Materials and Design, v. 54, p. 520-525, 2014.

LI, J.; ZHANG, B.; LI, L.; MA, H.; YU, M.; LI, J. Г-Ray Irradiation Effects on Graphene Oxide in an Ethylenediamine Aqueous Solution. Radiation Physics and Chemistry, v. 94, n. 1, p. 80-83, 2014.

MA, H. L.; ZHANG, Y.; HU, Q. H.; HE, S.; LI, X.; ZHAI, M.; YU, Z. Z. Enhanced 
mechanical properties of poly(vinyl alcohol) nanocomposites with glucosereduced graphene oxide. Materials Letters, v. 102-103, p. 15-18, 2013.

MACHADO, M. D. S.; GODOY, R. B.; SILVA, A.; LIMA, R.; OLIVEIRA, R. R.; VALENZUELA-DÍAZ, F.; MOURA, E. Influence of clay exfoliation on the properties of EVOH/CLAY flexible films. Characterization of Minerals, Metals, and Materials 2015, p. 273-279, 2016.

MARSH, K.; BUGUSU, B. Food packaging - Roles, materials, and environmental issues: Scientific status summary. Journal of Food Science, v. 72, n. 3, 2007.

MATEO, E. M.; GÓMEZ, J. V.; DOMÍNGUEZ, I.; GIMENO-ADELANTADO, J. V.; MATEO-CASTRO, R.; GAVARA, R.; JIMÉNEZ, M. Impact of bioactive packaging systems based on EVOH films and essential oils in the control of aflatoxigenic fungi and aflatoxin production in maize. International Journal of Food Microbiology, 2017.

MATOS, J.R. \& MACHADO, L. D. B. . Análise térmica -Termogravimetria. In: Técnicas de caracterização de polímeros. Artliber ed. São Paulo: [s.n.]. p. 209-228.

MATTEVI, C. et al. Evolution of electrical, chemical, and structural properties of transparent and conducting chemically derived graphene thin films. Advanced Functional Materials, v. 19, n. 16, p. 2577-2583, 2009.

MEHNERT, R. Electron beams in research and technology. Nuclear Inst. and Methods in Physics Research, B, v. 105, n. 1-4, p. 348-358, 1995.

MOHANTY, N.; NAGARAJA, A.; ARMESTO, J.; BERRY, V. High-throughput, ultrafast synthesis of solutiondispersed graphene via a facile hydride chemistry. Small, v. 6, n. 2, p. 226-231, 2010.

MOKWENA, K. K.; TANG, J. Ethylene Vinyl Alcohol: A Review of Barrier Properties for Packaging Shelf Stable Foods. Critical Reviews in Food Science and Nutrition, v. 52, n. 7, p. 640-650, 2012.

MOKWENA, K. K.; TANG, J.; LABORIE, M. P. Water absorption and oxygen barrier characteristics of ethylene vinyl alcohol films. Journal of Food Engineering, 2011. 
MOON, I. K.; LEE, J.; RUOFF, R. S.; LEE, H. Reduced graphene oxide by chemical graphitization. Nature Communications, v. 1, n. 6, p. 1-6, 2010.

MUKHOPADHYAY, P.; GUPTA, R. K. Trends and Frontiers in Graphene-Based Polymer. Plastic Engineering, n. January, p. 32-43, 2011.

NOGUEIRA, B. R. AVALIAÇÃO DOS EFEITOS DA RADIAÇÃO IONIZANTE POR FEIXE DE ELÉTRONS NA INCORPORAÇÃO DE FIBRA DE PIAÇAVA (ATTALEA FUNIFERA MART.) NO COPOLÍMERO DE ETILENO E ÁLCOOL VINÍLICO (EVOH). Dissertação de Mestrado. INSTITUTO DE PESQUISAS ENERGÉTICAS E NUCLEARES 2012. [s.I: s.n.].

NOGUEIRA, B. R.; CHINELLATO, A.; ORTIZ, A. V.; PARVEEN, A.; RANGARI, V. K.; MOURA, E. A. B. Thermal and Morphological Behavior of EVOH/Piassava Fiber Composites. Characterization of Minerals, Metals, and Materials, p. 373-380, 2012.

NOGUEIRA, B. R.; MARTINS, J. F. T.; OLIVEIRA, R. R.; MOURA, E. A. B. Crystallinity Changes of Electron-Beam Irradiated Ethylene-Vinyl Alcohol Copolymer ( Evoh ) As a Function of Radiation Dose. International Nuclear Atlantic Conference - INAC 2011, 2011.

NORTON, K. A.; POPEL, A. S.; PANDEY, N. B. Heterogeneity of chemokine cellsurface receptor expression in triple-negative breast cancer. American Journal of Cancer Research, v. 5, n. 4, p. 1295-1307, 2015.

PAPAGEORGIOU, D. G.; KINLOCH, I. A.; YOUNG, R. J. Mechanical properties of graphene and graphene-based nanocomposites. Progress in Materials Science, v. 90, p. 75-127, 2017.

PARK, E. Antimicrobial polymeric materials for packaging applications: A reviewThe Battle Against Microbial Pathogens: Basic Science, Technological Advances and Educational Programs. [s.l: s.n.].

PINTO, A. M. Effect of incorporation of graphene oxide and graphene nanoplatelets on mechanical and gas permeability properties of poly(lactic acid) films. Polymer International, v. 62, n. February, p. 33-40, 2013.

PRZYBYTNIAK, G. Cross-linking of polymers In Radiation Processing. In: 
Applications of ionizing radiation in materials processing. [s.l: s.n.]. p. 249267.

RAHEEM, D. Application of plastics and paper as food packaging materials - An overview. Emirates Journal of Food and Agriculture, v. 25, n. 3, p. 177-188, 2013.

RATHNAYAKE, R. M. N. M.; WIJAYASINGHE, H. W. M. A. C.; PITAWALA, H. M. T. G. A.; YOSHIMURA, M.; HUANG, H. H. Synthesis of graphene oxide and reduced graphene oxide by needle platy natural vein graphite. Applied Surface Science, 2017.

RODRIGUES, I. R. Efeito de Solventes Orgânicos e da Temperatura em Filmes Multicamadas. Dissertação (Mestrado) - Programa de PósGraduação em Ciências e Engenharia de Materiais e Área de Concentração em -- Escola de Engenharia de São Carlos da Universidade de São Paulo, 2. [s.l: s.n.].

ROY, R.; THAPA, R.; CHAKRABARTY, S.; JHA, A.; MIDYA, P. R.; KUMAR, E. M.; CHATTOPADHYAY, K. K. Role of oxygen functionality on the band structure evolution and conductance of reduced graphene oxide. Chemical Physics Letters, v. 677, p. 80-86, 2017.

SALAVAGIONE, H. J.; MARTíNEZ, G.; GÓMEZ, M. A. Synthesis of poly(vinyl alcohol)/reduced graphite oxide nanocomposites with improved thermal and electrical properties. Journal of Materials Chemistry, v. 19, n. 28, p. 50275032, 2009.

SEGUNDO, J. E. D. V.; VILAR, E. O. Grafeno: uma revisão sobre propriedades, mecanismos de produção e potenciais aplicações em sistemas energéticos. Revista Eletrônica de Materiais e Processos, v. 11, n. 2, p. 54-57, 2016.

SHAHRIARY, L.; ATHAWALE, A. A. Graphene Oxide Synthesized by using Modified Hummers ApproachInternational Journal of Renewable Energy and Environmental Engineering, 2014.

SHAHRIARY, L.; ATHAWALE, A. A. Synthesis of graphene using gamma radiations. Bulletin of Materials Science, v. 38, n. 3, p. 739-745, 2015. 
SHANKAR, S.; RHIM, J.-W. Polymer Nanocomposites for Food Packaging Applications. In: Functional and Physical Properties of Polymer Nanocomposites. [s.l: s.n.].

SOLTANI, T.; KYU LEE, B. A benign ultrasonic route to reduced graphene oxide from pristine graphite. Journal of Colloid and Interface Science, v. 486, p. 337343, 2017.

SÖYLEMEZ, M. A.; GÜVEN, O. Detailed positron annihilation lifetime spectroscopic investigation of atrazine imprinted polymers grafted onto PE/PP non-woven fabrics. Journal of Molecular Recognition, v. 31, n. 1, p. 1-10, 2018.

SÖYLEMEZ, M. A.; GÜVEN, O.; BARSBAY, M. Method for preparing a welldefined molecularly imprinted polymeric system via radiation-induced RAFT polymerization. European Polymer Journal, v. 103, n. March, p. 21-30, 2018.

SPINKS, J. W. T.; WOODS, R. J. Water and Inorganic Aqueous Systems. An introduction to radiation chemistry, p. 243-313, 1964.

STANKOVICH, S. et al. Synthesis of graphene-based nanosheets via chemical reduction of exfoliated graphite oxide. Carbon, v. 45, n. 7, p. 1558-1565, 2007.

TAUAHATA, LUIZ; SALATI, IVAN; PRINZIO, R. D. P.; ZIO, A. R. D. Radioproteção E Dosimetria : Fundamentos. In: Ird/Cnen. [s.l: s.n.]. p. 345.

VERMA, D.; GOPE, P. C.; SHANDILYA, A.; GUPTA, A. Mechanical-ThermalElectrical and Morphological Properties of Graphene Reinforced Polymer Composites: A Review. Transactions of the Indian Institute of Metals, v. 67, p. 803-816, 2014.

VIANNA, P. G. NANOCOMPÓSITO DE ÓXIDO DE GRAFENO E NANOPARTÍCULAS METÁLICAS PARA ESPECTROSCOPIA RAMAN AMPLIFICADA POR SUPERFÍCIE (SERS). [s.I: s.n.].

W.S. HUMMERS JR., R. E. O. Preparation of graphitic oxide. J. Am. Chem. Soc., v. 80, p. 1339-1339, 1958.

WANG, G.; SHEN, X.; WANG, B.; YAO, J.; PARK, J. Synthesis and characterisation of hydrophilic and organophilic graphene nanosheets. Carbon, 
v. 47 , n. 5 , p. 1359-1364, 2009.

WANG, P.; JIANG, T.; ZHU, C.; ZHAI, Y.; WANG, D.; DONG, S. One-step, solvothermal synthesis of graphene-CdS and graphene-ZnS quantum dot nanocomposites and their interesting photovoltaic properties. Nano Research, 2010.

XIAOMING YANG, LIANG LI, SONGMIN SHANG, X. T. Synthesis and characterization of layer-aligned poly(vinyl alcohol)/graphene nanocomposites. Polymer, v. 51, p. 3431-3435, 2010.

YANG, H.; LI, H.; ZHAI, J.; SUN, L.; YU, H. Simple synthesis of graphene oxide using ultrasonic cleaner from expanded graphite. Industrial and Engineering Chemistry Research, v. 53, n. 46, p. 17878-17883, 2014.

YANG, J.; BAI, L.; FENG, G.; YANG, X.; LV, M.; ZHANG, C.; HU, H.; WANG, X. Thermal reduced graphene based poly(ethylene vinyl alcohol) nanocomposites: Enhanced mechanical properties, gas barrier, water resistance, and thermal stability. Industrial and Engineering Chemistry Research, v. 52, n. 47, p. 16745-16754, 2013a.

YANG, J.; VOIRY, D.; AHN, S. J.; KANG, D.; KIM, A. Y.; CHHOWALLA, M.; SHIN, $\mathrm{H}$. S. Two-dimensional hybrid nanosheets of tungsten disulfide and reduced graphene oxide as catalysts for enhanced hydrogen evolution. Angewandte Chemie - International Edition, 2013b.

YANG, X.; WANG, X.; YANG, J.; LI, J.; WAN, L. Functionalization of graphene using trimethoxysilanes and its reinforcement on polypropylene nanocomposites. Chemical Physics Letters, v. 570, p. 125-131, 2013.

YEH, J. T.; CHEN, H. Y. Blending and oxygen permeation properties of the blown films of blends of modified polyamide and ethylene vinyl alcohol copolymer with varying vinyl alcohol contents. Journal of Materials Science, v. 42, n. 14, p. 5742-5751, 2007.

YEPES, O. O.; DI GIOGIO, L.; GOYANES, S.; MAURI, A.; FAMÁ, L. Influence of process (extrusion/thermo-compression, casting) and lentil protein content on physicochemical properties of starch films. Carbohydrate Polymers, v. 14, n. 4 , p. 291-305, 2018. 
YOO, B. M.; SHIN, H. J.; YOON, H. W.; PARK, H. B. Graphene and graphene oxide and their uses in barrier polymers. Journal of Applied Polymer Science, v. 131, n. 1, p. 1-23, 2014.

YOUNG, R. J.; KINLOCH, I. A.; GONG, L.; NOVOSELOV, K. S. The mechanics of graphene nanocomposites: A review. Composites Science and Technology, v. 72 , n. 12, p. 1459-1476, 2012.

ZHANG, Y. et al. Gamma Irradiation-Induced Preparation of Graphene-Ni Nanocomposites with Efficient Electromagnetic Wave Absorption. Materials, v. 11 , n. 11, p. 2145, 2018.

ZHANG, Y.; MA, H. L.; ZHANG, Q.; PENG, J.; LI, J.; ZHAI, M.; YU, Z. Z. Facile synthesis of well-dispersed graphene by $\mathrm{Y}$-ray induced reduction of graphene oxide. Journal of Materials Chemistry, v. 22, n. 26, p. 13064-13069, 2012.

ZHAO, X.; ZHANG, Q.; CHEN, D.; LU, P. Enhanced mechanical properties of graphene-based polyvinyl alcohol composites. Macromolecules, v. 43, n. 5, p. 2357-2363, 2010.

ZHU, C.; GUO, S.; FANG, Y.; DONG, S. Reducing sugar: New functional molecules for the green synthesis of graphene nanosheets. ACS Nano, v. 4, n. 4, p. 2429-2437, 2010. 